\author{
UNIVERSIDADE DE SÃO PAULO \\ ESCOLA DE ENGENHARIA DE SÃO CARLOS
}

RICARDO DE MEDEIROS

Desenvolvimento de uma metodologia computacional para determinar coeficientes efetivos de compósitos inteligentes

São Carlos

2012 



\section{RICARDO DE MEDEIROS}

Desenvolvimento de uma metodologia computacional para determinar coeficientes efetivos de compósitos inteligentes

Dissertação apresentada a Escola de

Engenharia de São Carlos, da Universidade de São Paulo, como parte dos requisitos para obtenção do título de Mestre em Engenharia Mecânica. Área de concentração: Aeronaves.

Orientador: Prof. Assoc. Volnei Tita

São Carlos

2012 
AUTORIZO A REPRODUÇÃO E DIVULGAÇÃO TOTAL OU PARCIAL DESTE TRABALHO, POR QUALQUER MEIO CONVENCIONAL OU ELETRÔNICO, PARA FINS DE ESTUDO E PESQUISA, DESDE QUE CITADA A FONTE.

Ficha catalográfica preparada pela Seção de Tratamento

da Informação do Serviço de Biblioteca - EESC/USP

Medeiros, Ricardo de.

M488d Desenvolvimento de uma metodologia computacional para determinar coeficientes efetivos de compósitos

inteligentes. / Ricardo de Medeiros ; orientador Volnei

Tita. São Carlos, 2011.

Dissertação (Mestrado - Programa de Pós-Graduação em Engenharia Mecânica e Área de Concentração em Aeronaves) - Escola de Engenharia de São Carlos da Universidade de São Paulo, 2011.

1. Compósito piezelétrico. 2. Active fiber composite. 3. Macro fiber composite. 4. Propriedades efetivas. 5. Modelagem de elementos finitos. I. Título. 


\section{FOLHA DE JULGAMENTO}

\section{Candidato: Engenheiro RICARDO DE MEDEIROS}

Título da dissertação: "Desenvolvimento de uma metodologia computacional para determinar coeficientes efetivos de compósitos inteligentes".

Data da defesa: 15/02/2012

\section{Comissão Julgadora:}

Prof. Associado Volnei Tita (Orientador)

(Escola de Engenharia de São Carlos/EESC)

Prof. Associado Marcelo Areias Trindade

(Escola de Engenharia de São Carlos/EESC)

Prof. Titular Emilio Carlos Nelli Silva

(Escola Politécnica/USP)
Resultado:
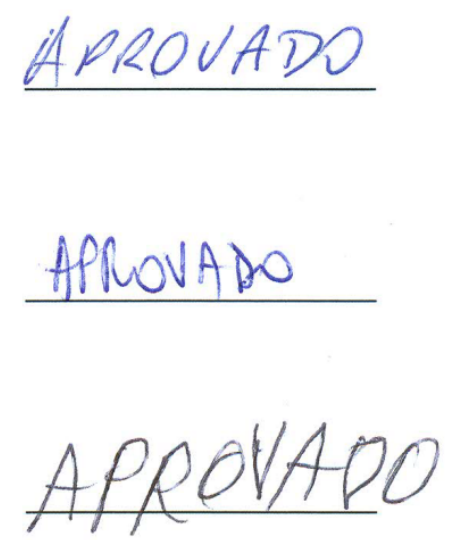

Coordenador do Programa de Pós-Graduação em Engenheira Mecânica:

Prof. Associado Marcelo Areias Trindade

Presidente da Comissão de Pós-Graduação:

Prof. Associado Paulo Cesar Lima Segantine 

"Dedico este trabalho a minha esposa Ângela, meus pais Adroaldo e Lourdes e meu irmão Carlos Rodrigo.” 



\section{AgRAdECIMENTOS}

Ao Professor Assoc. Volnei Tita, orientador, pela atenção, apoio e dedicação, e pelos momentos de orientação e discussão sobre o projeto.

Ao Prof. Dr. André João de Souza (UFRGS) pela amizade e desafio lançado.

Ao Prof. Dr. Mariano Eduardo Moreno (UFSCar) pelas importantes contribuições e discussões dadas no desenvolvimento dos modelos empregados neste trabalho.

Ao Prof. Assoc. Flávio Donizeti Marques (EESC/USP) pelas grandes discussões que enriqueceram o trabalho e pelo apoio com os ensaios experimentais.

Ao Prof Dr. Julian Bravo-Castilero (Universidad de La Habana) pelo apoio e auxilio.

Aos companheiros do Departamento de Engenharia Aeronáutica (USP/São Carlos) por momentos agradáveis.

Aos funcionários do Departamento de Engenharia Aeronáutica (USP/São Carlos) pelo auxílio nas questões burocráticas.

Ao CNPq (Conselho Nacional de Desenvolvimento Científico e Tecnológico), pela bolsa de estudo concedida.

Agradeço a minha esposa Ângela pela paciência, amor e cumplicidade a mim dedicados durante todo esse período.

Agradeço a toda minha família em especial aos meus pais Adroaldo e Lourdes e meu irmão Carlos pelo incentivo dado em todos os momentos difíceis que enfrentei.

À Deus, principalmente, por ter me dado saúde, paz e tranquilidade para superar esta etapa de minha vida. 



\section{RESUMO}

MEDEIROS, R., Desenvolvimento de uma Metodologia Computacional para Determinar Coeficientes Efetivos de Compósitos Inteligentes. 2012. 192p. Dissertação (Mestrado) Escola de Engenharia de São Carlos, Universidade de São Paulo, São Paulo, 2012.

O presente trabalho visa empregar uma metodologia numérica para determinar as propriedades macro mecânica de compósitos ativos (AFC - Active Fiber Composite ou MFC - Macro Fiber Composite), combinando o conceito de Volume Elementar Representativo (VER) com o Método dos Elementos Finitos (MEF). Inicialmente, apresenta-se a fundamentação teórica associada à abordagem numérica empregada. Posteriormente, os modelos numéricos desenvolvidos são aplicados na determinação dos coeficientes efetivos de materiais compósitos inteligentes transversalmente isotrópicos com fibras piezelétricas de seção com forma circular e quadrada, respectivamente. Finalmente, os resultados numéricos obtidos pela metodologia proposta são, então, comparados com resultados da literatura. Constata-se que os resultados obtidos são muito semelhantes aos resultados relatados pela literatura para arranjo quadrático e hexagonal com fibra de geometria circular, sendo que neste caso, compararam-se os resultados numéricos com analíticos obtidos através do Método de Homogeneização Assintótica. Em seguida, a metodologia é aplicada para determinação dos coeficientes efetivos para arranjo quadrático e hexagonal com fibra de geometria quadrada. Empregando diferentes frações volumétricas de fibras, os resultados via MEF foram comparados aos resultados analíticos obtidos através do Método dos Campos Uniformes (Uniform Field Method). Após a avaliação das limitações e potencialidades da metodologia, de forma direta, através de resultados analíticos, realizou-se a avaliação da mesma de forma indireta. Para tal, foram realizadas análises dinâmicas visando comparar as Funções de Resposta em Frequência (FRF) experimentais com as obtidas computacionalmente. Dessa forma, utilizou-se uma viga de alumínio estrutural engastada-livre, onde foram colados duas pastilhas piezelétricas, sendo uma para realizar a excitação da estrutura e, a outra para fazer a aquisição dos dados. Os modelos computacionais via MEF empregaram para o domínio das pastilhas, as propriedades efetivas determinadas através da metodologia desenvolvida. Os resultados obtidos demonstraram mais uma vez as potencialidades da metodologia proposta. Assim, conclui-se que a metodologia numérica não é somente uma boa alternativa para o cálculo de coeficientes efetivos de compósitos inteligentes, mas também uma ferramenta para o projeto de estruturas inteligentes monitoradas por materiais piezelétricos.

Palavras-chave: Compósito piezelétrico, active fiber composite, macro fiber composite, propriedades efetivas, modelagem por elementos finitos. 

MEDEIROS, R. Development of a Computational Methodology for Determining Effective Coefficients of the Smart Composites. 2012, 192p. Dissertation (Master of Science) - School of Engineering of São Carlos, University of São Paulo, São Carlos, SP, Brazil, 2012.

This work presents the development a numerical methodology to determine the mechanical properties of active macro composites (AFC - Active Fiber Composite, or MFC - Macro Fiber Composite), combining the concept of Representative Elementary Volume (REV) with the Finite Element Method (FEM). In the first instance, the theoretical framework associated with the numerical approach employed is presented. Later, numerical models based on unit cell are applied to predict the effective material coefficients of the transversely isotropic piezoelectric composite with circular cross section fibers. Finally, numerical results obtained by the proposed methodology are compared to other methods reported in the literature. It appears that the results are very similar to the literature results for square and hexagonal arrangement of fibers with circular geometry, in which case, it was compared numerical with analytical results calculated by Asymptotic Homogenization Method (AHM). After that, the methodology is applied to determine the effective coefficients for square and hexagonal array with square fiber geometry. Employing different fiber volume fractions, it follows that the results obtained by the proposed methodology were compared to analytical results calculated by the Uniform Field Method (UFM). After assessing the potential and limitations of the methodology, either directly, through analytical results, the evaluation took place in the indirect approach. Then, dynamic analyses were performed in order to compare the Frequency Response Functions (FRFs) determined by experimental tests with computational results. Thus, it was used a cantilever beam aluminum structure, which were bonded two piezoelectric patches, one to carry the excitement of the structure and the second to perform the data acquisition. The effective properties determined by the proposed methodology were applied for the dominium established by the piezoelectric patches. The results showed, again, the potential of the proposed methodology. Therefore, the numerical methodology is not only a good alternative for the calculation of effective coefficients of smart composite, but also a tool for the design of smart structures monitored by piezoelectric materials.

Keywords: Piezoelectric composites, active fiber composites, macro fiber composite, effective properties, finite element modeling. 



\section{LISTA DE FIGURAS}

FIGURA 1.1-1 - Exemplos de transdutores piezelétricos [adaptado de DERAEMAEKER; NASSER, 2010] 3

FIGURA 1.1-2 - Distribuição do Campo Elétrico para diferentes configurações de eletrodos

[DERAEMAEKER; NASSER, 2010]. 4

FIGURA 1.1-3 - Reforços piezelétricos: (a) fibras de seção circular e (b) fibras de seção retangular (SODANO, 2003)

FIGURA 1.1-4 - Conceito de um Sistema de Monitoramento de uma aeronave (GIURGIUTIU, 2010)6

FIGURA 1.3-1 - Dimensão característica $\delta$ [HASSANI; HINTON, 1998] .14

FIGURA 2.1-1 - Efeitos Piezelétrico Direto e Inverso [SILVA, 2007] .17

FIGURA 2.1-2 - Matrizes piezelétricas para as classes de simetria dos cristais [SILVA, 2007] .........20 FIGURA 2.1-3 - Matrizes Elásticas-Piezo-Dielétricas para as 32 Classes Cristalinas. [IEEE, 1987]23 FIGURA 2.1-4 - Ilustração esquemática da simetria do cristal de compósitos criada pela combinação de constituintes (matriz e fibras) com diferentes graus de anisotropia. [KAR-GUPTA, 2007a] .24

FIGURA 2.2-1 - Tipos de seção transversal de fibra PZT [SHINDE, 2005] 25

FIGURA 2.3-1 - Definição dos sistemas de coordenadas empregados [adaptado de BERGANDER, 2003].

FIGURA 2.3-2 - Terminologias e notações empregadas em piezeletricidade: índices subscritos e sobrescritos utilizados [http://www.sensortech.ca, 2012].

FIGURA 2.4-1 - Tipos de seção transversal de fibra PZT [SILVA, 2007].

FIGURA 2.8-1 - AFC (a) Compósito com fibras unidirecionais em um arranjo quadrático (b) Volume Elementar Representativo (VER) - célula unitária

FIGURA 2.8-2 - AFC (a) Compósito com fibras unidirecionais em um arranjo hexagonal (b) Volume Elementar Representativo (VER) - célula unitária

FIGURA 2.8-3 - AFC (a) Compósito com fibras unidirecionais em um arranjo hexagonal 1-2 (b)

Volume Elementar Representativo (VER) - célula unitária. .44

FIGURA 2.8-4 - AFC (a) Compósito com fibras unidirecionais em um arranjo hexagonal 2-3 (b)

Volume Elementar Representativo (VER) - célula unitária .

FIGURA 2.8-5 - Nomenclatura das superfícies utilizadas neste trabalho .45

FIGURA 2.8-6 - Condições de contorno periódicas aplicadas em um VER [adaptado de Jin, 2008] .46 
FIGURA 3.1-1 - Metodologia científica empregada no trabalho 54

FIGURA 3.2-1 - Fibra com seção transversal circular (AFC): (a) Arranjo quadrático; (b) Arranjo hexagonal; (c) Arranjo hexagonal para cisalhamento 1-2 e (d) Arranjo hexagonal para cisalhamento 2-3.

FIGURA 3.2-2 - Fibra com seção transversal retangular (AFC): (a) Arranjo quadrático; (b) Arranjo hexagonal; (c) Arranjo hexagonal para cisalhamento 1-2 e (d) Arranjo hexagonal para cisalhamento 2-3.

FIGURA 3.2-3 - Primeira análise: (a) Equação constitutiva incorporando as condições de contorno;

(b) Representação do problema local usado para determinar os coeficientes efetivos relacionados com deformações normais.

FIGURA 3.2-4 - Segunda análise: (a) Equação constitutiva incorporando as condições de contorno;

(b) Representação do problema local usado para determinar os coeficientes efetivos relacionados com diferenças de potenciais entre as faces $\mathrm{Z}-\mathrm{e} Z+$.

FIGURA 3.2-5 - Terceira análise: (a) Equação constitutiva incorporando as condições de contorno;

(b) Representação do problema local usado para determinar os coeficientes efetivos relacionados com deformações normais.

FIGURA 3.2-6 - Quarta análise: (a) Equação constitutiva incorporando as condições de contorno;

(b) Representação do problema local usado para determinar os coeficientes efetivos relacionados com diferenças de potenciais entre as faces $\mathrm{Z}-\mathrm{e} \mathrm{Z}+$.

FIGURA 3.2-7 - Quinta análise: (a) Equação constitutiva incorporando as condições de contorno;

(b) Representação do problema local usado para determinar os coeficientes efetivos relacionados com forças cisalhantes.

FIGURA 3.2-8 - Sexta análise: (a) Equação constitutiva incorporando as condições de contorno; (b)

Representação do problema local usado para determinar os coeficientes efetivos relacionados com forças cisalhantes.

FIGURA 3.2-9 - Carregamento de cisalhamento puro no plano XY.

FIGURA 3.3-1 - Configurações de Transdutores PZT: (a) AFC com seção transversal quadrada polarizada nas extremidades, (b) AFC com seção transversal quadrada polarizada em cada camada, (c) Pastilha piezelétrica, (d) $M F C^{T M}$.

FIGURA 4.1-1 - Modelos em elementos finitos utilizados nas simulações - células unitárias e arranjos: (a) quadrático; (b) hexagonal; (c) hexagonal plano 1-2; (d) hexagonal plano 2-3.

FIGURA 4.1-2 - Resultados numéricos para AFC - Arranjo quadrático (Estudo de Caso I).............. 73

FIGURA 4.1-3 - Resultados numéricos para AFC - arranjo hexagonal (Estudo de Caso I) ............... 74

FIGURA 4.1-4 - Modelo em elementos finitos utilizado nas simulações: (a) VER com uma única camada; (b) VER com três camadas (multicamadas). 
FIGURA 4.2-1 - Modelo em elementos finitos utilizado nas simulações - células unitárias e arranjos:

(a) quadrático; (b) hexagonal; (c) hexagonal plano 1-2; (d) hexagonal plano 2-3................81

FIGURA 4.2-2 - Resultados numéricos para AFC - arranjo quadrático (Estudo de Caso II).............82

FIGURA 4.2-3 - Resultados numéricos para AFC - arranjo hexagonal (Estudo de Caso II)..............83

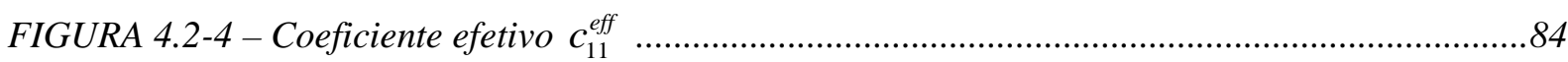

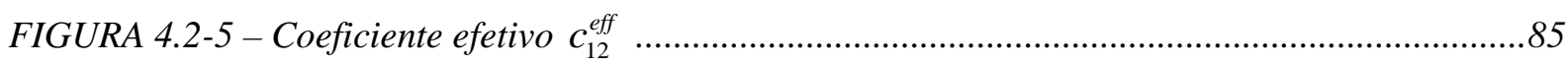

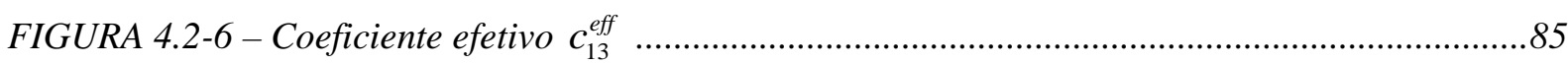

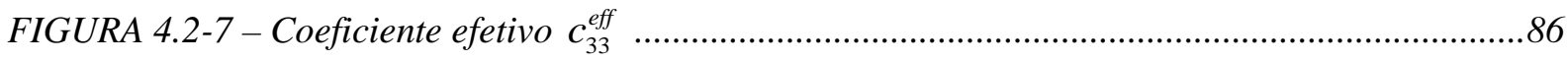

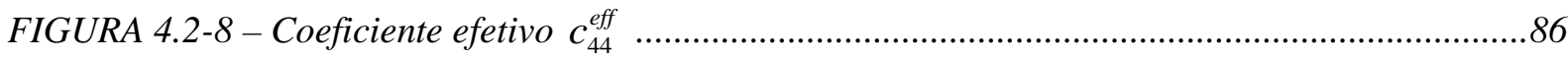

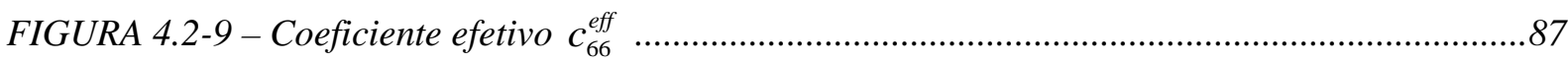

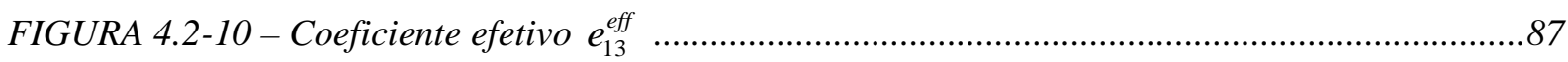

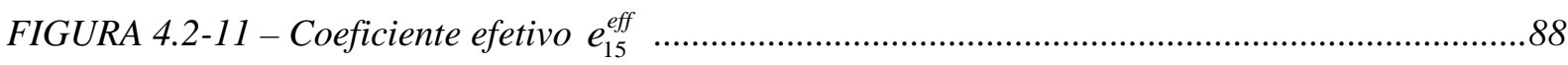

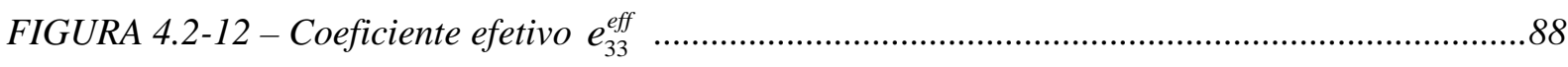

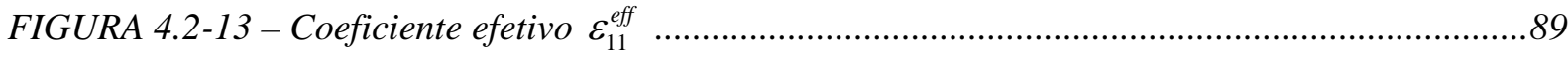

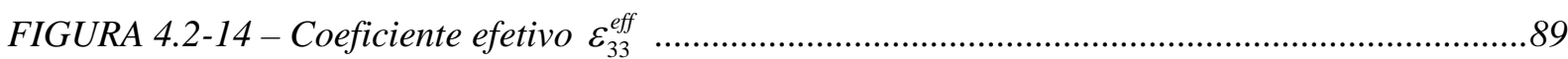

FIGURA 4.3-1 - (a) Pastilha piezelétrica Midé, (b) Espessura das camadas do transdutor (MIDÉ, 2010).

FIGURA 4.3-2 - Representação do esquemática do transdutor piezelétrico: (a) Célula unitária periódica selecionada; (b) Volume Elementar Representativo (VER) - correspondente à célula unitária.

FIGURA 4.3-3 - (a) Transdutor par o qual a metodologia foi desenvolvida; (b) Transdutor da Midé .

FIGURA 4.3-4 - Dimensões do Volume Elementar Representativo (VER) para representar o transdutor da Midé.

FIGURA 4.3-5 - Resultados das análises via MEF do modelo adotado para o Piezelétrico Midé QP10n

FIGURA 4.3-6 - (a) Esquema do ensaio experimental - equipamentos utilizados; (b) Modelo computacional (elementos tipo “shell”); (c) Modelo computacional(elementos tipo “solid”).

FIGURA 4.3-7 - Modos de vibrar da viga sem transdutores piezelétricos para elemento tipo Shell: (a) Modo 1; (b) Modo 2; (c) Modo 3; (d) Modo 4; (e) Modo 5 e (f) Modo6...................................98

FIGURA 4.3-8 - Modos de vibrar da viga sem transdutores piezelétricos para elemento tipo Solid: (a) Modo 1; (b) Modo 2; (c) Modo 3; (d) Modo 4; (e) Modo 5 e (f) Modo6. 
FIGURA 4.3-9 - FRF de uma viga sem elementos piezelétricos, gráfico linear x linear - Posição 1.

FIGURA 4.3-10 - FRF de uma viga sem elementos piezelétricos, gráfico log x linear - Posição 1.. 100

FIGURA 4.3-11 - FRF de uma viga sem elementos piezelétricos, gráfico linear x linear - Posição 2

FIGURA 4.3-12 - FRF de uma viga sem elementos piezelétricos, gráfico log x linear - Posição 2.. 101

FIGURA 4.3-13 - Representação esquemática da viga utilizada (dimensões em mm) ....................... 103

FIGURA 4.3-14 - Esquema do ensaio experimental - equipamentos utilizados. 104

FIGURA 4.3-15 - (a) Montagem da viga em balanço na base inercial - Ensaio experimental; (b) Modelo computacional da viga com transdutores piezelétricos. 105

FIGURA 4.3-16 - Modos de vibrar da viga com os transdutores piezelétricos: (a) Modo 1; (b) Modo 2; (c) Modo 3; (d) Modo 4; (e) Modo 5 e (f) Modo6. 106

FIGURA 4.3-17 - FRF de uma viga com elementos piezelétricos atuador e sensor, gráfico linear $x$ linear

FIGURA 4.3-18 - FRF de uma viga com elementos piezelétricos atuador e sensor, gráfico log x linear 108

FIGURA 4.3-19 - FRF de uma viga com elementos piezelétricos em circuito aberto, gráfico linear x linear - Posição 1 110

FIGURA 4.3-20 - FRF de uma viga com elementos piezelétricos em circuito aberto, gráfico log $x$ linear - Posição 1

FIGURA 4.3-21 - FRF de uma viga com elementos piezelétricos em circuito aberto, gráfico linear $x$ linear - Posição 2

FIGURA 4.3-22 - FRF de uma viga com elementos piezelétricos em circuito aberto, gráfico log $x$ linear - Posição 2

FIGURA 4.3-23 - FRF de uma viga sem elementos piezelétricos e com elementos piezelétricos em curto circuito, gráfico linear x linear - Posição 1

FIGURA 4.3-24 - FRF de uma viga sem elementos piezelétricos e com elementos piezelétricos em curto circuito, gráfico log x linear - Posição 1.

FIGURA 4.3-25 - FRF de uma viga sem elementos piezelétricos e com elementos piezelétricos em curto circuito, gráfico linear x linear - Posição 2

FIGURA 4.3-26 - FRF de uma viga sem elementos piezelétricos e com elementos piezelétricos em curto circuito, gráfico log x linear - Posição 2.

FIGURA 4.3-27 - FRF de uma viga com elementos piezelétricos modificando os coeficientes, gráfico linear $x$ linear

FIGURA 4.3-28 - FRF de uma viga com elementos piezelétricos modificando os coeficientes, gráfico $\log x$ linear 116

FIGURA 7.1-1 - Representação das Superfícies de Estudo. 135 
FIGURA 7.2-1 - Descrição do domínio periódico e sua respectiva célula unitáia. (BRAVO-

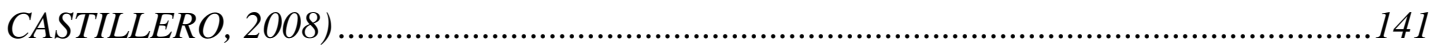

FIGURA 7.6-1 - Seleção da variável de entrada (voltagem pastilha 1) ..............................................157

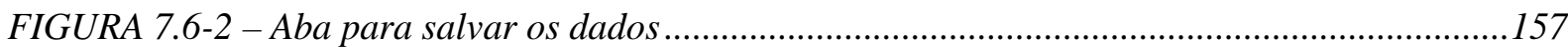

FIGURA 7.6-3 - Operando com os dados de entrada e saida...........................................................158

FIGURA 7.6-4 - Criação da equação da função de resposto em frequência (FRF)............................159

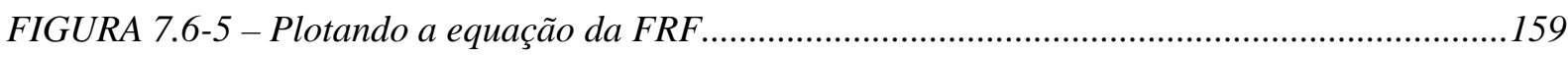

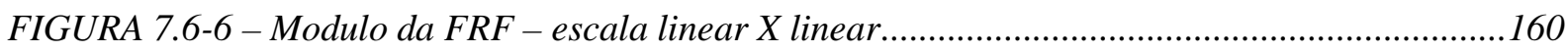

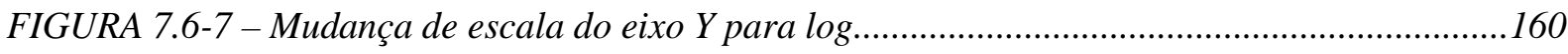

FIGURA 7.6-8 - Função de resposta em frequência - Escala log X linear ..........................................161 



\section{LiSTA DE TABELAS}

TABELA 2.1-1 - Lista de materiais piezelétricos e suas simetrias de cristais - (KAR-GUPTA;

VENKATESH, 2007a) .18

TABELA 2.3-1 - Descrição dos índices sobrescritos e condições de contorno.

TABELA 2.9-1 - Trabalhos científicos aplicados a algumas classes de materiais compósitos (adaptado de KAR-GUPTA; VENKATESH, 2007a)

TABELA 3.2-1 - Carregamentos e Condições de Contorno Requisitados .

TABELA 4.1-1 - Propriedades de materiais: matriz (resina epóxi) e fibra (PZT-5A) - (BERGER et al., 2005) .71

TABELA 4.1-2 - Avaliação da metodologia proposta para o Estudo de Caso I .76

TABELA 4.1-3 - Aplicação das Relações Universais para o Estudo de Caso I .78

TABELA 4.1-4 - Diferenças relativas dos resultados das Relações Universais: Arranjo Quadrático para o Estudo de Caso I.

TABELA 4.1-5 - Diferenças relativas dos resultados das Relações Universais: Arranjo Hexagonal para o Estudo de Caso I.

TABELA 4.1-6 - Avaliação da metodologia: tamanho de célula unitária.............................................80

TABELA 4.3-1 - Propriedades do reforço (“fibra”) (MIDÉ, 2010) .....................................................91

TABELA 4.3-2 - Dimensões do transdutor Midé Modelo QP10n (MIDÉ, 2010)..................................92

TABELA 4.3-3 - Propriedades Efetivas obtidas via metodologia para o transdutor Midé QP10n ......95

TABELA 4.3-4 - Valores das frequências para viga sem elemento piezelétrico 102

TABELA 4.3-5 - Valores das frequências para viga com elementos piezelétricos sensor e atuador: computacional $\times$ experimental. 108

TABELA 4.3-6 - Valores das frequências para viga com elementos piezelétricos em circuito aberto

TABELA 4.3-7 - Valores das frequências para viga: sem piezo x com piezo. 112

TABELA 4.3-8 - Valores das frequências para viga com elementos piezelétricos sensor e atuador: experimental $\times$ computacional $\times$ computacional com erro nos coeficientes 115

TABELA 4.3-9 - Valores das amplitudes máximas para viga com elementos piezelétricos sensor e atuador: experimental $\times$ computacional $\times$ computacional com erro nos coeficientes 115 TABELA 7.5-1 - Modos de Vibração para pastilhas piezelétricas (EIRAS, 2004) 156 



\section{LISTA DE SÍMBOLOS}

\begin{tabular}{|c|c|c|}
\hline$\epsilon_{0}$ & Permissividade no vácuo & $\mathrm{f} / \mathrm{m}$ \\
\hline$\epsilon_{i j}$ & Componentes de permissividade & $\mathrm{f} / \mathrm{m}$ \\
\hline$\epsilon_{i j k}$ & Tensor permutação & \\
\hline$\rho$ & Densidade & $\mathrm{kg} / \mathrm{m}^{3}$ \\
\hline$\tau$ & Tempo & $\mathrm{s}$ \\
\hline$\phi$ & Potencial elétrico escalar & $\mathrm{V}$ \\
\hline$\omega$ & Frequência angular $(2 \pi f)$ & $\mathrm{Hz}$ \\
\hline$\partial V$ & Fronteira do domínio & \\
\hline$\Delta$ & Diferenças relativas & \\
\hline$\delta_{\mathrm{ij}}$ & Delta de Kronecker & \\
\hline$a_{r}$ & Restrições da fase $a$ & \\
\hline c & Fração volumétrica de fibra & \\
\hline $\mathrm{C}$ & Rigidez mecânica (ou Tensor Constitutivo) & $\mathrm{Pa}$ \\
\hline $\mathrm{C}_{\mathrm{ijkl}}, \mathrm{C}_{\mathrm{pq}}$ & $\begin{array}{l}\text { Constantes elástica de rigidez } \\
\text { (ou Componentes do Tensor Constitutivo) }\end{array}$ & $\mathrm{Pa}$ \\
\hline$c a_{i}^{j}$ & Vetor deslocamento de um nó $i$ ao longo da & $j \mathrm{~m}$ \\
\hline $\mathrm{d}_{\mathrm{ijk}}, \mathrm{d}_{\mathrm{ip}}$ & Constantes piezelétricas & $\mathrm{m} / \mathrm{V}=\mathrm{C} / \mathrm{N}$ \\
\hline $\mathrm{D}$ (sobrescrito) & Para deslocamento elétrico constante & \\
\hline $\mathrm{D}$ & Deslocamento elétrico (densidade de fluxo e & $\mathrm{C} / \mathrm{m}^{2}$ \\
\hline $\mathrm{D}_{\mathrm{i}}$ & Componente de deslocamento elétrico & $\mathrm{C} / \mathrm{m}^{2}$ \\
\hline
\end{tabular}




$\begin{array}{lll}\mathrm{e}_{\mathrm{ijk}}, \mathrm{e}_{\mathrm{ip}} & \text { Constante piezelétrica } & \mathrm{C} / \mathrm{m}^{2} \\ \text { eff } & \text { Efetivo } & \\ \mathrm{E}_{\text {(sobrescrito) }} & \text { Para campo elétrico constante } & \\ \mathrm{E} & \text { Campo elétrico } & \mathrm{V} / \mathrm{m} \\ \mathrm{E}_{\mathrm{i}} & \text { Componente de campo elétrico } & \mathrm{V} / \mathrm{m} \\ f & \text { Frequência } & \mathrm{Hz} \\ \mathrm{f} & \text { Indicação de propriedades associadas à fibra } & \\ \mathrm{F}_{\mathrm{i}} & \text { Força aplicada em uma face } i & \mathrm{~N} \\ \mathrm{G}(\text { ) } & \text { Função densidade de energia } & \\ \mathrm{g}_{\mathrm{ijk}}, \mathrm{g}_{\mathrm{ip}} & \text { Constante piezelétrica } & \mathrm{V} \mathrm{m} / \mathrm{N}=\mathrm{m}^{2} / \mathrm{C} \\ \mathrm{h}_{\mathrm{ijk}}, \mathrm{h}_{\mathrm{ip}} & \text { Constante piezelétrica } & \mathrm{V} / \mathrm{m}=\mathrm{N} / \mathrm{C}\end{array}$

$k_{31}^{1} \quad$ Fator de acoplamento: deformação longitudinal com excitação transversal

$k_{33}^{1} \quad$ Fator de acoplamento: deformação longitudinal com excitação longitudinal

$k_{15}^{\mathrm{t}} \quad$ Fator de acoplamento: espessura-cisalhamento

$k_{33}^{\mathrm{t}} \quad$ Fator de acoplamento: espessura-deformação longitudinal

$k_{\mathrm{p}} \quad$ Fator de acoplamento planar

l Comprimento $\quad \mathrm{m}$

m Indicação de propriedades associadas a matriz

$\mathrm{S}_{\mathrm{ijkl}}, \mathrm{S}_{\mathrm{pq}} \quad$ Constante elástica de flexibilidade $\quad \mathrm{m}^{2} / \mathrm{N}$

(ou Tensor Constitutivo Inverso)

S Superfície arbitrária $\mathrm{m}^{2}$

S (sobrescrito) Para deformação constante

S Deformação mecânica (ou Tensor de Deformação)

$\mathrm{S}_{\mathrm{ij}}, \mathrm{S}_{\mathrm{p}} \quad$ Componentes de deformação (ou Componentes do Tensor de Deformação) 


$\begin{array}{lll}\mathrm{T}_{\text {(sobrescrito) }} & \text { Para tensão constante } & \mathrm{N} / \mathrm{m}^{2} \\ \mathrm{~T} & \text { Tensão mecânica (ou Tensor de Tensão) } & \mathrm{m} \\ \mathrm{t} & \text { Espessura } & \mathrm{N} / \mathrm{m}^{2} \\ \mathrm{~T}_{\mathrm{ij}}, \mathrm{T}_{\mathrm{p}} & \text { Transposta } & \\ & \text { Componentes de tensão } & \mathrm{m} \\ \mathrm{u}_{\mathrm{i}} & \text { (ou Componentes do Tensor de Tensões) } & \\ \mathrm{V} & \text { Vetor deslocamento mecânico } & \mathrm{m}^{3} \\ |\mathrm{~V}| & \text { Domínio } & \mathrm{m} \\ \mathrm{W} & \text { Volume da célula unitária } & \\ \mathrm{X}, \mathrm{Y}, \mathrm{Z} & \text { Largura } & \\ \mathrm{X}_{\mathrm{i}} & \text { Eixos de coordenadas de um cristal } & \\ \end{array}$



RESUMO XI

ABSTRACT XIII

LISTA DE FIGURAS XV

LISTA DE TABELAS XXI

LISTA DE SÍMBOLOS XXIII

SUMÁRIO XXVII

1. INTRODUCÃO, JUSTIFICATIVAS E OBJETIVOS 1

1.1. INTRODUÇÃO E JUSTIFICATIVAS

1.2. OвJETIVos

8

1.3. Estrutura do Trabalho

2. FUNDAMENTAÇÃO TEÓRICA E REVISÃO BIBLIOGRÁFICA 13

2.1. Piezeletricidade 15

2.2. SEÇÃo TranSVERSAL das Fibras 25

2.3. SiSTEMA dE NotAÇÃo E DE ORIENTAÇÃo 26

2.4. Equações Constitutivas para Materiais Piezelétricos 28

2.5. TeOrema das MÉdias - Formulação do Problema 34

2.6. Coeficientes Efetivos de Compósitos Inteligentes Piezelétricos 39

2.7. RELAÇÕES UNIVERSAIS 
2.8. Volume ElEMENTAR REPRESENTATIVo (VER) E CONDIÇÕES DE CONTORNo

2.9. Abordagens para Previsão de Comportamento de Compósitos

Piezelétricos

3. METODOLOGIA 53

3.1. Metodologia Científica

3.2. Metodologia Computacional Proposta

3.2.1. PRIMEIRA ANÁLISE

3.2.2. SEGUNDA ANÁLISE

3.2.3. TERCEIRA ANÁLISE

3.2.4. QUARTA ANÁLISE

3.2.5. QUINTA ANÁLISE

3.2.6. SEXTA ANÁLISE

3.2.7. CONSIDERAÇÕES

3.3. Discussões Acerca da Metodologia

4. APLICAÇÃO DA METODOLOGIA COMPUTACIONAL: LIMITAÇÕES E POTENCIALIDADES

4.1. Estudo de CAso I $\quad 71$

4.1.1. DAdOS DO MATERIAL

4.1.2. Modelo em Elementos Finitos 72

4.1.3. LiMitAÇÕES E POTENCIALIDADES

4.2. Estudo de CASo II 80

4.3. ESTUdo de CASO III 90

4.3.1. DeterminaÇÃo dos CoefiCientes EfETIVOS 91

4.3.2. CARACTERÍSTICAS VIGA SEM PASTILHAS PIEZELÉTRICAS 96

4.3.3. CARACTERÍSTICAS DA VIGA COM PASTILHAS PIEZELÉTRICAS 102

4.3.4. ANÁLISES ACERCA DOS RESULTADOS COM E SEM ELEMENTOS PIEZELÉTRICOS 109

5. CONCLUSÕES E PERSPECTIVAS FUTURAS

6. REFERÊNCIAS BIBLIOGRÁFICAS 
7.1. ANEXo 1 - TEOREMA DAS MÉdias 132

7.2. ANEXo 2-MÉTOdo HomogeneizAÇão AssintóticA 140

7.3. ANEXo 3-Método dos CAMPOS Uniformes 148

7.4. ANEXo 4 - EFEITO dAs CONDIÇÕES de CONTORNo ElÉtricAs E MECÂNICAS 150

7.5. ANeXo 5 - Modos de Vibração em Materiais Piezelétricos 155

7.6. ANEXO 5 - DETERMINAÇÃO DA FRF 157

7.7. Anexo 6 - Publicações Vinculadas ao Projeto 162 



\section{INTRODUÇÃO, JUSTIFICATIVAS E OBJETIVOS}

\subsection{INTRODUÇÃO E JUSTIFICATIVAS}

Os materiais nas mais variadas formas podem adquirir uma ampla faixa de propriedades. Contudo, apenas um material não é suficiente para proporcionar um balanço perfeito das propriedades requeridas para uma aplicação específica. Na prática, muitas vezes de maneira acidental ou empírica, descobriu-se que a mistura de dois ou mais materiais, muito frequentemente, é uma combinação vantajosa de propriedades. Dessa forma, constata-se a importância de se desenvolver uma metodologia científica rigorosa, que seja capaz de predizer o comportamento global de meios heterogêneos e, assim, fornecer informações para a melhor utilização do material. Esta situação chamou a atenção de muitos pesquisadores (engenheiros, físicos, matemáticos, etc.), que através de resultados de suas investigações, têm contribuído para o desenvolvimento de um ramo muito importante designado por Mecânica de Materiais Compósitos (BRAVO-CASTILLERO, 2010).

Levando em consideração o atual cenário tecnológico, onde se busca reduzir a quantidade de componentes nos sistemas, especialmente nos sistemas miniaturizados e sistemas onde o peso total é fator crítico (por exemplo: sistemas embarcados), tem-se que as pesquisas em Mecânica de Materiais Compósitos são extremamente estratégicas. Para isso, dispositivos inteligentes capazes de realizar mais de uma função tem sido desenvolvidos, muitas vezes empregando um material ativo inteligente, que por sua vez é um dispositivo de conversão de energia, transformando uma dada forma de energia em outra. Em sendo assim, a utilização destes dispositivos se traduz em redução de peso, de espaço e de custo, dependendo da aplicação.

Neste contexto, a tendência crescente é o estudo de materiais com características físicas que possibilitem a realização de tarefas múltiplas, como as ligas com memória de forma, polímeros eletroativos e materiais piezelétricos. Cada um destes materiais aceita um tipo de campo de entrada e resulta em um campo de saída de outra forma. Por exemplo, uma 
liga com memória de forma produz um campo de deslocamento em resposta a um campo térmico de entrada; já um polímero eletroativo produz um campo de deslocamento em resposta a um campo elétrico de entrada. Em alguns casos, os materiais ativos exibem uma reversível relação entrada/saída, e o campo de entrada do material é permutável com o campo de saída, por exemplo, uma entrada elétrica resulta em uma saída mecânica e, uma entrada mecânica resulta em uma saída elétrica.

A inserção destes materiais no projeto de equipamentos permite o desenvolvimento de dispositivos mais eficientes, compactos e até mesmo mais silenciosos, com a vantagem extra da possibilidade de controle integrado ao sistema, dispensando o uso de controladores externos. Em função desses aspectos positivos, a utilização de materiais piezelétricos tem crescido consideravelmente nas indústrias aeronáutica, automobilística e naval, sendo tais materiais requisitados em aplicações diversas. Por exemplo, em aeronaves, materiais inteligentes são empregados na supressão de vibrações estruturais e em sistemas de posicionamento e sensoriamento, aumentado o desempenho dos equipamentos e até mesmo o conforto dos passageiros.

No caso dos satélites, onde a redução de peso é um fator de grande importância, os motores e atuadores piezelétricos têm sido utilizados em sistemas de posicionamento precisos, substituindo os servomotores na manipulação de pequenos mecanismos. Os materiais piezelétricos estão também presentes em manipuladores robóticos e na robótica móvel, assim como em aplicações que utilizem sistemas embarcados, tais como: submarinos, helicópteros e outros tipos de veículos.

Em se tratando, particularmente, da indústria aeronáutica, sistemas atuadores e de sensoriamento constituem um vital componente na aplicação de controle de estruturas. Dessa forma, sensores fornecem informação sobre o estado da estrutura, o qual pode ser alimentado por um algoritmo de controle para produzir a resposta apropriada, ordenando que o atuador aplique determinados esforços na estrutura. Assim, os materiais ativos têm sua aplicação aumentada, substituindo os tradicionais projetos eletromecânicos para atuação e sensoriamento. Diante desse contexto, verifica-se que as aplicações de materiais ativos resultaram aos cientistas, novas possibilidades tecnológicas para o controle de resposta de estruturas.

Com base no que foi supracitado, constata-se o crescente emprego de materiais inteligentes e, assim, o número de pesquisas efetuadas sobre o referido tema vem aumentando 
de forma significativa. Portanto, um dos desafios impostos consiste em caracterizar o mais fidedignamente possível o comportamento dos materiais piezelétricos sob diferentes condições de utilização. Sendo que dentre essas condições, tem-se o uso desses materiais na forma de transdutores, sensores, atuadores, motores, filtros, entre outros.

Um transdutor piezelétrico típico é fabricado a partir de uma camada ativa ensanduichada entre duas camadas finas encapsuladas (Figura (1.1-1)). O encapsulamento desempenha duas funções distintas: (i) aplicar pré-esforços para a camada ativa, a fim de evitar fissuras; (ii) produzir campo elétrico na camada ativa através da utilização de um eletrodo na superfície (DERAEMAEKER; NASSER, 2010).

Modo d31 - Eletrodo Contínuo

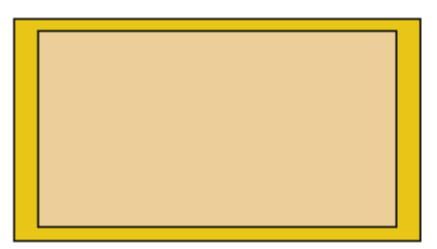

Modo d 33 - Eletrodos Interdigitais

(Hagood, 1993)

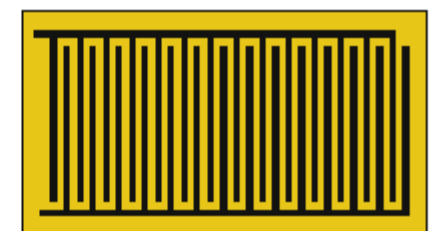

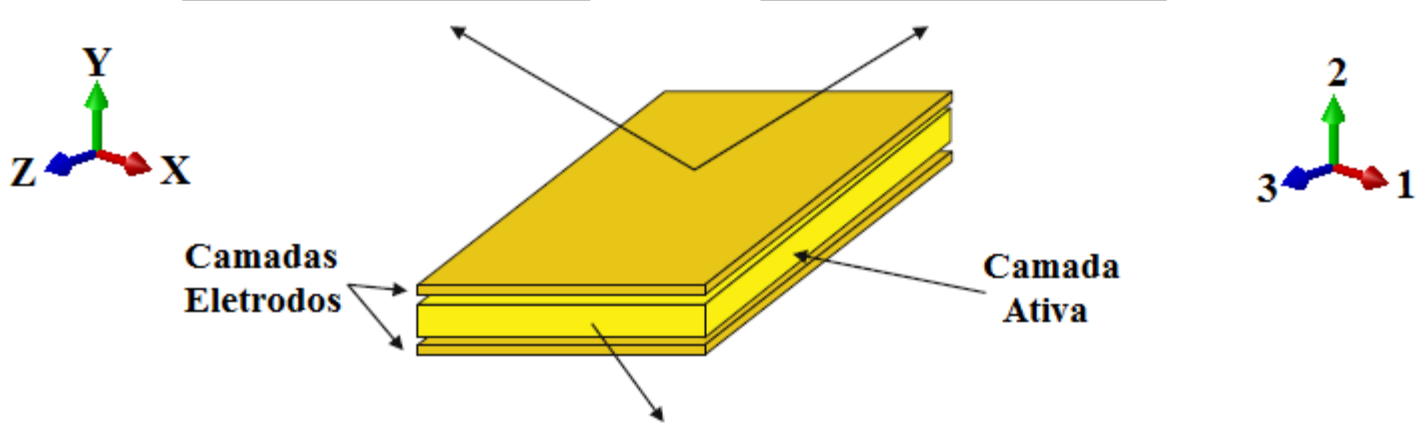

Pastilha Cerâmica

QuickPack (Lazarus, 1997)

Flexpatch (Horner, 2002)

DuraAct (Wierach, 2002)

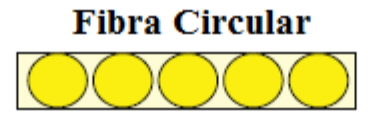

Active Fiber Composite

(AFC) (Hagood, 1993)

(Bowen, 1994)

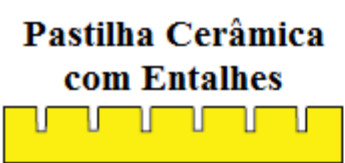

Poweract (Master, 2002)

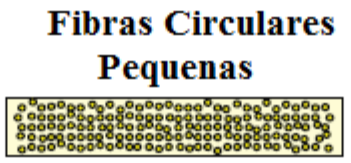

Piezo Fiber Composite (PFC)

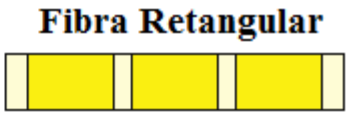

Macro Fiber Composite

(MFC) (Wilkie, 2000) 
Os eletrodos podem ser tanto contínuos como interdigitais (Figura (1.1-2)), influenciando assim, na polarização do material. No caso dos contínuos, verifica-se que há uma diferença de tensão aplicada entre os eletrodos do topo e da base, resultando em um campo elétrico perpendicular ao plano do transdutor. No caso dos interdigitais, constata-se a ocorrência de um campo elétrico “curvo”, preferencialmente alinhado na direção 3 do material piezelétrico, por exemplo, na direção longitudinal das fibras ativas (HAGOOD et al., 1993). Ao comparar as fibras piezelétricas acionadas no modo $d_{31}$ com as acionadas no modo $\mathrm{d}_{33}$, tem-se uma maior deformação, entretanto, as tensões elétricas aplicadas são mais elevadas para o referido modo.

(a) Modo d31

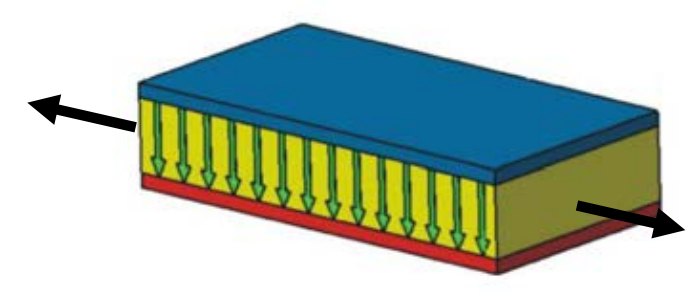

Eletrodo Positivo
Eletrodo Negativo
Campo Elétrico
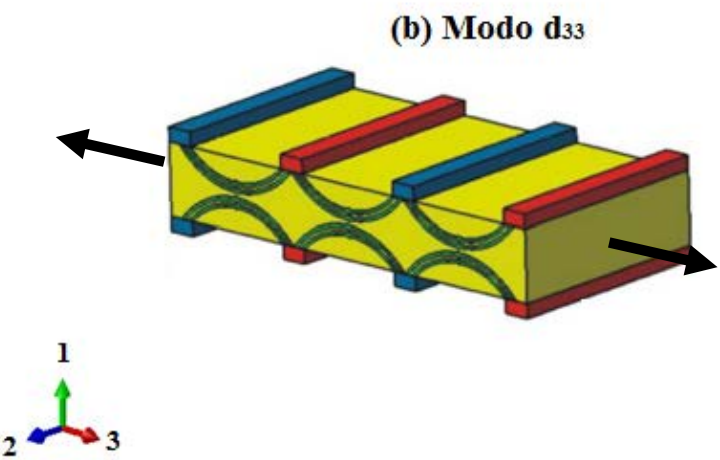

FIGURA 1.1-2 - Distribuição do Campo Elétrico para diferentes configurações de eletrodos [DERAEMAEKER; NASSER, 2010]

Na família de transdutores piezelétricas, existem muitos tipos diferentes, diferindo principalmente na configuração do eletrodo e do tipo de camada ativa, que pode consistir de um material cerâmico (LAZARUS et al, 1997;. HORNER, 2002; WIERACH, 2002; MASTER, 2002), de geometria cilíndrica (BENT e HAGOOD, 1993, 1995, 1997; BOWEN, 1994), também chamado AFC (Active Fiber Composite) e, que foi desenvolvido pelo MIT (Massachusetts Institute of Technology). Por outro lado, há também as fibras de seções transversais quadradas (WILKIE et al., 2000), também chamadas MFC ${ }^{\mathrm{TM}}$ (Macro Fiber Composite) e, que foram desenvolvidas pela Nasa Langley Resarch Center, ou ainda, pequenas fibras abordadas por Wierach (2006) e Williams et al. (2002a) e (2002b). Vale ressaltar que no presente trabalho serão abordadas principalmente os compósitos inteligentes fabricados a partir de AFCs. 
Ainda com relação aos PFCs (Piezo Fiber Composites - Figura (1.1-1)), tem-se que estas fibras podem ser incorporadas a um dado material compósito (por exemplo, um laminado constituído de camadas de fibra de carbono embebidas em resina epóxi), de modo que as mesmas façam parte da estrutura final. Desta forma, evita-se que o material piezelétrico tenha de ser aplicado posteriormente (em geral através de colagem) na superfície de interesse. Ademais, expandem-se as possibilidades de projeto, uma vez que as fibras piezelétricas podem ser em teoria, adicionadas em qualquer camada do compósito, de acordo com os requisitos em questão. Atualmente, no mercado, encontra-se, por exemplo, os atuadores piezelétricos desenvolvidos pela Smart Material Corporation. Tais PFCs consistem de reforços piezelétricos embebidos em uma matriz polimérica. O material cerâmico piezelétrico está alinhado com a direção longitudinal, enquanto que o polímero é contínuo, resultando num compósito ativo do tipo 1-3, pois é acionado no modo $\mathrm{d}_{13}$. Cabe destacar que o processo de fabricação desenvolvido possibilita obtenção de fibras ativas com seção circular (diâmetros de 70 micrometros e espaços de 50 micrometros), bem como, seção retangular (aresta de 80 micrometros com espaços de 50 micrometros) como mostrado na Figura (1.1-3) (SODANO, 2003).

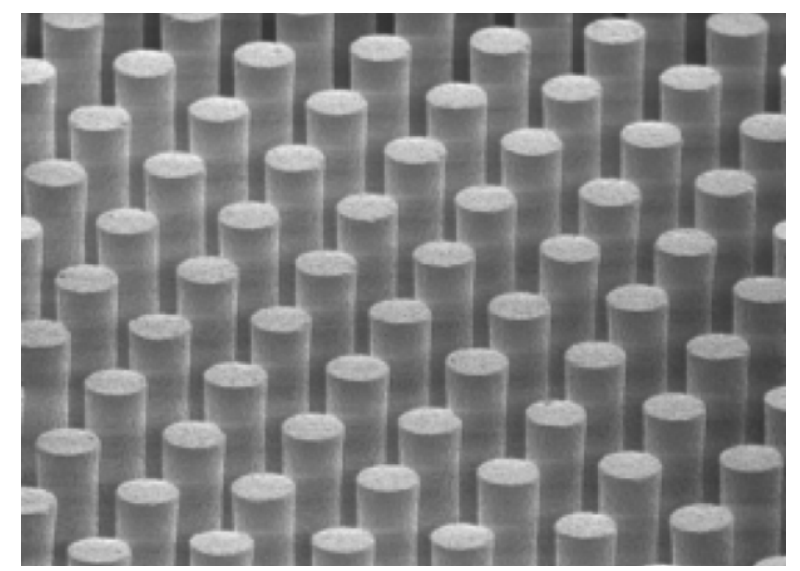

(a)

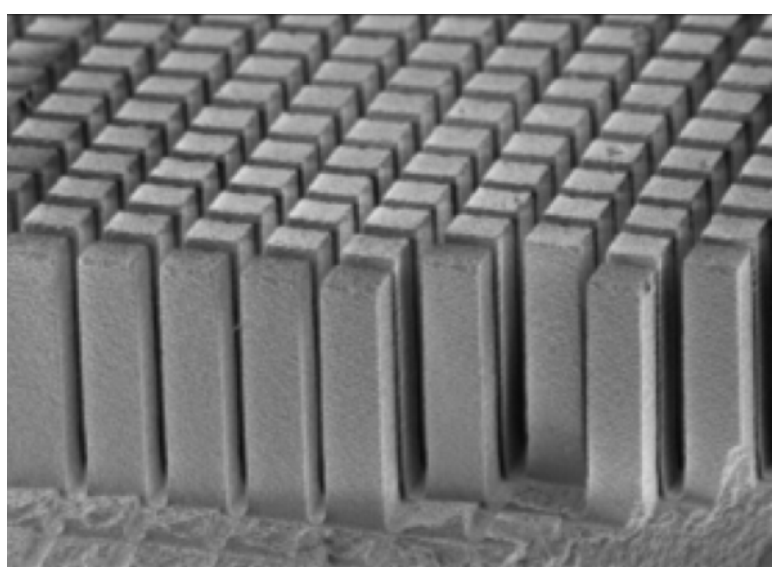

(b)

FIGURA 1.1-3 - Reforços piezelétricos: (a) fibras de seção circular e (b) fibras de seção retangular (SODANO, 2003)

As fibras supracitadas possuem grande potencial para solução de problemas de engenharia, devido à sua capacidade de atender criteriosos requisitos de projeto, necessários, sobretudo na indústria aeronáutica e aeroespacial. Sendo que um dos grandes destaques consiste em aplicar tais compósitos inteligentes em monitoramento da integridade estrutural 
(SHM - Structural Health Monitoring) (Figura (1.1-4)). No caso específico de aplicações aeronáuticas, verifica-se que duas grandes frentes têm sido abordadas. A primeira consiste na utilização destes materiais como sensores, monitorando a integridade estrutural de peças primárias da aeronave, bem como no monitoramento de reparos realizados ao longo da vida útil da aeronave. A segunda aplicação, mais complexa, consiste na utilização como atuadores, aplicados a pás de hélices, de turbinas, asas de aviões entre outras, de modo a suprimir ou diminuir vibrações indesejáveis provenientes de carregamentos aerodinâmicos. A utilização como atuador exige o trabalho em conjunto com um sistema de controle adequadamente implementado. No entanto, deve-se destacar que o principal enfoque deste trabalho, quanto a aplicações aeronáuticas, é o emprego de materiais inteligentes como sensores, com especial atenção em monitoramento da integridade estrutural (SHM), conforme a Figura (1.1-4).

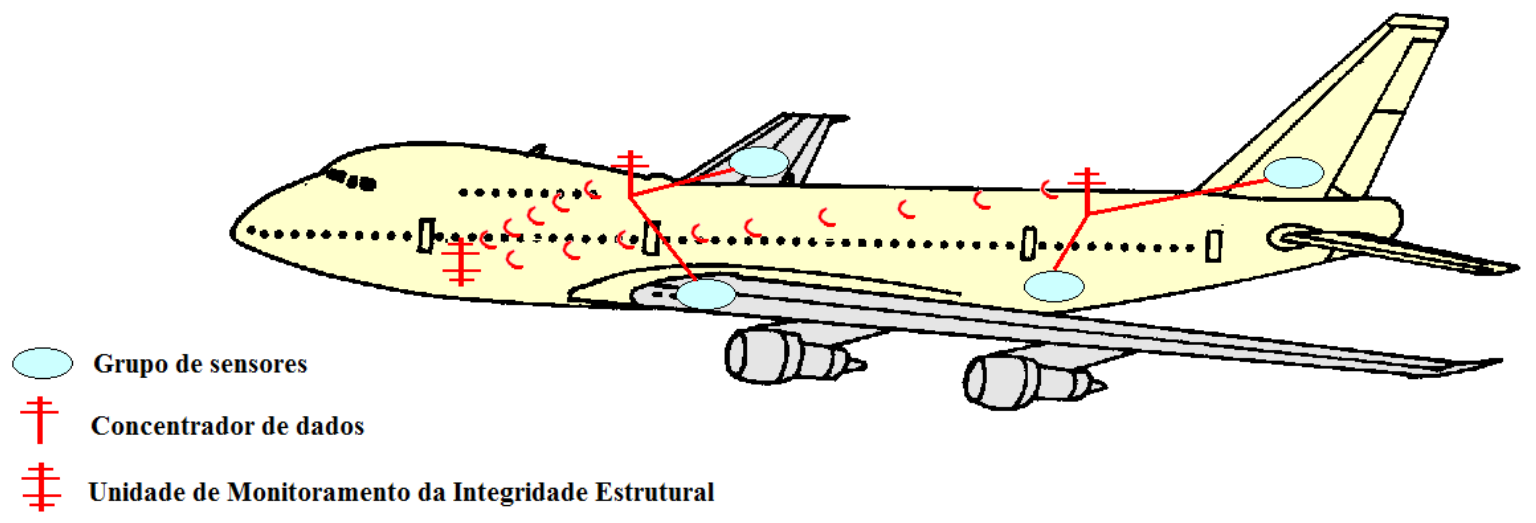

FIGURA 1.1-4 - Conceito de um Sistema de Monitoramento de uma aeronave (GIURGIUTIU, 2010)

Portanto, conclui-se que as aplicações como um todo exigem o desenvolvimento de metodologias de cálculo e previsão do comportamento e das propriedades destes materiais inteligentes. Essas metodologias devem possuir um alto nível de confiabilidade e muitas vezes são baseadas em abordagens numéricas, experimentais, analíticas ou híbridas. Dentre as abordagens numéricas, uma das mais utilizadas baseia-se no Método dos Elementos Finitos. Entretanto, atualmente, os pacotes comerciais disponíveis possuem uma capacidade limitada para tratar este tipo de problema. Por exemplo, é possível a simulação integrada considerando efeitos piezelétricos e mecânicos, mas não estão disponíveis elementos finitos laminados, que também apresentem a opção de material com multicamadas contendo propriedades mecânicas e/ou eletromecânicas diferente. 
Dessa forma, a solução geralmente consiste em "ensaiar numericamente” corpos-deprova do material compósito e obter parâmetros médios, de tal forma que nas simulações computacionais considera-se a hipótese de que o material é homogêneo. Verifica-se assim, que esta hipótese não é muito adequada, pois o material, na verdade, é heterogêneo e, portanto, pode-se acertadamente deduzir que é muito difícil a obtenção de todos os parâmetros associados ao mesmo.

Uma solução, largamente empregada neste sentido, é a utilização de uma abordagem micromecânica baseando-se num Volume Elementar Representativo (VER), que é tipicamente definido como sendo a menor porção simplificada do meio contínuo capaz de representar o domínio completo de uma lâmina de material compósito. Este volume é analisado analiticamente ou numericamente com condições de contorno apropriadas para representar o comportamento do compósito com fibras ativas. Com base nos resultados do VER, pode-se determinar, então, os parâmetros efetivos do material compósito piezelétrico (material compósito ativo ou inteligente), incluindo o acoplamento eletromecânico.

A partir deste ponto existem divergências sobre como abordar o problema de estruturas complexas fabricadas em materiais compósitos ativos. Sendo que é possível encontrar na literatura, pesquisadores que utilizam a abordagem micro mecânica para caracterização (CHAN, 1989; BENVENISTE E DVORAK, 1992; BISEGNA, 1997; SILVA et al. 1999; BERGER et al., 2005; KAR-GUPTA E VENKATESH, 2007a; MORENO et al., 2009; TRINDADE E BENJEDDOU, 2010, 2011), utilizando o conceito de volume elementar representativo (VER). Por outro lado, há pesquisadores que utilizam uma abordagem macro mecânica associada a ensaios experimentais (HAGOOD E FLOTOW, 1991; AGNES E INMAN, 1996; GUENNAM E LUCCIONI, 2006; MELNYKOWYCZ et al., 2006; LARBI et al., 2012). Sendo que no presente trabalho, será empregada uma abordagem micro mecânica baseada no conceito de VER.

Por fim, diante do cenário apresentado, constata-se que vários fatores justificam e motivam o estudo e o desenvolvimento de metodologias capazes de prever, com um alto nível de precisão e confiabilidade, o comportamento e as propriedades efetivas de materiais compósitos ativos. 


\subsection{OBJETIVOS}

O presente trabalho visa propor uma metodologia computacional para a determinação das propriedades (coeficientes efetivos) de materiais compósitos ativos, empregando uma abordagem micromecânica baseada no conceito de VER. Sendo que as limitações e potencialidades da referida metodologia serão criteriosamente avaliadas. Devido à amplitude do presente objetivo geral, o mesmo é dividido nos objetivos específicos a seguir:

$\square$ Realizar uma revisão bibliográfica visando compreender os trabalhos científicos mais relevantes, bem como, os mais recentes que foram desenvolvidos na área de análise de materiais compósitos ativos, empregando abordagem numérica, analítica e/ou experimental;

$\square$ Desenvolver uma metodologia computacional baseada em conceitos de Volume Elementar Representativo (VER), com solução via Método dos Elementos Finitos (MEF), a fim de se obter as propriedades mecânicas, elétricas e piezelétricas, mais especificamente, os coeficientes efetivos associados ao tensor constitutivo de materiais compósitos ativos;

$\square$ Avaliar as potencialidades e limitações da metodologia proposta, através de estudos de caso. Sendo que a referida avaliação basear-se-á tanto em abordagens diretas como indiretas. $\mathrm{Na}$ abordagem direta, as propriedades obtidas pela metodologia serão confrontadas com resultados da literatura e/ou analíticos. Na abordagem indireta, temse praticamente um exemplo prático de aplicação da metodologia proposta. Haja vista que os resultados experimentais de elementos estruturais (ex: vigas em alumínio) monitorados por transdutores (pastilhas) piezelétricos de material ativo deverão ser confrontados com resultados computacionais via MEF, cujas propriedades atribuídas ao domínio do compósito ativo serão provenientes da metodologia proposta.

\subsection{ESTRUTURA Do TrabalHo}

A organização desta dissertação foi planejada de tal forma que a filosofia do processo de homogeneização aplicado ao problema da determinação das propriedades efetivas dos materiais compósitos piezelétricos fosse apresentada como a base da metodologia proposta. Sendo assim, o trabalho foi estruturado da seguinte forma: 
$\square$ Capitulo 1 - Introdução, Justificativas e Objetivos: neste primeiro capítulo, apresenta-se um breve estudo sobre o fenômeno piezelétrico e suas aplicações através dos materiais piezelétricos, bem como a motivação para compreender o comportamento desses materiais. Além disso, mostra-se como um conhecimento mais aprofundado nesta área pode fornecer grandes melhorias para a tecnologia atual. Por fim, os objetivos principais foram sumarizados de forma a apresentar as principais contribuições referentes ao presente trabalho.

】 Capitulo 2 - Fundamentação Teórica e Revisão Bibliográfica: neste capítulo, expõem-se a teoria dedicada ao estudo dos materiais compósitos e piezelétricos, abordando diferentes tópicos. Dentre esses se destacam: as Equações Constitutivas, que regem o comportamento destes materiais; o Teorema das Médias, que é empregado como hipótese para determinação dos coeficientes; as Relações Universais, que representam uma forma de medir o erro associado aos coeficientes determinados; o conceito de Volume Elementar Representativo, que é utilizado num modelo computacional, visando idealizar um meio homogêneo equivalente ao compósito original. Somado a isto tudo, se apresenta ainda uma revisão da literatura sobre as abordagens para previsão dos coeficientes efetivos.

$\square$ Capitulo 3 - Metodologia Proposta: primeiramente este capítulo apresenta a método científico utilizado neste trabalho para determinação e comparação, além da aplicação dos coeficientes efetivos. Em seguida este capítulo versa sobre o desenvolvimento de uma metodologia computacional para previsão dos coeficientes efetivos para materiais piezelétricos, utilizando toda a fundamentação teórica apresentada no Capítulo 2. Sendo que a base desta metodologia consiste em avaliar um meio global homogêneo equivalente ao compósito original, onde a energia armazenada nos dois sistemas são aproximadamente as mesmas, com ênfase especial nas condições de contorno adequadas.

$\square$ Capitulo 4 - Aplicação da Metodologia Proposta/Resultados e Discussões: neste capítulo, primeiramente os modelos numéricos solucionados via Método dos Elementos Finitos (MEF) são aplicados na determinação dos coeficientes efetivos de materiais compósitos inteligentes transversalmente isotrópicos com fibras piezelétricas de seção com forma circular e quadrada, respectivamente. Sendo que os resultados numéricos obtidos pela metodologia proposta são, então, comparados com resultados da literatura, resultados estes obtidos através do Método de Homogeneização Assintótica. Em seguida, a metodologia é aplicada para a determinação dos 
coeficientes efetivos para arranjo quadrático e hexagonal com fibra de seção quadrada, empregando diferentes frações volumétricas. Sendo que os resultados via metodologia foram comparados com resultados analíticos obtidos através do Método dos Campos Uniformes (Uniform Field Method). Após demonstrar a avaliação das limitações e potencialidades da metodologia, através de resultados analíticos, demonstra-se a aplicação da mesma de forma indireta, ou seja, através de uma aplicação prática da metodologia. Para tal, foram realizadas análises dinâmicas visando comparar as Funções de Resposta em Frequência (FRF) experimentais com as obtidas computacionalmente. Dessa forma, utilizou-se uma viga de alumínio estrutural sob a condição engastada-livre, contendo dois transdutores piezelétricos colados em sua superfície. Assim, a metodologia proposta foi avaliada, apresentando suas potencialidades e limitações, uma vez que as propriedades efetivas associadas aos transdutores foram obtidas através da referida metodologia.

$\square$ Capitulo 5 - Conclusões e Perspectivas para Trabalhos Futuros: este capítulo apresenta as principais conclusões obtidas do presente trabalho com base na discussão de resultados efetuada no Capítulo 4. Dessa forma, finaliza-se a dissertação, sumarizando as principais contribuições e, apresentando também as perspectivas para trabalhos futuros.

Ø Capitulo 6 - Referências Bibliográficas: este capítulo contempla toda a literatura utilizada na elaboração deste trabalho, desde as citadas em partes do texto como as consultadas para obtenção de dados adicionais.

$\square$ Anexos: Textos suplementares esclarecedores relativos ao conteúdo do trabalho:

$\checkmark$ Anexo 1 - Teorema das Médias: dedução das equações mecânicas e elétricas, demonstrando que a média de uma grandeza é igual a grandeza média.

$\checkmark$ Anexo 2 - Método da Homogeneização Assintótica (AHM - Asymptotic Homogenization Method): aplicação do método na determinação das equações para os cálculos dos coeficientes efetivos de materiais piezelétricos.

$\checkmark$ Anexo 3 - Método dos Campos Uniformes (UFM - Uniform Field Method): aplicação do método na determinação das equações para os cálculos dos coeficientes efetivos de materiais piezelétricos.

$\checkmark$ Anexo 4 - Efeito das condições de contorno elétricas: As propriedades de materiais piezelétricos são expressas matematicamente como uma relação entre as variáveis mecânicas, tensão e deformação, e duas variáveis elétricas, o campo elétrico e o deslocamento elétrico. Dessa forma, os efeitos piezelétricos 
diretos e inversos são escritos como um conjunto de equações lineares. Esse conjunto de equações para o efeito piezelétrico direto e inverso pode ser combinado em uma expressão matricial, relacionando, assim, a deformação e o deslocamento elétrico como uma função da tensão mecânica e do potencial elétrico aplicado.

$\checkmark$ Anexo 5 - Modos de vibração em materiais piezelétricos apresenta as geometrias mais comuns utilizadas para analisar transdutores piezelétricos, bem como as condições de contorno aplicadas e os coeficientes que podem ser determinados.

$\checkmark$ Anexo 6 - Determinação de Função de Resposta em Frequência utilizando o software Abaqus.

$\checkmark$ Anexo 7 - Lista de publicações vinculadas ao presente trabalho. 



\section{FUNDAMENTAÇÃo TEÓRICA E REVISÃo BIBLIOGRÁFICA}

Em uma escala suficientemente pequena, todos os materiais são heterogêneos. Isto pode ser confirmado com base no elevado grau de desordem e variabilidade que pode acontecer na escala de átomos e moléculas. Se os materiais de engenharia fossem projetados neste nível, a teoria poderia ser inconsistente. Para solucionar esta dificuldade, se introduz a hipótese de meio contínuo. Esta hipótese envolve um processo de média estatística, sendo que a estrutura e a construção real do material são idealizadas por um meio contínuo.

Além disso, define-se ainda a existência de certas medidas associadas às propriedades, que regem a deformação deste meio contínuo. Estas propriedades médias são muito complicadas de serem obtidas a partir de uma escala atômica ou molecular. Em sendo assim, recorre-se ao conceito de homogeneidade. Deve-se destacar que para um meio homogêneo, as propriedades intrínsecas, que o caracterizam, são iguais em todos os pontos de um meio contínuo.

Por outro lado, as condições de heterogeneidade podem ocorrer se as propriedades do contínuo variam espacialmente, ou se existem mudanças ou contrastes substanciais das propriedades nas interfaces. Neste trabalho será abordado, particularmente, o segundo caso, incluindo uma combinação de fases, que permanecem diferentes, ou seja, um material composto por n-fases homogêneas. Cabe ressaltar que este tipo de heterogeneidade é um dos mais importantes sob o ponto de vista de aplicações de engenharia.

Considerando a existência de uma dimensão característica associada à homogeneidade, por exemplo, a distância entre duas inclusões, tem-se que esta dimensão característica é uma idealização grosseira de uma distribuição estatística para um sistema heterogêneo real. No entanto, é natural que se aceite a existência de uma escala de comprimento sobre a qual é possível calcular a média das propriedades.

A escala de comprimento de cálculo da média $(\delta)$ deve ser uma dimensão maior que a dimensão característica da homogeneidade e, muito menor quando comparada com a dimensão característica do meio em análise. Com base nesta hipótese, o material pode ser 
considerado como um meio globalmente homogêneo e o problema de contorno sobre este corpo pode ser resolvido empregando propriedades médias associadas com a escala de comprimento $\delta$, conforme mostra a Figura (1.3-1).

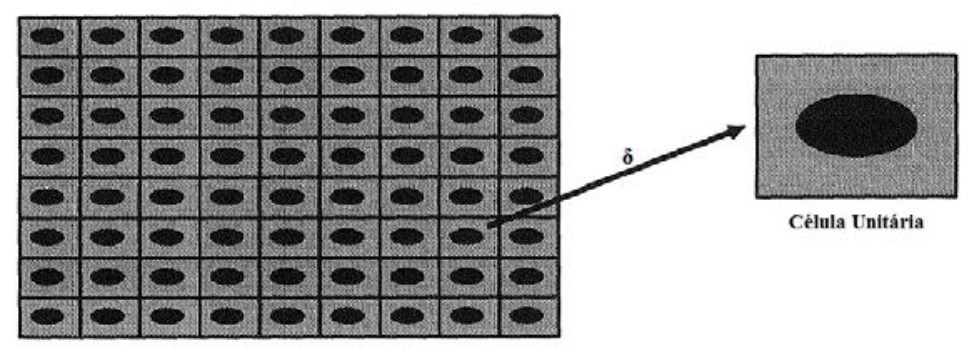

FIGURA 1.3-1 - Dimensão característica $\delta$ [HASSANI; HINTON, 1998]

Destaca-se que em todas as análises deste trabalho será considerada uma escala de propriedades médias representativa. Tal escala de homogeneidade assumirá ordens de grandeza muito menores que as dimensões características do problema de interesse, de tal maneira que existe a dimensão intermediária sobre a qual as propriedades médias podem ser calculadas.

A condição supracitada é designada como condição de homogeneidade efetiva ou equivalente e a amostra do material (meio contínuo) que a satisfaz, recebe o nome de Volume Elementar Representativo (VER). Este conceito é amplamente empregado no estudo das propriedades globais (efetivas) de materiais compósitos, devido ao enorme trabalho que resultaria em estudar separadamente cada região homogênea do material. Esta pode ser uma tarefa quase que impraticável em sistemas heterogêneos providos de milhares de partículas ou fibras, principalmente, caso sejam consideradas as condições de continuidade dos deslocamentos e das tensões em cada uma das interfaces.

Admitindo o conceito de homogeneidade equivalente, o problema fundamental relativo ao comportamento de materiais heterogêneos pode ser estabelecido. Dessa forma, o problema básico consiste em estabelecer o processo de cálculo das médias para predizer as propriedades efetivas do meio homogêneo idealizado. Sendo que este processo de cálculo será função das propriedades físicas das fases individuais e da forma geométrica das interfaces. Uma vez calculadas as propriedades efetivas, torna-se possível transformar o problema original de contorno, sobre um meio heterogêneo, em um problema de contorno sobre um meio homogeneizado equivalente caracterizado por tais propriedades efetivas. 
No caso específico de fibras de materiais piezelétricos embebidas em uma matriz polimérica não condutora, dentre as abordagens empregadas, têm-se o desenvolvimento de técnicas analíticas, que consistem em uma homogeneização das propriedades do material, bem como de técnicas experimentais, onde se procura fazer a caracterização dos materiais constituintes e do compósito final. Todavia, as técnicas que empregam análise numérica, sobretudo o Método dos Elementos Finitos (MEF), têm sido muito exploradas. A análise via MEF divide-se em análises micro mecânicas e em análises macro mecânicas. Nas análises micro mecânicas, simula-se a fibra e a matriz como uma célula unitária com condições de contorno apropriadas para torná-la representativa para toda a camada constituída por materiais ativos. Nas análises macro mecânicas, com suporte de ensaios experimentais do laminado final, utilizam-se propriedades médias nas regiões com a presença de compósitos inteligentes. Assim, um material heterogêneo é analisado como um meio homogêneo anisotrópico.

Diante do que foi exposto, justifica-se a necessidade de detalhar alguns assuntos relevantes para um melhor entendimento do presente trabalho. Dentre esses assuntos destacam-se: piezeletricidade; Teorema das Médias; coeficientes efetivos de compósitos inteligentes piezelétricos; Relações Universais; Volume Elementar Representativo (VER), bem como abordagens para previsão de comportamento de compósitos piezelétricos.

\subsection{PieZeletricidade}

Em 1880, Pierre e Jacques Curie descobriram o efeito piezelétrico, que é encontrado em muitos materiais, tais como turmalina, quartzo, topázio, cana de açúcar e sal Rochelle (SILVA, 2007). Eles descobriram que uma carga de superfície pode ser medida quando uma força mecânica é aplicada a certos cristais, que tinham sofrido um tratamento na superfície. Os irmãos Curie também descobriram que havia uma relação entre temperatura e intensidade de carga de superfície. No entanto, não conseguiram prever o "efeito piezelétrico inverso” (ou seja, obter uma saída elétrica a partir de uma força mecânica, como entrada). Até que em 1881, Gabriel Lippmann provou matematicamente a existência do "efeito piezelétrico inverso” (SILVA, 2007). Sendo assim, os irmãos Curie, em seguida, concluíram seus experimentos para mostrar que tal efeito era fisicamente possível (SILVA, 2007). O então efeito piezelétrico foi utilizado em uma aplicação prática pela primeira vez por Paul Langevin, no desenvolvimento de sonares durante a primeira guerra mundial. Langevin 
utilizou cristais de quartzo acoplados a massas metálicas (coincidentemente, o pesquisador estava inventando o transdutor tipo Langevin) para gerar ultrassom na faixa de algumas dezenas de kHz. Após a primeira guerra mundial, devido à dificuldade de se excitar transdutores construídos com cristais de quartzo, por estes demandarem geradores de alta tensão, iniciou-se o desenvolvimento de materiais piezelétricos sintéticos. Estes esforços levaram a descoberta e aperfeiçoamento nas décadas de 40 e 50 (do século XX), das cerâmicas piezelétricas de Titanato de Bário pela então URSS e Japão, e das cerâmicas piezelétricas de Titanato Zirconato de Chumbo (PZT) pelos EUA (ZAMBRANO; PEREIRA, 2004). O desenvolvimento das cerâmicas piezelétricas foi revolucionário. Além de apresentarem melhores propriedades que os cristais após “polarizadas”, também oferecem geometrias e dimensões flexíveis por serem fabricadas através da sinterização de póscerâmicos conformados via prensagem ou extrusão (ZAMBRANO; PEREIRA, 2004).

A piezeletricidade é definida como a interação linear entre o estado mecânico e o estado elétrico em cristais sem centro de simetria. A ausência de centro de simetria é a condição mais importante para a presença de piezeletricidade. Quando não há centro de simetria os íons positivos e negativos se movimentam, um em relação ao outro (como resultado da pressão), produzindo dipolos elétricos (polarização). Entre os minerais que possuem esta propriedade, o quartzo é marcante, pois ao se aplicar pequenas pressões paralelamente a um de seus eixos, produz uma corrente elétrica capaz de ser detectada. A turmalina também é piezelétrica, sendo muito usada como detectora de pressão, isto é, cálculo da pressão a partir da corrente gerada. Substâncias artificiais que também apresentam piezeletricidade: Sal de Rochelle, cerâmicas, PVDF-fluoreto de polivinilideno. Portanto, a piezeletricidade é a propriedade que certos materiais cristalinos apresentam de desenvolver eletricidade quando submetidos à pressão mecânica, sendo então denominados materiais piezelétricos (ISOLDI, 2008). Estes materiais podem ser empregados em diferentes áreas, como: instrumentações médicas, controle de processos industriais, aplicações elétricas domésticas, indústria aeronáutica e automobilística, geração de energia, entre outras. De uma maneira geral, as aplicações dos materiais piezelétricos são divididas em quatro categorias: geradores, sensores, atuadores e transdutores (ISOLDI, 2008).

A Figura (2.1-1) apresenta um esquema dos efeitos piezelétrico direto e inverso, verifica-se, assim, que as respostas mecânicas e dielétricas estão acopladas em materiais piezelétricos. Consequentemente, as variáveis mecânicas de tensão e deformação estão relacionadas entre si, bem como as variáveis elétricas de campo elétrico e "deslocamento 
elétrico” (densidade de fluxo elétrico). O acoplamento entre os campos elétrico e mecânico é, então, descrito por coeficientes. Deve-se destacar que para o presente trabalho, considerar-seá que os materiais piezelétricos apresentam deformações muito pequenas e possuem resposta linear devido a mudanças no campo elétrico, no “deslocamento elétrico”, bem como nas tensões ou nas deformações mecânicas.

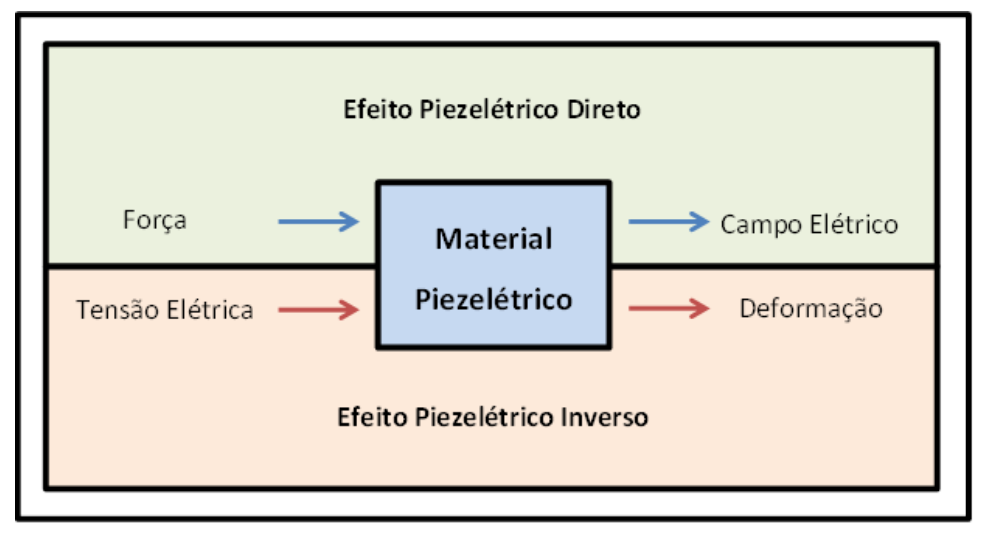

FIGURA 2.1-1 - Efeitos Piezelétrico Direto e Inverso [SILVA, 2007]

Dependendo da natureza de anisotropia elástica (por exemplo: completamente anisotrópico, transversalmente isotrópico, ou isotrópico) e da atividade piezelétrica (por exemplo: ativo ou passivo) da matriz e da fibra, tem-se que 36 classes de materiais compósitos podem ser identificadas. Além disso, para cada classe de material compósito piezelétrico, diversas subclasses podem ser reconhecidas com base na orientação relativa das direções de polarização dos constituintes, matriz e fibra. Kar-Gupta e Venkatesh (2007a) agruparam os materiais compósitos piezelétricos como: (a) "longitudinal” - a matriz e a fibra são polarizadas na direção longitudinal; (b) "transversal” - a matriz e a fibra são polarizadas na direção transversal.

Os grupos pontuais ou classes cristalinas representam a simetria ou combinações de simetria, que levam a um padrão de repetição distinto. Toda e qualquer molécula pode ser classificada em um dos 32 grupos pontuais possíveis. Os 32 grupos pontuais possíveis são formados pelos 10 elementos básicos de simetria e mais 22 combinações entre estes. Apenas 22 combinações são possíveis, pois muitas levam a repetições de simetria e, outras são incompatíveis com a simetria cristalina, ou seja, os elementos de simetria não podem ser combinados arbitrariamente. Os 10 elementos básicos são dados por:

$$
\begin{array}{llllllllll}
m & \overline{1} & 1 & 2 & 3 & 4 & 6 & \overline{3} & \overline{4} & \overline{6}
\end{array}
$$


Sendo que as 22 combinações são dadas por:

$\begin{array}{lllllll}2 / m & 4 / m & 6 / m & & & & \\ 222 & 32 & 422 & 622 & 432 & 23 & \\ m m m & 3 m & 4 / m m m & 6 / m m m & m \overline{3} m & m \overline{3} & \\ m m 2 & 3 m & 4 m m & \overline{4} m 2 & 6 m m & \overline{6} m 2 & \overline{4} 3 m\end{array}$

A Tabela (2.1-1) ilustra os principais materiais compósitos piezelétricos, suas respectivas classes cristalinas e o arranjo cristalino.

TABELA 2.1-1 - Lista de materiais piezelétricos e suas simetrias de cristais - (KAR-GUPTA; VENKATESH, 2007a)

\begin{tabular}{|c|c|c|}
\hline Material & Classe & Arranjo cristalino \\
\hline Sulfeto de cádmio & \multirow{5}{*}{$6 \mathrm{~mm}$} & \multirow{5}{*}{ Hexagonal } \\
\hline Titanato zirconato de chumbo (PZT) & & \\
\hline Difluoreto de polivinilideno (PVDF) & & \\
\hline Óxido de zinco & & \\
\hline Sulfeto de zinco & & \\
\hline Dihidrogenofosfato de amônio & \multirow{2}{*}{$\overline{4} 2 m$} & \multirow{2}{*}{ Tetragonal } \\
\hline Dihidrogenofosfato de potássio & & \\
\hline Niobato de sódio de bário & $\mathrm{mm} 2$ & Ortorrômbico \\
\hline Titanato de bário & $4 \mathrm{~mm}$ & Tetragonal \\
\hline Niobato de lítio & \multirow{2}{*}{$3 \mathrm{~m}$} & \multirow{2}{*}{ Trigonal } \\
\hline Tantalita de lítio & & \\
\hline Sal de Rochelle & 222 & Rômbico \\
\hline Bismuto óxido de germânio & \multirow{2}{*}{$\overline{4} 3 m$} & \multirow{2}{*}{ Cubico } \\
\hline Arseneto de gálio & & \\
\hline Dióxido de telúrio & 422 & Tetragonal \\
\hline
\end{tabular}

Dentre as diversas classes de simetria existentes para materiais piezelétricos, a escolha neste trabalho foi utilizar a classe $6 \mathrm{~mm}$, que apresenta um tipo de simetria hexagonal, dado o grande número de informações sobre as propriedades físicas deste PZT em literatura e catálogos de fabricantes (Ver Figura 2.1-2 - Retângulo em destaque). A classe de simetria de um PZT tem uma influência direta no formato do tensor de constantes piezelétricas como pode ser observado na Figura (2.1-2). 


\section{LEGENDA}

. elemento nulo

- $\quad$ elemento não nulo

- elementos idênticos

- - elementos simétricos

( ) elemento duas vezes menor e de sinal contrário ao seu par.

TRICLÍNICO

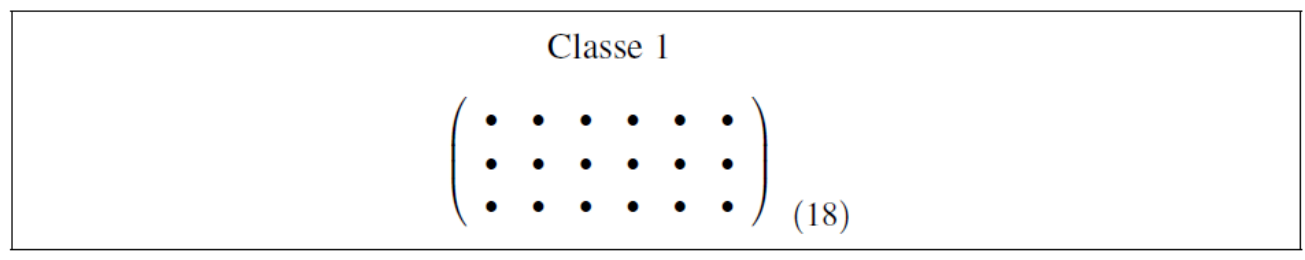

MONOCLÍNICO

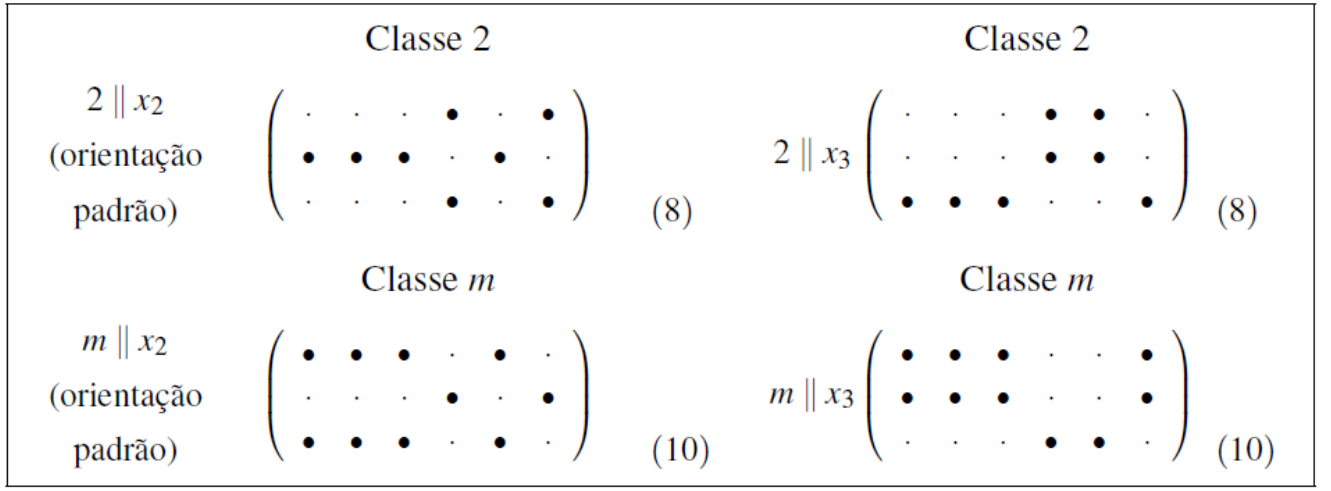

ORTORRÔMBICO

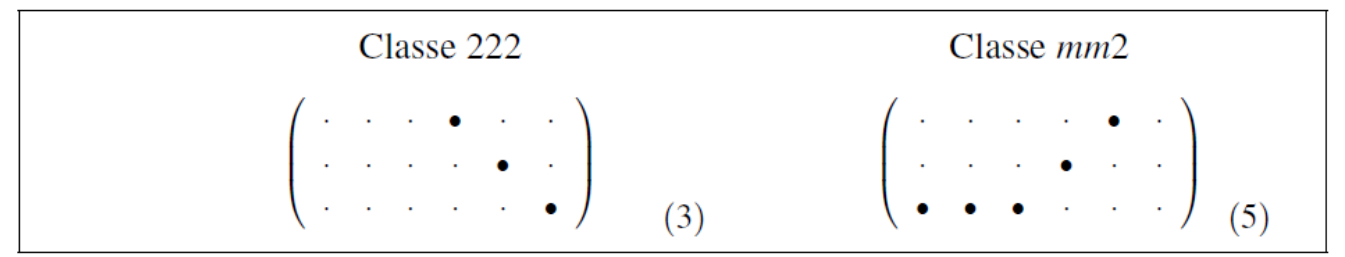

ROMBOÉDRICO OU TRIGONAL

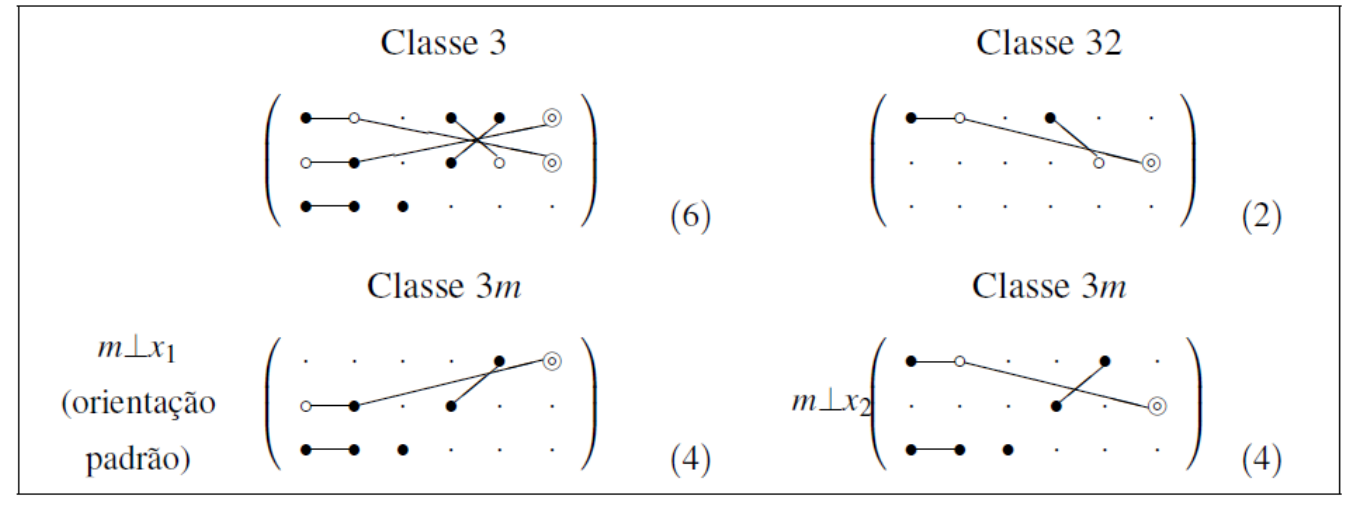


TETRAGONAL

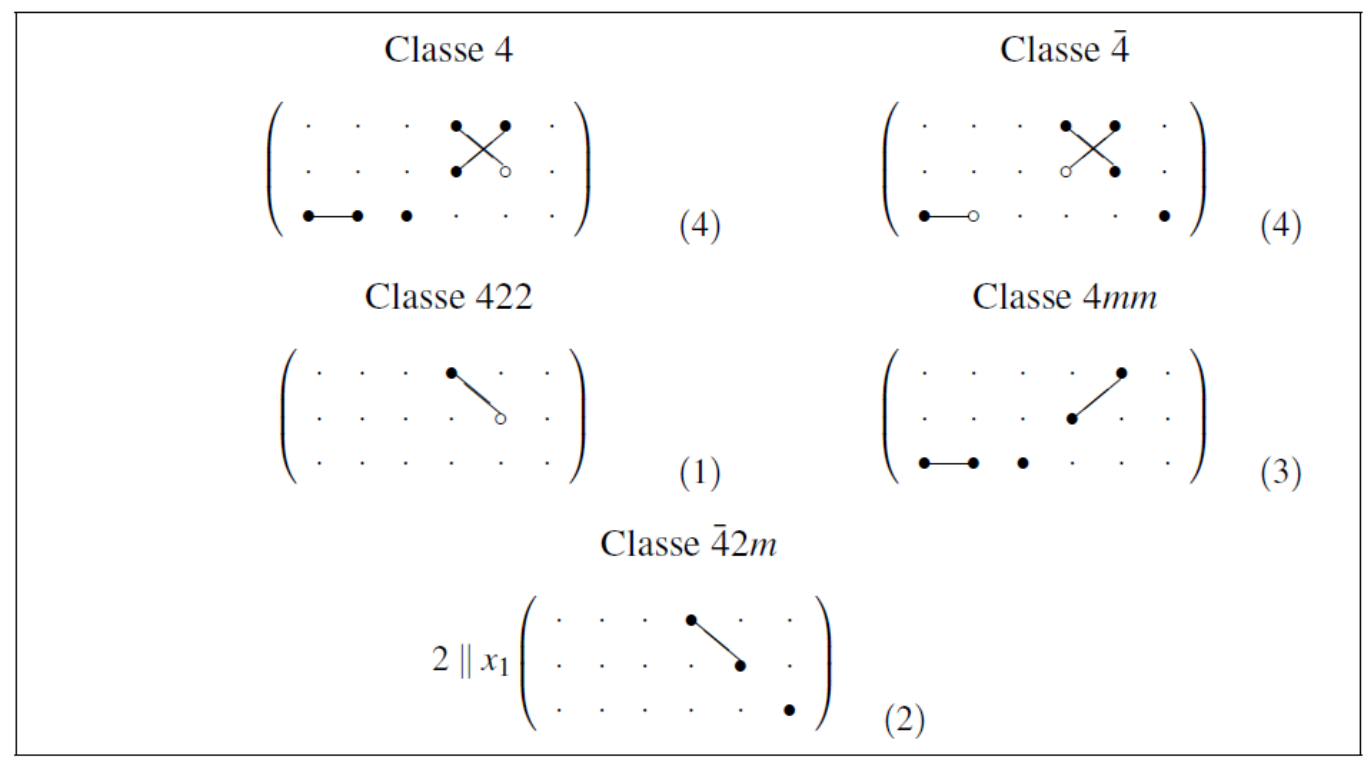

\section{CÚBICO}

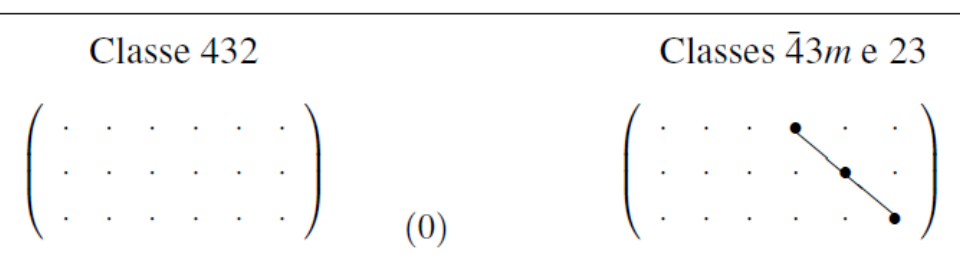

Todos os coeficientes nulos

\section{HEXAGONAL}

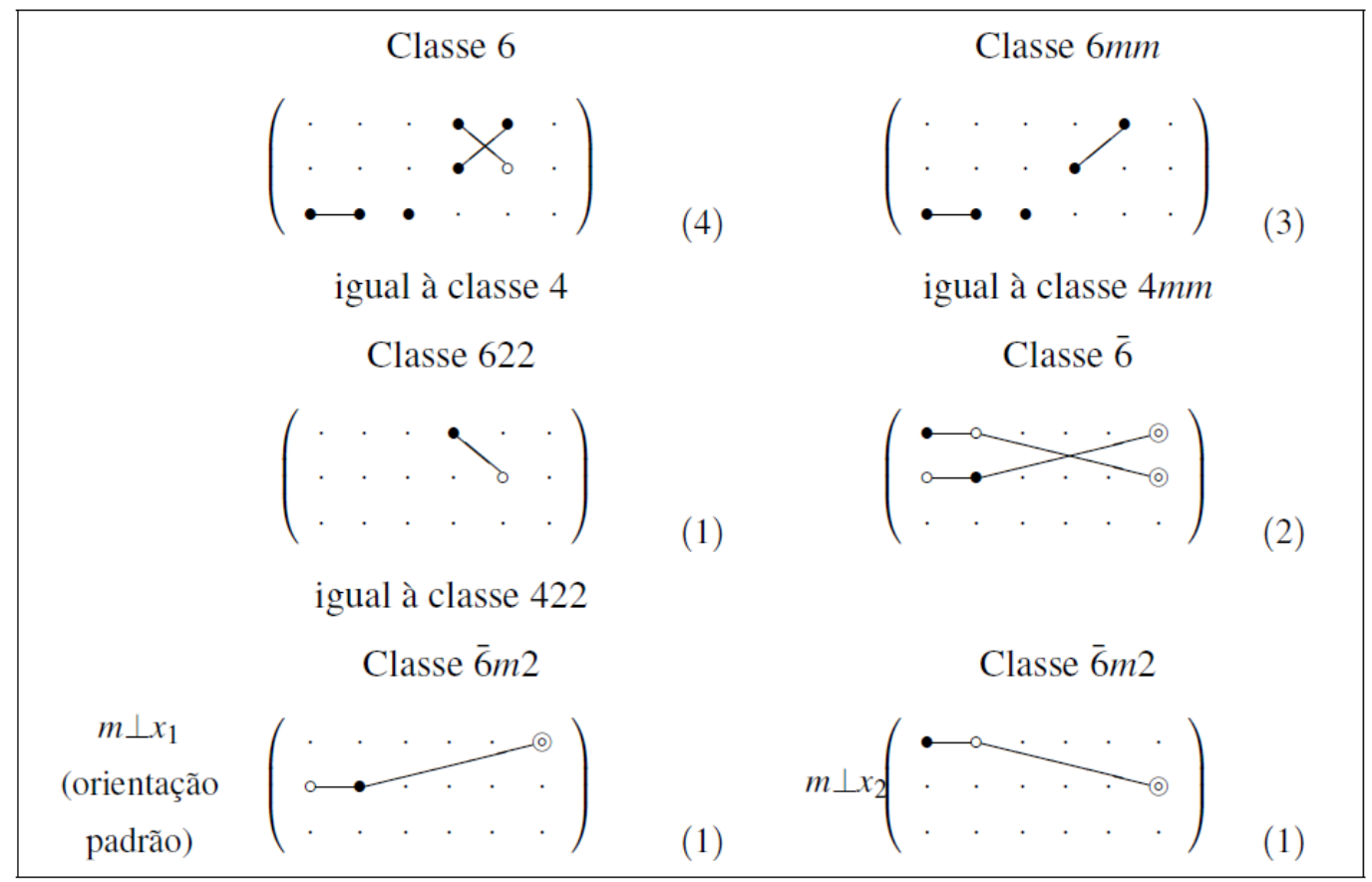

FIGURA 2.1-2 - Matrizes piezelétricas para as classes de simetria dos cristais [SILVA, 2007] 
Vale ressaltar que dadas às diferenças na matriz piezelétrica, cada classe de simetria apresentará um comportamento único. Apesar deste, trabalho utilizar um formato de matriz piezelétrica referente à Classe Hexagonal $(6 \mathrm{~mm})$, uma simples alteração do formato da matriz [e], tornará o modelo capaz de representar qualquer outro tipo de classe. Por exemplo, uma mudança no tipo de material, passando da Classe Hexagonal (6mm) para Classe Ortorrômbico (mm2), modificaria a matriz piezelétrica, uma vez que a mesma apresentaria 3 ao invés de 5 coeficientes independentes. Entretanto, realizando a alteração no formato de entrada de dados, a metodologia proposta neste trabalho seria capaz de determinar estes coeficientes.

Para materiais que não são piezelétricos, o comportamento mecânico e o comportamento elétrico são independentes um do outro. Porém, para materiais piezelétricos, os comportamentos mecânico e elétrico estão acoplados, onde as variáveis mecânicas de tensão, e de deformação, estão relacionadas entre si e também com as variáveis elétricas (campo elétrico e deslocamento elétrico). Estas equações constitutivas acopladas podem ser entendidas empiricamente com uma combinação linear dos efeitos puramente mecânicos ou puramente elétricos com o efeito piezelétrico (CHEE, 2000). A fim de avaliar as fases de resposta eletro-elástica do compósito, a estrutura do modelo é introduzido, para isso a Figura (2.1-3) apresenta uma forma simplificada das matrizes elasto-piezelétrica-dielétrica para todos os 7 sistemas cristalinos e as 32 classes cristalográficas, usando as notações internacionais de Hermann-Mauguin e Schoenflies (IEEE, 1987).

Os sistemas tetragonal e trigonal são divididos em 2 grupos designados como (a) e (b). Para o sistema tetragonal IV(b), $\mathrm{S}_{16}$ é igual a zero, enquanto para o sistema trigonal V(b), $\mathrm{S}_{25}$ é igual a zero. As 20 matrizes de constantes piezelétricas se reduzem a 16 matrizes independentes, desde que operações de simetria para $n=4$ e $n=6$ tenham o mesmo efeito na matriz piezelétrica e, as matrizes para as classes 23 e 3m sejam iguais (IEEE, 1987). Os números localizados ao lado direito de cada matriz indicam de cima para baixo, o número de constantes independentes elásticas, piezelétricas e dielétricas.

As Figuras (2.1-3) e (2.1-4) sumarizam as classes de simetria observada para compósitos, que corresponde a diversas combinações de constituintes (matriz e fibra), sendo que o retângulo em destaque representa a hipótese adotada neste trabalho para a matriz constitutiva dos constituintes, bem como para a matriz constitutiva resultante da combinação dos mesmos, para o compósito piezelétrico. 

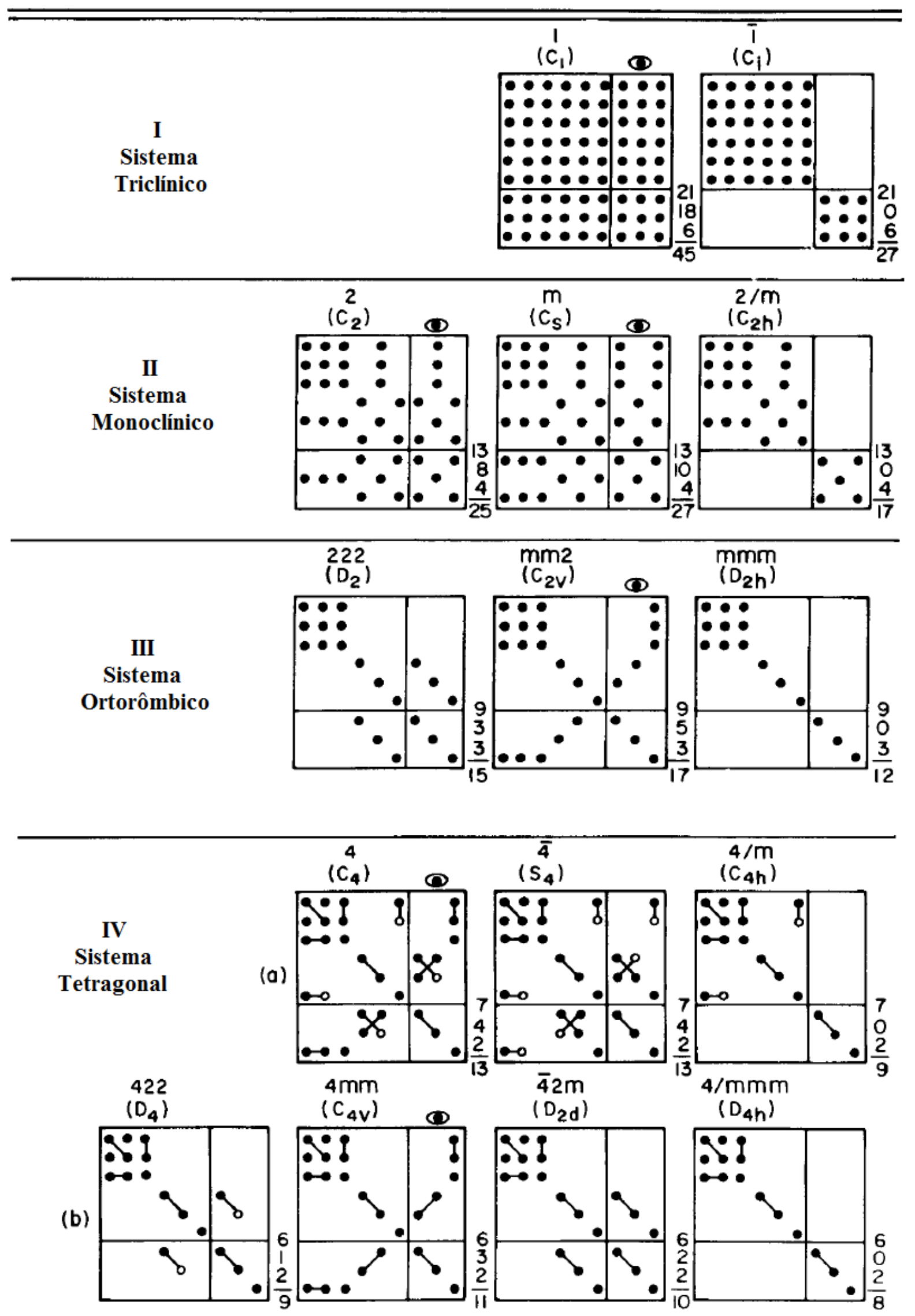


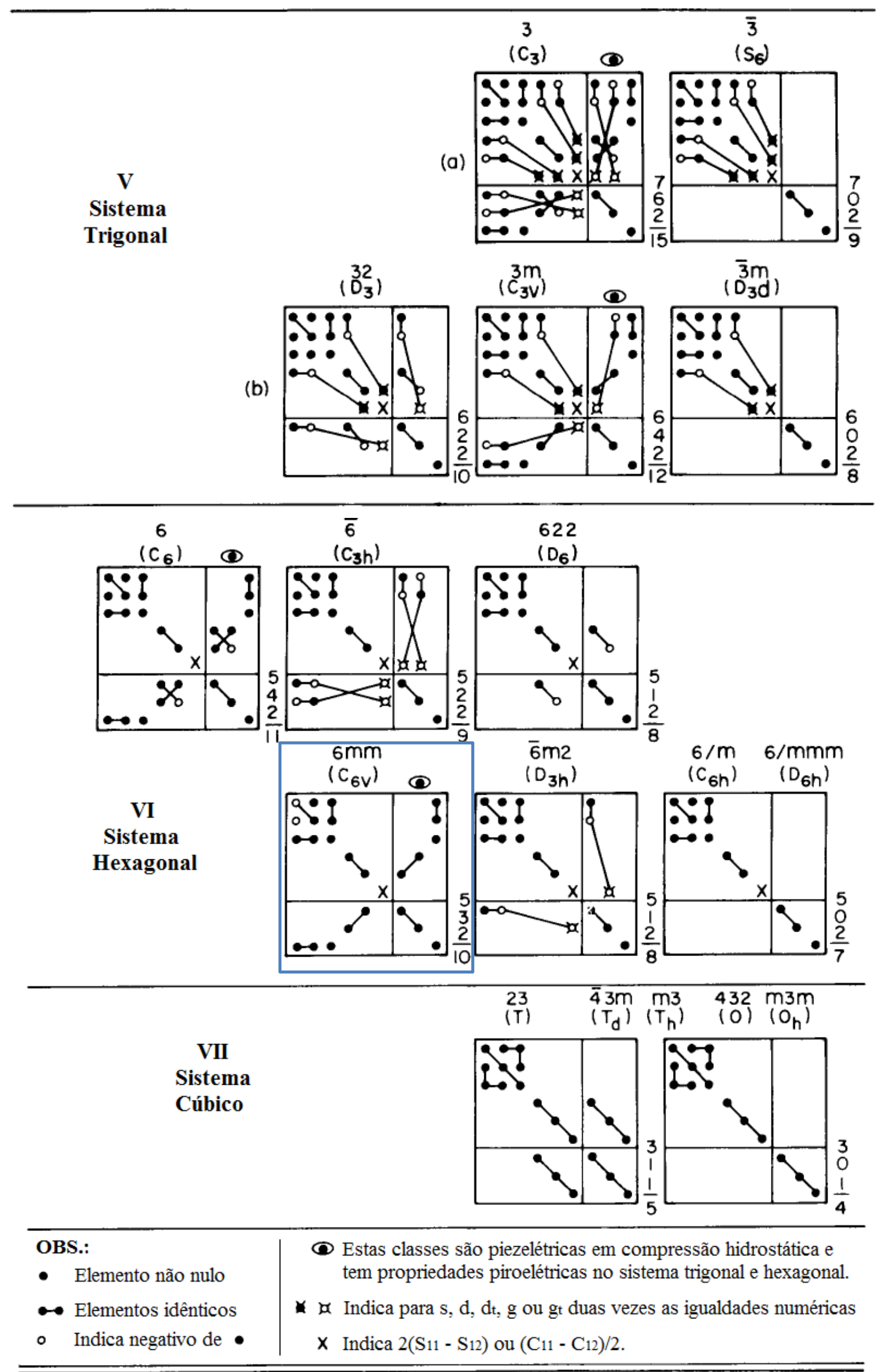

FIGURA 2.1-3 - Matrizes Elásticas-Piezo-Dielétricas para as 32 Classes Cristalinas. [IEEE, 1987] 


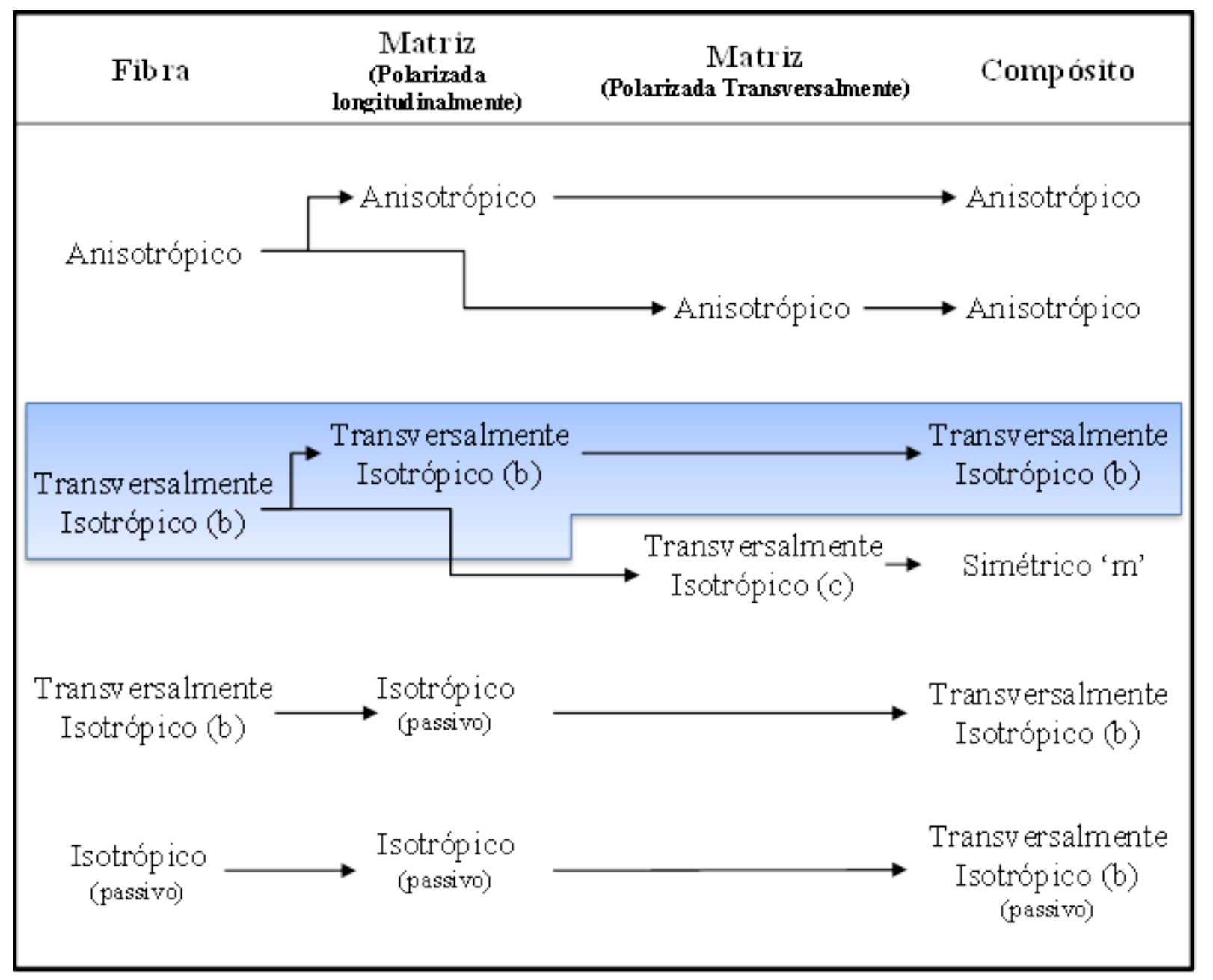

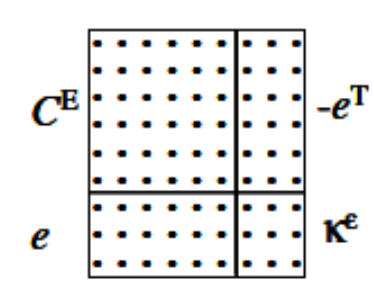

(a) Anisotrópico

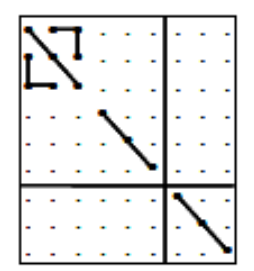

(d) Isotrópico (passivo)
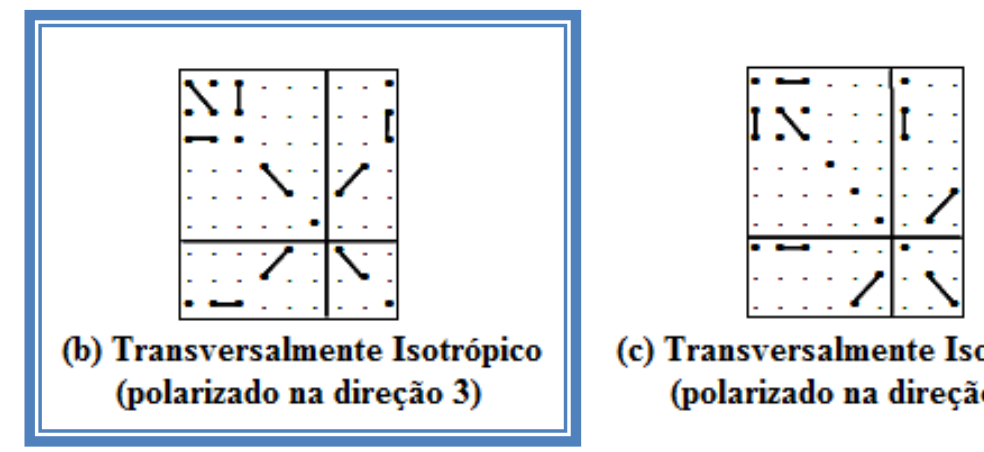

(c) Transversalmente Isotrópico (polarizado na direção 1)

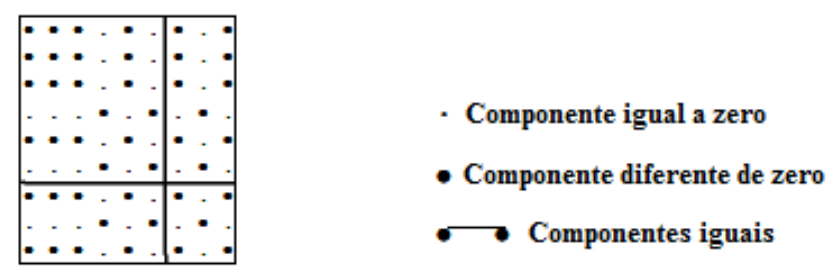

(e) Simétrico

'm'

FIGURA 2.1-4 - Ilustração esquemática da simetria do cristal de compósitos criada pela combinação de constituintes (matriz e fibras) com diferentes graus de anisotropia. [KAR-GUPTA; VENKATESH, 2007a] 


\subsection{SEÇÃO TRANSVERSAL DAS FIBRAS}

As fibras piezelétricas podem ser encontradas em diferentes formatos. Na Figura (2.21), apresentam-se três diferentes seções transversais de fibras PZT.
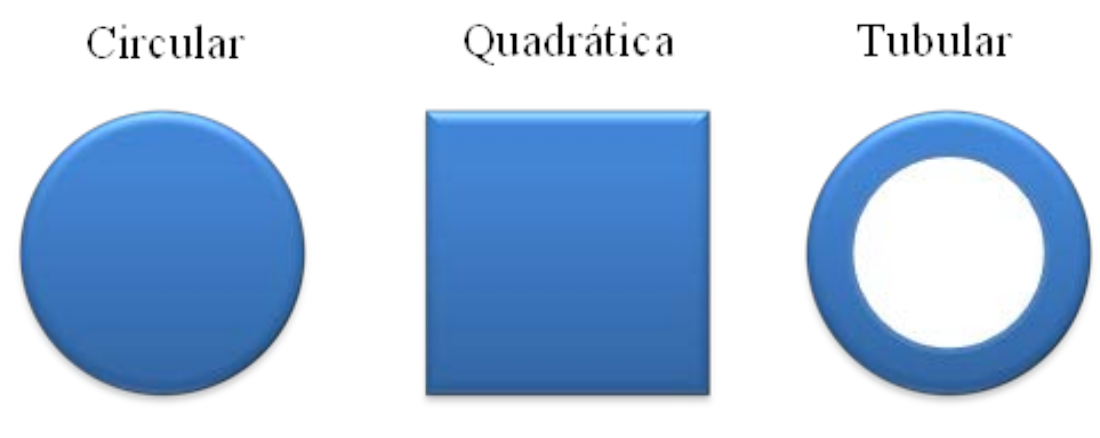

FIGURA 2.2-1 - Tipos de seção transversal de fibra PZT [SHINDE, 2005]

As fibras retangulares, que possuem seção transversal "quadrada”, têm certas vantagens e desvantagens quando comparadas com as circulares. Por um lado, as fibras retangulares têm uma maior quantidade de material piezelétrico para a mesma espessura do compósito, caso a aresta da mesma seja comparada ao diâmetro da fibra circular. Tal característica é interessante, pois uma maior espessura de material PZT é desejada para que se tenha o máximo de sensibilidade. Além disso, a área da superfície em contato com o eletrodo também é maior em fibras retangulares.

Por outro lado, o formato circular favorece uma melhor distribuição das tensões mecânicas, proporcionando uma vida em fadiga mais longa. Somado a isto, tem-se que se a área de contato para polarização for normalizada por sua massa para um determinado volume, a vantagem aparente das fibras retangulares é reduzida. Contudo as fibras retangulares são mais fáceis de manusear.

Sendo assim, a escolha da seção transversal da fibra é uma etapa muito estratégica no desenvolvimento de um sistema inteligente e depende fortemente da sua aplicação. Diante do que foi exposto, no presente trabalho, em um primeiro momento a metodologia proposta será empregada para fibras de seção circular, e num segundo momento, a mesma metodologia será empregada para fibras de seção retangular. 


\subsection{SISTEMA DE NOTAÇÃO E DE ORIENTAÇÃO}

A notação matricial simplificada é comumente utilizada em engenharia, especialmente para materiais piezelétricos, visando descrever as propriedades do tensor constitutivo do material. Esta notação simplificada se torna possível devido à simetria no cristal. Sendo assim, os coeficientes que descrevem as propriedades piezelétricas possuem índices $i$ e $j$ com base nas direções (sistema de orientação) evidenciadas pelo sistema de coordenadas ortogonal da Figura (2.3-1a).

Em cerâmicas piezelétricas, características do material dependem da direção do campo elétrico, deslocamento, tensão e deformação aplicados. Assim, o sobrescrito e subscrito indicando a direção são adicionados aos símbolos. A direção de polarização é geralmente designada pelo eixo Z. Dessa forma, os eixos X, Y e Z são, respectivamente, representados como 1, 2 e 3, que estão associados com as tensões normais, ao passo que as tensões de cisalhamento são representadas s por 4, 5 ou 6. Isto é mostrado esquematicamente na Figura (2.3-1b).
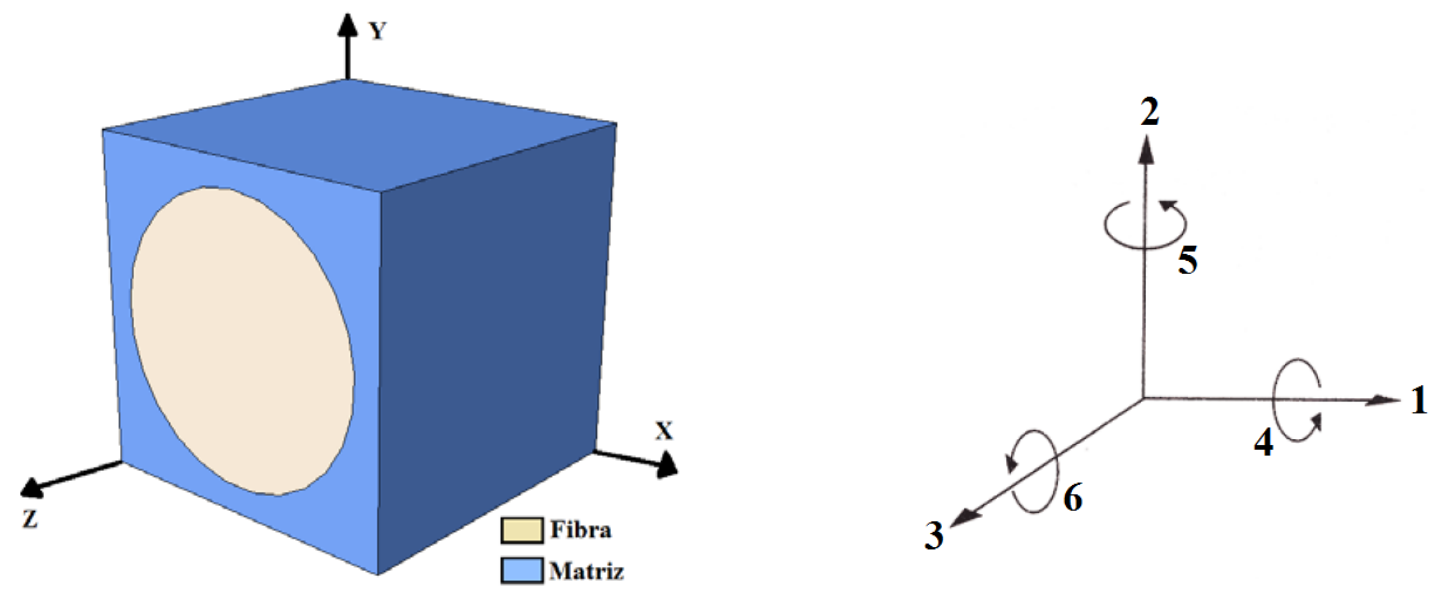

FIGURA 2.3-1 - Definição dos sistemas de coordenadas empregados [adaptado de BERGANDER, 2003]

As várias constantes associadas aos materiais piezelétricos são geralmente expressas com índices subscritos e sobrescritos, como mostra a Figura (2.3-2). O primeiro subscrito provê a direção do campo elétrico associado com a tensão aplicada ou a carga produzida. O segundo subscrito provê a direção da deformação ou tensão mecânica. Portanto, o subscrito i 
denota a direção da causa de um fenômeno físico (por exemplo: potencial elétrico), ao passo que $j$ denota a resposta no material (por exemplo: tensão mecânica). Por exemplo, para o coeficiente piezelétrico $\mathrm{e}_{13}$, tem-se um potencial elétrico aplicado na direção 1 e uma resposta do material na direção 3, ou seja, ao longo da fibra. Por outro lado, os índices sobrescritos indicam uma condição de contorno mecânica ou elétrica. Uma descrição geral dos sobrescritos empregados associados a uma dada condição de contorno é evidenciada na Tabela (2.3-1).

TABELA 2.3-1 - Descrição dos índices sobrescritos e condições de contorno

\begin{tabular}{ccc}
\hline Parâmetros & Símbolo & Condição \\
\hline Tensão & $\mathrm{T}$ & Mecanicamente engastado \\
\hline Potencial Elétrico & $\mathrm{E}$ & Elétrico - Curto circuito \\
Deslocamento Elétrico & $\mathrm{D}$ & Elétrico - Circuito aberto \\
\hline Deformação & $\mathrm{S}$ & Mecanicamente engastado \\
\hline
\end{tabular}
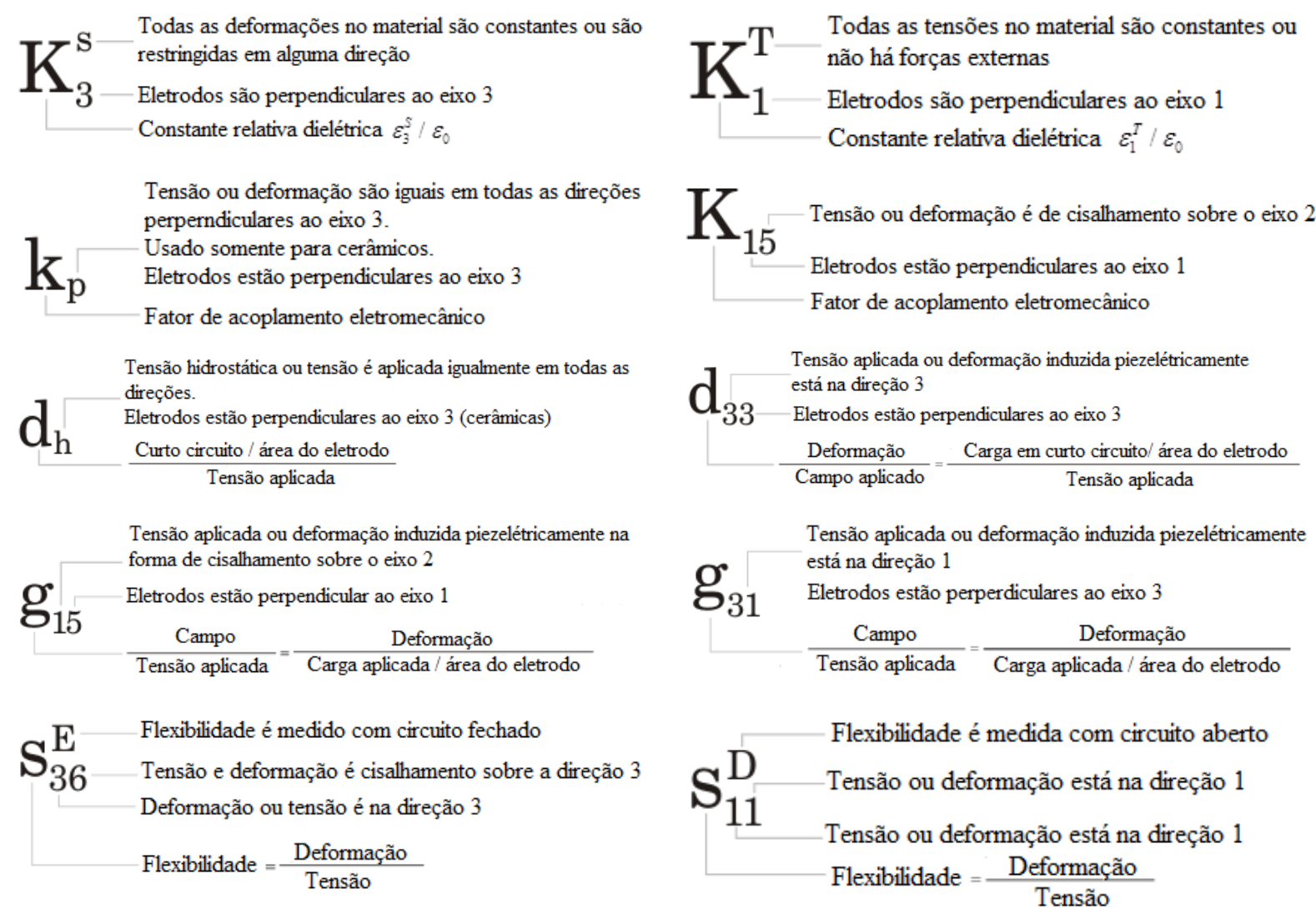

FIGURA 2.3-2 - Terminologias e notações empregadas em piezeletricidade: índices subscritos e sobrescritos utilizados [http://www.sensortech.ca, 2012] 


\subsection{EQUAÇÕES CONSTITUTIVAS PARA MATERIAIS Piezelétricos}

Para que haja o efetivo emprego de materiais piezelétricos, a resposta da tensão e do campo elétrico aplicado a um dado PZT deve ser capaz de ser prevista. Para tal, pode-se estabelecer uma equação constitutiva linear para relacionar os campos mecânicos e elétricos de materiais piezelétricos.

De uma maneira geral as equações constitutivas para materiais PZT são obtidas através das relações mecânicas e dielétricas, adicionando a essas relações os termos de acoplamento piezelétricos. Portanto, as tensões ou deformações mecânicas podem ser calculadas com base na Lei de Hooke, adicionando ao tensor constitutivo os termos para efeito piezelétrico. Deve-se ressaltar que as equações constitutivas piezelétricas estão estabelecidas na norma IEE ANSI/IEEE Std. 176 (1987), que fundamenta toda a modelagem elétrica de AFS (Active Fiber Sensor). De uma maneira mais detalhada, as referidas equações constitutivas para materiais PZT serão demonstradas a seguir.

Quando um material ativo é submetido a tensões mecânicas “ $T$ ” com unidade em Newton por metro quadrado $\left(\mathrm{N} / \mathrm{m}^{2}\right)$, o mesmo produz um deslocamento elétrico " $D$ " com unidade em Coulomb por metro quadrado $\left(\mathrm{C} / \mathrm{m}^{2}\right)$. O referido deslocamento elétrico " $\mathrm{D}$ ” é uma função linear de “ $T$ " e, pode ser escrito como $D=d T$, onde $d$ é o coeficiente de acoplamento piezelétrico com unidade em Coulomb por Newton $(\mathrm{C} / \mathrm{N})$.

Por outro lado, quando um campo elétrico “ $E$ ” com unidade em Volts por metro (V/m) é aplicado através de eletrodos do PZT, o mesmo produz uma deformação "S”, a qual é dada por $S=d E$. Para um material elástico, a relação de tensão “T” com a deformação "S” é dada por $T=c S$, onde c é a "rigidez mecânica” do material para tensão mecânica e possui unidade em Newton por metro quadrado $\left(\mathrm{N} / \mathrm{m}^{2}\right)$. Para um material dielétrico, o deslocamento elétrico “ $D$ ” e o campo elétrico são relacionados por $D=\varepsilon E$, onde $\varepsilon$ é a permissividade dielétrica com unidade de Faraday por metro $(F / m)$.

Baseando-se no Princípio da Conservação de Energia (IEEE, 1987) para um dado material piezelétrico linear continuo, tem-se assim a Primeira Lei da Termodinâmica dada por: 


$$
\dot{U}=T_{i j} \dot{S}_{i j}+E_{i} \dot{D}_{i}
$$

onde U é a densidade de energia armazenada para o material piezelétrico continuo.

Por outro lado, a densidade de entalpia elétrica H (IEEE, 1987) é definida por:

$$
H=U-E_{i} D_{i}
$$

Assim das Equações (2.1) e (2.2) tem-se como resultado:

$$
\dot{H}=T_{i j} \dot{S}_{i j}-D_{i} \dot{E}_{i}
$$

A Equação (2.3) implica que:

$$
H=H\left(S_{k l}, E_{k}\right)
$$

E das Equações (2.3) e (2.4) tem-se como resultado:

$$
\begin{gathered}
T_{i j}=\partial H / \partial S_{i j} \\
D_{i}=-\partial H / \partial E_{i}
\end{gathered}
$$

Pode-se notar que:

$$
\partial S_{i j} / \partial S_{j i}=0, \quad i \neq j
$$


Considerando a teoria piezelétrica linear, a forma dada por H é:

$$
H=\frac{1}{2} C_{i j k l}^{E} S_{i j} S_{k l}-e_{k i j} E_{k} S_{i j}-\frac{1}{2} \varepsilon_{i j}^{S} E_{i} E_{j}
$$

onde $c_{i j k l}^{E}$, $e_{i j k}$ e $\varepsilon_{i j}^{S}$ são as constantes elástica, piezelétrica e dielétrica, respectivamente. Em geral há 21 constantes elásticas independentes, 18 constantes piezelétricas independentes e 6 constantes dielétricas independentes.

Das Equações (2.5), (2.6) e (2.8) com a Equação (2.7) para um material piezelétrico, onde a direção 3 está orientada com as fibras piezelétricas (como mostra a Figura (2.3-1) do Item 2.2), as relações eletromecânicas podem ser escritas da seguinte forma:

$$
\begin{gathered}
T_{i j}=c_{i j k l}^{E} S_{k l}-e_{i j k} E_{k}, \\
D_{i}=e_{i k l} S_{k l}+\varepsilon_{i j}^{S} E_{j},
\end{gathered}
$$

estas equações são conhecidas como a forma tensão - fluxo elétrico ( $T$ - D), onde o tensor das tensões de segunda ordem $T_{i j}$, e o vetor de deslocamento elétrico $D_{i}$, estão linearmente relacionadas com o tensor das deformações de segunda ordem $S_{i j}$, e o vetor campo elétrico $E_{i}$. As propriedades do material são expressas através do tensor de "rigidez" de quarta ordem medido em campo elétrico constante $c_{i j k l}^{E}$, ao passo que o tensor piezelétrico de terceira ordem $e_{i j k}$ e o tensor de permissividade elétrica de segunda ordem são medidos em deformação constante $\varepsilon_{i j}^{S}$. Os subscritos $i, j, k, l$ variam de 1 a 3 , o sobrescrito $E$ indica campo elétrico constante, enquanto que o sobrescrito $S$ indica deformação constante.

Ressaltando que as propriedades de material, descritas no Item 2.1, satisfazem determinados critérios de simetria, verifica-se que: 


$$
c_{i j k l}=c_{j i k l}=c_{k l i j}, \quad e_{k i j}=e_{k j i}, \quad \varepsilon_{i j}=\varepsilon_{j i}
$$

A fim de escrever os tensores elástico e piezelétrico na forma de matrizes, uma notação matricial comprimida é introduzida no lugar da notação tensorial. Esta notação matricial consiste da substituição de $i j$ ou $k l$ por $p$ ou $q$, onde $i, j, k, l$ variam em 1,2,3 e p,q variam em 1,2,3,4,5,6 de acordo com a Equação (2.15).

Assim as Equações constitutivas (2.9) e (2.10) podem ser reescritas como:

$$
\begin{aligned}
& T_{p}=c_{p q}^{E} S_{q}-e_{k p} E_{k}, \\
& D_{i}=e_{i q} S_{q}+\varepsilon_{i k}^{S} E_{k},
\end{aligned}
$$

onde:

$$
\begin{array}{lll}
S_{i j}=S_{p} & \text { quando } i=j, & p=1,2,3 \\
2 S_{i j}=S_{p} & \text { quando } i \neq j, & p=4,5,6
\end{array}
$$

$11 \Rightarrow 1, \quad 22 \Rightarrow 2, \quad 33 \Rightarrow 3, \quad 23$ ou $32 \Rightarrow 4, \quad 31$ ou $13 \Rightarrow 5, \quad 12$ ou $21 \Rightarrow 6$,

Portanto, as equações constitutivas piezelétricas em forma matricial podem ser escritas da seguinte forma:

$$
\left\{\begin{array}{l}
\{T\} \\
\{D\}
\end{array}\right\}=\left[\begin{array}{cc}
{[C]^{E}} & -[e] \\
{[e]^{t}} & {[\varepsilon]^{S}}
\end{array}\right]\left\{\begin{array}{l}
\{S\} \\
\{E\}
\end{array}\right\},
$$

Sendo que a Equação (2.16) é uma equação de campos acoplados que relaciona o campo elétrico aplicado $(E)_{3 \times 1}$, deslocamento elétrico $(D)_{3 \times 1}$, a deformação $(S)_{6 \times 1}$ e a tensão 
$(T)_{6 \times 1}$. As propriedades de material, tais como a permissividade dielétrica $\left(\varepsilon^{S}\right)_{3 \times 3}$, o acoplamento piezelétrico $(e)_{3 \times 6}$ e a rigidez $\left(c^{E}\right)_{6 \times 6}$ são empregadas para relacionar os campos mecânico e elétrico. O sobrescrito $t$ representa a operação de transposição da matriz.

Portanto, considerando um sólido piezelétrico transversalmente isotrópico, tem-se que a matriz constitutiva completa (rigidez, piezelétrica e dielétrica) irá possuir 11 coeficientes independentes. Aplicando condições de periodicidade piezelétrica, constata-se que o modelo computacional é utilizado para representar um meio homogêneo equivalente ao compósito original. Em sendo assim, obter-se-á um material que tem as mesmas propriedades nas duas direções perpendiculares ao comprimento da fibra, ou seja, a célula unitária utilizada na presente metodologia deverá possuir repetibilidade para a montagem ao longo das direções $\mathrm{X}$, Y e Z. Tais hipóteses, portanto, permitem que Equação (2.16) seja escrita da seguinte forma expandida:

$$
\left\{\begin{array}{l}
T_{11} \\
T_{22} \\
T_{33} \\
T_{12} \\
T_{23} \\
T_{31} \\
D_{1} \\
D_{2} \\
D_{3}
\end{array}\right\}=\left[\begin{array}{ccccccccc}
c_{11}^{E} & c_{12}^{E} & c_{13}^{E} & 0 & 0 & 0 & 0 & 0 & -e_{13} \\
c_{12}^{E} & c_{11}^{E} & c_{13}^{E} & 0 & 0 & 0 & 0 & 0 & -e_{13} \\
c_{13}^{E} & c_{13}^{E} & c_{33}^{E} & 0 & 0 & 0 & 0 & 0 & -e_{33} \\
0 & 0 & 0 & c_{66}^{E} & 0 & 0 & 0 & 0 & 0 \\
0 & 0 & 0 & 0 & c_{44}^{E} & 0 & 0 & -e_{15} & 0 \\
0 & 0 & 0 & 0 & 0 & c_{44}^{E} & -e_{15} & 0 & 0 \\
0 & 0 & 0 & 0 & 0 & e_{15} & \varepsilon_{11}^{S} & 0 & 0 \\
0 & 0 & 0 & 0 & e_{15} & 0 & 0 & \varepsilon_{11}^{S} & 0 \\
e_{13} & e_{13} & e_{33} & 0 & 0 & 0 & 0 & 0 & \varepsilon_{33}^{S}
\end{array}\right]\left\{\begin{array}{l}
S_{11} \\
S_{22} \\
S_{33} \\
S_{12} \\
S_{23} \\
S_{31} \\
E_{1} \\
E_{2} \\
E_{3}
\end{array}\right\}
$$

Deve-se ressaltar que para um meio piezelétrico infinito, a única forma das equações constitutivas que os valores são facilmente e diretamente determinados é dada pelas Equações (2.9) e (2.10). Algumas outras formas da equação constitutiva são dadas por:

$$
\begin{gathered}
S_{i j}=s_{i j k l}^{E} T_{k l}+d_{k i j} E_{k} \\
D_{i}=d_{i k l} T_{k l}+\varepsilon_{i k}^{T} E_{k}
\end{gathered}
$$


E,

$$
\begin{aligned}
& S_{i j}=s_{i j k l}^{D} T_{k l}+g_{k i j} D_{k} \\
& E_{i}=-g_{i k l} T_{k l}+\beta_{i k}^{T} D_{k}
\end{aligned}
$$

E,

$$
\begin{aligned}
& T_{i j}=c_{i j k l}^{D} S_{k l}-h_{k i j} D_{k} \\
& E_{i}=-h_{i k l} S_{k l}+\beta_{i k}^{S} D_{k}
\end{aligned}
$$

Essas últimas formas das equações constitutivas, embora sejam exatas, são empregadas em aproximações que são válidas para determinadas circunstâncias. A utilidade de qualquer uma destes três pares de equações constitutivas depende do fato de que algumas variáveis serem aproximadamente iguais a “zero" em circunstâncias adequadas. Consequentemente, o conjunto a ser utilizado em uma determinada instancia, depende crucialmente das circunstâncias geométricas, mecânicas e elétricas que estão associadas ao modelo empregado. Por exemplo, para baixas frequências de vibração de uma haste, pode-se utilizar tanto as Equações (2.18)-(2.19) como as Equações (2.20)-(2.21), porque nestas circunstâncias todas as componentes de tensão são nulas, exceto a tensão ao longo do comprimento da haste. No entanto, não está claro se pretende utilizar o primeiro ou o segundo conjunto de equações, a menos que mais informações específicas quanto a forma da seção transversal e a colocação dos eletrodos sejam dadas. Entretanto, no exemplo dado, é possível que os dois conjuntos de equações possa ser utilizado. As relações entre os coeficientes nos quatro conjuntos de equações constitutivas possíveis, Equações (2.12)-(2.13) e Equações (2.18) a (2.23), podem ser escritas da seguinte forma:

$$
\begin{array}{ll}
c_{p r}^{E} s_{q r}^{E}=\delta_{p g}, & c_{p r}^{D} s_{q r}^{D}=\delta_{p q}, \\
\beta_{i k}^{S} \varepsilon_{j k}^{S}=\delta_{i j}, & \beta_{i k}^{T} \varepsilon_{j k}^{T}=\delta_{i j}, \\
c_{p q}^{D}=c_{p q}^{E}+e_{k p} h_{k p}, & s_{p q}^{D}=s_{p q}^{E}-d_{k p} g_{k p}, \\
\varepsilon_{i j}^{T}=\varepsilon_{i j}^{S}+D_{i q} e_{j q}, & \beta_{i j}^{T}=\beta_{i j}^{S}-g_{i q} h_{j q}, \\
e_{i p}=d_{i q} c_{q p}^{E}, & d_{i p}=\varepsilon_{i k}^{T} g_{k p}, \\
g_{i p}=\beta_{i k}^{T} d_{k p}, & h_{i p}=g_{i q} c_{q p}^{D} .
\end{array}
$$


A Figura (2.4-1) apresenta as relações possíveis entre os domínios, juntamente com as variáveis associadas a cada fenômeno.

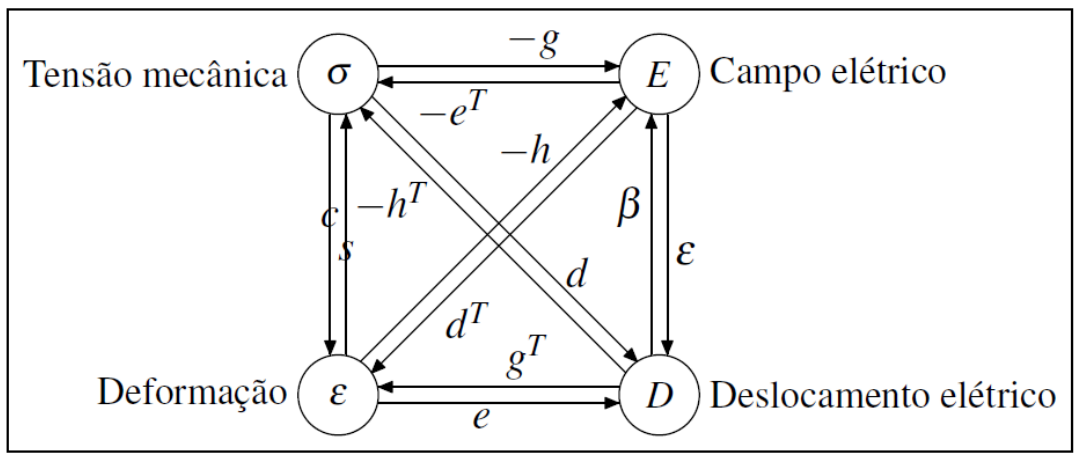

FIGURA 2.4-1 - Tipos de seção transversal de fibra PZT [SILVA, 2007]

\subsection{TEOREMA DAS MÉDIAS - FORMULAÇÃo DO PROBLEMA}

Segundo Pérez-Fernandez (2009), considerar-se-á que o compósito piezelétrico em estudo seja periódico e que cada célula ocupe um domínio $\mathrm{V}$ de fronteira $\partial V$ suave e de volume $|V|$. Somado a isto, ter-se-á que o mesmo seja formado pela continuidade de células unitárias. Então, este compósito heterogêneo é formado por $N$ fases hipoteticamente acopladas de forma perfeita, ou seja, as magnitudes são consideradas contínuas através da superfície de contato entre as faces. Assim, na formulação para o caso estático, com ausência de forças inerciais e livre de carregamentos, as relações constitutivas eletro-elásticas podem ser expressas da seguinte forma:

$$
\begin{array}{ll}
\varepsilon_{i j}=\varepsilon_{i j}(x ; \sigma, E), & D_{m}=D_{m}(x ; \sigma, E), \\
\varepsilon_{i j}=\frac{\partial G(x ; \sigma, E)}{\partial \sigma_{i j}}, & D_{m}=\frac{\partial G(x ; \sigma, E)}{\partial E_{m}} .
\end{array}
$$

As equações supracitadas, juntamente com as equações de equilíbrio eletro-elásticas conduzem a: 


$$
\sigma_{i j, j}=0, \quad D_{m, m}=0,
$$

onde a vírgula denota diferenciação espacial. $\sigma$ e $D$ são chamadas de grandezas autoequilibradas, caso satisfaçam a Equação (2.26).

Na Equação (2.25) assume-se que existe um potencial diferenciável $\mathrm{G}(\mathrm{x} ; \sigma, \mathrm{E})$ associado a Equação (2.25), sendo que $\mathrm{G}(\mathrm{x} ; \sigma, \mathrm{E})$ corresponde a uma função de densidade de energia. Dessa forma, $\mathrm{G}(\mathrm{x} ; \sigma, \mathrm{E})$ é definido como uma Transformada de Legendre, consistindo em uma transformação matemática, que ao ser aplicada a uma função diferenciável em relação a suas variáveis independentes, fornece como resultado uma nova equação na qual as derivadas parciais associadas figuram como variáveis independentes e, portanto, tem-se:

$$
a(x ; \sigma, E)=\chi_{r}(x) a_{r}(\sigma, E),
$$

onde $a_{r}$ são as restrições da fase $a$ em relação as fases $r=\overline{1, N}$ e $\chi_{r}$ é sua função característica. Além disso, $\varepsilon$ e $E$ são designadas compatíveis caso:

$$
\epsilon_{i j k}=\left\{\begin{array}{c}
1, \text { seijk éuma permutação par de }\{1,2,3\}, \\
-1, \text { seijk éuma permutação impar de }\{1,2,3\}, \\
0, \text { outro caso. }
\end{array}\right.
$$

Por conseguinte, as equações de compatibilidade são dadas por:

$$
\in_{i k m} \in_{j \ln } \varepsilon_{k n, l m}=0, \quad \quad \in_{i j k} E_{k, j}=0
$$


A equação (2.29) expressa que $\varepsilon$ e $E$ são conservativos, ou seja, irrotacionais, permitindo sua representação potencial ao garantir a existência de funções $u$ e $\varphi$, tais que:

$$
\varepsilon_{i j}=\frac{1}{2}\left(u_{i, j}+u_{j, i}\right), \quad E_{m}=-\phi_{, m}
$$

Dada a periodicidade do compósito descrito por Pérez-Fernandez (2009), assim todas as variáveis são 1-periódicas. Portanto, com esta consideração, a Equação (2.26) dever ser entendida como um sistema de equações diferenciais parciais, ou seja,

$$
\left\langle\sigma_{i j} \varphi_{, j}\right\rangle=0, \quad\left\langle D_{m} \varphi_{, m}\right\rangle=0
$$

sendo operador do cálculo da média definido como: $\langle F\rangle=\frac{1}{|V|_{V}} \int_{V} F d V$. Além disso, as condições de contorno são dadas por:

$$
\left.u_{i}\right|_{\partial V_{u}}=u_{i}^{0},\left.\quad \phi\right|_{\partial V_{\phi}}=\phi^{0},\left.\quad \sigma_{i j} n_{j}\right|_{\partial V_{\sigma}}=t_{i}^{0},\left.\quad D_{m} n_{m}\right|_{\partial V_{D}}=d^{0},
$$

onde $n$ é o vetor unitário normal exterior a $\partial V$.

Para o caso de condições de contorno uniformes, tem-se:

$$
u_{I}^{0}=\bar{\varepsilon}_{i j} X_{j}, \quad \phi^{0}=-\bar{E}_{m} X_{m}, \quad t_{i}^{0}=\bar{\sigma}_{i j} n_{j}, \quad d^{0}=\bar{D}_{m} n_{m}
$$

sendo que a barra indica uma valor constante. 
A homogeneização de um compósito consiste, portanto, em encontrar a dependência funcional entre as médias das variáveis do modelo, que descreve o comportamento físico do mesmo. Anteriormente ao passo da homogeneização, busca-se conhecer as médias em termos das relações superficiais das variáveis, ou seja, as condições de contorno aplicadas ao compósito, independentemente das restrições constitutivas, segundo Pérez-Fernandez (2009).

Seja, portanto, $\varepsilon$ e $E$ compatíveis e tanto $\sigma$ como $D$ auto-equilibradas, tem-se:

(a) Para as condições de contorno gerais da Equação (2.32) em $\partial \mathrm{V}$,

$$
\left\langle\varepsilon_{i j}\right\rangle=\frac{1}{2|V|} \int_{\partial V}\left(u_{i}^{0} n_{j}+u_{j}^{0} n_{i}\right) d S, \quad\left\langle E_{m}\right\rangle=\frac{1}{|V|} \int_{\partial V} \phi^{0} n_{m} d S
$$

onde no caso de condições de contorno uniformes da Equação (2.33) em $\partial V$, tem-se:

$$
\left\langle\varepsilon_{i j}\right\rangle=\bar{\varepsilon}_{i j}, \quad\left\langle E_{m}\right\rangle=\bar{E}_{m}
$$

(b) Para as condições de contorno gerais da Equação (2.32) em $\partial V$,

$$
\left\langle\sigma_{i j}\right\rangle=\frac{1}{|V|} \int_{\partial V} t_{i}^{0} x_{j} d S, \quad\left\langle D_{m}\right\rangle=\frac{1}{|V|} \int_{\partial V} d^{0} x_{m} d S
$$

onde no caso de condições de contorno uniformes da Equação (2.33) em $\partial V$, tem-se:

$$
\left\langle\sigma_{i j}\right\rangle=\bar{\sigma}_{i j}, \quad\left\langle D_{m}\right\rangle=\bar{D}_{m}
$$


Segundo Pérez-Fernandez (2009), considerando as magnitudes $F$ e $G$, tais que, $F_{i}$ e $G_{i}$ $\epsilon L^{2}(V)$ com $F_{i, j}=$ " 0 " e que existe $\gamma \in H^{1}(V)$, tal que, $G_{i}=\gamma_{, i}$. Nota-se que $G$ é irrotacional, ou seja, $\epsilon_{i j k} G_{k, j}=0$. Logo, impondo as condições de contorno $\left.\gamma\right|_{\partial V}=\gamma^{0}$ e $\left.F_{i} n_{i}\right|_{\partial V}=\phi^{0}$ que, neste caso são uniformes, tem-se $\phi^{0}=\bar{F}_{i} n_{i}$ e $\gamma^{0}=\bar{G}_{i} X_{i}$.

Evidentemente, pode-se permutar $\sigma$ e $D$ por $F$, bem como, $\varepsilon$ e $E$ por $G$. Também, considerando o Teorema da Divergência e, em particular para o delta de Kronecker, tem-se que $\delta_{i j}=\left\langle\delta_{i j}\right\rangle=\left\langle x_{i, j}\right\rangle=\frac{1}{|V|} \int_{\partial V} x_{i} n_{j} d S$.

Portanto,

(a) Seja $G$ tal que $G_{i}=\left.\gamma_{, i} \operatorname{com} \gamma\right|_{\partial V}=\gamma^{0}$ e $\gamma^{0}=\bar{G}_{i} X_{i}$ são uniformes, logo,

$$
\left\langle G_{i}\right\rangle=\left\langle\gamma_{, i}\right\rangle=\frac{1}{|V|} \int_{\partial V} \gamma n_{i} d S=\frac{1}{|V|} \int_{\partial V} \gamma^{0} n_{i} d S=\bar{G}_{i}
$$

onde no caso de condições de contorno uniformes, tem-se:

$$
\left\langle G_{i}\right\rangle=\frac{1}{|V|} \int_{\partial V} \gamma^{0} n_{i} d S=\frac{1}{|V|} \int_{\partial V} \bar{G}_{j} X_{j} n_{i} d S=\bar{G}_{i}
$$

(b) Seja $F$ tal que $F_{j, i}=0$ e com $\left.F_{i} n_{i}\right|_{\partial V}=\phi^{0}$ e $\phi^{0}=\bar{F}_{i} n_{i}$ são uniformes, logo,

$$
\left\langle F_{i}\right\rangle=\left\langle F_{j} \delta_{i j}\right\rangle=\left\langle F_{j} x_{i, j}\right\rangle=\left\langle\left(F_{j} x_{i}\right)_{, j}-\left(F_{j, j} x_{i}\right)\right\rangle=\left\langle\left(F_{j} x_{i}\right)_{j}\right\rangle=\frac{1}{|V|} \int_{\partial V} F_{j} n_{j} x_{i} d S,
$$

onde no caso de condições de contorno uniformes da Equação (2.33) em $\partial V$, tem-se: 


$$
\left\langle F_{i}\right\rangle=\frac{1}{|V|} \int_{\partial V} F_{j} n_{j} x_{i} d S=\frac{1}{|V|} \int_{\partial V} \varphi^{0} x_{i} d S=\frac{1}{|V|} \int_{\partial V} \bar{F}_{j} n_{j} x_{i} d S=\bar{F}_{i} .
$$

Conclui-se assim, pelo Teorema das Médias, que $\sigma, D$ e $F$, bem como, $\varepsilon$, $E$ e $G$ podem ser obtidas com base numa integral de volume dos sub-domínios, que está relacionada a referida grandeza, dividida pelo volume total do domínio. Assim, a média da grandeza para condições de contorno uniformes é igual a grandeza média.

\subsection{COEFICIENTES EFETIVOS DE COMPÓSITOS INTELIGENTES PIEZELÉTRICOS}

As Equações (2.35) e (2.37) são gerais no sentido de que são válidas independentemente da forma geométrica das interfaces, que limitam as fases dos componentes do meio heterogêneo. Além disso, as propriedades efetivas de um material compósito inteligente podem ser denotadas pelo tensor constitutivo tomando como base a relação constitutiva dada por valores médios:

$$
\left\{\begin{array}{l}
\langle T\rangle \\
\langle D\rangle
\end{array}\right\}=\left[\begin{array}{ll}
{[c]^{E}} & -[e] \\
{[e]^{t}} & {[\varepsilon]^{S}}
\end{array}\right]\left\{\begin{array}{l}
\langle S\rangle \\
\langle E\rangle
\end{array}\right\} \text {. }
$$

Supondo que o Volume Elementar Representativo (VER) esteja submetido a condições de contorno homogêneas dadas pela Equação (2.32). Alternativamente, através da solução de um problema inverso, determinam-se as propriedades efetivas a partir das Equações (2.35) e (2.37) e, então, tem-se que: 


$$
\left\{\begin{array}{l}
\langle S\rangle \\
\langle E\rangle
\end{array}\right\}=\left[\begin{array}{cc}
{[s]^{D}} & {[g]} \\
-[g]^{t} & {[\beta]^{T}}
\end{array}\right]\left\{\begin{array}{c}
\langle T\rangle \\
\langle D\rangle
\end{array}\right\} .
$$

Estas relações são obtidas supondo que o VER esteja submetido a condições homogêneas. Portanto, para obter as propriedades efetivas dos meios heterogêneos, se necessita efetuar o processo de média especificado pelas Equações (2.35) e (2.37). Dessa forma, calculam-se as matrizes de rigidez, acoplamento e dielétrica utilizando as Equações (2.42) ou (2.43) segundo cada caso. Este processo, aparentemente simples, para que seja rigorosamente operado, necessita de soluções exatas, nos meios heterogêneos, para os campos de tensão $\left(T_{i j}(x k)\right)$ e para as deformações $\left(S_{i j}(x k)\right)$, bem como para o campo elétrico $\left(E_{i}(x k)\right)$ e para os deslocamentos elétricos $\left(D_{i}\left(x_{k}\right)\right)$. Sendo que isto, somente, é possível para uma classe muito restrita de problemas. Em sendo assim, as propriedades efetivas do compósito ativo (dada pelo subscrito eff) podem ser definidas pelos campos médios da mesma forma que na Equação (2.16). Portanto, escrevendo na forma compacta de matriz tem-se:

$$
\left\{\begin{array}{l}
\{\bar{T}\} \\
\{\bar{D}\}
\end{array}\right\}=\left[\begin{array}{cc}
{[c]_{e f f}^{E}} & -[e]_{e f f} \\
{[e]_{e f f}^{t}} & {[\varepsilon]_{e f f}^{S}}
\end{array}\right]\left\{\begin{array}{l}
\{\bar{S}\} \\
\{\bar{E}\}
\end{array}\right\} .
$$

Assumindo que a média das propriedades mecânicas e elétricas de uma célula unitária é igual à média das propriedades de um compósito particular, como demonstrado anteriormente, verifica-se que as médias dos campos de tensão, deformação, campo elétrico e deslocamento elétrico no VER são definidas por:

$$
\begin{array}{lll}
\bar{T}_{i j}=\frac{1}{|V|} \int_{\mid V} T_{i j}^{0} d V, & \bar{S}_{i j}=\frac{1}{|V|} \int_{V} S_{i j}^{0} d V, \\
\bar{D}_{i}=\frac{1}{|V|} \int_{V} D_{i}^{0} d V, & \bar{E}_{i}=\frac{1}{|V|} \int_{V} E_{i}^{0} d V,
\end{array}
$$

onde $V$ é o volume da célula unitária e a barra denota valores médios. 
Ao empregar o Método dos Elementos Finitos, a média dos valores pode ser calculada em função dos elementos que discretizam o volume em questão. Portanto, a Equação (2.45) pode ser reescrita da seguinte forma:

$$
\begin{array}{ll}
\bar{T}_{i j}=\frac{1}{V} \sum_{n=1}^{n e l} T_{i j}^{(n)} V^{(n)}, & \bar{S}_{i j}=\frac{1}{V} \sum_{n=1}^{n e l} S_{i j}^{(n)} V^{(n)}, \\
\bar{D}_{i}=\frac{1}{V} \sum_{n=1}^{n e l} D_{i}^{(n)} V^{(n)}, & \bar{E}_{i}=\frac{1}{V} \sum_{n=1}^{n e l} E_{i}^{(n)} V^{(n)},
\end{array}
$$

onde $V$ é o volume de uma célula unitária, nel é o número de elementos finitos contidos na célula unitária, $V^{(n)}$ é o volume do enésimo-elemento e, finalmente, $T^{(n)}, S^{(n)}, D^{(n)}$ e $E^{(n)}$ são os campos determinados para o enésimo-elemento.

\subsection{RELAÇÕES UNIVERSAIS}

Um procedimento para avaliar as potencialidades e limitações de uma dada metodologia, que visa determinar os coeficientes efetivos para materiais piezelétricos, consiste na utilização das Relações Universais (BENVENISTE; DVORAK, 1992). Estas relações consideram o compósito piezelétrico estatisticamente homogêneo e, as constantes do material correspondente a um cristal hexagonal de classe de simetria $6 \mathrm{~mm}$. Portanto, para as matrizes da Equação (2.16), tem-se que $c_{11}=c_{22}, c_{12}=c_{21}, c_{13}=c_{23}, c_{44}=c_{55}, e_{13}=e_{23}, e_{15}$ $=\mathrm{e}_{24}, \varepsilon_{11}=\varepsilon_{22}$. Considerando ainda que o compósito piezelétrico seja transversalmente isotrópico, as relações apresentadas por Benveniste e Dvorak (1992) para materiais piezelétricos são dadas por:

$$
\begin{array}{ll}
k=\left(c_{11}+c_{12}\right) / 2, & c_{13}=l, \quad c_{33}=n, \\
e_{13}=j, \quad e_{33}=g, & e_{15}=h, \quad \varepsilon_{11}=t, \quad \varepsilon_{33}=q .
\end{array}
$$




$$
\begin{gathered}
F_{1}=\frac{k-v_{f} k_{f}-v_{m} k_{m}}{l-v_{f} l_{f}-v_{m} l_{m}}, \quad F_{2}=\frac{l-v_{f} l_{f}-v_{m} l_{m}}{n-v_{f} n_{f}-v_{m} n_{m}} \\
F_{3}=\frac{j-v_{f} j_{f}-v_{m} j_{m}}{g-v_{f} g_{f}-v_{m} g_{m}}, \quad F_{4}=\frac{k_{f}-k_{m}}{l_{f}-l_{m}} \\
F_{1}=F_{2}=F_{3}=F_{4} \\
F_{5}=\frac{j-v_{f} j_{f}-v_{m} j_{m}}{l-v_{f} l_{f}-v_{m} l_{m}}, \quad F_{6}=\frac{g-v_{f} g_{f}-v_{m} g_{m}}{n-v_{f} n_{f}-v_{m} n_{m}} \\
F_{7}=\frac{-q+v_{f} q_{f}+v_{m} q_{m}}{g-v_{f} g_{f}-v_{m} g_{m}}, \quad F_{8}=\frac{j_{f}-j_{m}}{l_{f}-l_{m}} \\
F_{5}=F_{6}=F_{7}=F_{8} \\
F_{9}=\operatorname{det}\left[\begin{array}{ll}
C_{44} \quad \varepsilon_{11}^{f} & t_{f} \\
G_{L}^{m} & t_{m}
\end{array}\right],
\end{gathered}
$$

onde os subscritos $f$ e $m$ denotam as propriedades associadas à fibra e à matriz, respectivamente. Ao passo que $v$ denota a fração volumétrica. Mais detalhes sobre o referido assunto podem ser encontrados em Benveniste e Dvorak (1992).

Por fim, vale ressaltar que as Relações Universais serão utilizadas no presente trabalho visando avaliar a qualidade dos resultados obtidos através da metodologia computacional desenvolvida.

\subsection{Volume Elementar Representativo (VER) E CONDIÇÕES DE CONTORNO}

Como verificado anteriormente, uma das abordagens numéricas para a determinação das propriedades efetivas de materiais ativos consiste no emprego de um Volume Elementar Representativo (VER) modelado por elementos finitos. Este modelo computacional é 
utilizado para determinar um meio homogêneo equivalente ao compósito original. Sendo que diversos arranjos de fibras podem ser utilizados, conforme discutido por Kar-Gupta e Venkatesh (2007a).

As Figuras (2.8-1a), (2.8-2a), (2.8-3a) e (2.8-4a) ilustram um compósito com fibras piezelétricas unidirecionais para um arranjo quadrático, hexagonal, hexagonal 1-2 e hexagonal 2-3, respectivamente. Por outro lado, têm-se as Figuras (2.8-1b), (2.8-2b), (2.8-3b) e (2.8-4b) ilustram as células unitárias correspondentes (VER). Tal célula com a imposição de condições de simetria adequadas pode representar o comportamento do compósito inteligente como um todo, assumindo-se que o mesmo tenha comprimento infinito (ou muito maior que o diâmetro da fibra) nas três direções de ortotropia (1-2-3).

A hipótese supracitada acarreta, portanto, em um material que tenha as mesmas propriedades nas duas direções perpendiculares ao comprimento da fibra, ou seja, que haja isotropia transversal. Utilizando-se o Método dos Elementos Finitos, pode-se fazer a análise apenas da célula unitária, que é discretizada em uma quantidade apropriada de elementos. Assim, aplicando as propriedades de cada material individualmente, obtêm-se as propriedades efetivas do compósito. Desta maneira, os coeficientes da matriz constitutiva são obtidos através de combinações de carregamentos e condições de contorno apropriadas, podendo-se estimar inclusive os valores dos termos de acoplamento eletromecânicos.

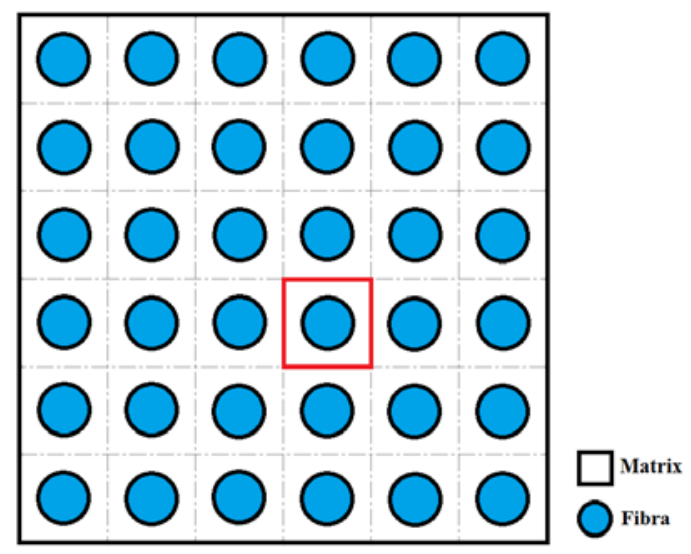

(a)

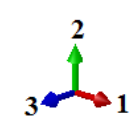

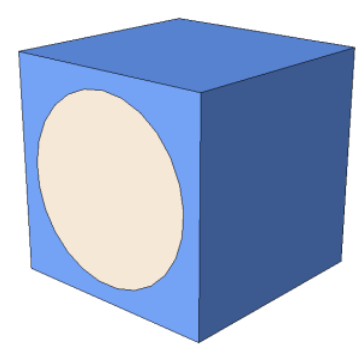

(b)

FIGURA 2.8-1 - AFC (a) Compósito com fibras unidirecionais em um arranjo quadrático (b) Volume Elementar Representativo (VER) - célula unitária 


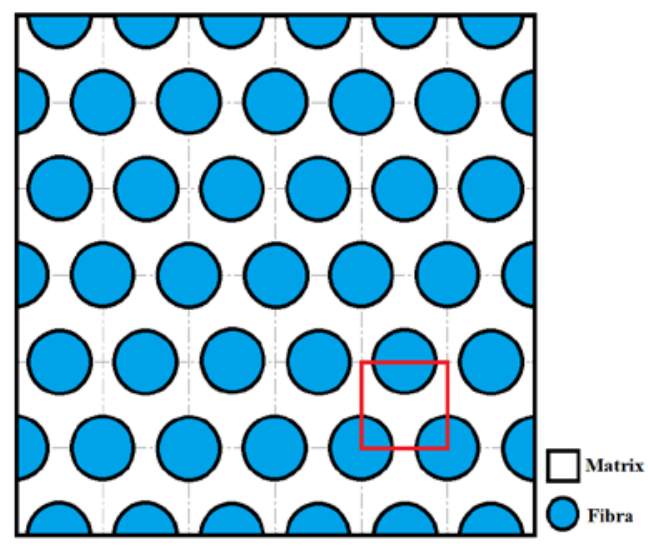

(a)

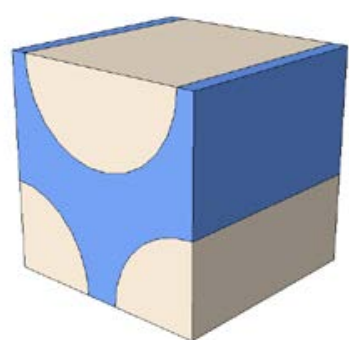

(b)

FIGURA 2.8-2 - AFC (a) Compósito com fibras unidirecionais em um arranjo hexagonal (b) Volume Elementar Representativo (VER) - célula unitária

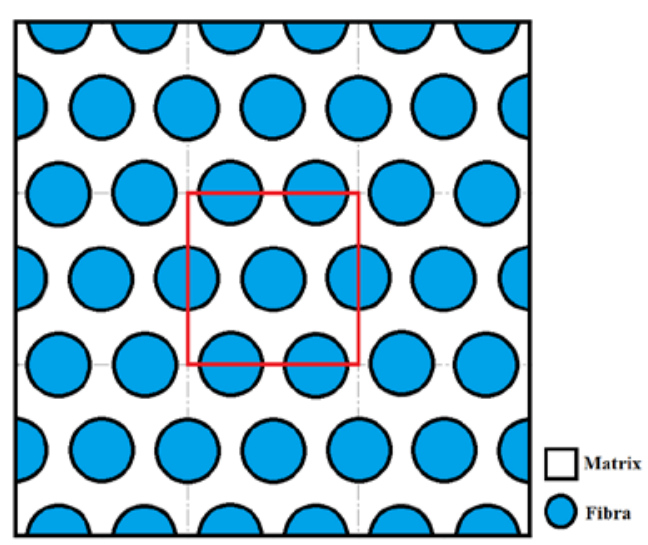

(a)

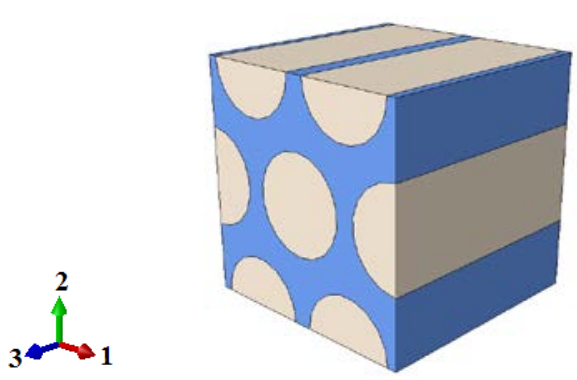

(b)

FIGURA 2.8-3 - AFC (a) Compósito com fibras unidirecionais em um arranjo hexagonal 1-2 (b) Volume Elementar Representativo (VER) - célula unitária

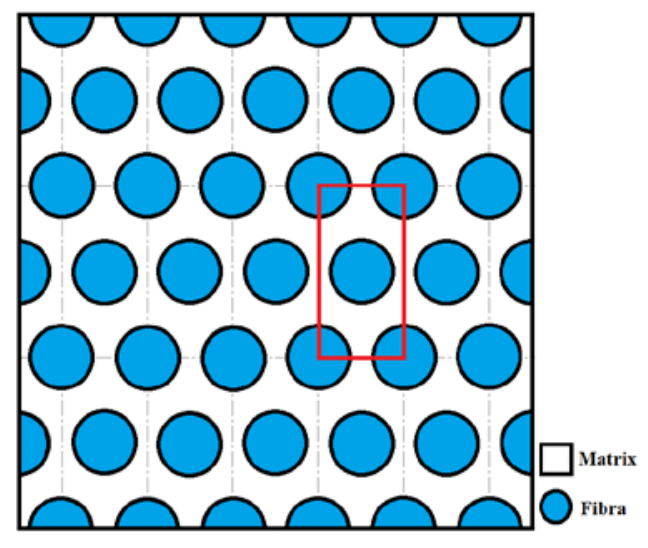

(a)

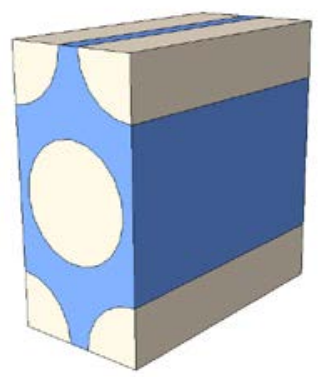

(b)

FIGURA 2.8-4 - AFC (a) Compósito com fibras unidirecionais em um arranjo hexagonal 2-3 (b) Volume Elementar Representativo (VER) - célula unitária 


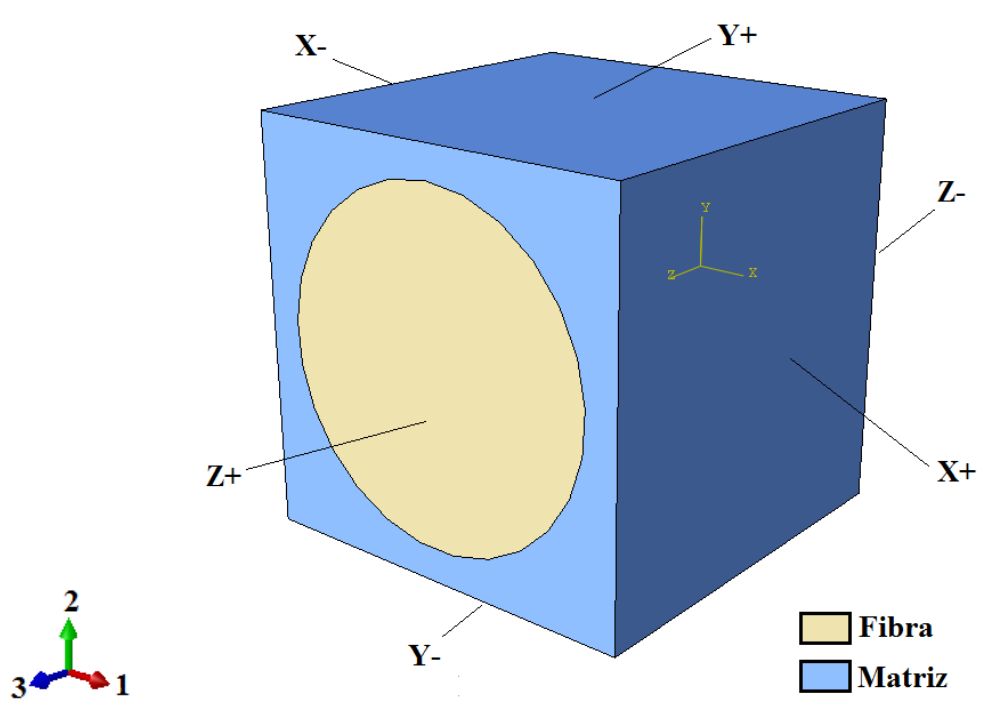

FIGURA 2.8-5 - Nomenclatura das superfícies utilizadas neste trabalho

A Figura (2.8-5) apresenta à designação dada as superfícies do VER. De acordo com sua localização, as superfícies do VER são designadas como X+, X-, Y+, Y-, Z+ e Z-. Vale lembrar que em todas as análises, para material piezelétrico, a fibra é considerada contínua e orientada ao longo do eixo z (eixo 3).

Adotando a hipótese de que a célula unitária se deforma de maneira repetida e idêntica aos seus vizinhos, em um VER, tem-se que as condições de periodicidade decorrem das exigências de compatibilidade com relação às bordas opostas. Um aspecto importante a ser considerado refere-se às condições de contorno aplicadas no VER adotado. Dessa forma, o comportamento eletro-mecânico é modelado com base na deformação micro estrutural do VER, que deve refletir o comportamento de seus vizinhos. Com isto, tem-se que as condições de periodicidade espacial no VER devem seguir as condições de compatibilidade com relação às faces opostas. Haja vista que VERs adjacentes devem ter deformações idênticas, não ocorrendo a sobreposição, nem a separação dos elementos do volume.

Considerando materiais compósitos como uma matriz periódica de células unitárias (Figuras (2.8-1) a (2.8-4)), as condições de contorno periódicas descritas por Xia et al. (2003) e Jin et al. (2008) devem ser aplicadas para garantir a repetibilidade de resposta das respectivas células, que constituem o material. Ademais, as condições de contorno propostas pelos pesquisadores são aplicadas de tal forma que não ocorra separação ou sobreposição entre os VERs vizinhos. 
Tal condição de compatibilidade supramencionada é conhecida como condição de paralelismo. Portanto, as condições de contorno periódicas podem ser expressas da seguinte forma:

$$
u_{i}^{+j}-u_{i}^{-j}=c_{i}^{j} \quad(i, j=x, y, z)
$$

onde $u_{i}^{j}$ indica o deslocamento ao longo da direção $i$ de um nó localizado na fronteira da face cujo vetor normal está ao longo da direção $j$. O sinal de mais sobrescrito significa que o vetor normal da fronteira da face é positivo em relação à direção $j$, enquanto o sinal de menos significa o oposto. Na verdade, $u^{+j}{ }_{i}$ e $u^{-j}{ }_{i}$ são deslocamentos de um par de nós em faces opostas da fronteira, com coordenadas idênticas nas outras duas direções, exceto na direção $j$. Assim, $c_{i}^{j}$ é constante, por isso todos os pares de nós definidos acima têm a mesma diferença de deslocamento na direção i (JIN et al., 2008).

A Figura (2.8-6) mostra uma ilustração esquemática de condições de contorno periódicas aplicadas em um VER. Sendo que a direção X está alinhada com o eixo 1, ao passo que a direção Y está alinhada com o eixo 2.
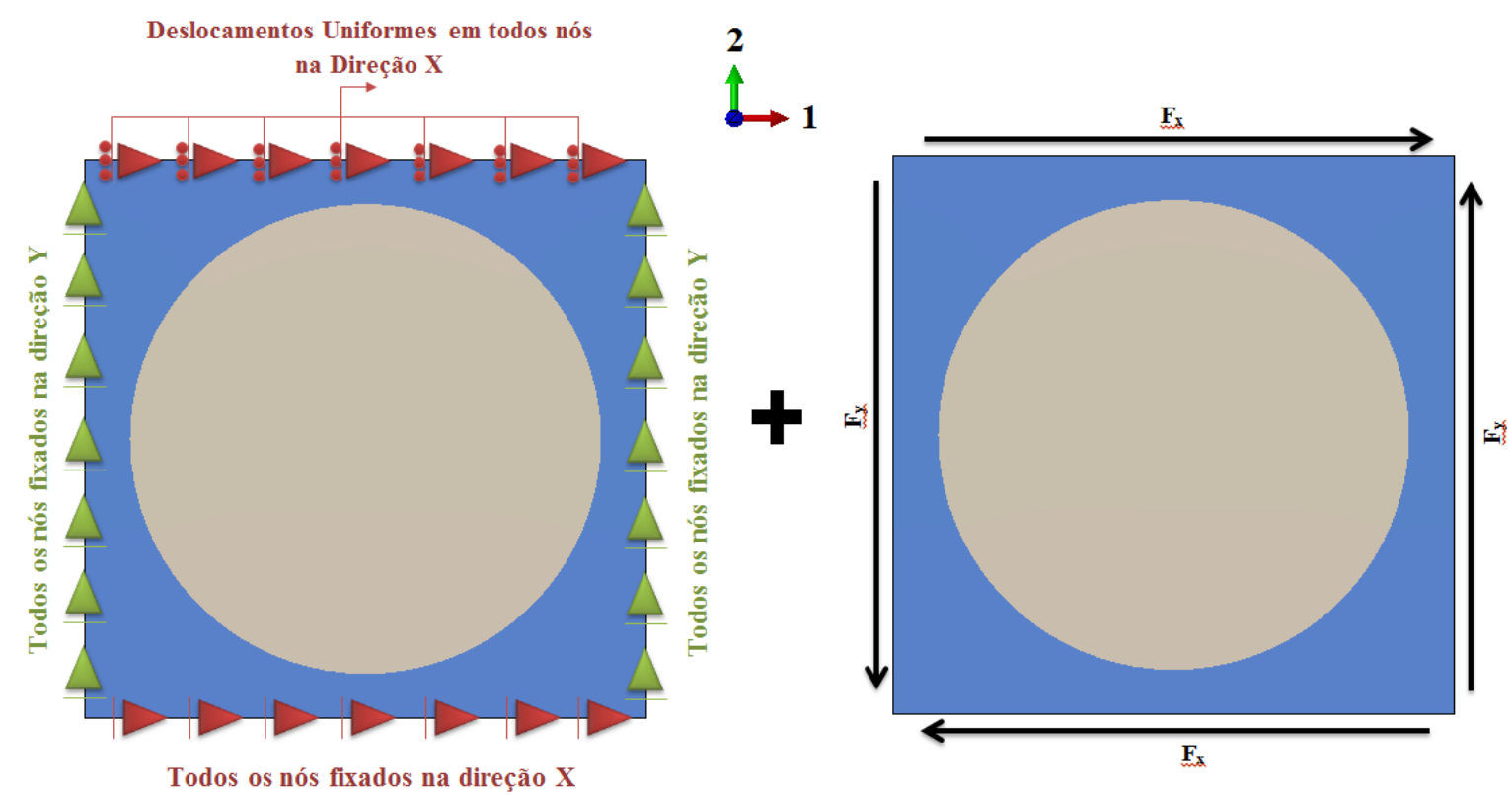

FIGURA 2.8-6 - Condições de contorno periódicas aplicadas em um VER [adaptado de JIN et al., 2008] 
Cabe ressaltar que esta condição de paralelismo deve ser aplicada para cada par de nós em lados opostos da célula unitária (em sentido vertical e horizontal) e, deve ser repetida ao longo da profundidade da célula. No entanto, não é necessário especificar essas condições para todos os casos de carregamento, porque em alguns casos específicos, o deslocamento e as condições de contorno elétricas já asseguram essa restrição de paralelismo. É aconselhável evitar a aplicação excessiva dessas condições, pois, um número excessivo de equações será introduzido na solução numérica, podendo causar problemas de “overconstraints”. Todavia, a ausência de algumas dessas equações pode levar a ocorrência de movimento de corpo rígido por parte do modelo. Sendo assim, conclui-se as condições de contorno devem ser criteriosamente empregadas a fim de se garantir a qualidade dos resultados computacionais (MORENO et al., 2010).

Por fim, um número elevado de equações de restrição acarreta também em erros comuns na própria geração do modelo em elementos finitos. Dessa forma, procedimentos automáticos para localizar nós opostos e, aplicar as restrições necessárias devem ser utilizados. No presente trabalho, optou-se pelo desenvolvimento de sub-rotinas em Python visando à automação desse procedimento, que foi utilizado principalmente para os casos de carga envolvendo forças de cisalhamento. Por outro lado, para a aplicação das condições de paralelismo entre as faces, empregou-se uma ferramenta já implementada no pacote de elementos finitos ABAQUS, denotada como “Cyclic Symmetry”. Para o emprego de tal ferramenta, deve-se selecionar as superfícies relativas e criar um eixo paralelo às faces, passando pelo centroide do VER.

\subsection{ABordagens PARA PREVISÃo de COMPORTAMENTO dE COMPÓsitos PiEZELÉtRIcos}

Diferentes tipos de abordagens foram estudados ao longo do tempo para descrever o acoplamento piezelétrico-mecânico em materiais compósitos utilizados em diversas aplicações, que vão desde fibras integradas à estrutura durante a fabricação da mesma até o processo de colagem de pastilhas piezelétricas. Dentre os diferentes tipos de abordagens, têmse as experimentais, as analíticas, as numéricas e as híbridas, sendo que frequentemente, os 
pesquisadores utilizam mais de um tipo de abordagem de modo a avaliar melhor os resultados obtidos.

Em se tratando das abordagens analíticas, tem-se que os trabalhos como os de Chan e Unsworth (1989) e Smith e Auld (1991) apresentam abordagens analíticas básicas, limitadas em termos de condições de carregamentos específicas. Posteriormente, Schulgasser (1992) considerou duas fases em um compósito reforçado com fibras piezelétricas, adotando que os materiais apresentavam isotropia transversal e, assim, determinou suas propriedades elásticas, piezelétricas e de permissividade. No mesmo ano, Benveniste e Dvorak (1992) estabeleceram a existência de campos uniformes, que podem ser gerados pela aplicação de certas condições de contorno mecânica e elétrica em compósitos, sendo que os constituintes foram assumidos como transversalmente isotrópicos.

No ano seguinte, Nan (1993a, 1993b), Nan e Jin (1993c) e Nan et al. (1996) sintetizou seus resultados analíticos e, também, comentou com mais profundidade os resultados obtidos para as propriedades efetivas de compósitos piezelétricos transversalmente isotrópicos descrito por Schulgasser (1992). Ainda em 1993, Dunn e Taya (1993) acoplaram teorias micro-mecânicas com a solução eletro-elástica para representar inclusões de formato elipsoidal em um meio piezelétrico infinito a fim de estimar as propriedades eletromecânicas de piezocompósitos. Linhas de pesquisa similares foram adotadas por Beneviste (1993) e Chen (1993). Posteriormente, Bisegna e Luciano (1996 e 1997) generalizaram os princípios de Hashin-Shtrikman para determinar os limites de todas as propriedades piezelétricas de materiais. Crawley (1994) e Chopra (2002) apresentaram uma revisão sobre o estado da arte de estruturas inteligentes e sistemas integrados. Ghasemi-Nejhad et al. (2005, 2006) trabalharam na fabricação e em testes de painéis de compósitos ativos (ACPs) com sensores e atuadores piezelétricos embutidos, além disso os resultados analíticos, numéricos e experimentais foram empregados para verificar o desempenho dos materiais piezelétricos, bem como, determinar as frequências naturais de estruturas tipo painel.

Em se tratando, especificamente, do Método de Homogeneização Assintótica (AHM Asymptotic Homogenization Method), tem-se os trabalhos produzidos por Bensoussan et al. (1978), Newham et al. (1978), Cioranescu e Paulin (1979), Sanchez-Palencia (1980), Bendsùe and Kikuchi (1988), Bakhvalov e Panasenko (1989), Guedes e Kikuchi (1990), Aboudi (1991), Suzuki e Kikuchi (1991), Silva et al. (1997, 1998 e 1999), Panasenko (2005). Por fim, na última década, destaca-se, principalmente, os trabalhos publicados por pesquisadores da 
Universidade de Havana (Cuba). Dentre esses trabalhos, deve-se ressaltar os desenvolvidos por Bravo-Castillero et al (1998), Rodríguez-Ramos et al. (2001) e Bravo-Castillero et al. (2001), que utilizaram AHM para determinar, num primeiro momento, as propriedades efetivas de compósitos reforçados com fibras estruturais, possuindo simetria quadrada na distribuição e, em seguida, para compósitos contendo fibras piezelétricas. Seguindo esta mesma linha de pesquisa, Guinovart-Díaz et al. (2001 e 2002) e Sabina et al. (2001) utilizaram AHM para determinar a resposta de materiais compósitos, sendo que a disposição das fibras apresenta simetria hexagonal. Sevostianov (2001) também utilizou AHM e, encontrou bons resultados para materiais compósitos com distribuição aleatória de fibras.

Em se tratando de abordagens numéricas, tem-se que as mesmas foram impulsionadas com o aumento da demanda por fibras ativas, destacando-se, principalmente, o emprego do Método dos Elementos Finitos (MEF). Na década de 80, Teply e Dvorak (1988) apresentaram modelos de células unitárias com condições de contorno capazes de prever o comportamento de um compósito. Na década seguinte, Gaudenzi (1997) estudou a implementação de uma célula unitária como modo de simular o comportamento de uma pastilha de fibras ativas para ser aplicada em placas metálicas. Aplicando as devidas condições de simetria, o pesquisador demonstrou que é possível uma boa estimativa do comportamento do material através da simulação de apenas uma célula unitária submetida a diversos tipos de carregamentos. Em seguida, Poizat e Sester (1999) determinaram numericamente dois coeficientes efetivos piezelétricos (o longitudinal e o transversal). Posteriormente, Petterman e Suresh (2000) aplicaram a célula unitária a compósitos piezelétricos com ênfase na formulação das condições de contorno apropriadas.

Apesar da importância das contribuições anteriores supracitadas, verifica-se que na última década houve de fato um crescente aumento do emprego das abordagens numéricas, impulsionado pelos avanços das tecnologias computacionais. Sendo que no início da década, Azzouz et al (2001) trabalharam na extensão das propriedades do elemento MIN6 (elemento aniso-paramétrico de três nós) de modo a incorporá-lo na modelagem de AFC (Active Fiber Composite) е MFC ${ }^{\mathrm{TM}}$ (Macro-Fiber Composite).

Berger et al. (2003, 2005, 2006, 2007) apresentaram as propriedades efetivas de compósitos piezelétricos (Active Fiber Composite - AFC), comparando os resultados analíticos via homogeneização assintótica com resultados numéricos via MEF (através do 
programa Ansys) para diferentes arranjos de célula unitária e diferentes materiais piezelétricos.

Odegard (2004) propôs um método para determinar as propriedades eletromecânicas de compósitos piezelétricos, este método oferece o mesmo nível de conveniência quando comparado ao método Mori-Tanaka. As propriedades eletromecânicas do material compósito polimérico piezelétrico são calculadas através dos métodos de Mori-Tanaka, Auto Consistente (Self-consistent), o método proposto.

Em meados da década, Tan e Vu-Quoc (2005) apresentaram a formulação de um elemento finito “solid-shell” para aplicação em estruturas ativas de compósitos, contabilizando grandes deformações e grandes deslocamentos. O elemento possuía graus de liberdade de deslocamento mecânico e elétricos, porém, não possuía graus de liberdade de rotação. Os autores asseguraram a eficiência e a precisão da análise de estruturas com grandes deformações, fabricadas em materiais compósitos laminados, incluindo camadas piezelétricas. Kar-Gupta e Venkatesh (2005 e 2007a e 2007b) estudaram a influência da distribuição de fibras nos compósitos piezelétricos. Em seus estudos consideraram tanto a fibra como a matriz, como possuindo propriedades piezelétricas.

Melnykowycz et al. (2006) estudaram os compósitos com fibras de PZT integrados a laminados reforçados com fibra de vidro para caracterização do desempenho desses, como componente de um material inteligente. No ano seguinte, Paradies e Melnykowycz (2007) empregaram também um modelo de célula unitária com o objetivo de estudar a influência dos eletrodos interdigitais nas propriedades mecânicas das fibras ativas. Os autores afirmaram que apesar de existirem diversos trabalhos na área relacionados à determinação de propriedades eletromecânicas, tem-se que não existem ferramentas adequadas para avaliar as tensões nos elementos piezelétricos (PZT), incluindo condições de campo elétrico não-homogêneo, bem como a alteração de propriedades de material.

Panda e Ray (2006, 2008a e 2008b) avançaram no estudo de compósitos piezelétricos, incluindo a influência da temperatura junto às propriedades piezelétricas do compósito. A estrutura estudada foi uma placa de compósito integrada com pastilhas piezelétricas. Mais recentemente, Paik et al. (2007) modelou e simulou todos os constituintes de um compósito AFC (fibra piezelétrica, matriz polimérica, kapton e fibra de vidro), comparando os resultados com dados encontrados na literatura e investigando a densidade da malha e distribuição de tensão local. 
Moreno et al. (2009, 2010) investigaram fibras com a mesma seção transversal de área e dois diferentes arranjos periódicos de célula unitária: quadrática e hexagonal. No último artigo, os pesquisadores investigaram, ainda, a influência das condições de contorno aplicadas na determinação dos coeficientes efetivos para AFC. Deraemaeker e Nasser (2010) focaram na avaliação das propriedade homogêneas da camada ativa de transdutores MFC usando o método dos elementos finitos através homogeneização periódica. O método proposto é aplicado a MFCs $d_{31}$ e $d_{33}$ e os resultados são comparados com Deraemaeker et al. (2009, 2007). Sendo que este artigo apresenta a modelagem de transdutores MFC, baseado no método dos campos uniformes, do qual é derivada a regra das misturas analiticamente para determinação dos coeficientes efetivos para os transdutores MFC $d_{31}$ e $d_{33}$, sendo que estes resultados são validados usando resultados numéricos e experimentais encontrado na literatura. Trindade e Benjeddou (2010, 2011) apresentou um método de homogeneização baseado em elementos finitos para caracterização das propriedades efetivas de um atuador piezelétrico (MFC) composto de sete camadas.

Biscasni et al. (2011) modelou e calculou os coeficientes efetivos eletromecânicos para transdutores Macro Fiber Composite (MFC) usando o método de Homogeneização Expansão Assintótica (Asymptotic Expansion Homogenization - AEH), métodos dos campos uniformes (Uniform Field Method - UFM) e método da homogeneização periódica (Periodic Homogenization Method - PHM). O método AEH é resolvido analiticamente sem considerar os efeitos dos eletrodos, e numericamente considerando os eletrodos.

Finalmente, a Tabela (2.9-1) apresenta de forma sumarizada, alguns trabalhos científicos, que preveem o comportamento eletromecânico, correlacionando os mesmos com algumas classes de materiais compósitos piezelétricos. Sendo que esta foi baseada na natureza da anisotropia elástica e na atividade piezelétrica dos constituintes (matriz e fibra).

Constata-se, assim, pelo texto supracitado e pela Tabela (2.9-1) que apesar das inúmeras contribuições científicas existentes, há ainda lacunas a serem preenchidas. Portanto, isto justifica o desenvolvimento de novas metodologias analíticas e/ou numéricas, visando não somente, o cálculo mais preciso das propriedades efetivas para materiais compósitos inteligentes, mas também, o cálculo para determinadas classes de materiais compósitos piezelétricos. Ademais, busca-se, também, uma solução que seja mais eficiente quanto ao custo computacional. 
TABELA 2.9-1 - Trabalhos científicos aplicados a algumas classes de materiais compósitos - (adaptado de KAR-GUPTA; VENKATESH, 2007a)

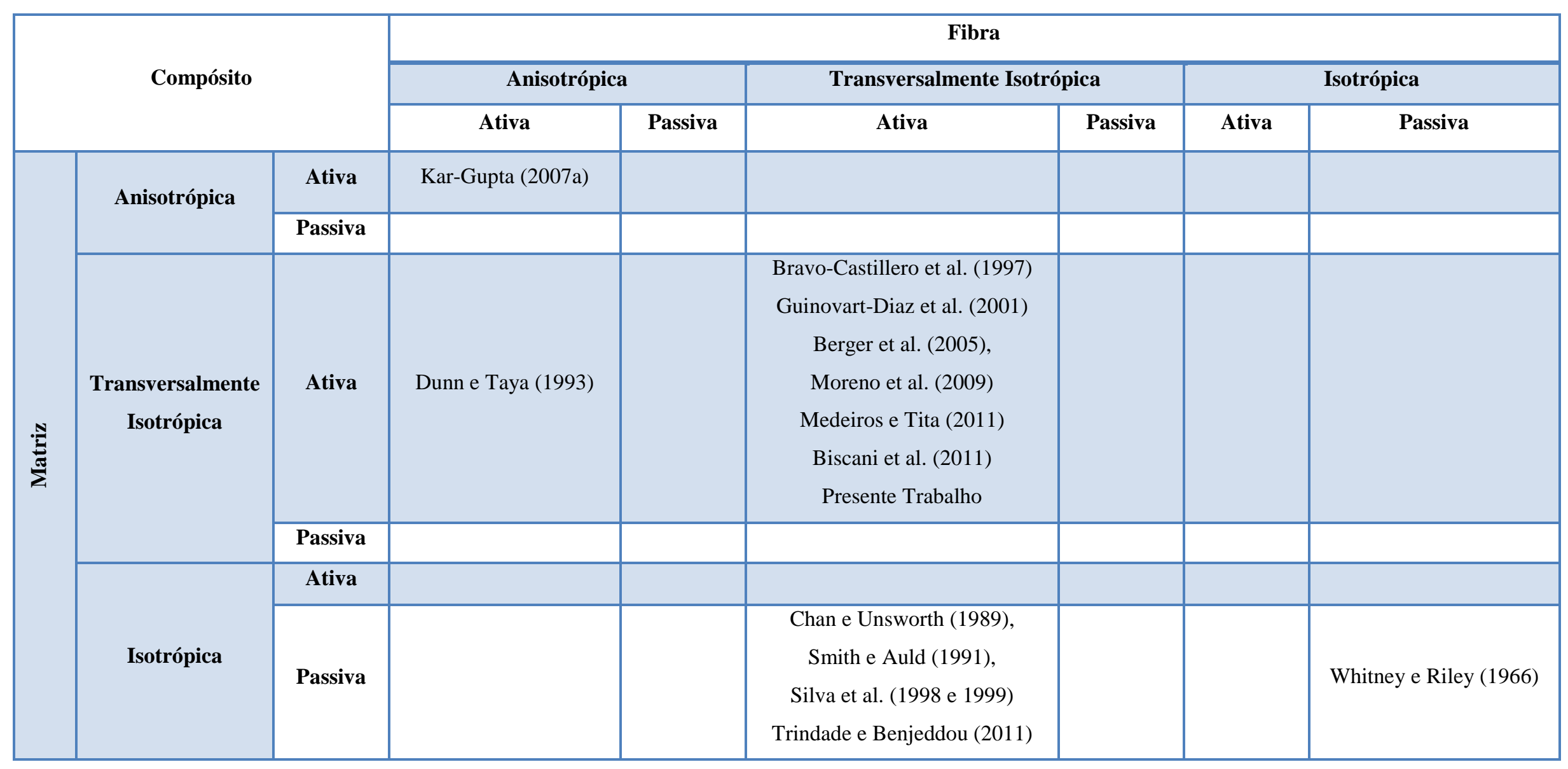




\subsection{Metodologia Científica}

A metodologia científica adotada para o presente trabalho visa num primeiro momento, apresentar os modelos micromecânicos (VER - Volume Elementar Representativo) solucionados via MEF (Método dos Elementos Finitos), que são propostos para prever comportamento de compósitos ativos, ou seja, discute-se em detalhes a metodologia computacional proposta neste trabalho para a determinação dos coeficientes efetivos. Num segundo momento, apresenta-se como os modelos computacionais são validados, ou seja, como a metodologia é avaliada. Inicialmente, de uma forma direta (Primeira Fase) e posteriormente, de uma forma indireta (Segunda Fase). Com isto, tem-se que metodologia científica adotada está baseada nas seguintes etapas (Figura (3.1-1)): 1) Revisão bibliográfica de compósitos ativos; 2) Seleção dos estudos de caso da literatura; 3) Modelos micromecânicos via MEF para compósitos ativos (metodologia computacional); 4) Verificação I: comparação direta dos resultados computacionais com os resultados da literatura; 5) Aplicação da metodologia computacional: modelos homogeneizados, visando a simulação computacional de uma viga engastada-livre com dois "patches" (pastilhas) piezelétricos (atuador e sensor); 6) Ensaios experimentais dinâmicos em uma viga com “patches” de compósitos ativos colados na superfície; 7) Verificação II: avaliação das potencialidades e limitações da metodologia desenvolvida, comparando os resultados das análises via MEF com os resultados experimentais.

Na Primeira Fase, a Etapa 1 consiste numa revisão bibliográfica da literatura sobre trabalhos relacionados com ensaios e modelos para material compósito ativo. Seguindo-se para Etapa 2, realiza-se uma seleção de estudos de caso mais relevantes com base na literatura investigada. Sendo que os resultados da literatura auxiliam na determinação dos parâmetros associados aos modelos de material para compósitos ativos. Na Etapa 3, são realizadas as análises micromecânicas dos compósitos ativos via Método dos Elementos Finitos (MEF), 
empregando um tipo de elemento e um modelo de material adequado. Estas análises consistem em um modelo baseado numa célula unitária (VER), onde é determinante a escolha correta das condições de contorno a serem aplicadas. Esta etapa é, portanto, uma das mais importantes, pois trata especificamente da metodologia computacional proposta. Em seguida, busca-se, inicialmente, reproduzir trabalhos similares da literatura para validar os modelos a serem empregados, ou seja, para avaliar as potencialidades e limitações da metodologia com base em Estudos de Caso. Portanto, a Primeira Fase da metodologia científica encerra-se na Etapa 4 (Verificação I), quando os resultados obtidos via MEF e os resultados experimentais são confrontados de forma direta. Sendo que no Estudo de Caso I, avalia-se a metodologia para um compósito ativo com fibra PZT de seção transversal circular e, no Estudo de Caso II, para um compósito ativo com fibra PZT de seção transversal retangular.

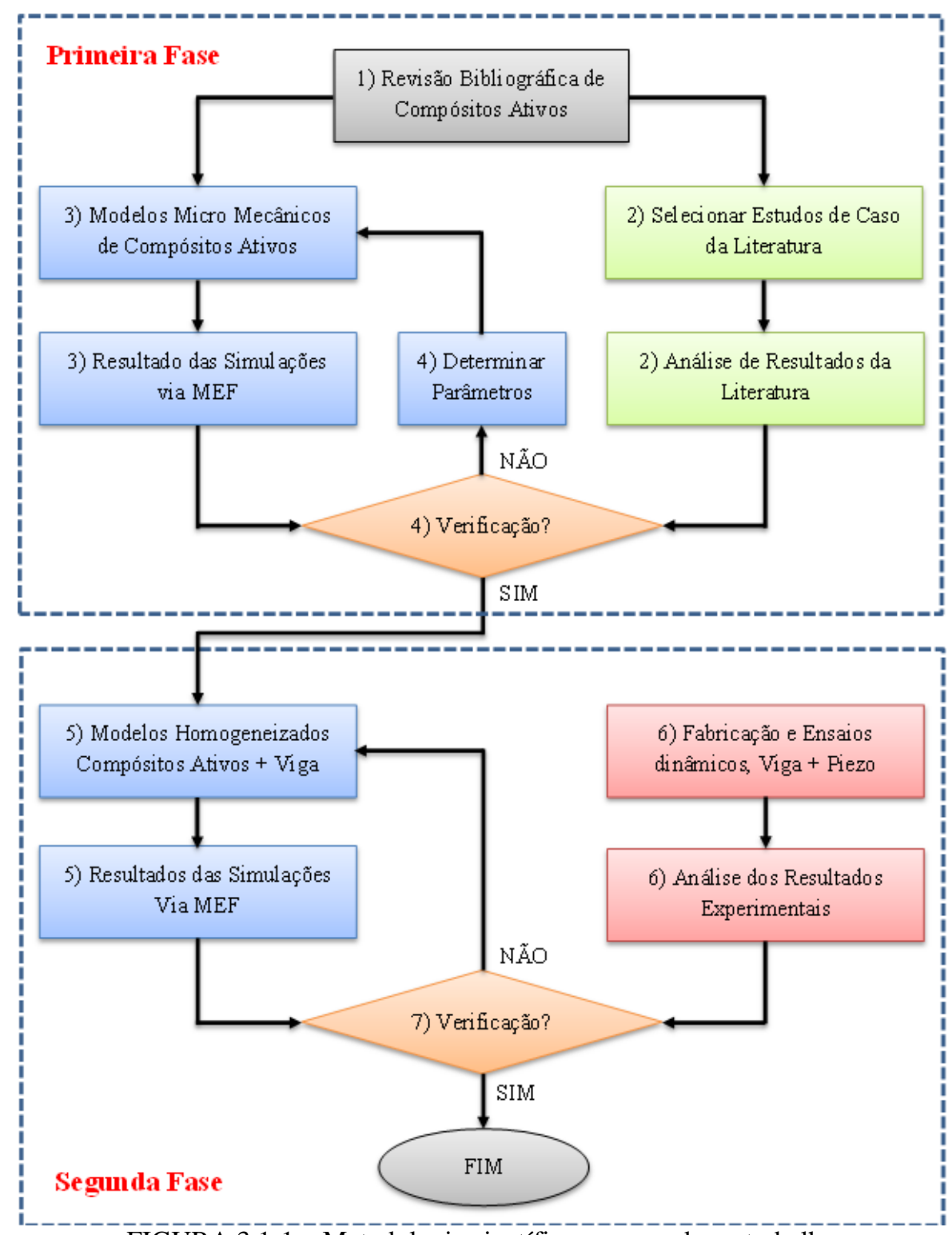

FIGURA 3.1-1- Metodologia científica empregada no trabalho 
Na Segunda Fase, tem-se inicialmente, a Etapa 5 que engloba análises dinâmicas via Método dos Elementos Finitos (MEF) de estruturas contendo compósitos ativos (por exemplo: pastilhas piezelétricas). Para tais análises são empregados modelos homogeneizados, visando representar o domínio do compósito ativo. Dessa forma modela-se uma viga engastada-livre em alumínio contendo duas pastilhas piezelétricas, sendo que as propriedades são determinadas a partir da metodologia desenvolvida (Estudo de Caso III). Paralelamente, na Etapa 6, são fabricados corpos-de-prova (CDPs) do tipo viga com pastilhas piezelétricas colados na superfície.

Em seguida, são executados ensaios experimentais dinâmicos, de tal forma que a estrutura é excitada através de um "patche” e monitorada através do outro e vice-versa. Sendo assim, os resultados experimentais obtidos para os compósitos ativos são analisados de maneira mais criteriosa ao final da Etapa 6. Sob posse dos resultados experimentais, tem-se que os mesmos são comparados aos resultados obtidos via MEF na Etapa 7 (Avaliação II). Caso os resultados via MEF produzam um nível de convergência insatisfatório em relação aos resultados experimentais, retorna-se para a Etapa 5, modificando os modelos empregados (tipo de elemento finito e/ou modelos de material). Após as referidas modificações, pode-se verificar novamente o nível de convergência entre os resultados via MEF e os resultados experimentais, discutindo as potencialidades e limitações da metodologia proposta.

\subsection{Metodologia Computacional Proposta}

Neste trabalho, propõem-se uma metodologia computacional visando a determinação dos 11 coeficientes efetivos para materiais compósitos inteligentes, ou seja, para compósitos ativos transversalmente isotrópicos, mais especificamente AFC (“Active Fiber Composite”). Vale ressaltar que a metodologia computacional proposta está baseada em modelos de célula unitária (VER) solucionados numericamente via MEF.

A referida metodologia é resultado de uma ampla consulta junto à literatura e, por sua vez, combina de forma singular uma série de boas práticas utilizadas em outros trabalhos. Dentre os quais, pode-se citar: Dun e Taya (1993); Silva et. al. (1997, 1998, 1999); Xia et al. 
(2003); Berger et al. (2005, 2006); Kar-Gupta et al. (2005, 2007a, 2007b); Panda e Ray (2007a, 2007b, 2008); Jin et al. (2008); Moreno (2009, 2010); Trindade e Benjeddou (2011).

Inicialmente, considerando que a metodologia irá prever as propriedades de AFC com fibra de seção transversal circular e retangular (mais especificamente, quadrada), tem-se que duas configurações diferentes foram utilizadas de acordo com as condições de carregamento e arranjo das fibras. Assim, arranjos quadráticos e hexagonais foram aplicados para fibras de seção transversal circular e retangular (AFC) (Figuras (3.2-1) e (3.2-2)). Sendo que o arranjo quadrático foi utilizado para todas as condições de carregamento, devido ao seu elevado grau de simetria, como mostra as figuras (3.2-1a) e (3.2-2a). Por outro lado, o arranjo hexagonal foi utilizado de acordo com as condições de paralelismo, previamente, discutidas no Capítulo 2.

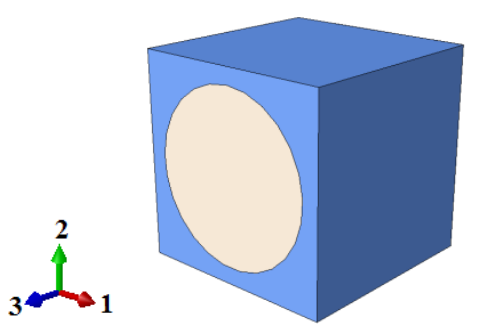

(a)

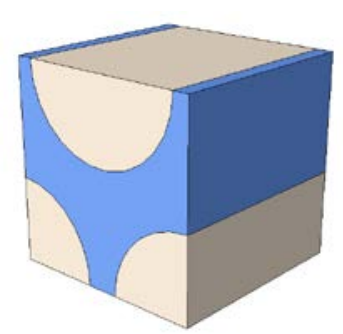

(b)

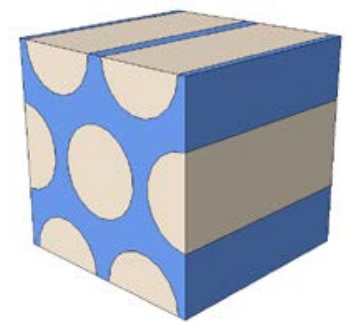

(c)

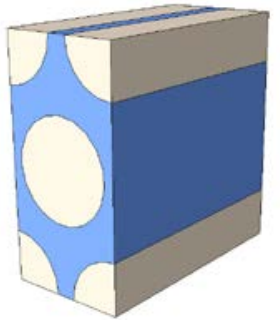

(d)

FIGURA 3.2-1 - Fibra com seção transversal circular (AFC): (a) Arranjo quadrático; (b) Arranjo hexagonal; (c) Arranjo hexagonal para cisalhamento 1-2 e (d) Arranjo hexagonal para cisalhamento 2-3.
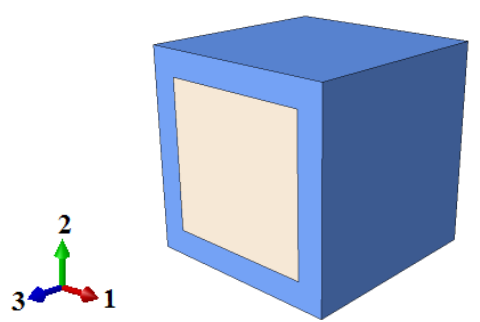

(a)

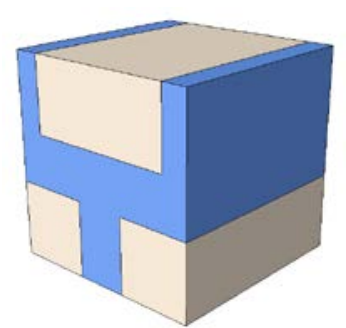

(b)

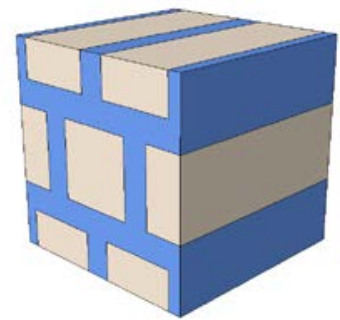

(c)

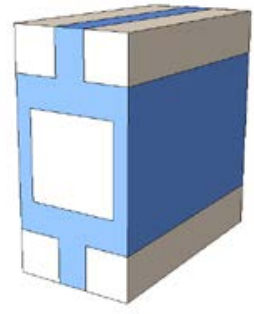

(d)

FIGURA 3.2-2 - Fibra com seção transversal retangular (AFC): (a) Arranjo quadrático; (b) Arranjo hexagonal; (c) Arranjo hexagonal para cisalhamento 1-2 e (d) Arranjo hexagonal para cisalhamento 2-3.

Destaca-se ainda que o modelo hexagonal, mostrado nas figuras (3.2-1b) e (3.2-2b), foi utilizado para casos de carregamento em que o deslocamento ou o potencial elétrico é fixado diferente de zero somente em uma das faces da célula unitária. Esta estratégia foi empregada para reduzir o tempo de simulação, contudo, esta célula unitária não apresenta simetria entre as faces $\mathrm{Y}$ - e $\mathrm{Y}+$, implicando na impossibilidade de utiliza-la para casos que 
envolvam cisalhamento. Portanto, quando a componente de cisalhamento é aplicada, verificase que o VER deve ser estendido para obter a completa simetria entre os lados opostos das superfícies, a fim de que haja a correta aplicação da restrição dada pela Equação (2.50). Sendo assim, para o caso de cisalhamento atuante no plano $X Y$ (plano 1-2), empregam-se os modelos mostrados nas figuras (3.2-1c) e (3.2-2c), entretanto para o caso de cisalhamento atuante no plano YZ (plano 2-3), emprega-se os modelo apresentados nas Figuras (3.2-1d) e (3.2-2d).

Nota-se, portanto, que metodologia computacional proposta, possibilita uma gama de combinações para a determinação dos coeficientes efetivos, empregando diferentes modelos de célula unitária com diferentes tipos de seção transversal. Além disso, com base no conjunto simplificado das equações constitutivas (Equação (2.6)), devido às condições de contorno aplicadas ao VER, constata-se que mais de um coeficiente é obtido para cada análise.

Cabe ressaltar que os resultados mais confiáveis produzem uma dada simetria de resposta da célula analisada. Sendo que os resultados mais precisos são obtidos quando o carregamento é aplicado na direção da fibra. Portanto, torna-se estratégico, dentro da presente metodologia computacional, estabelecer um procedimento de análise de tal forma que a primeira simulação envolva a determinação de coeficientes obtidos através da aplicação de deslocamentos ou gradiente de potencial elétrico na direção $Z$ (direção 3). Dessa forma, tal procedimento será detalhado nos próximos sub-itens.

\subsubsection{Primeira ANálise}

Com base na observação supracitada, tem-se, portanto, que ao aplicar a metodologia proposta, os coeficientes $c_{13}^{\text {eff }}$ e $c_{33}^{\text {eff }}$ são os primeiros a serem determinados, impondo deslocamentos normais iguais à zero nas superfícies $X^{+}, X-, Y+, Y$ - e $Z$-. Para tal, aplica-se um deslocamento positivo na direção $Z$, ou seja, prescrito na superfície $Z+$. Sendo que o potencial elétrico deve ser fixado em zero em todas as superfícies do modelo. Estas condições de contorno asseguram a compatibilidade da célula unitária.

A condição de potencial elétrico prescrito como zero assegura que $\{\bar{E}\}=\{0\}$ e, as restrições de deslocamento nulo asseguram que $\bar{S}_{11}=\bar{S}_{22}=\bar{S}_{12}=\bar{S}_{23}=\bar{S}_{31}=0$. Assim, apenas $S_{33}$ é diferente de zero e, portanto, a primeira e a terceira linha da Equação (2.17) são utilizadas para obter $c_{13}^{\text {eff }}$ e $c_{33}^{\text {eff }}$. 


$$
\left\{\begin{array}{l}
\bar{T}_{11} \\
\bar{T}_{22} \\
\bar{T}_{33} \\
\bar{T}_{12} \\
\bar{T}_{23} \\
\bar{T}_{31} \\
\bar{D}_{1} \\
\bar{D}_{2} \\
\bar{D}_{3}
\end{array}\right\}=\left[\begin{array}{ccccccccc}
c_{11}^{\text {eff }} & c_{12}^{\text {eff }} & c_{13}^{\text {eff }} & 0 & 0 & 0 & 0 & 0 & -e_{13}^{\text {eff }} \\
c_{12}^{\text {eff }} & c_{11}^{\text {eff }} & c_{13}^{\text {eff }} & 0 & 0 & 0 & 0 & 0 & -e_{13}^{\text {eff }} \\
c_{13}^{\text {eff }} & c_{13}^{\text {eff }} & c_{33}^{\text {eff }} & 0 & 0 & 0 & 0 & 0 & -e_{33}^{\text {eff }} \\
0 & 0 & 0 & c_{66}^{\text {eff }} & 0 & 0 & 0 & 0 & 0 \\
0 & 0 & 0 & 0 & c_{44}^{\text {eff }} & 0 & 0 & -e_{15}^{\text {eff }} & 0 \\
0 & 0 & 0 & 0 & 0 & c_{44}^{\text {eff }} & -e_{15}^{\text {eff }} & 0 & 0 \\
0 & 0 & 0 & 0 & 0 & e_{15}^{\text {eff }} & \varepsilon_{11}^{\text {eff }} & 0 & 0 \\
0 & 0 & 0 & 0 & e_{15}^{\text {eff }} & 0 & 0 & \varepsilon_{11}^{\text {eff }} & 0 \\
e_{13}^{e \text { eff }} & e_{13}^{\text {eff }} & e_{33}^{\text {eff }} & 0 & 0 & 0 & 0 & 0 & \varepsilon_{33}^{\text {eff }}
\end{array}\right]\left\{\begin{array}{c}
0 \\
0 \\
\bar{S}_{33} \\
0 \\
0 \\
0 \\
0 \\
0 \\
0
\end{array}\right\}
$$

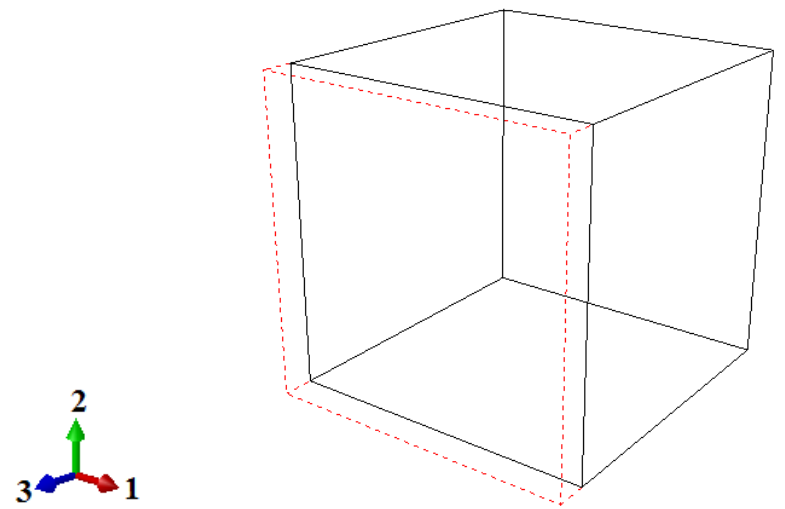

(b)

FIGURA 3.2-3 - Primeira análise: (a) Equação constitutiva incorporando as condições de contorno; (b) Representação do problema local usado para determinar os coeficientes efetivos relacionados com deformações normais.

$$
\begin{gathered}
c_{13}^{\text {eff }}=\frac{\bar{T}_{11}}{\bar{S}_{33}}, \\
c_{33}^{\text {eff }}=\frac{\bar{T}_{33}}{\bar{S}_{33}} .
\end{gathered}
$$

\subsubsection{SEgUNDA ANÁLISE}

Em seguida, encaminha-se para a determinação dos coeficientes $e_{13}^{\text {eff }}$, $e_{33}^{\text {eff }}$ e $\varepsilon_{33}^{\text {eff }}$. Neste caso, os deslocamentos são prescritos como zero em todas as faces do modelo. O potencial elétrico é prescrito zero na superfície $Z$ - e, aplica-se um valor arbitrário na superfície $Z+$. Estas condições de contorno asseguram a compatibilidade da célula unitária. Portanto, a condição prescrita de deslocamento igual à zero em todas as superfícies assegura que $\{\bar{S}\}=\{0\}$ 
e, a aplicação da diferença potencial elétrico nas superfícies $Z+$ e $Z$ - assegura gradiente apenas na direção Z. Consequentemente, da primeira, terceira e última linha da Equação (2.17), obtêm-se respectivamente os valores dos coeficientes $e_{13}^{\text {eff }}, e_{33}^{\text {eff }}$ e $\varepsilon_{33}^{\text {eff }}$, da seguinte forma.

$$
\left\{\begin{array}{l}
\bar{T}_{11} \\
\bar{T}_{22} \\
\bar{T}_{33} \\
\bar{T}_{12} \\
\bar{T}_{23} \\
\bar{T}_{31} \\
\bar{D}_{1} \\
\bar{D}_{2} \\
\bar{D}_{3}
\end{array}\right\}=\left[\begin{array}{ccccccccc}
c_{11}^{\text {eff }} & c_{12}^{\text {eff }} & c_{13}^{\text {eff }} & 0 & 0 & 0 & 0 & 0 & -e_{13}^{\text {eff }} \\
c_{12}^{\text {eff }} & c_{11}^{\text {eff }} & c_{13}^{\text {eff }} & 0 & 0 & 0 & 0 & 0 & -e_{13}^{\text {eff }} \\
c_{13}^{\text {eff }} & c_{13}^{\text {eff }} & c_{33}^{\text {eff }} & 0 & 0 & 0 & 0 & 0 & -e_{33}^{\text {eff }} \\
0 & 0 & 0 & c_{66}^{\text {eff }} & 0 & 0 & 0 & 0 & 0 \\
0 & 0 & 0 & 0 & c_{44}^{\text {eff }} & 0 & 0 & -e_{15}^{\text {eff }} & 0 \\
0 & 0 & 0 & 0 & 0 & c_{44}^{\text {eff }} & -e_{15}^{\text {eff }} & 0 & 0 \\
0 & 0 & 0 & 0 & 0 & e_{15}^{\text {eff }} & \varepsilon_{11}^{e f f} & 0 & 0 \\
0 & 0 & 0 & 0 & e_{15}^{\text {eff }} & 0 & 0 & \varepsilon_{11}^{\text {eff }} & 0 \\
e_{13}^{\text {efff }} & e_{13}^{\text {eff }} & e_{33}^{\text {eff }} & 0 & 0 & 0 & 0 & 0 & \varepsilon_{33}^{e f f}
\end{array}\right]\left\{\begin{array}{c}
0 \\
0 \\
0 \\
0 \\
0 \\
\bar{E}_{1} \\
\bar{E}_{2} \\
\bar{E}_{3}
\end{array}\right\}(\mathrm{a})
$$

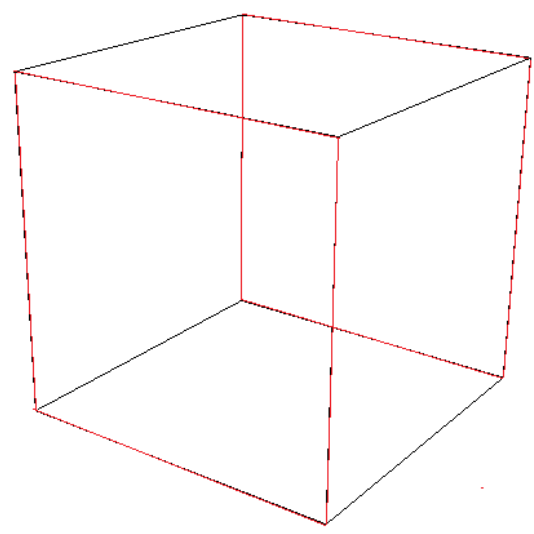

FIGURA 3.2-4 - Segunda análise: (a) Equação constitutiva incorporando as condições de contorno; (b) Representação do problema local usado para determinar os coeficientes efetivos relacionados com diferenças de potenciais entre as faces $\mathrm{Z}$ - e Z+.

$$
\begin{gathered}
e_{13}^{\text {eff }}=\frac{\bar{T}_{11}}{\bar{E}_{3}}, \\
e_{33}^{e f f}=-\frac{\bar{T}_{33}}{\bar{E}_{3}}, \\
\varepsilon_{33}^{e f f}=\frac{\bar{D}_{3}}{\bar{E}_{3}} .
\end{gathered}
$$




\subsubsection{TERCEIRA ANÁLISE}

Como próximo passo, tem-se a determinação dos coeficientes $c_{11}^{\text {eff }}$ e $c_{12}^{\text {eff }}$, impondo que os deslocamentos normais às superfícies $X-, Y+, Y$-, $Z+$ e $Z$ - sejam iguais à zero, bem como, alguns valores de tensão média $\left(\bar{S}_{22}=\bar{S}_{12}=\bar{S}_{23}=\bar{S}_{31}=\bar{S}_{33}=0\right)$. Então, deslocamentos positivos são prescritos na superfície $X+$ na direção do eixo $X$. O potencial elétrico é fixado em zero para todas as superfícies do modelo, assim $\{\bar{E}\}=\{0\}$. Portanto, da primeira e segunda linha da Equação (2.17) obtém-se os referidos coeficientes.

$$
\left\{\begin{array}{l}
\bar{T}_{11} \\
\bar{T}_{22} \\
\bar{T}_{33} \\
\bar{T}_{12} \\
\bar{T}_{23} \\
\bar{T}_{31} \\
\bar{D}_{1} \\
\bar{D}_{2} \\
\bar{D}_{3}
\end{array}\right\}=\left[\begin{array}{ccccccccc}
c_{11}^{\text {eff }} & c_{12}^{\text {eff }} & c_{13}^{\text {eff }} & 0 & 0 & 0 & 0 & 0 & -e_{13}^{\text {eff }} \\
c_{12}^{\text {eff }} & c_{11}^{\text {eff }} & c_{13}^{\text {eff }} & 0 & 0 & 0 & 0 & 0 & -e_{13}^{\text {eff }} \\
c_{13}^{\text {eff }} & c_{13}^{\text {eff }} & c_{33}^{\text {eff }} & 0 & 0 & 0 & 0 & 0 & -e_{33}^{\text {eff }} \\
0 & 0 & 0 & c_{66}^{\text {eff }} & 0 & 0 & 0 & 0 & 0 \\
0 & 0 & 0 & 0 & c_{44}^{\text {eff }} & 0 & 0 & -e_{15}^{\text {eff }} & 0 \\
0 & 0 & 0 & 0 & 0 & c_{44}^{\text {eff }} & -e_{15}^{\text {eff }} & 0 & 0 \\
0 & 0 & 0 & 0 & 0 & e_{15}^{\text {eff }} & \varepsilon_{11}^{\text {eff }} & 0 & 0 \\
0 & 0 & 0 & 0 & e_{15}^{\text {eff }} & 0 & 0 & \varepsilon_{11}^{\text {eff }} & 0 \\
e_{13}^{\text {eff }} & e_{13}^{\text {eff }} & e_{33}^{\text {eff }} & 0 & 0 & 0 & 0 & 0 & \varepsilon_{33}^{\text {eff }}
\end{array}\right]\left\{\begin{array}{c}
\bar{S}_{11} \\
0 \\
0 \\
0 \\
0 \\
0 \\
0 \\
0 \\
0
\end{array}\right\}(\mathrm{a})
$$

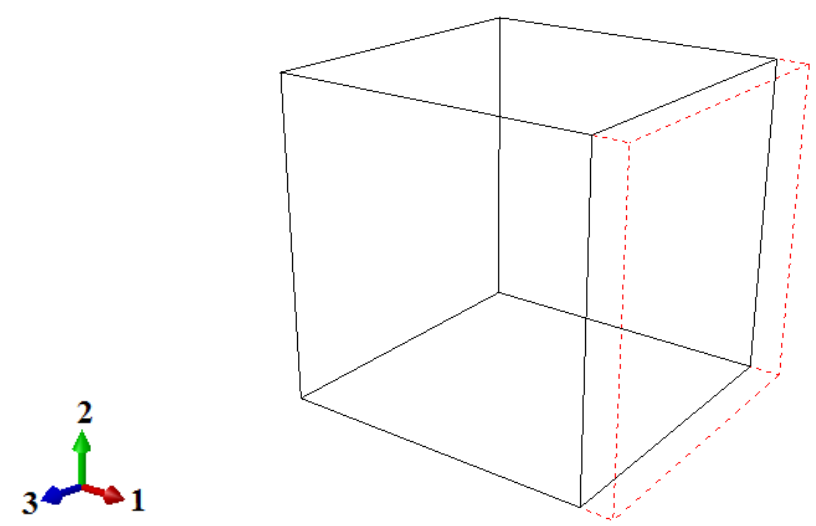

(b)

FIGURA 3.2-5 - Terceira análise: (a) Equação constitutiva incorporando as condições de contorno; (b) Representação do problema local usado para determinar os coeficientes efetivos relacionados com deformações normais.

$$
\begin{gathered}
c_{11}^{\text {eff }}=\frac{\bar{T}_{11}}{\bar{S}_{11}}, \\
c_{12}^{\text {eff }}=\frac{\bar{T}_{22}}{\bar{S}_{11}} .
\end{gathered}
$$




\subsubsection{QUARTA ANÁLISE}

Posteriormente, para a determinação do coeficiente $\varepsilon_{11}^{\text {eff }}$, os deslocamentos normais são fixados em zero para todas as superfícies do modelo. O potencial elétrico é prescrito igual a zero na superfície $X$-, e, diferente de zero na superfície $X+$. Esta condição assegura a compatibilidade da célula unitária. Os deslocamentos prescritos iguais a zero asseguram que $\{\bar{S}\}=\{0\}$, ao passo que a aplicação de potencial elétrico assegura apenas gradiente na direção

$X$. Portanto, da sétima linha da Equação (2.17) tem-se.

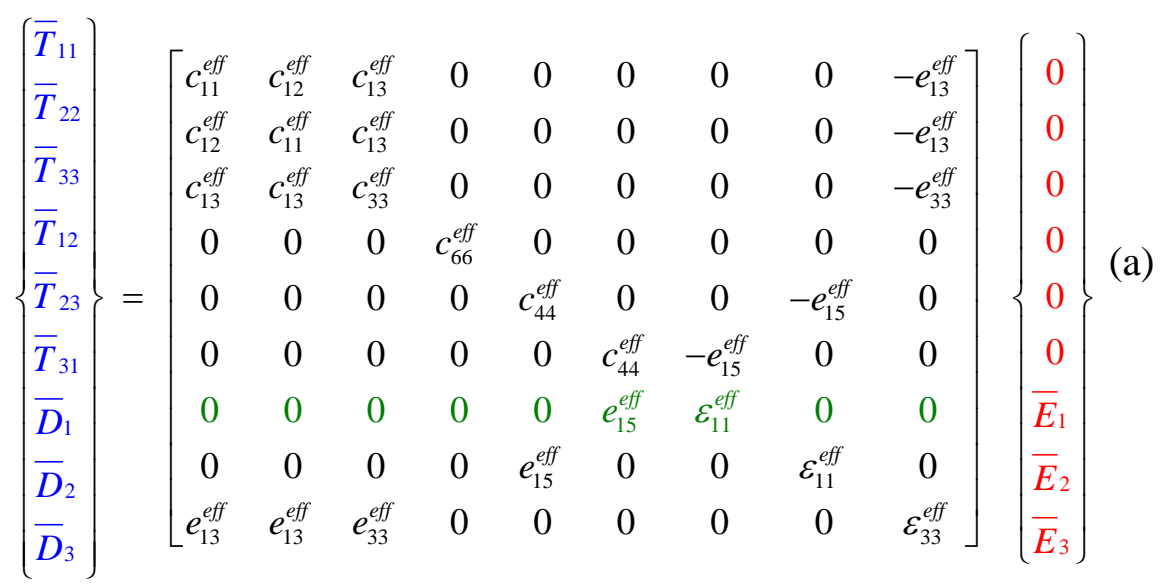
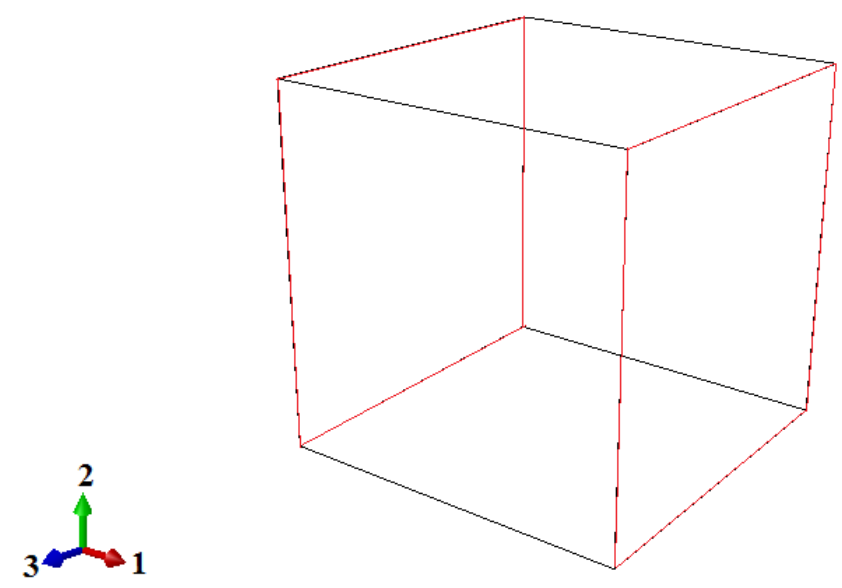

(b)

FIGURA 3.2-6 - Quarta análise: (a) Equação constitutiva incorporando as condições de contorno; (b) Representação do problema local usado para determinar os coeficientes efetivos relacionados com diferenças de potenciais entre as faces $\mathrm{Z}-\mathrm{e} \mathrm{Z}+$.

$$
\varepsilon_{11}^{e f f}=\frac{\bar{D}_{1}}{\bar{E}_{1}}
$$




\subsubsection{QUINTA ANÁLISE}

Para a determinação do coeficiente $c_{66}^{\text {eff }}$, todos os nós da face $Y$ - são restringidos na direção $X$; todos os nós da face $X$ - e $X+$ são restringidos na direção $Y$ e em todos os nós da face $Y+$ são aplicados deslocamentos uniformes prescritos na direção $X$. O potencial elétrico é prescrito zero em todas as superfícies do modelo. Forças de cisalhamento de mesmo módulo e orientações opostas são aplicadas nas superfícies $Y+$ e $Y$ - na direção $X$, e, nas superfícies $X+$ e $X$ - na direção $Y$, produzindo um estado de cisalhamento puro no plano $X Y$ onde somente a componente $\bar{S}_{12}$ de $\{\bar{S}\}$ é diferente de zero (Figura 2.13). Estas condições de contorno garantem a compatibilidade da célula unitária. As condições de potencial elétrico são prescritas iguais à zero em todas as superfícies e produzem $\{\bar{E}\}=\{0\}$. Portanto, com base na quarta linha da Equação (2.17) tem-se.

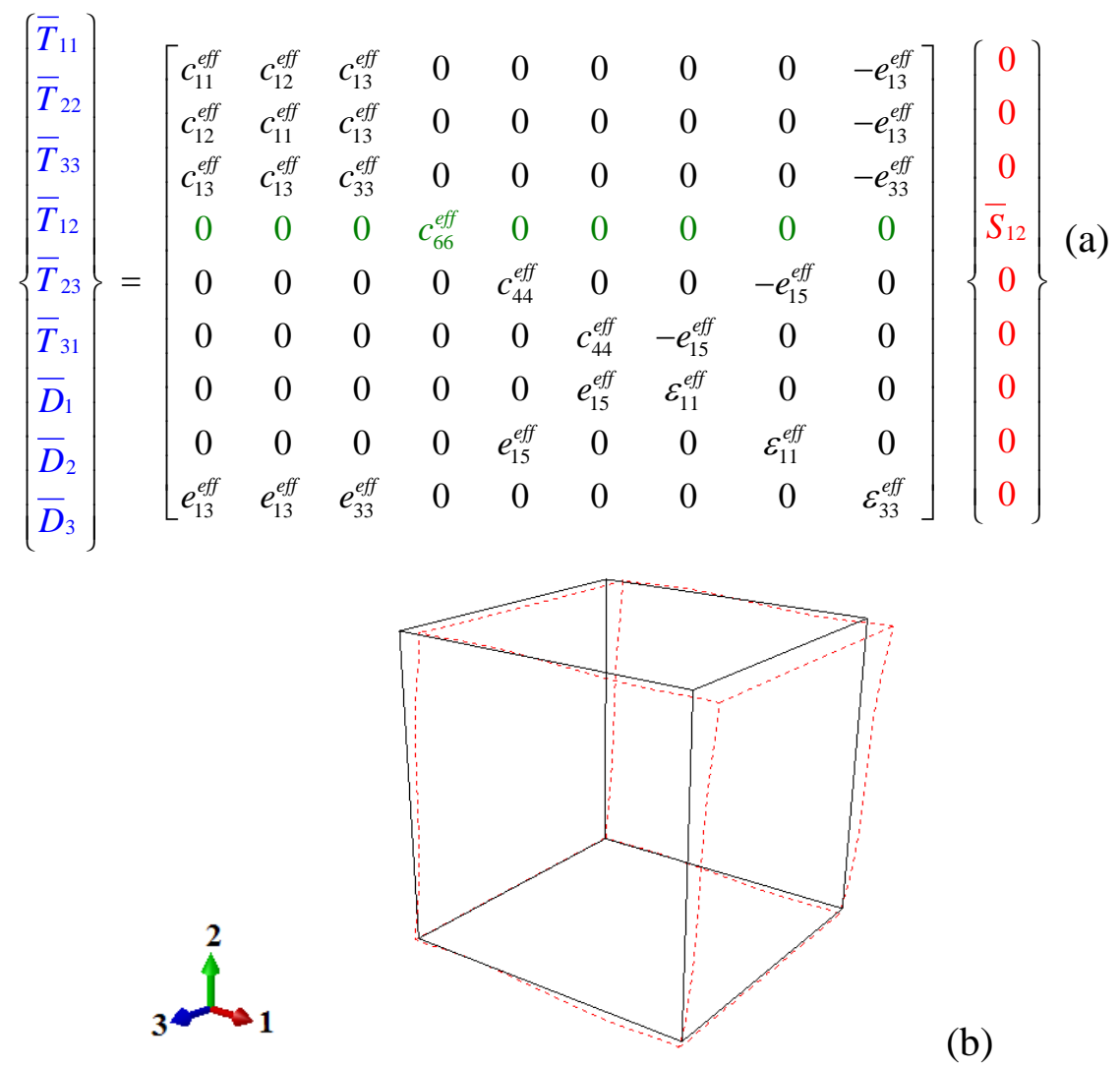

FIGURA 3.2-7 - Quinta análise: (a) Equação constitutiva incorporando as condições de contorno; (b) Representação do problema local usado para determinar os coeficientes efetivos relacionados com forças cisalhantes.

$$
C_{66}^{\text {eff }}=\frac{\bar{T}_{12}}{\bar{S}_{12}} .
$$




\subsubsection{SEXTA ANÁlisE}

Num próximo passo, segue-se para a determinação dos coeficientes $e_{15}^{\text {eff }}$ e $c_{44}^{\text {eff }}$. Neste caso, todos os nós da face $Y$ - são restringidos na direção $Z$; todos os nós da face $Z$ - e $Z$ + são restringidos na direção $Y$ e em todos os nós da face $Y+$ são aplicados deslocamentos uniformes prescritos na direção Z. O potencial elétrico é prescrito igual à zero na superfície Ze, diferente de zero na superfície $Z+$. Forças de cisalhamento são aplicadas nas superfícies $Y+$ e $Y$ - na direção $Z$, com mesmo módulo. Contudo, com orientações opostas, são também aplicadas forças de cisalhamento nas superfícies $Z+$ e $Z$ - na direção $Y$, produzindo, assim, um estado de cisalhamento puro YZ. Estas condições de contorno asseguram a compatibilidade da célula unitária. Assim, o coeficiente efetivo $\varepsilon_{11}^{\text {eff }}$ pode ser obtido da equação (3.8). Consequentemente, os valores dos coeficientes $e_{15}^{\text {eff }}$ e $c_{44}^{\text {eff }}$ podem ser obtidos da quinta e da oitava linha da Equação (2.17) da seguinte forma.

$$
\left\{\begin{array}{l}
\bar{T}_{11} \\
\bar{T}_{22} \\
\bar{T}_{33} \\
\bar{T}_{12} \\
\bar{T}_{23} \\
\bar{T}_{31} \\
\bar{D}_{1} \\
\bar{D}_{2} \\
\bar{D}_{3}
\end{array}\right\}=\left[\begin{array}{ccccccccc}
c_{11}^{\text {eff }} & c_{12}^{\text {eff }} & c_{13}^{\text {eff }} & 0 & 0 & 0 & 0 & 0 & -e_{13}^{\text {eff }} \\
c_{12}^{\text {eff }} & c_{11}^{\text {eff }} & c_{13}^{\text {eff }} & 0 & 0 & 0 & 0 & 0 & -e_{13}^{\text {eff }} \\
c_{13}^{\text {eff }} & c_{13}^{\text {eff }} & c_{33}^{\text {eff }} & 0 & 0 & 0 & 0 & 0 & -e_{33}^{\text {eff }} \\
0 & 0 & 0 & c_{66}^{\text {eff }} & 0 & 0 & 0 & 0 & 0 \\
0 & 0 & 0 & 0 & c_{44}^{\text {eff }} & 0 & 0 & -e_{15}^{\text {eff }} & 0 \\
0 & 0 & 0 & 0 & 0 & c_{44}^{\text {eff }} & -e_{15}^{\text {eff }} & 0 & 0 \\
0 & 0 & 0 & 0 & 0 & e_{15}^{\text {eff }} & \varepsilon_{11}^{\text {eff }} & 0 & 0 \\
0 & 0 & 0 & 0 & e_{15}^{\text {eff }} & 0 & 0 & \varepsilon_{11}^{\text {eff }} & 0 \\
e_{13}^{\text {eff }} & e_{13}^{\text {eff }} & e_{33}^{\text {eff }} & 0 & 0 & 0 & 0 & 0 & \varepsilon_{33}^{\text {eff }}
\end{array}\right]\left\{\begin{array}{c}
0 \\
0 \\
0 \\
0 \\
\bar{S}_{23} \\
\bar{E}_{1} \\
\bar{E}_{2} \\
\bar{E}_{3}
\end{array}\right\}
$$

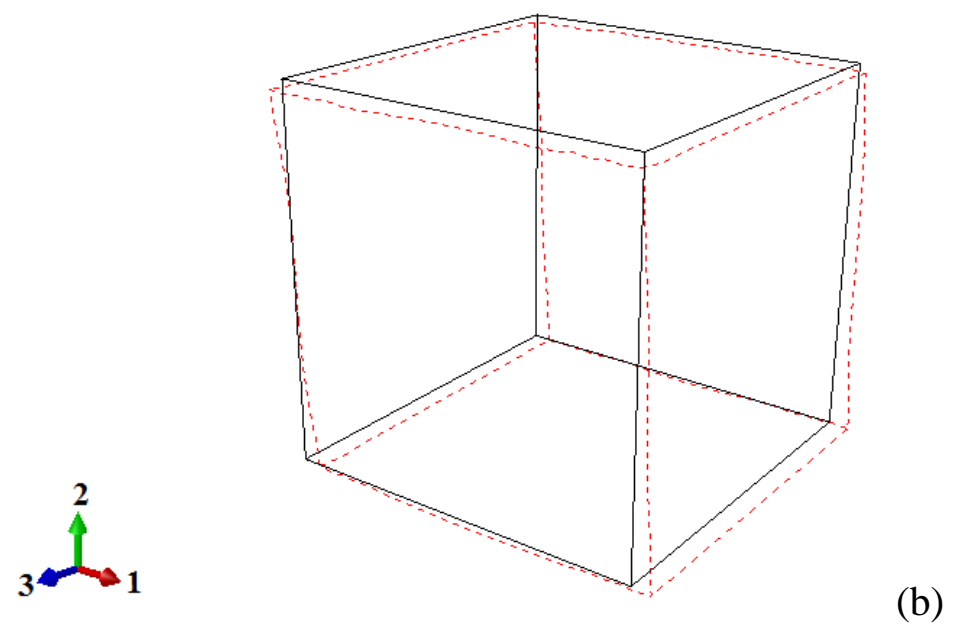

(b)

FIGURA 3.2-8 - Sexta análise: (a) Equação constitutiva incorporando as condições de contorno; (b) Representação do problema local usado para determinar os coeficientes efetivos relacionados com forças cisalhantes. 


$$
\begin{gathered}
e_{15}^{\text {eff }}=\frac{\left(-\bar{E}_{2} \cdot \varepsilon_{11}^{\text {eff }}+\bar{D}_{2}\right)}{\bar{S}_{23}}, \\
c_{44}^{\text {eff }}=\frac{\left(\bar{T}_{23}+\bar{E}_{2} \cdot e_{15}^{\text {eff }}\right)}{\bar{S}_{23}} .
\end{gathered}
$$

\subsubsection{CONSIDERAÇõES}

A metodologia computacional proposta pode ser sintetizada basicamente em 6 análises. A primeira e a segunda análises envolvem o carregamento aplicado na direção $Z$ (direção das fibras, ou ainda, direção 3). Sendo, a primeira, com carregamento mecânico e a segunda, com carregamento elétrico. As condições de contorno aplicadas já asseguram as condições de paralelismo da Equação (2.51), assim não se faz necessária à aplicação das equações de restrição. A terceira e a quarta análises são similares a primeira e a segunda, contudo os carregamentos mecânicos e elétricos são aplicados na direção $X$ (direção 1) Mais uma vez, as equações de restrição já estão garantidas pelas condições de contorno.

No entanto, as últimas duas análises descritas, envolvem o VER submetido a um carregamento de cisalhamento. Na quinta análise, o carregamento de cisalhamento é definido no plano $X Y$ e na sexta análise, no plano $Y Z$. Ambos os casos requerem a implementação explícita de equações de restrição, que imponham o paralelismo entre as faces, uma vez que o material compósito como um todo deva possuir continuidade de resposta. A Tabela (3.2-1) sintetiza os carregamentos e as condições de contorno requisitados para a aplicação da metodologia proposta. 
TABELA 3.2-1 - Carregamentos e Condições de Contorno Requisitados

\begin{tabular}{|c|c|c|c|c|c|c|c|c|}
\hline & & $\begin{array}{c}\text { Equação } \\
{ }^{(a}\end{array}$ & $\begin{array}{l}\text { Deslocamento } \\
\text { Prescrito [m] }\end{array}$ & $\begin{array}{c}\text { Força } \\
\text { Prescrita [N] }\end{array}$ & $\begin{array}{c}\text { Potencial } \\
\text { Elétrico } \\
\text { Prescrito [V] }\end{array}$ & $\begin{array}{c}\text { Condições Contorno } \\
\text { Deslocamento [m] }\end{array}$ & $\begin{array}{c}\text { Condições } \\
\text { Contorno } \\
\text { Potencial Elétrico } \\
{[\text { [V] }}\end{array}$ & VER \\
\hline 1. & $\begin{array}{l}C_{13}^{e f f} \\
c_{33}^{e f f}\end{array}$ & $\begin{array}{l}1^{\circ} \text { linha } \\
3^{\circ} \text { linha }\end{array}$ & $\begin{array}{l}\text { Positivo em } u_{z} \\
\text { na face } Z+\end{array}$ & - & - & $\begin{array}{c}\text { Deslocamento normal } \\
\text { igual a Zero nas faces } X^{+} \text {, } \\
\qquad-, Y+, Y-, Z-\end{array}$ & $\begin{array}{l}\text { Zero em todas as } \\
\text { faces }\end{array}$ & \\
\hline 2. & $\begin{array}{l}e_{13}^{e f f} \\
e_{33}^{e f f} \\
\varepsilon_{33}^{e f f}\end{array}$ & $\begin{array}{l}1^{\circ} \text { linha } \\
3^{\circ} \text { linha } \\
9^{\circ} \text { linha }\end{array}$ & - & - & $\begin{array}{c}\text { Voltagem positiva } \\
\text { na face } Z^{+}\end{array}$ & $\begin{array}{l}\text { Deslocamento normal } \\
\text { igual a Zero em todas as } \\
\text { faces }\end{array}$ & - & \\
\hline 3 & $\begin{array}{l}c_{11}^{e f f} \\
c_{12}^{e f f}\end{array}$ & $\begin{array}{l}1^{\circ} \text { linha } \\
2^{\circ} \text { linha }\end{array}$ & $\begin{array}{l}\text { Positivo em } u_{x} \\
\text { na face } X^{+}\end{array}$ & - & - & $\begin{array}{c}\text { Deslocamento normal } \\
\text { igual a Zero nas faces } X \text {-, } \\
Y+, Y-, Z+, Z-\end{array}$ & $\begin{array}{l}\text { Zero em todas as } \\
\text { faces }\end{array}$ & \\
\hline 4. & $\varepsilon_{11}^{e f f}$ & $7^{\circ}$ linha & - & - & $\begin{array}{c}\text { Voltagem positiva } \\
\text { na face } X^{+}\end{array}$ & $\begin{array}{l}\text { Deslocamento normal } \\
\text { igual a Zero em todas as } \\
\text { faces }\end{array}$ & - & \\
\hline
\end{tabular}


$+F_{y}$ e $-F_{y}$

faces $X+$ e $X$ -

5. $c_{66}^{\text {eff }} 4^{\circ}$ linha

$+F_{X}$ e $-F_{X} /$

faces $Y+$ e $Y$ -

$+F_{y} \mathrm{e}-F_{y} /$

faces $Z+$ e $Z$ -

$+F_{z}$ e $-F_{z} /$

faces $Y+$ e $Y$ -

6. $\begin{array}{cc}c_{44}^{\text {eff }} & 5^{\circ} \text { linha } \\ e_{15}^{\text {eff }} & 8^{\circ} \text { linha }\end{array}$
Deslocamentos em Y igual

a Zero nas faces $X^{+}, X_{-}$

Deslocamentos em $X$ igual a Zero na face $\mathrm{Y}$ -

Zero em todas as

Deslocamentos uniformes em $\mathrm{X}$ na face $\mathrm{Y}+$

\section{Deslocamentos em Y igual} a Zero nas faces $Z+, Z$ Zero na face Y-

Deslocamentos uniformes em $\mathrm{Z}$ na face $\mathrm{Y}+$ faces

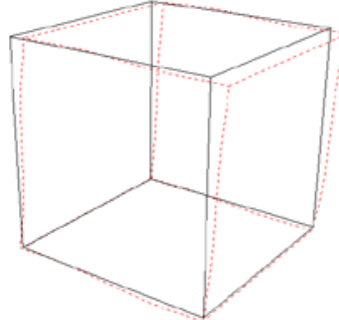

Zero nas faces $\mathrm{X}+, \mathrm{X}-, \mathrm{Y}+$,

$\mathrm{Y}-$

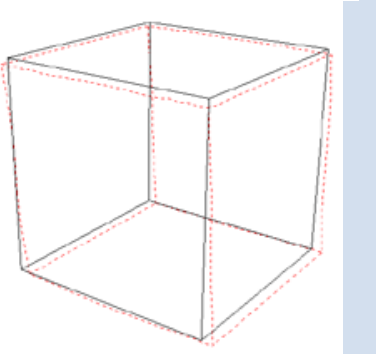

(a): Linhas numeradas referentes a Equação 2.6 
Vale ressaltar que no presente trabalho, todas as análises numéricas previstas pela metodologia supracitada são realizadas através do emprego do pacote de elementos finitos Abaqus e da Linguagem Python. Isto permite a parametrização das variáveis do problema (por exemplo: dimensões e propriedades), devido ao acesso direto aos dados do modelo. Deve-se destacar que o procedimento de parametrização é aplicado facilmente para a quinta análise devido à simetria da malha em todas as direções (Figura (3.2-9)). A correspondência entre os nós de faces opostas e, a repetição do procedimento na direção $Z$ é regular para todos os nós. Sendo que estes nós estão dispostos em uma linha reta como evidenciado pela Figura (3.2-9). Para a sexta análise, há correspondência entre os nós das faces opostas ao longo da direção $X$ apenas para as faces $Y+$ e $Y$-.

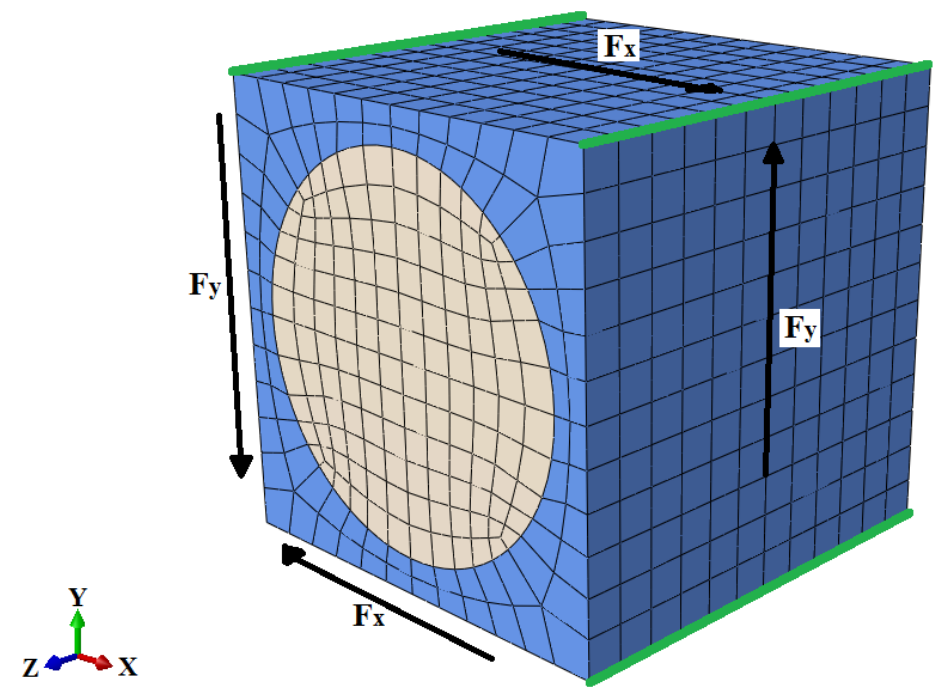

FIGURA 3.2-9 - Carregamento de cisalhamento puro no plano $X Y$

Sendo assim, se faz necessário incluir alguns comentários sobre a metodologia proposta para impor as condições às referidas análises:

1. Os nós pertencentes ao longo da linha da borda da célula unitária perpendicular ao plano de cisalhamento não devem sofrer a imposição das condições de paralelismo entre as faces opostas da célula unitária. Por exemplo, na Figura (3.2-9) para carregamento de cisalhamento no plano $X Y$, os nós da borda não são vinculados (linhas destacadas na Figura (3.2-9)). 
2. Ao aplicar as forças de cisalhamento, a carga é distribuída entre os nós da face exceto para os nós indicados pela linha destacada na Figura (3.2-9). Sendo que um procedimento similar é adotado para as condições de paralelismo. Para o caso de cisalhamento no plano $Y Z$, adota-se procedimento análogo, ou seja, os nós nas extremidades alinhadas com as linhas do eixo $X$ não sofrem a imposição das condições de paralelismo.

Como já mencionado anteriormente no Capítulo 2, um procedimento automático foi desenvolvido, empregando a linguagem Python, e visando aplicar todas as condições necessárias, bem como calcular todos os coeficientes efetivos do modelo de célula unitária. Este procedimento reduz o trabalho manual, economiza tempo e minimiza prováveis erros. Além disso, pode ser empregado como uma ferramenta computacional capaz de avaliar os coeficientes efetivos de um dado material compósito com fibras piezelétricas, considerando diferentes variações para determinados parâmetros, tais como: frações volumétricas de fibra; tipos de matriz polimérica; tipos de fibras; dimensões do volume elementar e etc.

\subsection{Discussões ACERCA da Metodologia}

Considerando os modelos apresentados pela Figura 3.3-1, que evidencia diferentes configurações de transdutores piezelétricos encontrados no mercado e/ou descritos na literatura consultada, algumas considerações devem ser discutidas a cerca da metodologia proposta no presente trabalho.

Inicialmente, deve-se ressaltar que a metodologia proposta foi desenvolvida para transdutores fabricados a partir de compósitos piezelétricos empilhados em camadas (multicamadas), considerando que a polarização poderia ocorrer tanto entre cada camada (Figura (3.3-1b)), como entre as faces mais externas do transdutor ((Figura 3.3-1a)). Sendo que isto será demonstrado no Capítulo 4, quando da aplicação da metodologia para o Estudo de Caso 1. Contudo, a metodologia pode ser estendida para outros tipos de transdutores, mostrados nas Figuras (3.3-1c) e (3.3-1d), ou seja, para aqueles fabricados a partir de compósitos com apenas uma única camada. Sendo que isto será demonstrado no Capítulo 4, quando da aplicação da metodologia para o Estudo de Caso 3. Por hora, destaca-se apenas que 
para determinar as propriedades efetivas de uma pastilha piezelétrica (Figuras (3.3-1c)), aplicando a metodologia proposta, faz-se necessária a hipótese de repetição da célula unitária ao longo da direção 2. Portanto, tem-se que tal consideração não representará fielmente o transdutor real, porém, as limitações e as potencialidades da metodologia proposta serão melhor discutidas e avaliadas no próximo Capítulo.

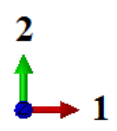

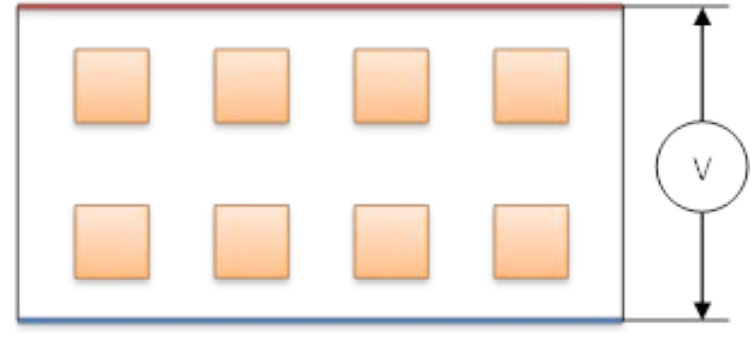

(a)

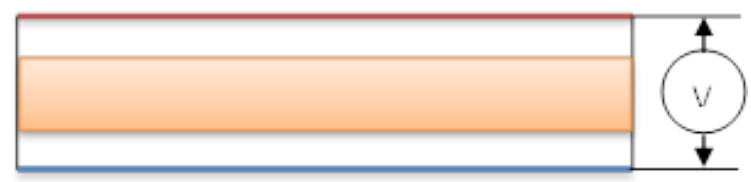

(c)

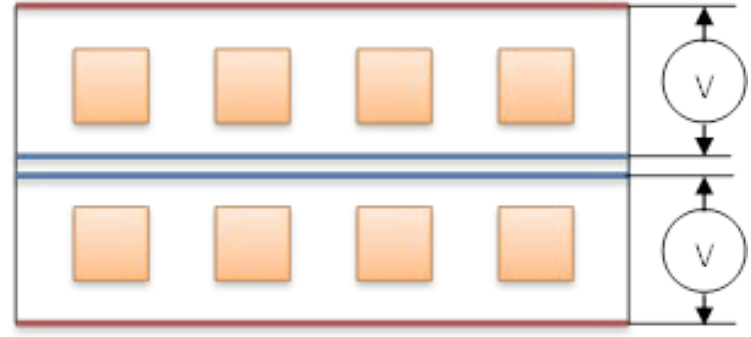

(b)

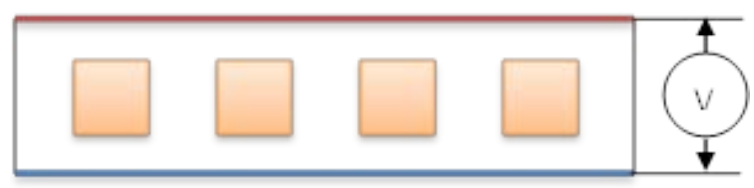

(d)

FIGURA 3.3-1 - Configurações de Transdutores PZT: (a) AFC com seção transversal quadrada polarizada nas extremidades, (b) AFC com seção transversal quadrada polarizada em cada camada, (c) Pastilha piezelétrica, (d) $\mathrm{MFC}^{\mathrm{TM}}$.

Outro aspecto importante a ser discutido relacionado com a metodologia proposta consiste na hipótese da isotropia transversal tanto por parte da fibra como por parte da matriz. Isto, portanto, demonstra que a metodologia dever ser aplicada para materiais compósitos inteligentes, que sejam transversalmente isotrópicos e, que estejam polarizados ao longo da direção 3. No entanto, efetuando alterações adequadas na Lei Constitutiva, pode-se abranger outros tipos de anisotropia existentes (vide Figura (2.1-3) - Capítulo 2), e, assim, aplicar a metodologia proposta. Sendo que isto poderá ser verificado em futuros trabalhos. 
Deve-se destacar ainda que para o desenvolvimento da metodologia, optou-se pela utilização do campo elétrico constante (E) e pela deformação mecânica constante (S). No Item 2.4 é demonstrado que os coeficientes piezelétricos podem ser obtidos para quaisquer condições de contorno elétricas ou mecânicas aplicadas inicialmente, pois, em seguida, os mesmos podem ser calculados para outras condições. Sendo que estes cálculos baseiam-se em relações estabelecidas pelo coeficiente de acoplamento piezelétrico. 


\section{APLiCAÇÃo da METOdologia COMPUTACIONAL: LIMITAÇÕES E POTENCIALIDADES}

\subsection{ESTUdo DE CASO I}

Neste primeiro estudo de caso, considerou-se o emprego da metodologia proposta para a determinação de coeficientes efetivos de compósitos ativos de seção transversal circular (AFC - Active Fiber Composite). Os referidos compósitos ativos possuem diâmetro de fibra igual a 1mm e fração volumétrica de fibra igual a 55,5\%, tanto para arranjos quadráticos como para hexagonais (como abordado no Capítulo 3).

\subsubsection{DAdos do MATERIAL}

A fim de avaliar as potencialidades e limitações da metodologia computacional proposta, utilizou-se a fibra piezelétrica PZT-5A envolvida em uma matriz não piezelétrica de resina epóxi (matriz polimérica). Tal escolha deve-se ao fato de que estes materiais não somente são amplamente utilizados em aplicações de engenharia, mas também, as informações sobre os mesmos são facilmente encontradas na literatura. Por exemplo, na Tabela (4.1-1), verifica-se as propriedades providas por Berger et al. (2005). No entanto, cabe ressaltar que a metodologia proposta pode ser empregada para qualquer outro material compósito ativo. Desde que o mesmo seja constituído por fibras PZT de seção circular ou retangular, transversalmente isotrópica, que estejam envolvidas por uma matriz polimérica.

TABELA 4.1-1 - Propriedades de materiais: matriz (resina epóxi) e fibra (PZT-5A) - (BERGER et al., 2005)

\begin{tabular}{|c|c|c|c|c|c|c|c|c|c|c|c|}
\hline & $\mathrm{c}_{11}$ & $\mathrm{c}_{12}$ & $\mathbf{c}_{13}$ & $\mathbf{c}_{33}$ & $\mathrm{C}_{44}$ & $\mathrm{c}_{66}$ & $\mathbf{e}_{13}$ & $\mathbf{e}_{15}$ & $\mathbf{e}_{33}$ & $\varepsilon_{11}$ & $\varepsilon_{33}$ \\
\hline & \multicolumn{6}{|c|}{ GPa } & \multicolumn{3}{|c|}{$\mathrm{C} / \mathrm{m}^{2}$} & \multicolumn{2}{|c|}{$\mathbf{n F} / \mathbf{m}$} \\
\hline Fibra & 121,0 & 75,4 & 75,2 & 111,0 & 21,1 & 22,8 & $-5,4$ & 12,3 & 15,8 & 8,11 & 7,35 \\
\hline Matriz & 3,86 & 2,57 & 2,57 & 3,86 & 0,64 & 0,64 & - & - & - & 0,0797 & 0,0797 \\
\hline
\end{tabular}




\subsubsection{MODELO EM ELEMENTOS FINITOS}

Como discutido anteriormente, todas as análises via elementos finitos requisitadas pela metodologia foram realizadas utilizando o programa Abaqus ${ }^{\mathrm{TM}}$ versão 6.10 (ABAQUS, 2010). A matriz polimérica e a fibra foram modeladas através de elementos sólidos com interpolação parabólica, possuindo 20 nós com 4 graus de liberdade por nó (C3D20E), sendo 3 para as translações e 1 para potencial elétrico. Além disso, para os modelos, adotou-se a hipótese de adesão perfeita entre os constituintes através do comando "tie" do programa ABAQUS. A Figura (4.1-1) mostra os modelos empregados conforme mencionado na metodologia, juntamente com a malha utilizada para os mesmos. Tais volumes elementares representativos foram obtidos de forma parametrizada com auxílio de uma sub-rotina escrita em linguagem Python, a qual está acoplada ao software de elementos finitos.

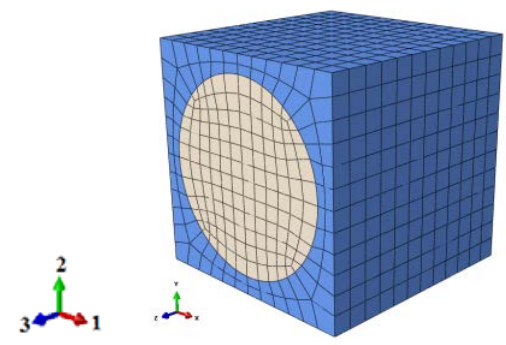

(a)

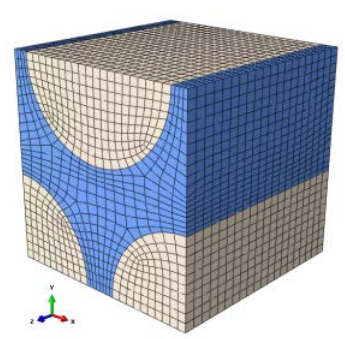

(b)

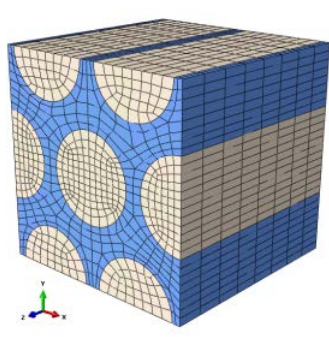

(c)

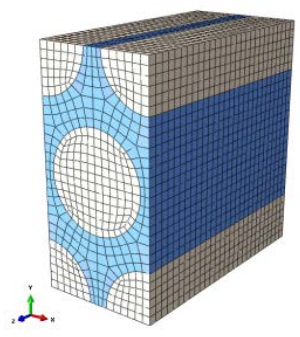

(d)

FIGURA 4.1-1 - Modelos em elementos finitos utilizados nas simulações - células unitárias e arranjos: (a) quadrático; (b) hexagonal; (c) hexagonal plano 1-2; (d) hexagonal plano 2-3.

Nas Figuras (4.1-2) e (4.1-3), pode-se observar os resultados numéricos obtidos para todas as seis análises apresentadas na metodologia, considerando arranjos quadráticos e hexagonais, respectivamente. Vale ressaltar que o sistema de coordenadas apresentado na Primeira Análise (Figura (4.1-2a) e (4.1-3a) serão utilizados como referência para as demais, ou seja, a fibra está orientada com o Eixo 3. Sob posse dos resultados das análises via MEF, sub-rotinas escritas em linguagem Python foram desenvolvidas, visando obter de forma automatizada não somente os resultados das grandezas envolvidas nas Equações (2.46), mas também, os valores médios das mesmas. Com base nesses resultados, as sub-rotinas em Python podem, então, calcular os coeficientes efetivos, seguindo as orientações da metodologia computacional apresentada no Capítulo 3. 


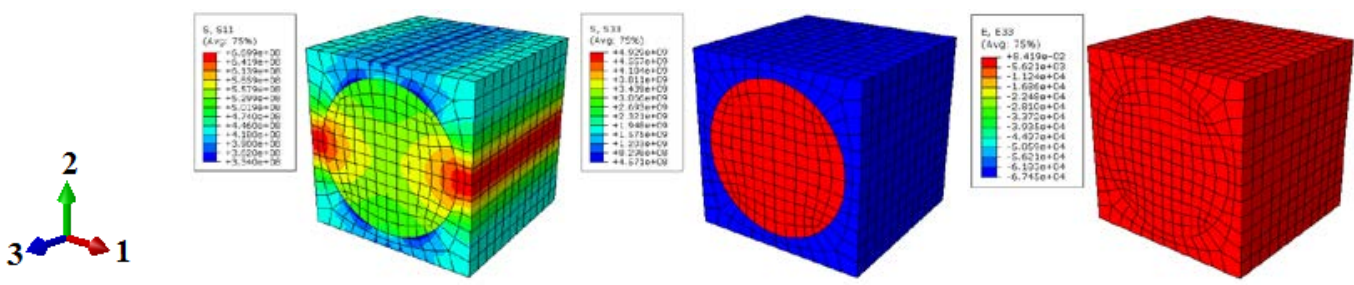

(a) Primeira análise: $T_{11}, T_{33}$ e $S_{33}$
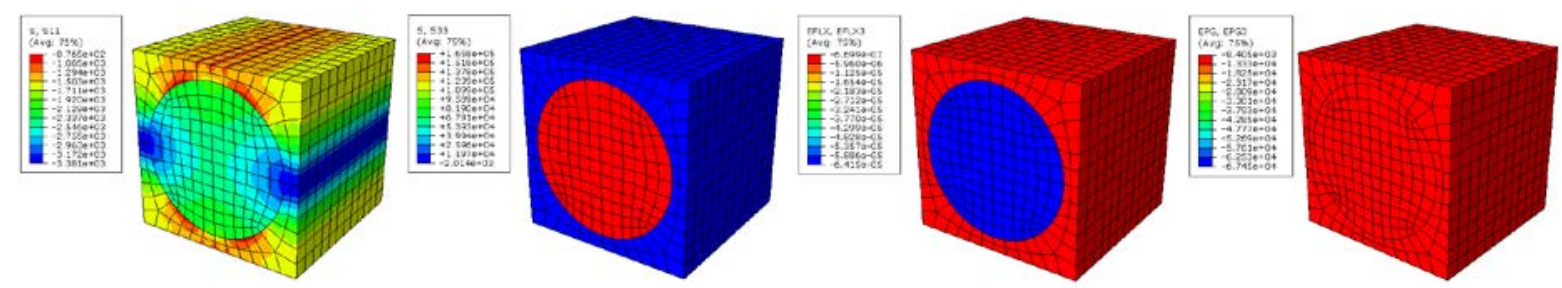

(b) Segunda análise: $T_{11}, T_{33} D_{3}$ e $E_{3}$
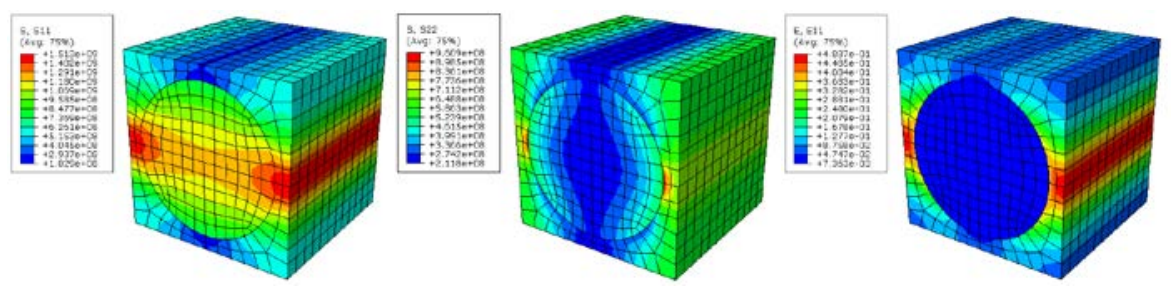

(c) Terceira análise: $\mathrm{T}_{11}, \mathrm{~T}_{22}$ e $\mathrm{S}_{11}$
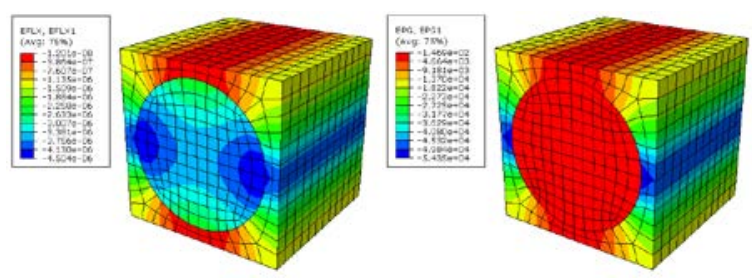

(d) Quarta análise: $\mathrm{D}_{1}$ e $\mathrm{E}_{1}$
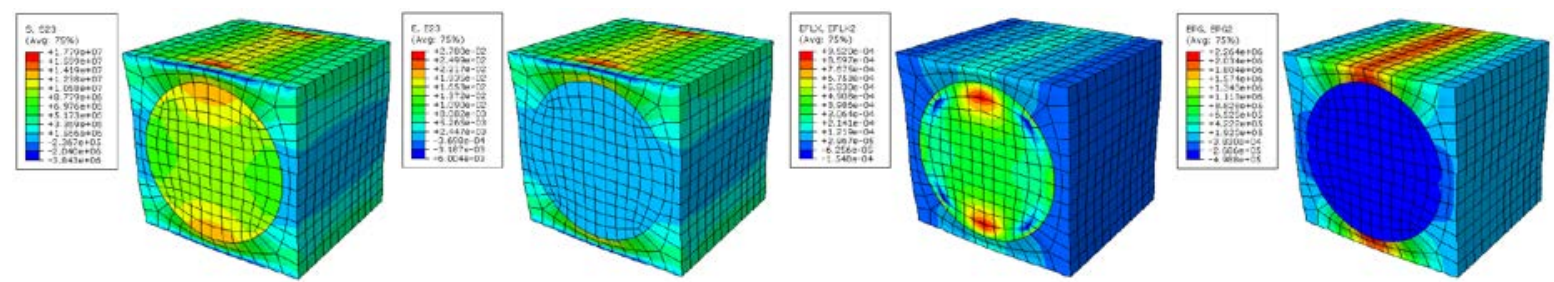

(f) Sexta análise: $T_{23}, S_{23} D_{2}$ e $E_{2}$ 

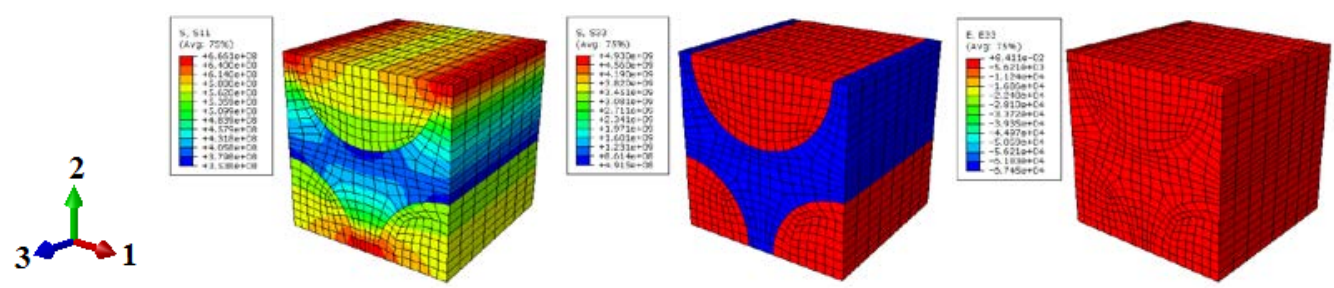

(a) Primeira análise: $T_{11}, T_{33}$ e $S_{33}$
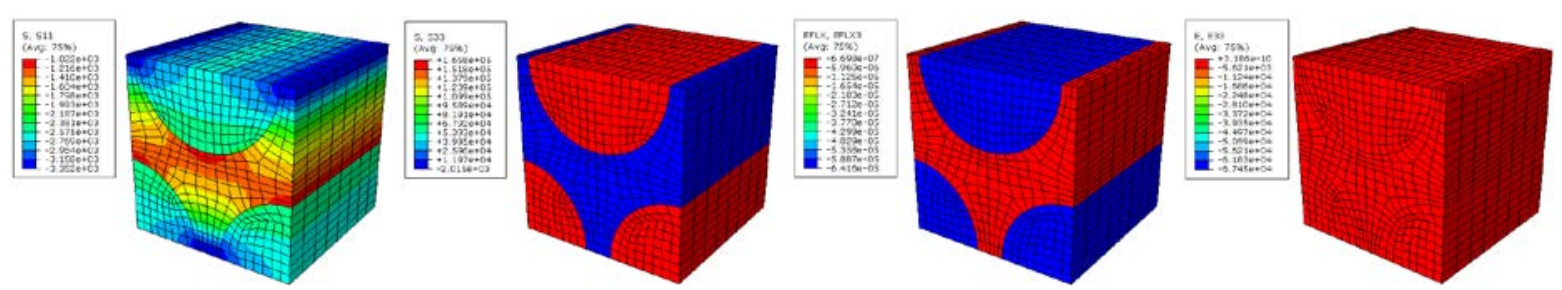

(b) Segunda análise: $T_{11}, T_{33} D_{3}$ e $E_{3}$
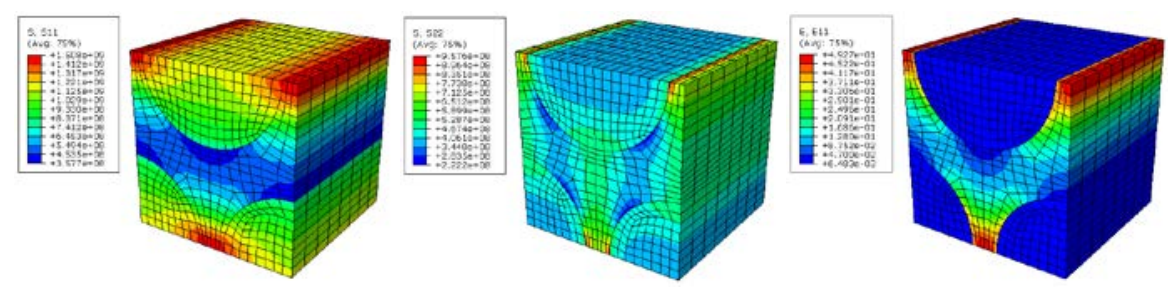

(c) Terceira análise: $T_{11}, T_{22}$ e $S_{11}$
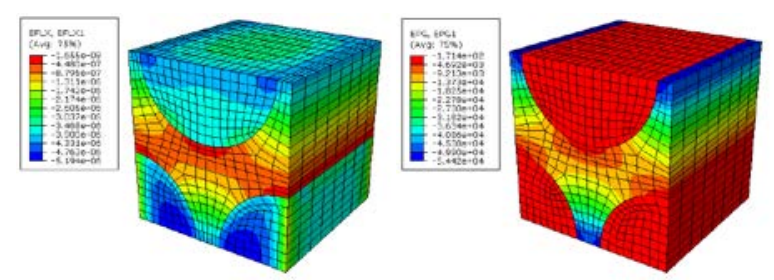

(d) Quarta análise: $\mathrm{D}_{1}$ e $\mathrm{E}_{1}$
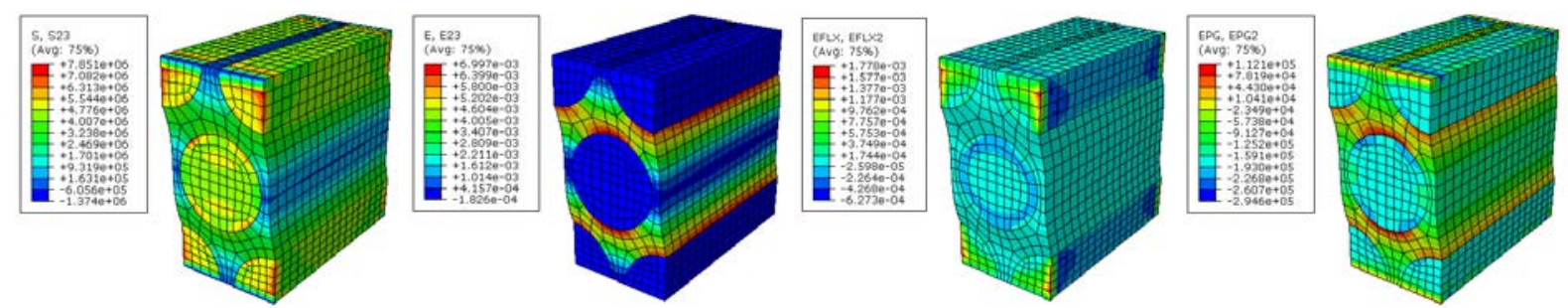

(f) Sexta análise: $T_{23}, S_{23} D_{2}$ e $E_{2}$ 
Como descrito na Metodologia Científica apresentada no Capítulo 3, tem-se que a metodologia proposta deve ser avaliada quanto as suas potencialidades e limitações. Dessa forma, os resultados numéricos obtidos são comparados com resultados analíticos e numéricos disponíveis na literatura, Berger et al. (2005) e Moreno et al. (2009), respectivamente, e apresentados na Tabela (4.1-2).

A coluna designada como (1) refere-se aos resultados obtidos por Berger et al. (2005). Enquanto as colunas (2) e (3) referem-se aos resultados obtidos por Moreno et al. (2009). A coluna (1) está relacionada à formulação analítica obtida pela abordagem conhecida como Método da Homogeneização Assintótica para AFC (discutida no Capítulo 2). As colunas (2) e (3) apresentam os resultados empregando análises via MEF, utilizando o software Ansys, para um arranjo quadrático e para um arranjo hexagonal, respectivamente. As colunas (4) e (5) apresentam os coeficientes efetivos calculados pela metodologia numérica proposta neste trabalho. Sendo que foram empregados arranjo quadrático e hexagonal, respectivamente, bem como utilizou-se o Teorema das Médias, juntamente com o MEF, através do auxílio do software Abaqus.

As diferenças $(\Delta)$ entre os resultados são apresentadas nas últimas quatro colunas da Tabela (4.1-2). As diferenças $\Delta_{1}$ e $\Delta_{2}$ são calculadas a partir dos resultados analíticos obtidos por Berger et al. (2005) e dos resultados numéricos de Moreno et al. (2009) para arranjos quadráticos e hexagonais, respectivamente. As diferenças $\Delta_{3}$ e $\Delta_{4}$ estão relacionadas com os resultados analíticos obtidos por Berger et al. (2005) e os resultados numéricos do presente trabalho para arranjos quadráticos e hexagonais, respectivamente.

Ressalta-se que no trabalho publicado por Berger et al. (2005) há também resultados numéricos utilizando células unitárias modeladas via MEF e a aplicação do Teorema das Médias, assim como em Moreno et al. (2009). Todavia, os resultados foram obtidos através do programa Ansys com auxílio de sub-rotinas Fortran para a aplicação automática das condições de contorno. Todavia, no presente trabalho, os resultados foram obtidos através do programa Abaqus com auxílio de sub-rotinas Python para a aplicação automática das condições de contorno. Neste trabalho, as condições de contorno de paralelismo foram aplicadas através equações diferentes dos trabalhos de Berger et al. (2005) e de Moreno et al. (2009). Além disso, o tipo de elemento utilizado por Berger et al. (2005) foi um elemento com integração linear, ao passo que no presente trabalho, utilizou-se um elemento com integração parabólica, o que permitiu determinar resultados mais precisos. Por fim, algumas condições de contorno empregadas por Berger et al. (2005), não foram aplicadas no presente 
trabalho a fim de evitar problemas de excesso de restrições (over-constraints) discutidas no Capítulo 3.

TABELA 4.1-2 - Avaliação da metodologia proposta para o Estudo de Caso I

\begin{tabular}{|c|c|c|c|c|c|c|c|c|c|c|}
\hline Coef. & Unid. & $\begin{array}{c}\text { AHM } \\
\text { (1) }\end{array}$ & $\begin{array}{c}\text { Ansys } \\
\text { (2) }\end{array}$ & $\begin{array}{c}\text { Ansys } \\
\text { (3) }\end{array}$ & $\begin{array}{c}\text { Abaqus } \\
\text { (4) }\end{array}$ & $\begin{array}{c}\text { Abaqus } \\
\text { (5) }\end{array}$ & $\begin{array}{c}\Delta_{1} \\
{[\%]}\end{array}$ & $\Delta_{2}[\%]$ & $\begin{array}{c}\Delta_{3} \\
{[\%]}\end{array}$ & $\begin{array}{c}\Delta_{4} \\
{[\%]}\end{array}$ \\
\hline$c_{11}^{e f f}$ & \multirow{6}{*}{ GPa } & 9,7394 & 10,8800 & 10,6800 & 10,8560 & 10,6629 & 11,71 & 9,66 & 11,46 & 9,48 \\
\hline$c_{12}^{e f f}$ & & 5,5898 & 4,6500 & 5,2200 & 4,6656 & 5,2334 & 16,81 & 6,62 & 16,53 & 6,38 \\
\hline$c_{13}^{e f f}$ & & 6,0792 & 6,0400 & 6,1900 & 6,0434 & 6,1874 & 0,64 & 1,82 & 0,59 & 1,78 \\
\hline$c_{33}^{e f f}$ & & 35,0707 & 35,2500 & 35,2100 & 35,1268 & 35,0809 & 0,51 & 0,40 & 0,16 & 0,03 \\
\hline$c_{44}^{e f f}$ & & 2,1462 & 2,1500 & 1,9500 & 2,2050 & 1,9809 & 0,18 & 9,14 & 2,74 & 7,70 \\
\hline$c_{66}^{e f f}$ & & 2,0853 & 1,5400 & 1,8100 & 1,5277 & 1,8247 & 26,15 & 13,20 & 26,74 & 12,50 \\
\hline$e_{13}^{e f f}$ & \multirow{3}{*}{$\mathrm{C} / \mathrm{m}^{2}$} & $-0,2496$ & $-0,2580$ & $-0,2690$ & $-0,2584$ & $-0,2691$ & 3,37 & 7,77 & 3,53 & 7,81 \\
\hline$e_{15}^{e f f}$ & & 0,0221 & 0,0241 & 0,0164 & 0,0250 & 0,0196 & 9,05 & 25,79 & 13,12 & 11,31 \\
\hline$e_{33}^{e f f}$ & & 10,8611 & 10,8600 & 10,8600 & 10,8642 & 10,8676 & 0,01 & 0,01 & 0,03 & 0,06 \\
\hline$\varepsilon_{11}^{e f f}$ & \multirow{2}{*}{$\mathrm{nF} / \mathrm{m}$} & 0,2778 & 0,2840 & 0,3030 & 0,2867 & 0,3025 & 2,23 & 9,07 & 3,20 & 8,89 \\
\hline$\varepsilon_{33}^{e f f}$ & & 4,2088 & 4,2700 & 4,2700 & 4,2704 & 4,2707 & 1,45 & 1,45 & 146 & 1,47 \\
\hline $\begin{array}{l}\Delta_{1}=\mid(1 \\
\Delta_{2}=\mid(1 \\
\Delta_{3}=\mid(1 \\
\Delta_{4}=\mid(1\end{array}$ & $\begin{array}{l}-(2) \mid /(1) \\
-(3) \mid /(1) \\
-(4) / /(1) \\
-(5) \mid /(1)\end{array}$ & $\begin{array}{l}\text { Berger et } \\
\text { Berger et } \\
\text { Berger et } \\
\text { Berger et }\end{array}$ & $\begin{array}{l}\text { al. (2005) x } \\
\text { al. }(2005) x \\
\text { al. }(2005) x \\
\text { al. }(2005) x\end{array}$ & $\begin{array}{l}\text { Moreno et } \\
\text { Moreno et } \\
\text { Presente tI } \\
\text { Presente tr }\end{array}$ & $\begin{array}{l}\text { al. (2009) } \\
\text { al. (2009) } \\
\text { abalho par } \\
\text { abalho par }\end{array}$ & $\begin{array}{l}\text { ara célula } \\
\text { ara célula } \\
\text { célula con } \\
\text { célula con }\end{array}$ & $\begin{array}{l}\text { om arra } \\
\text { om arra } \\
\text { arranjo } \\
\text { arranjo }\end{array}$ & $\begin{array}{l}\text { o quadrátic } \\
\text { o hexagona } \\
\text { ladrático } \\
\text { exagonal }\end{array}$ & & \\
\hline
\end{tabular}

Como demonstrado na Tabela (4.1-2), os coeficientes efetivos que apresentam a maior diferença $(\Delta)$ entre os procedimentos analíticos e os resultados obtidos pela metodologia proposta foram $c_{11}^{\text {eff }}, c_{12}^{\text {eff }}, c_{66}^{\text {eff }}$ e $e_{15}^{\text {eff }}$. Similarmente, essas diferenças de valores são encontradas na literatura em vários outros autores (SMITH; AULD 1991; POIZAT; SESTER 1999; SEVOSTIANOV et al. 2001; TAN; TONG 2001; BERGER et al. 2003, 2005, 2006, 2007; KAR-GUPTA; VENKATESH 2005, 2007a, 2007b; RAO; PRASAD 2010; TRINDADE; BENJEDDOU, 2011, entre outros). Estes coeficientes são influenciados principalmente pelo comportamento do material compósito ao cisalhamento transversal, principalmente o coeficiente $c_{66}^{\text {eff }}$. Além disso, estes valores diferem para arranjos hexagonais e quadráticos, 
pois os carregamentos são aplicados de forma diferente. No caso do arranjo quadrático, temse que os carregamentos são aplicados em toda a resina epóxi, ao passo que no arranjo hexagonal, os carregamentos são aplicados tanto sobre a resina epóxi como sobre a fibra. Os outros coeficientes calculados pela metodologia numérica demonstraram uma boa concordância e coerência com os coeficientes obtidos pelo Método de Homogeneização Assintótica (resultados analíticos), principalmente o coeficiente $c_{33}^{\text {eff }}$ que está relacionado com a direção 3.

Como discutido anteriormente no Capítulo 2, várias hipóteses podem ser adotadas para ilustrar a simetria do cristal de compósitos, criando assim uma variedade de combinações para a matriz e fibras com diferentes graus de anisotropia. Neste trabalho, adotou-se que as piezo-fibras (polarizadas ao longo de direção 3) fossem transversalmente isotrópicas e a matriz (comportamento passivo) fosse isotrópica. Consequentemente, o resultado para essa combinação de hipóteses leva a um comportamento transversalmente isotrópico para o Volume Elementar Representativo (polarizado ao longo de 3-direção), conforme evidencia figura (2.5). Devido ao sistema de cristal tetragonal, apresentando simetria 4mm, e do sistema de cristal hexagonal, apresentando simetria $6 \mathrm{~mm}$, a metodologia proposta evidenciou melhores previsões para os coeficientes efetivos calculados para o modelo com arranjo hexagonal. Isto ocorre, pois, o material PZT possui simetria $6 \mathrm{~mm}$.

Por outro lado, o modelo com arranjo hexagonal é altamente influenciado pelas condições de contorno aplicadas nas faces, devido ao fato de que os valores são da ordem de Giga e Nano. Por essa razão, o modelo pode ser altamente sensível às mudanças de condições de contorno e, assim, a determinação de alguns coeficientes efetivos torna-se complicada. Porém, outros coeficientes efetivos demonstram que a aplicação da metodologia proposta tanto para arranjos quadráticos como para hexagonais é adequada. Haja vista que os resultados obtidos quando comparados com os resultados apresentados pelo Método de Homogeneização Assintótica (Berger et al., 2005) proporcionam diferenças muito pequenas.

Por fim, após a aplicação da metodologia, pode-se verificar que os coeficientes efetivos satisfazem as Relações Universais propostas por Benveniste e Dvorak (1992), sendo que estas relações correspondem a cristais hexagonais de classe $6 \mathrm{~mm}$ e, considerando compósitos piezelétrico transversalmente isotrópico. A Tabela (4.1-3) apresenta valores calculados com base nas Relações Universais apresentadas no Capítulo 2, e as Tabelas (4.1-4) e (4.1-5) apresentam as diferenças relativas encontradas para os arranjos quadrático e hexagonal. 
TABELA 4.1-3 - Aplicação das Relações Universais para o Estudo de Caso I

\begin{tabular}{|c|c|c|c|c|c|c|c|c|}
\hline Eq. 2.48 & Eq. 2.48 & Eq. 2.48 & Eq. 2.48 & Eq. 2.49 & Eq. 2.49 & Eq. 2.49 & Eq. 2.49 & Eq. 2.50 \\
\hline$F_{1}$ & $\mathbf{F}_{2}$ & $\mathbf{F}_{3}$ & $F_{4}$ & $\mathbf{F}_{5}$ & $F_{6}$ & $\mathbf{F}_{7}$ & $F_{8}$ & $\mathbf{F}_{9}$ \\
\hline \multicolumn{9}{|c|}{ Arranjo quadrático } \\
\hline 1.3077 & 1.3064 & 1.3071 & 1.3078 & - & - & - & - & - \\
\hline- & - & - & - & $-7,4344 \mathrm{E}-2$ & $-7.4308 \mathrm{E}-2$ & $-7.4309 \mathrm{E}-2$ & $-7,4349 \mathrm{E}-2$ & - \\
\hline- & - & - & - & - & - & - & - & 0.007867 \\
\hline \multicolumn{9}{|c|}{ Arranjo hexagonal } \\
\hline 1.3077 & 1.2992 & 1.2999 & 1.3078 & - & - & - & - & - \\
\hline- & - & - & - & $-7,4346 \mathrm{E}-2$ & $-7.4308 \mathrm{E}-2$ & $-7.4310 \mathrm{E}-2$ & $-7,4349 \mathrm{E}-2$ & - \\
\hline- & - & - & - & - & - & - & - & 0.370924 \\
\hline
\end{tabular}

TABELA 4.1-4 - Diferenças relativas dos resultados das Relações Universais: Arranjo Quadrático para o Estudo de Caso I

\begin{tabular}{llllll}
\hline (1) Equação 2.48 & & & & \\
\hline$\Delta\left(\mathrm{F}_{1}\right)-\left(\mathrm{F}_{2}\right)$ & $\Delta\left(\mathrm{F}_{1}\right)-\left(\mathrm{F}_{3}\right)$ & $\Delta\left(\mathrm{F}_{1}\right)-\left(\mathrm{F}_{4}\right)$ & $\Delta\left(\mathrm{F}_{2}\right)-\left(\mathrm{F}_{3}\right)$ & $\Delta\left(\mathrm{F}_{2}\right)-\left(\mathrm{F}_{4}\right)$ & $\Delta\left(\mathrm{F}_{3}\right)-\left(\mathrm{F}_{4}\right)$ \\
\hline 0,097 & 0,048 & 0,07 & 0,048 & 0,103 & 0,055 \\
& & & & & \\
(2) Equação 2.49 & & & & & \\
\hline$\Delta\left(\mathrm{F}_{1}\right)-\left(\mathrm{F}_{2}\right)$ & $\Delta\left(\mathrm{F}_{1}\right)-\left(\mathrm{F}_{3}\right)$ & $\Delta\left(\mathrm{F}_{1}\right)-\left(\mathrm{F}_{4}\right)$ & $\Delta\left(\mathrm{F}_{2}\right)-\left(\mathrm{F}_{3}\right)$ & $\Delta\left(\mathrm{F}_{2}\right)-\left(\mathrm{F}_{4}\right)$ & $\Delta\left(\mathrm{F}_{3}\right)-\left(\mathrm{F}_{4}\right)$ \\
0,048 & 0,048 & 0,007 & 0,000 & 0,055 & 0,055 \\
$\Delta=\left[\left|\left(a_{\mathrm{n}}\right)-\left(\mathrm{a}_{\mathrm{n}}+1\right)\right| /\left(\left(\mathrm{a}_{\mathrm{n}}+\mathrm{a}_{\mathrm{n}+1}\right) / 2\right)\right] \times 100$ & & & \\
\hline
\end{tabular}

TABELA 4.1-5 - Diferenças relativas dos resultados das Relações Universais: Arranjo Hexagonal para o Estudo de Caso I

\begin{tabular}{llllll}
\hline (1) Equação 2.48 & & & & & \\
\hline$\Delta\left(\mathrm{F}_{1}\right)-\left(\mathrm{F}_{2}\right)$ & $\Delta\left(\mathrm{F}_{1}\right)-\left(\mathrm{F}_{3}\right)$ & $\Delta\left(\mathrm{F}_{1}\right)-\left(\mathrm{F}_{4}\right)$ & $\Delta\left(\mathrm{F}_{2}\right)-\left(\mathrm{F}_{3}\right)$ & $\Delta\left(\mathrm{F}_{2}\right)-\left(\mathrm{F}_{4}\right)$ & $\Delta\left(\mathrm{F}_{3}\right)-\left(\mathrm{F}_{4}\right)$ \\
\hline 0,651 & 0,600 & 0,005 & 0,051 & 0,660 & 0,609
\end{tabular}

(2) Equação 2.49

\begin{tabular}{llllll}
\hline$\Delta\left(\mathrm{F}_{1}\right)-\left(\mathrm{F}_{2}\right)$ & $\Delta\left(\mathrm{F}_{1}\right)-\left(\mathrm{F}_{3}\right)$ & $\Delta\left(\mathrm{F}_{1}\right)-\left(\mathrm{F}_{4}\right)$ & $\Delta\left(\mathrm{F}_{2}\right)-\left(\mathrm{F}_{3}\right)$ & $\Delta\left(\mathrm{F}_{2}\right)-\left(\mathrm{F}_{4}\right)$ & $\Delta\left(\mathrm{F}_{3}\right)-\left(\mathrm{F}_{4}\right)$ \\
0,051 & 0,049 & 0,005 & 0,002 & 0,056 & 0,054 \\
$\Delta=\left[\mid\left(\mathrm{a}_{\mathrm{n}}\right)-\left(\mathrm{a}_{\mathrm{n}}+1\right) / /\left(\left(\mathrm{a}_{\mathrm{n}}+\mathrm{a}_{\mathrm{n}+1}\right) / 2\right)\right] \times 100$ & & & \\
\hline
\end{tabular}

Observando as Tabelas (4.1-4) e (4.1-5), verifica-se que as diferenças relativas associadas aos coeficientes determinados pela metodologia proposta são menores que 1,0\%. Isto evidencia a potencialidade da metodologia proposta, complementando as considerações supracitadas. No próximo item, discutir-se-á com mais profundidade outros aspectos relacionados com as limitações e potencialidades da metodologia proposta. 


\subsubsection{Limitações E Potencialidades}

Conforme mencionado no Item 3.3, a metodologia foi desenvolvida para transdutores fabricados a partir de compósitos piezelétricos empilhados em camadas (multicamadas), considerando que a polarização poderia ocorrer tanto entre cada camada (Figura (3.3-1b)), como entre as faces mais externas do transdutor (Figura (3.3-1a)). Até então, foram apresentados resultados para uma célula unitária, representando um laminado cuja polarização ocorreria entre cada camada (Figura (4.1-4a)). Todavia, deve-se demonstrar que a metodologia possa ser também aplicada para um laminado cuja polarização ocorra entre as faces mais externas do transdutor.

A fim de avaliar o aspecto supracitado, tem-se que uma célula unitária com 3 camadas e escala de comprimento $\delta$ (Figura (4.1-4b)), maior que o conceito de Volume Elementar Representativo, foi empregada para determinar as propriedades de um compósito com multicamadas polarizadas apenas nas faces mais externas, como mostrado pela Figura (3.31a). Como mencionado anteriormente, todas as análises via MEF requisitadas pela metodologia foram realizadas utilizando o programa ABAQUS ${ }^{\mathrm{TM}}$ versão 6.10 (ABAQUS, 2010). A matriz e a fibra foram modeladas através de elementos sólidos com interpolação parabólica, possuindo 20 nós com 4 graus de liberdade por nó (C3D20E), sendo 3 para as translações e 1 para potencial elétrico.

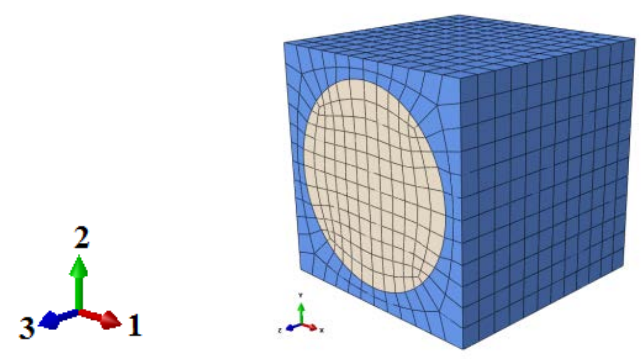

(a)

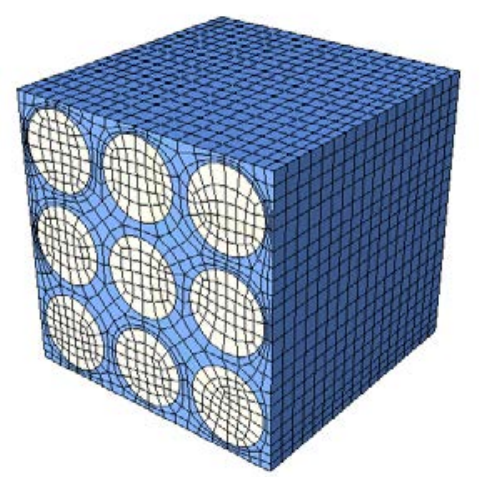

(b)

FIGURA 4.1-4 - Modelo em elementos finitos utilizado nas simulações: (a) VER com uma única camada; (b) VER com três camadas (multicamadas).

Com base nos resultados obtidos através das análises via MEF e, da aplicação do Teorema das Médias, constata-se na Tabela (4.1-6), os valores dos coeficientes para os modelos apresentados na Figura (4.1-4). 
TABELA 4.1-6 - Avaliação da metodologia: tamanho de célula unitária

\begin{tabular}{|c|c|c|}
\hline $\begin{array}{c}\text { Coeficiente } \\
\text { Efetivo }\end{array}$ & $\begin{array}{l}\text { VER uma } \\
\text { camada }\end{array}$ & $\begin{array}{c}\text { VER } \\
\text { multicamada }\end{array}$ \\
\hline$c_{11}^{\text {eff }}$ [GPa] & 10,856 & 10,860 \\
\hline$c_{12}^{e f f}$ [GPa] & 4,665 & 4,663 \\
\hline$C_{13}^{\text {eff }}$ [GPa] & 6,043 & 6,044 \\
\hline$c_{33}^{e f f}$ [GPa] & 35,126 & 35,127 \\
\hline$C_{44}^{e f f}$ [GPa] & 2,205 & 2,216 \\
\hline$c_{66}^{e f f}[\mathrm{GPa}]$ & 1,528 & 1,539 \\
\hline$e_{13}^{e f f}\left[\mathrm{C} / \mathbf{m}^{2}\right]$ & $-0,258$ & $-0,258$ \\
\hline$e_{15}^{e f f}\left[\mathbf{C} / \mathbf{m}^{2}\right]$ & 0,025 & 0,024 \\
\hline$e_{33}^{e f f}\left[\mathrm{C} / \mathrm{m}^{2}\right]$ & 10,864 & 10,863 \\
\hline$\varepsilon_{11}^{e f f}[\mathbf{n F} / \mathbf{m}]$ & 0,288 & 0,287 \\
\hline$\varepsilon_{33}^{e f f}[\mathbf{n F} / \mathbf{m}]$ & 4,271 & 4,270 \\
\hline * considerando $c^{\mathrm{E}}$ & & \\
\hline
\end{tabular}

Observando a Tabela (4.1-6), conclui-se que a metodologia apresentada neste trabalho pode ser aplicada tanto para compósitos com uma única camada, respeitando o conceito de VER, como para compósitos multicamadas polarizados apenas nas faces mais externas. Isto demonstra que o tensor constitutivo determinado é o mesmo para o compósito com uma única camada e para o compósito multicamadas, haja vista que ambos são constituídos pelo mesmo material, ou seja, matriz transversalmente isotrópica não-piezelétrica e fibra transversalmente isotrópica piezelétrica.

\subsection{ESTUdO DE CASO II}

Neste segundo estudo de caso, a metodologia foi empregada para fibras com seção transversal retangular, ou seja, ainda para Active Fiber Composites (AFC). Sendo que o referido compósito ativo inteligente é constituído por hastes retangulares de cerâmica piezelétrica ensanduichada entre camadas de adesivo, e filme de eletrodos de poliamida. Os 
eletrodos são ligados ao filme em um padrão de interdigitais em forma de fita, que por sua vez, transfere a tensão aplicada diretamente para as hastes.

Assim, analogamente ao Estudo de Caso I, foram determinados os coeficientes efetivos para compósitos com fibras piezelétricas envolvidas por um material não-piezelétrico (resina epóxi). Contudo neste Estudo de Caso II, foram avaliadas diferentes frações volumétricas de fibra, de $10 \%$ até $75 \%$. Sendo que para as análises via MEF do Volume Elementar Representativo, considerou-se que a fibra do compósito ativo possuía seção transversal quadrática (quadrado com aresta de 1mm).

A Figura (4.2-1) mostra os modelos empregados, juntamente com a malha utilizada para os mesmos. Empregou-se novamente um elemento tridimensional com função de forma de segunda ordem (C3D20E - nomenclatura do Abaqus) e, que possui três graus de liberdade de deslocamento e um grau de liberdade adicional elétrico.

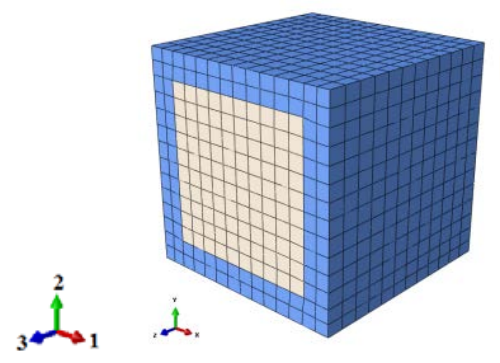

(a)

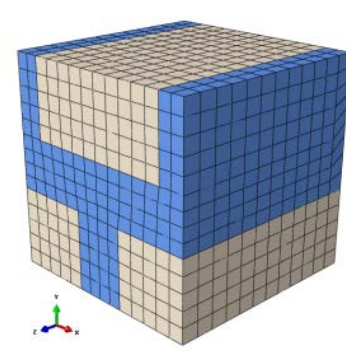

(b)

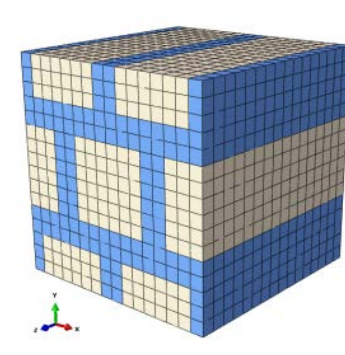

(c)

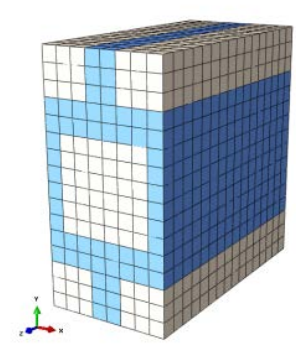

(d)

FIGURA 4.2-1 - Modelo em elementos finitos utilizado nas simulações - células unitárias e arranjos: (a) quadrático; (b) hexagonal; (c) hexagonal plano 1-2; (d) hexagonal plano 2-3.

Nas figuras (4.1-2) e (4.1-3), pode-se observar os resultados numéricos obtidos para todas as seis análises requisitadas pela metodologia proposta, considerando arranjos quadráticos e hexagonais, respectivamente. Vale ressaltar que o sistema de coordenadas apresentado na Primeira Análise (Figura (4.2-2a) e Figura (4.2-3a)) será utilizado como referência para as demais, ou seja, a fibra está orientada com o Eixo 3. Com base nesses resultados numéricos, calcula-se os coeficientes efetivos seguindo as orientações da metodologia computacional apresentada no Capítulo 3. 


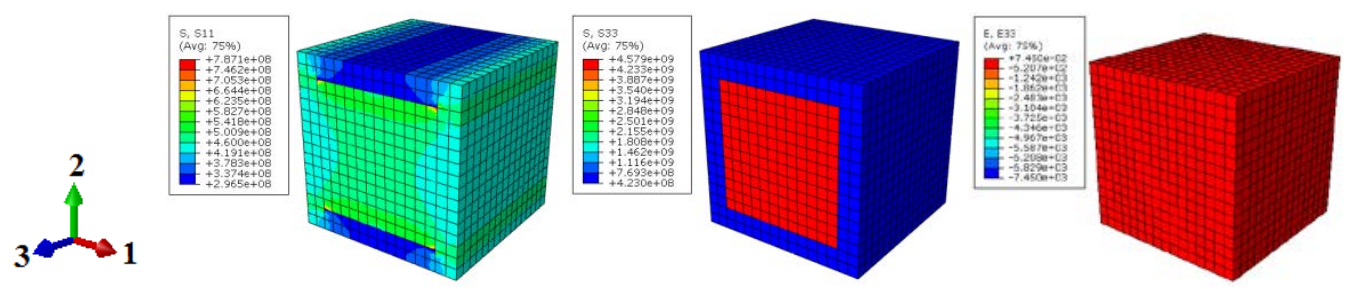

(a) Primeira análise: $T_{11}, T_{33}$ e $S_{33}$
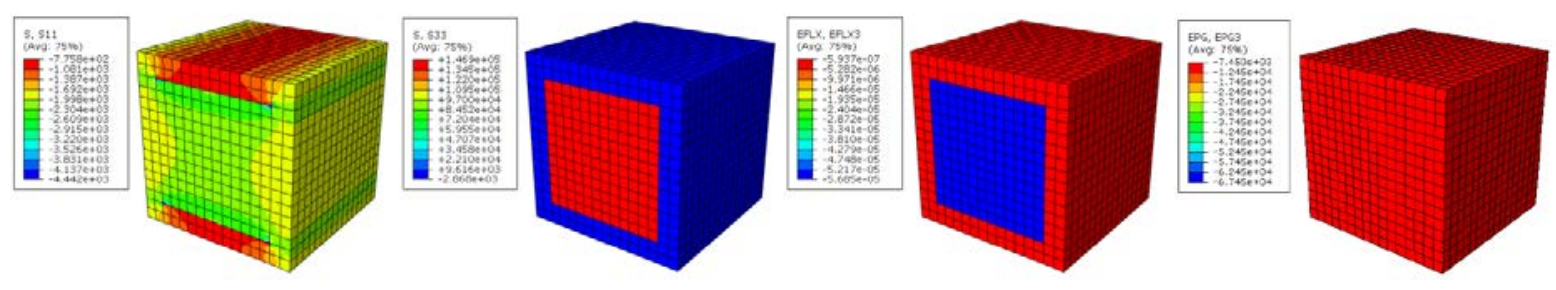

(b) Segunda análise: $T_{11}, T_{33} D_{3}$ e $E_{3}$
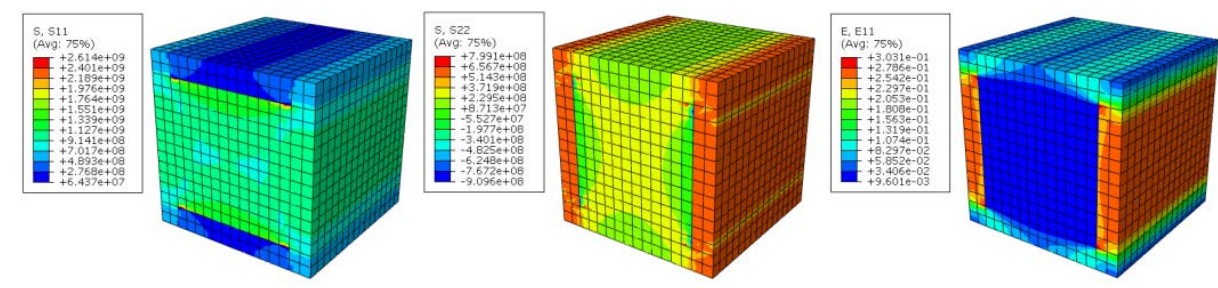

(c) Terceira análise: $T_{11}, T_{22}$ e $S_{11}$

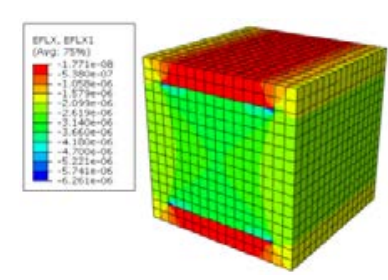

(d) Quarta análise: $\mathrm{D}_{1}$ e $\mathrm{E}_{1}$
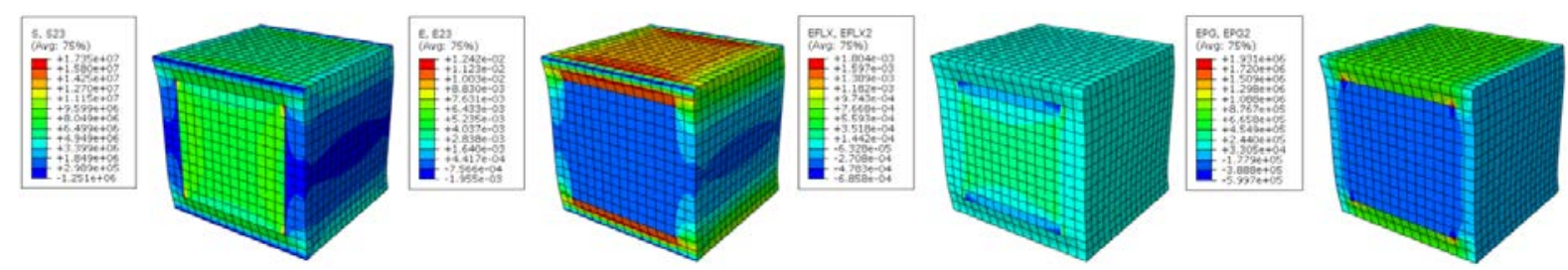

(f) Sexta análise: $T_{23}, S_{23} D_{2}$ e $E_{2}$ 

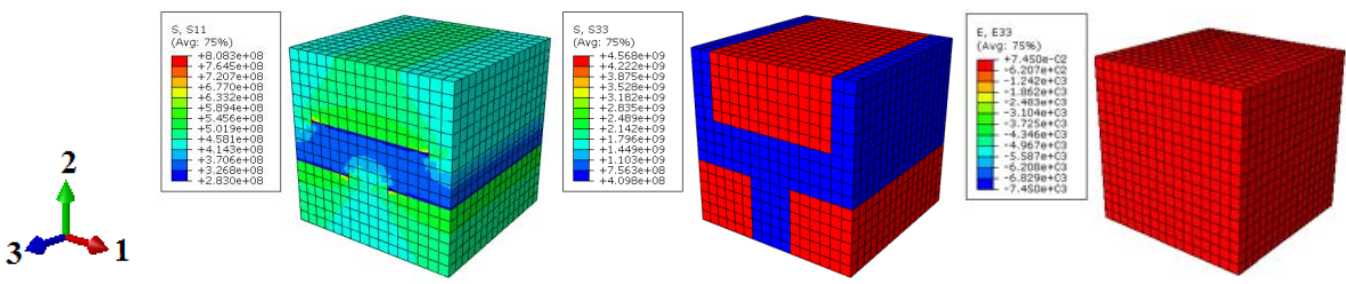

(a) Primeira análise: $T_{11}, T_{33}$ e $S_{33}$
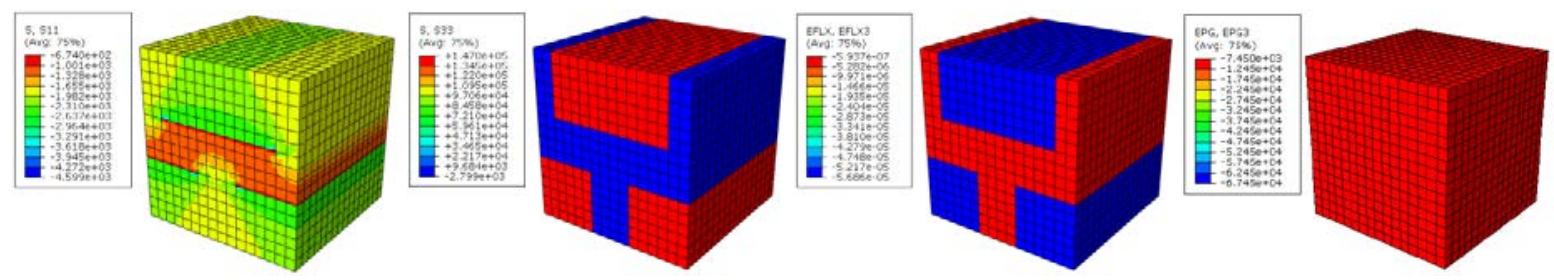

(b) Segunda análise: $T_{11}, T_{33} D_{3}$ e $E_{3}$
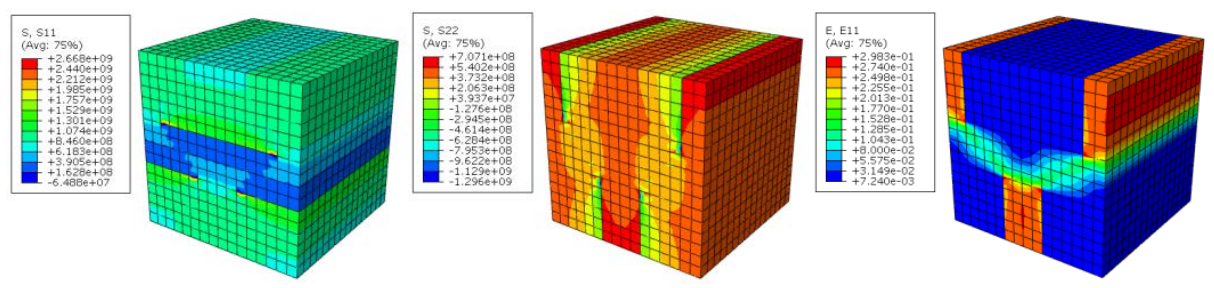

(c) Terceira análise: $\mathrm{T}_{11}, \mathrm{~T}_{22}$ e $\mathrm{S}_{11}$

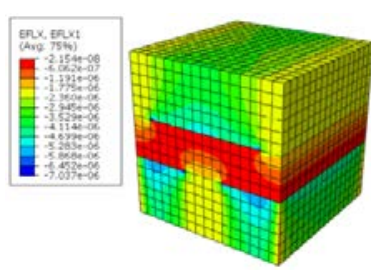

(d) Quarta análise: $\mathrm{D}_{1}$ e $\mathrm{E}_{1}$
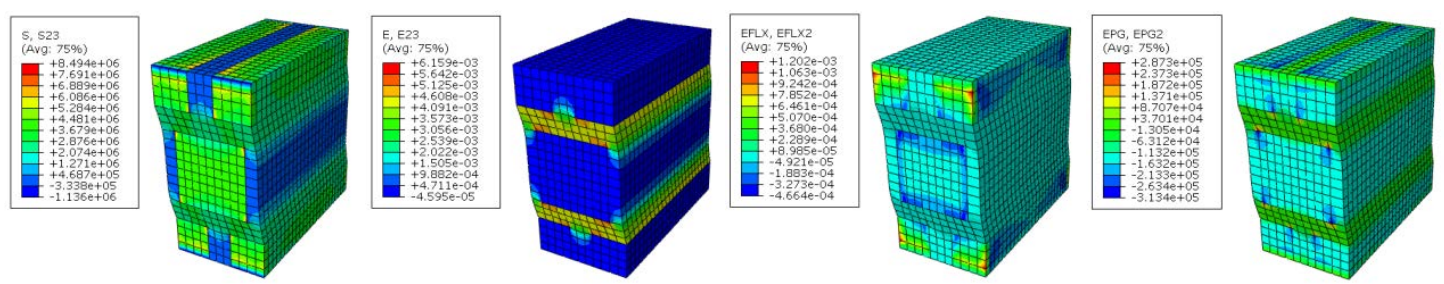

(f) Sexta análise: $T_{23}, S_{23} D_{2}$ e $E_{2}$

(e) Quinta análise: $\mathrm{T}_{12}$ e $\mathrm{S}_{12}$

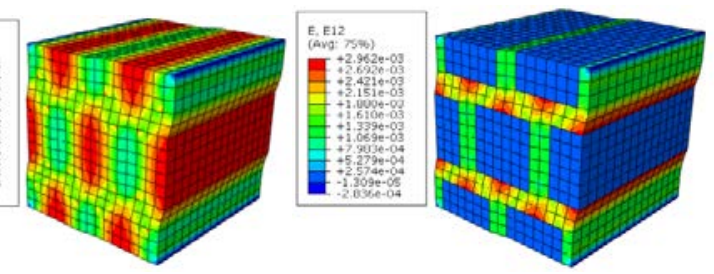

FIGURA 4.2-3 - Resultados numéricos para AFC - arranjo hexagonal (Estudo de Caso II) 
Como descrito na Metodologia Científica apresentada no Capítulo 3, tem-se que a metodologia proposta deve ser avaliada quanto as suas potencialidades e limitações. Dessa forma, neste Estudo de Caso II, além da aplicação da metodologia proposta, empregou-se o Método dos Campos Uniformes (Uniform Field Method - UFM) para a obtenção de resultados analíticos. Sendo assim, os resultados analíticos para o compósito inteligente em questão foram calculados com base no equacionamento apresentado por Nan e Jin (1993). Deve-se destacar que os referidos pesquisadores apresentaram uma teoria geral para prever as propriedades efetivas de compósitos de fibras piezelétricas, que possuem um comportamento transversalmente isotrópico e, que estão envolvidas por uma matriz isotrópica. As equações para a determinação dos coeficientes foram escritas em função das frações volumétricas dos constituintes do compósito, facilitando, assim, a avaliação da metodologia. Sendo que tais equações são apresentadas de forma mais detalhada no Anexo 3 deste trabalho.

De posse dos valores de coeficientes efetivos obtidos para diferentes frações volumétricas de fibras tanto via Método dos Campos Uniformes, como via metodologia proposta, são construídos os gráficos evidenciados nas Figuras de (4.2-4) a (4.2-14).

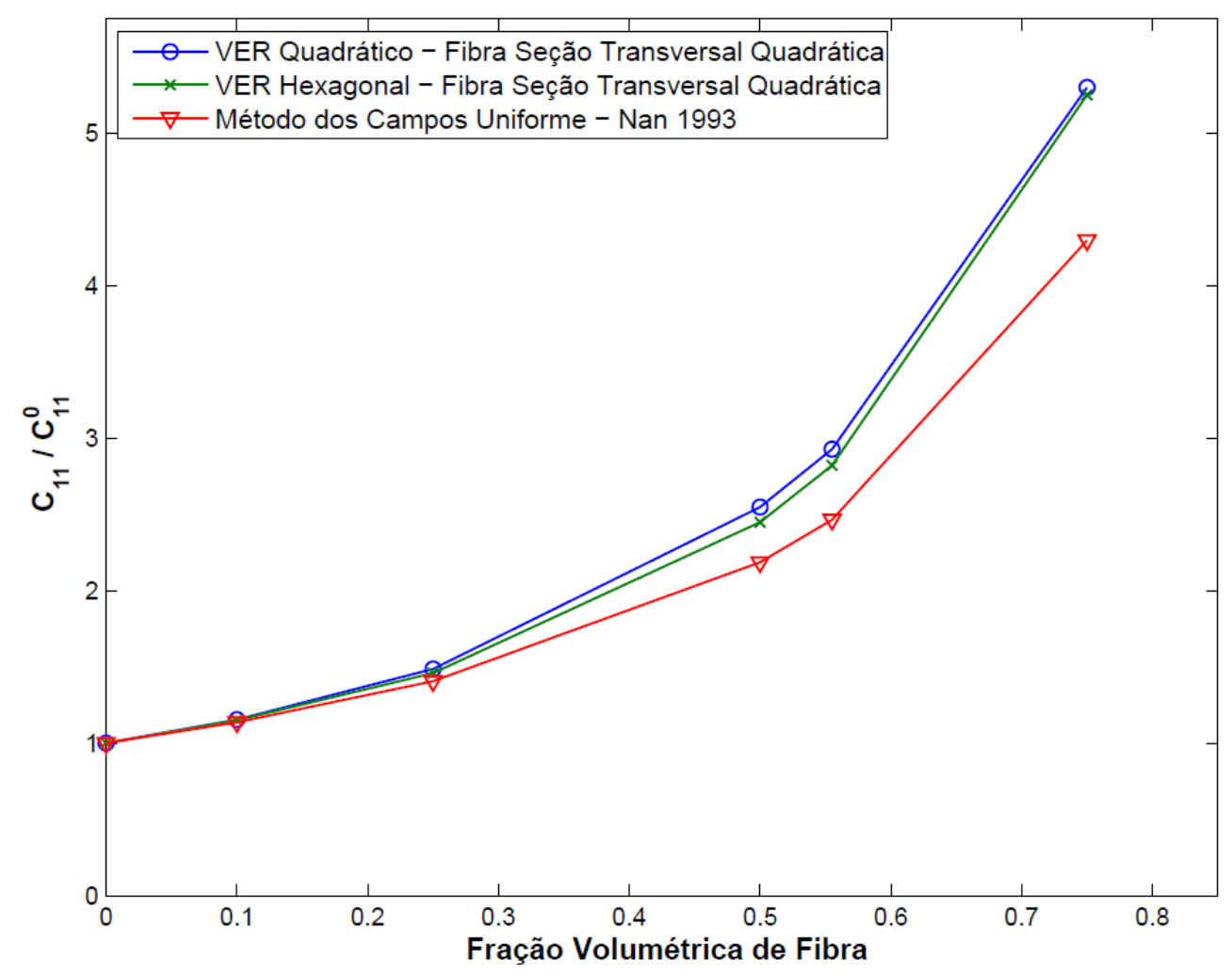

FIGURA 4.2-4 - Coeficiente efetivo $c_{11}^{\text {eff }}$ 


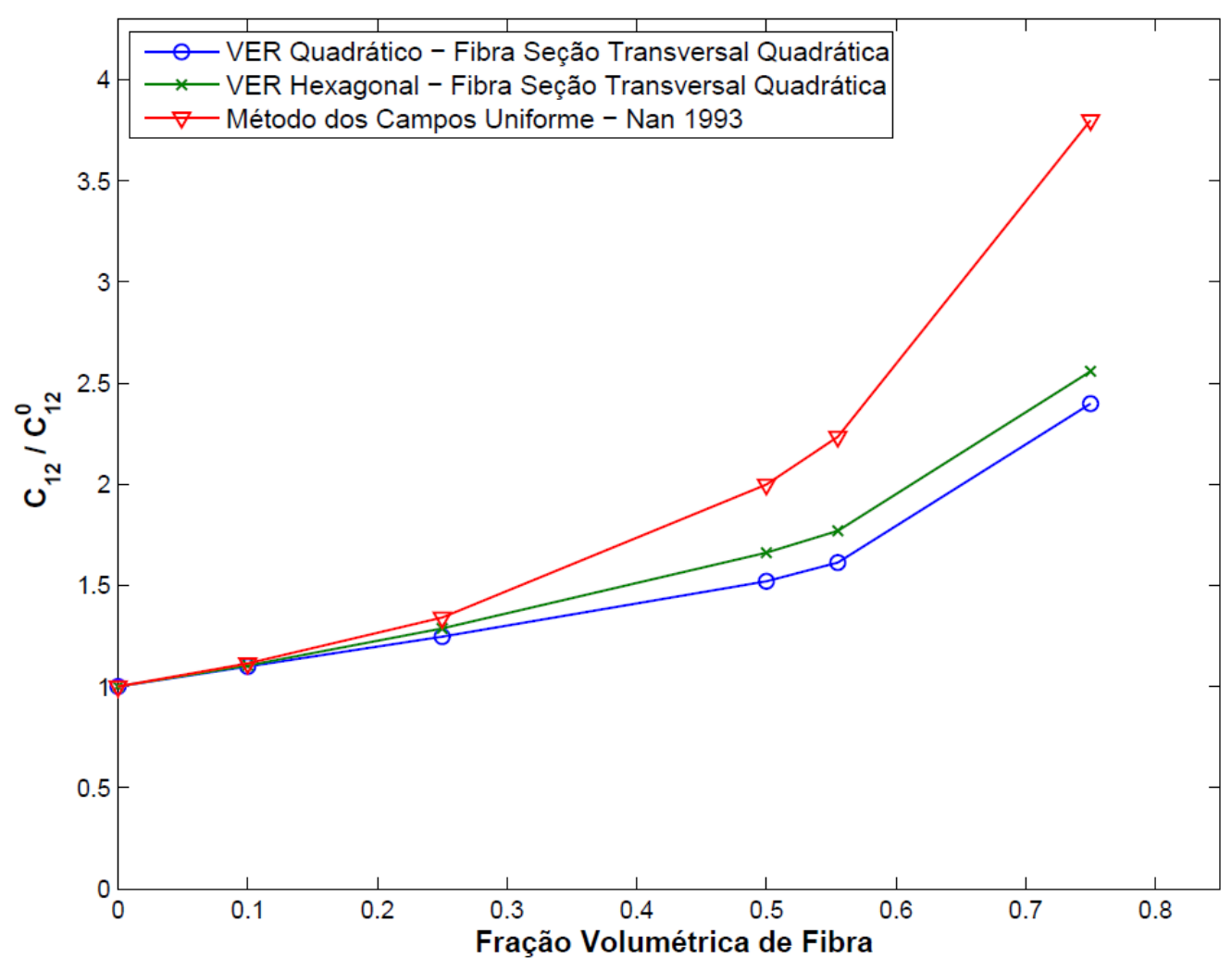

FIGURA 4.2-5 - Coeficiente efetivo $C_{12}^{\text {eff }}$

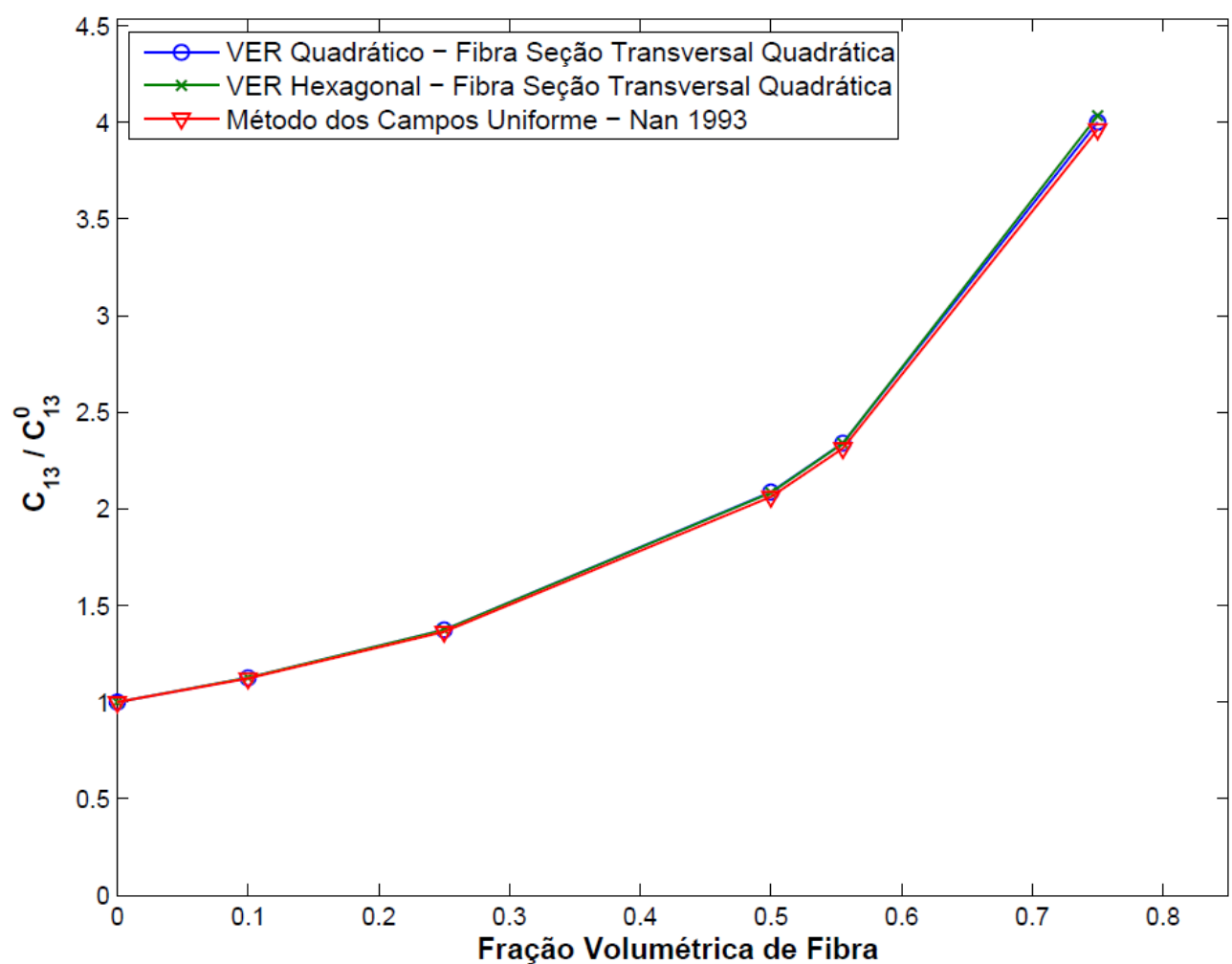

FIGURA 4.2-6 - Coeficiente efetivo $C_{13}^{\text {eff }}$ 


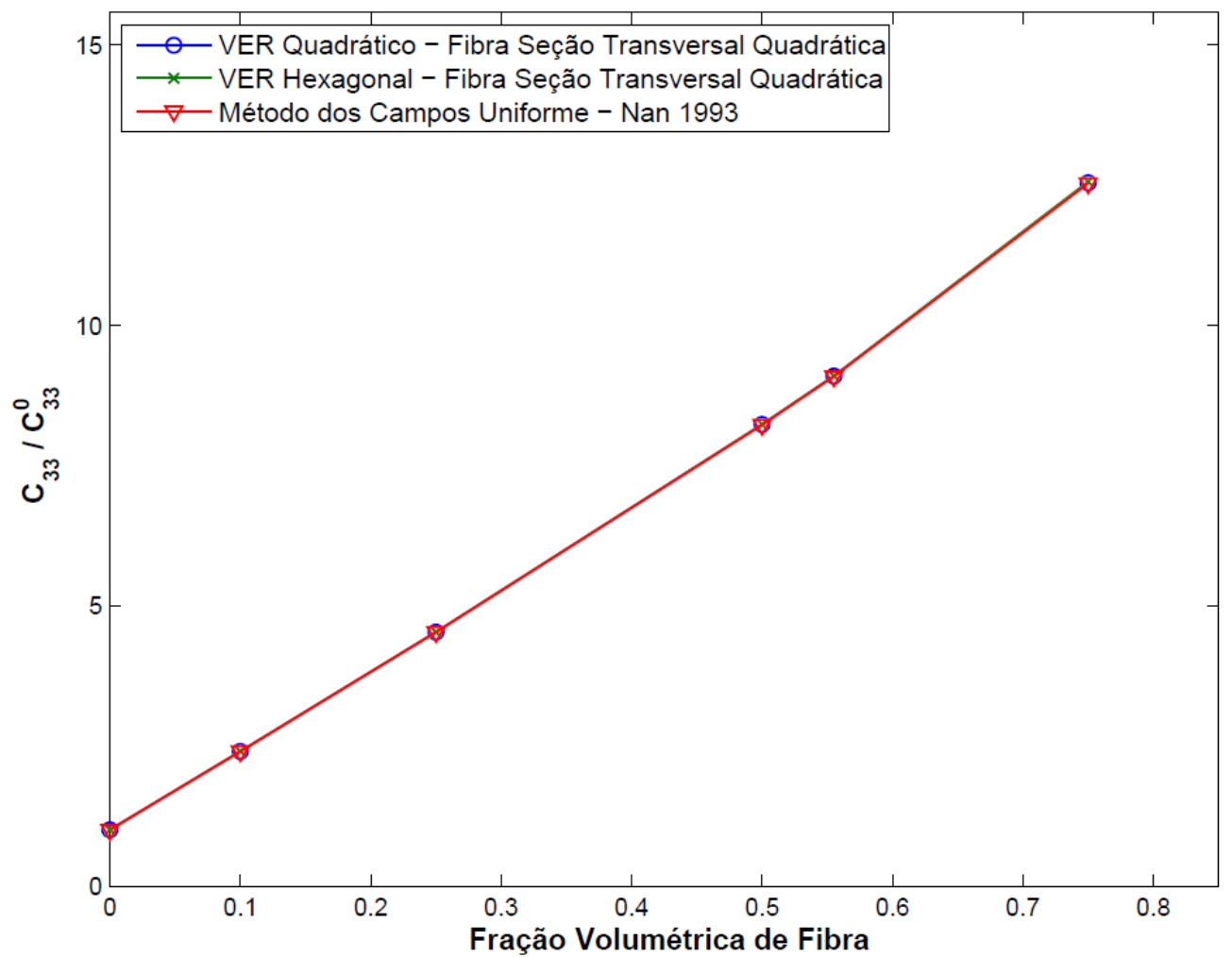

FIGURA 4.2-7 - Coeficiente efetivo $c_{33}^{\text {eff }}$

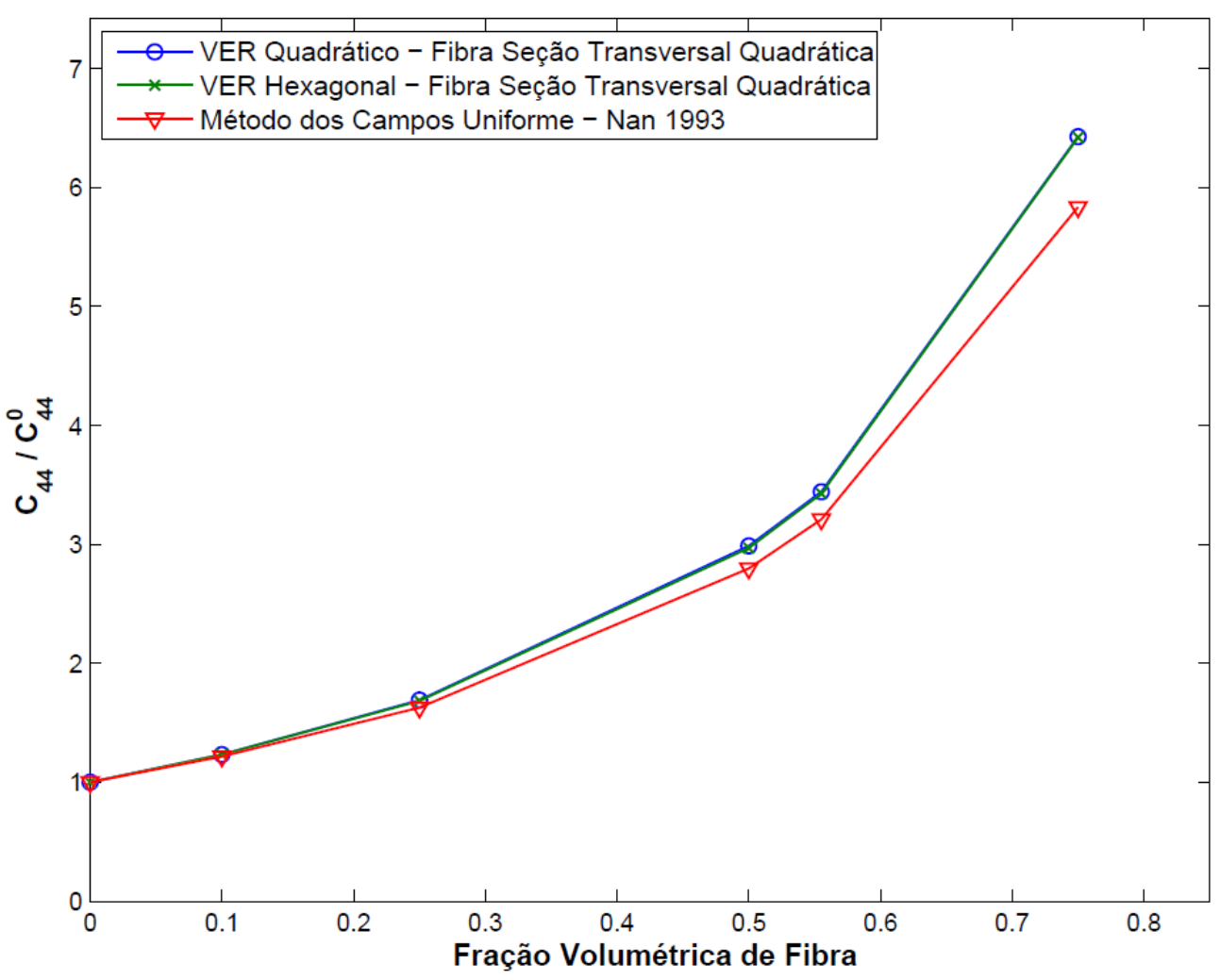

FIGURA 4.2-8 - Coeficiente efetivo $c_{44}^{\text {eff }}$ 


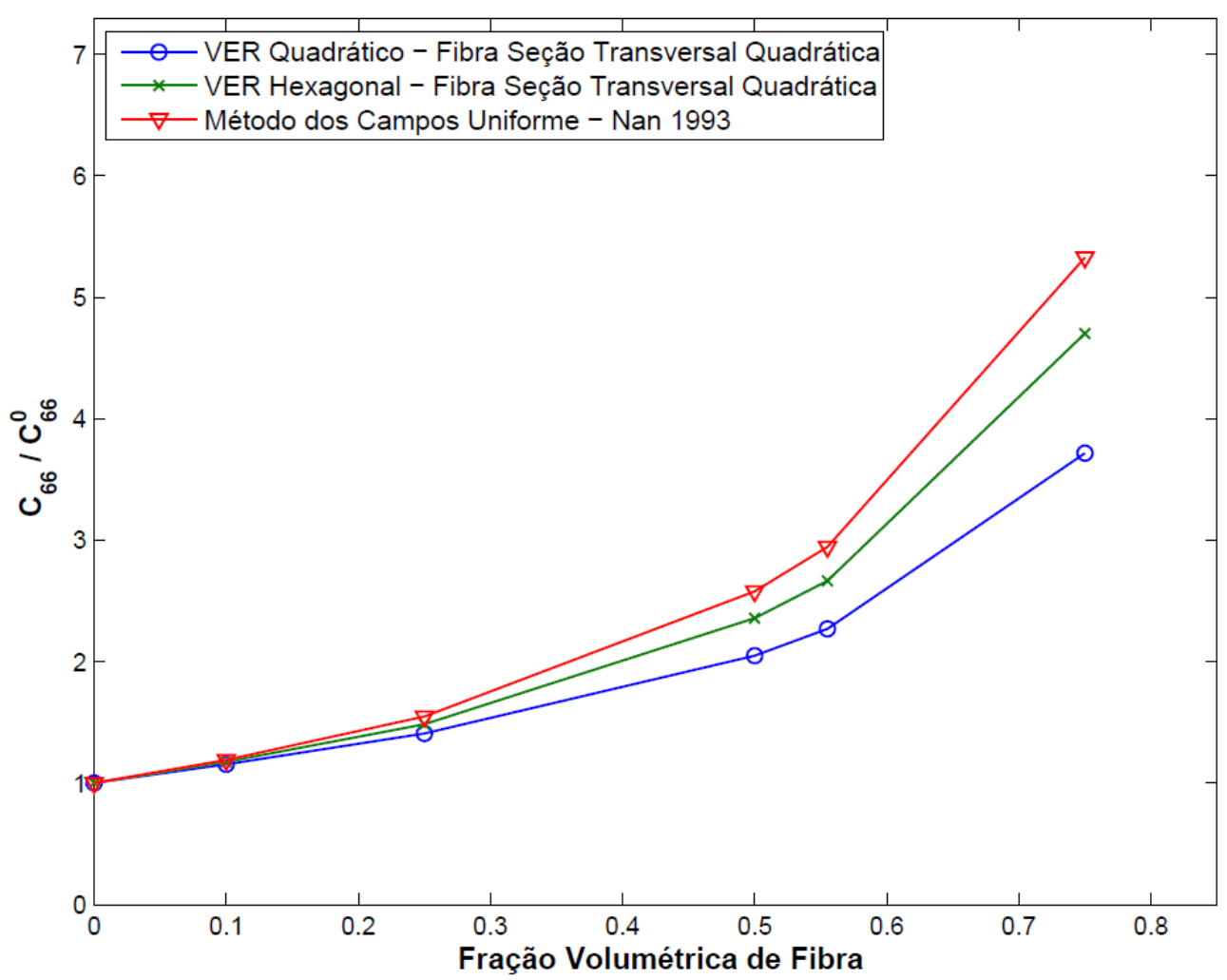

FIGURA 4.2-9 - Coeficiente efetivo $C_{66}^{\text {eff }}$

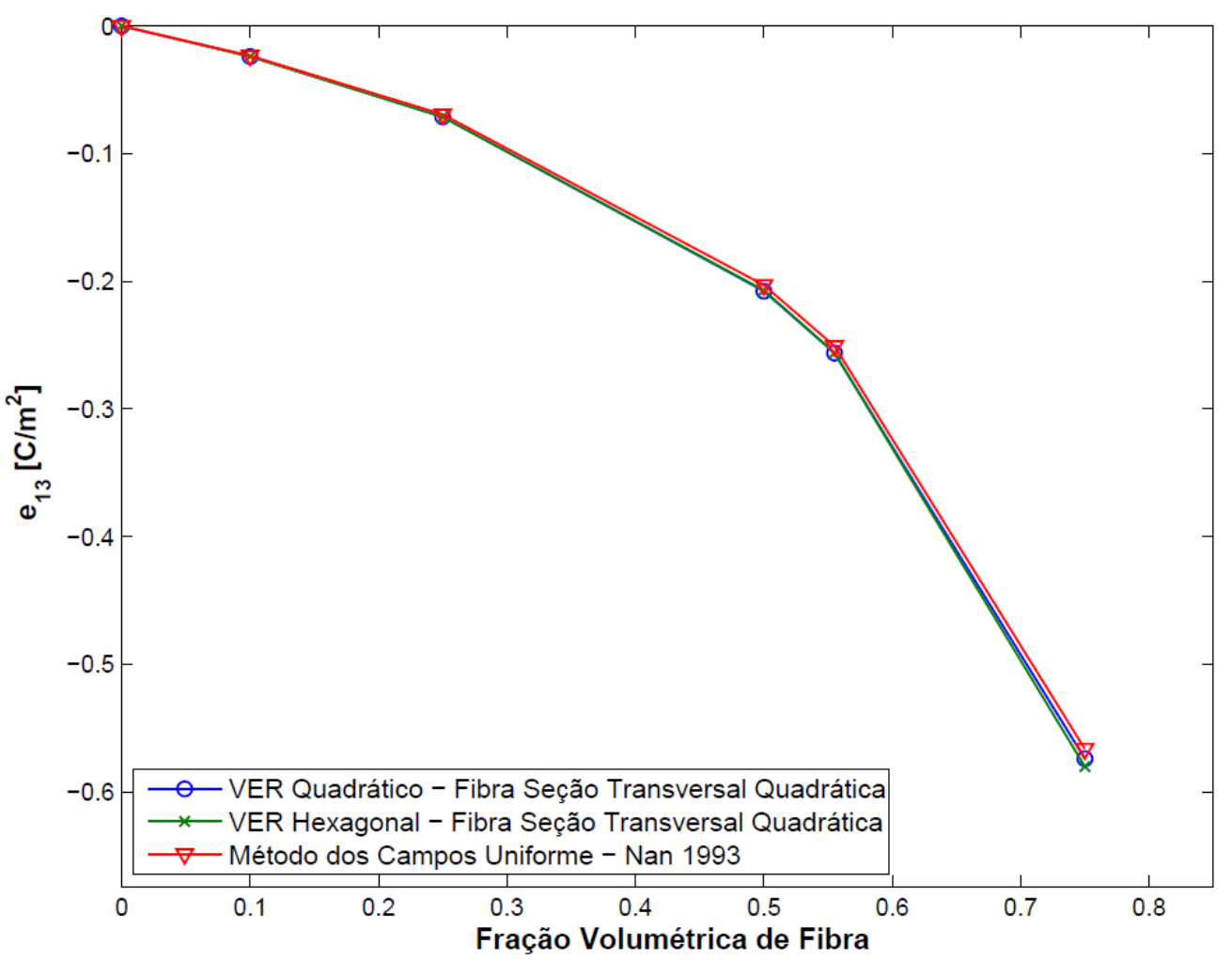

FIGURA 4.2-10 - Coeficiente efetivo $e_{13}^{\text {eff }}$ 


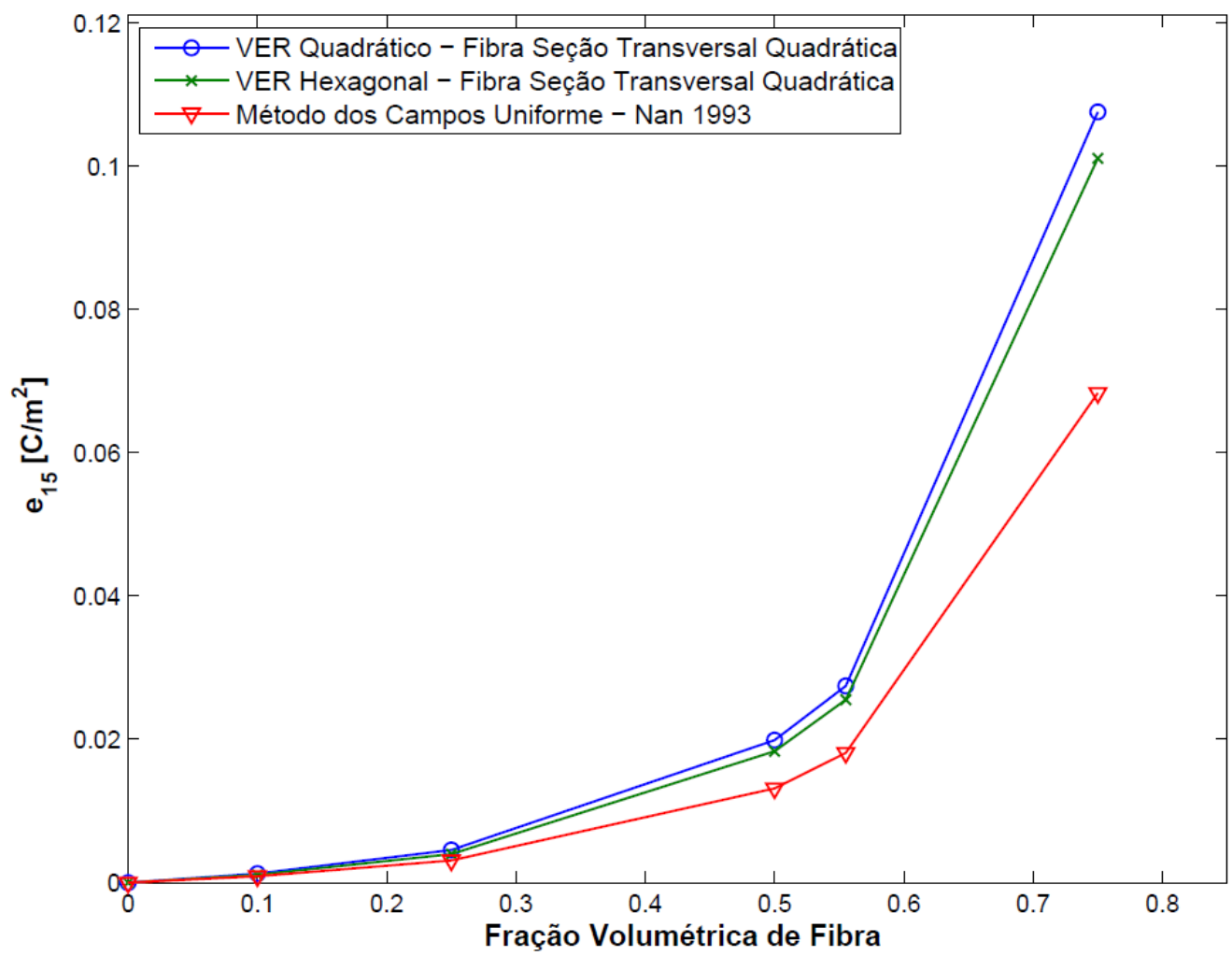

FIGURA 4.2-11 - Coeficiente efetivo $e_{15}^{\text {eff }}$

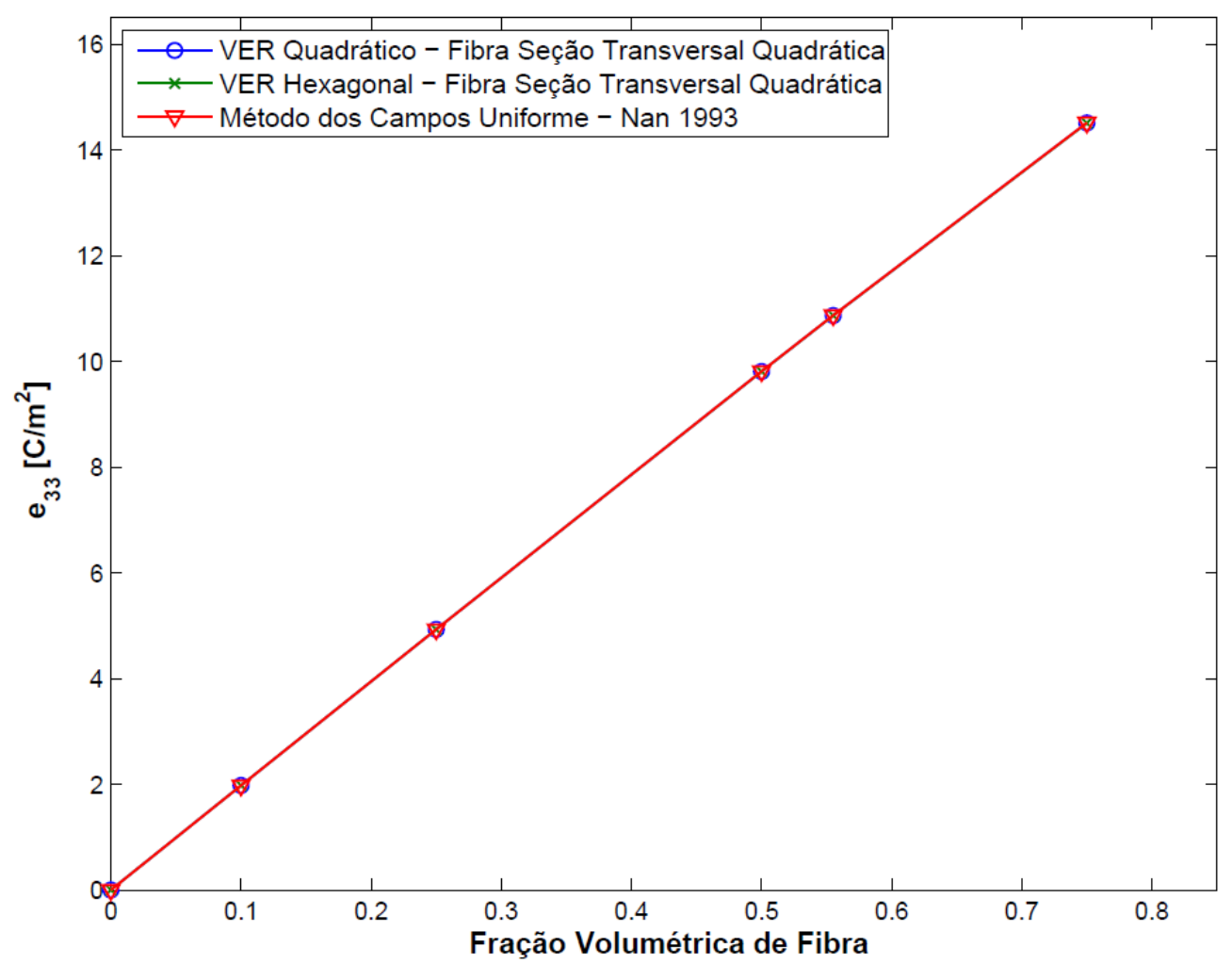

FIGURA 4.2-12 - Coeficiente efetivo $e_{33}^{\text {eff }}$ 


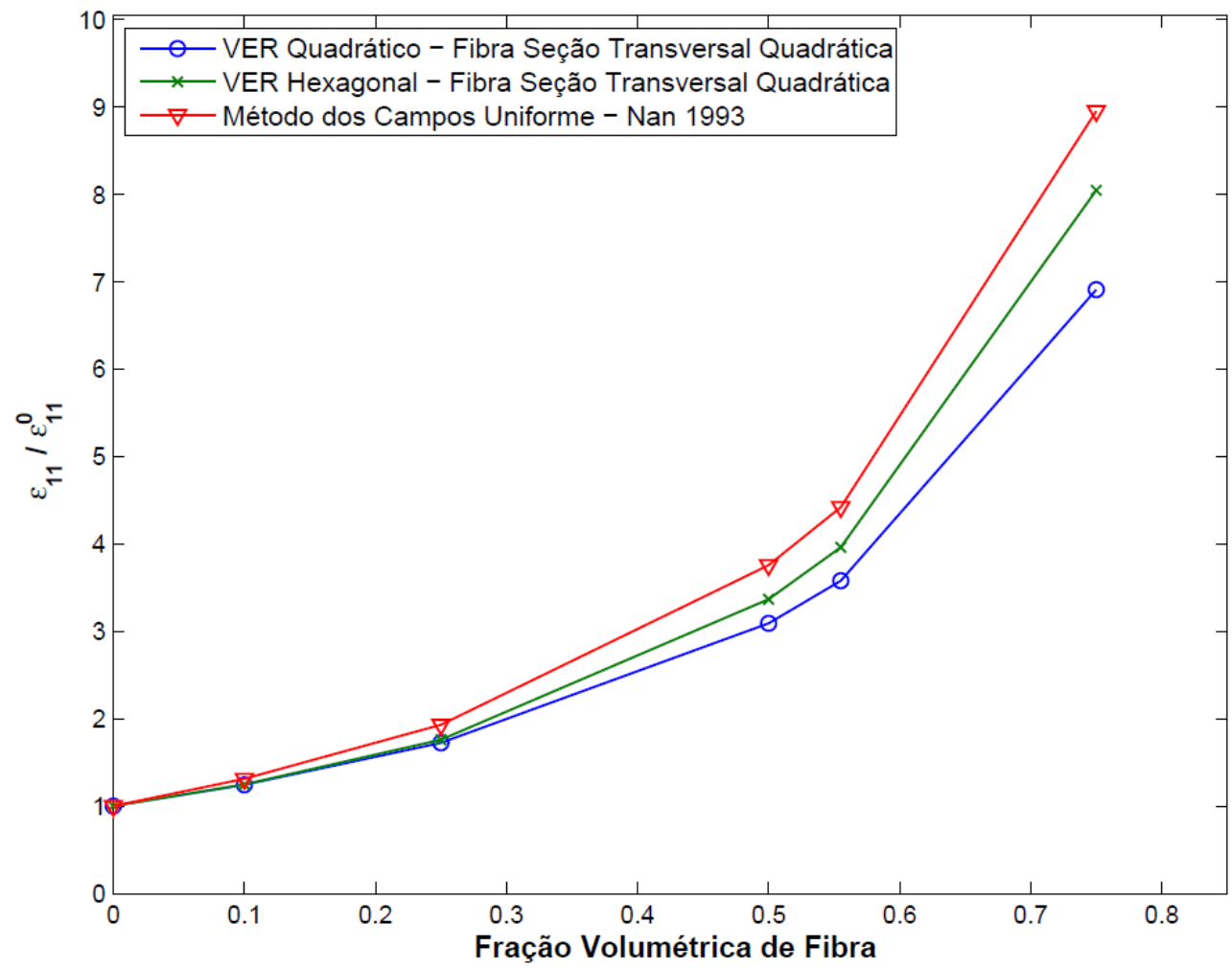

FIGURA 4.2-13 - Coeficiente efetivo $\varepsilon_{11}^{\text {eff }}$

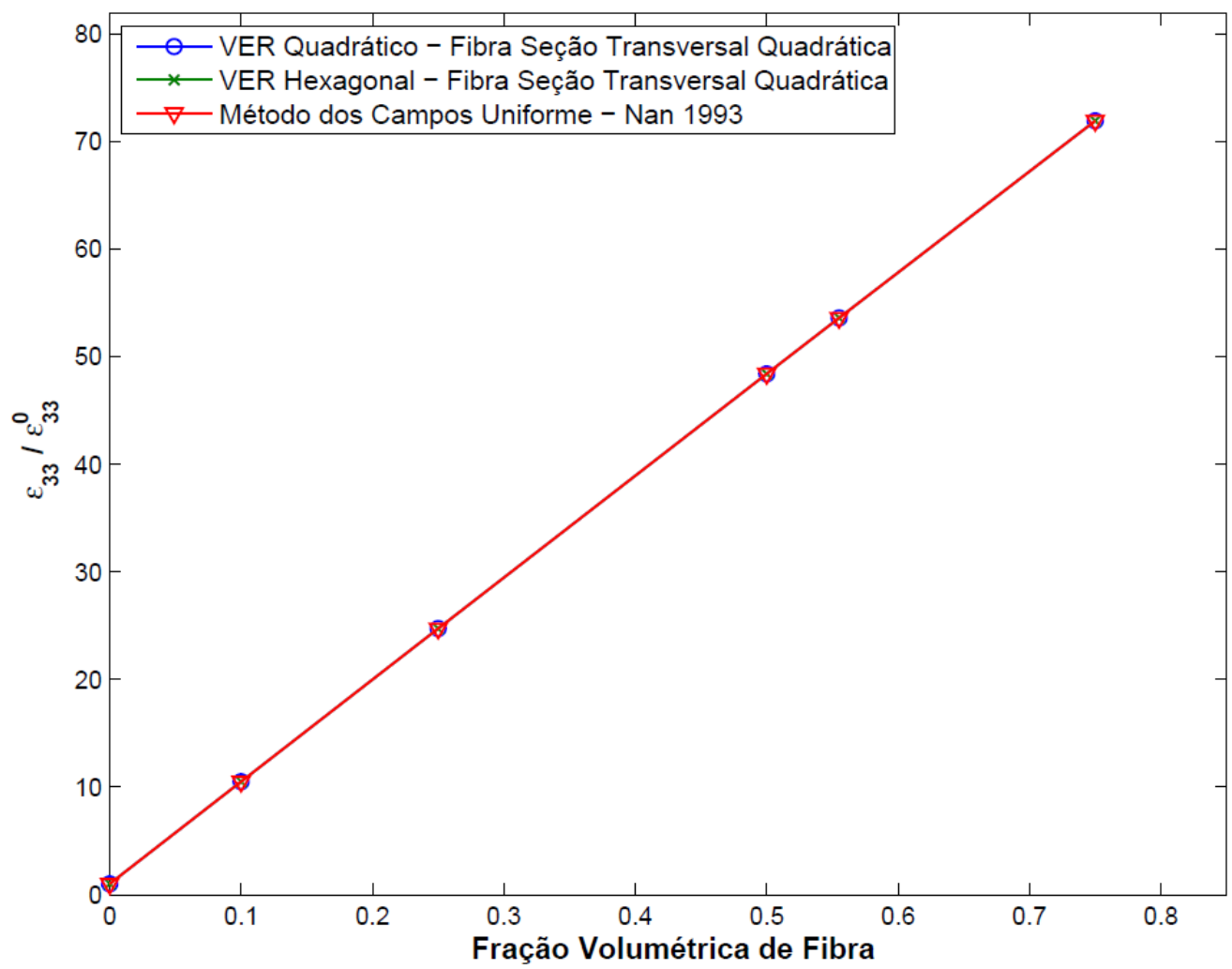

FIGURA 4.2-14 - Coeficiente efetivo $\varepsilon_{33}^{\text {eff }}$ 
De um modo geral, como mostrado nas Figuras de (4.2-4) a (4.2-14), os coeficientes efetivos para os arranjos quadrático e hexagonal (para diferentes frações volumétricas de fibra) apresentam na sua grande maioria uma boa convergência para os resultados analíticos. Todavia, para determinadas frações volumétricas de fibra, determinados coeficientes efetivos apresentam diferenças de resposta tanto entre os arranjos entre si como para com os resultados analíticos.

Como no estudo de caso anterior, verifica-se novamente que os coeficientes $c_{11}^{\text {eff }}, c_{12}^{\text {eff }}$, $c_{66}^{\text {eff }}$ e $e_{15}^{\text {eff }}$ mostraram diferenças de resultados para ambos os tipos de arranjos (quadrático e hexagonal), devido aos aspectos previamente discutidos para AFC com fibra de seção transversal circular e, evidenciados na Tabela (4.1-2).

Verifica-se também que todos os coeficientes efetivos dependentes da resposta do compósito na direção 3 (direção longitudinal), por exemplo, $c_{33}^{\text {eff }}$, mostraram as melhores convergências, mesmo para uma grande variação da fração volumétrica de fibra. Por outro lado, os coeficientes efetivos que dependiam das respostas nas direções 1 e 2 (“direção transversal”), por exemplo, $c_{11}^{\text {eff }} \mathrm{e} c_{12}^{\text {eff }}$, demonstraram diferenças relativas maiores entre os resultados analíticos e os obtidos via metodologia.

Por fim, observa-se que para frações volumétricas reduzidas, ou seja, para os casos em que a matriz governa a resposta, tem-se que as duas abordagens não apresentam significativas diferenças entre os resultados. Entretanto, quanto maior a fração volumétrica de fibra, maiores são as diferenças encontradas entre os coeficientes efetivos. Contudo essa diferença relativa não é tão elevada (sendo no máximo 20,0\% com fração volumétrica de fibra igual a 75\%), evidenciando, assim, a potencialidade da metodologia proposta para prever (com precisão) as propriedades efetivas de compósitos inteligentes com fração volumétrica de fibra até $60 \%$.

\subsection{ESTUdO DE CASO III}

Neste terceiro estudo de caso, a metodologia computacional foi aplicada para a determinação das propriedades efetivas de duas pastilhas piezelétricas, que estavam monitorando o comportamento dinâmico de uma viga de alumínio em balanço. Sendo assim, primeiramente, selecionou-se a pastilha piezelétrica Midé QP10n, em seguida, aplicou-se a metodologia proposta para a determinação das propriedades efetivas da mesma. 


\subsubsection{DETERMinAÇÃo dOS COEFICIENTES EFETIVOS}

A Figura (4.3-1) apresenta o modelo de pastilha piezelétrica utilizada e as especificações de espessura de cada material. A Tabela (4.3-1) apresenta as propriedades de cada material e a Tabela (4.3-2) apresenta as dimensões da pastilha piezelétrica Midé modelo QP10n.

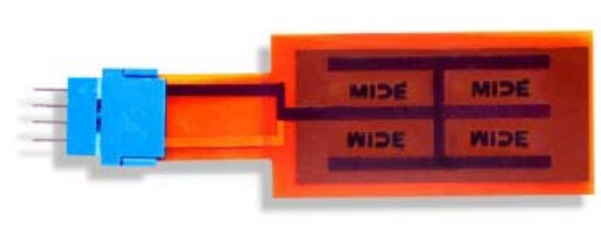

(a)

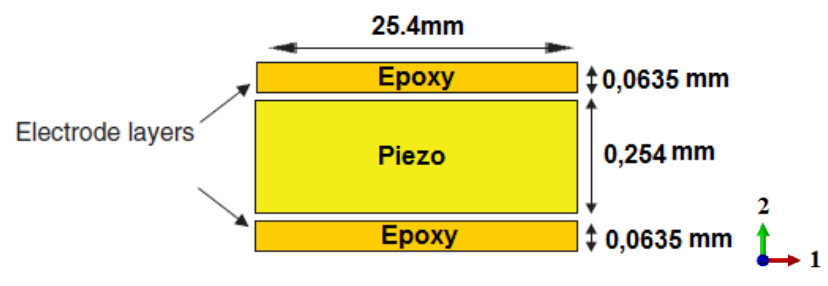

(b)

FIGURA 4.3-1 - (a) Pastilha piezelétrica Midé, (b) Espessura das camadas do transdutor (MIDÉ, 2010)

TABELA 4.3-1 - Propriedades do reforço (“fibra”) (MIDÉ, 2010)

\begin{tabular}{cc}
\hline Coeficiente Efetivo & Valor \\
\hline$S_{11}^{E}\left[\mathbf{m}^{2} / \mathbf{N}\right]$ & $16,4 \times 10^{-12}$ \\
$S_{12}^{E}\left[\mathbf{m}^{2} / \mathbf{N}\right]$ & $-5,74 \times 10^{-12}$ \\
$S_{13}^{E}\left[\mathbf{m}^{2} / \mathbf{N}\right]$ & $-7,22 \times 10^{-12}$ \\
$S_{33}^{E}\left[\mathbf{m}^{2} / \mathbf{N}\right]$ & $18,8 \times 10^{-12}$ \\
$S_{44}^{E}\left[\mathbf{m}^{2} / \mathbf{N}\right]$ & $47,5 \times 10^{-12}$ \\
$S_{66}^{E}\left[\mathbf{m}^{2} / \mathbf{N}\right]$ & $44,3 \times 10^{-12}$ \\
$d_{13}[\mathbf{m} / \mathbf{V}]$ & $-190,0 \times 10^{-12}$ \\
$d_{15}[\mathbf{m} / \mathbf{V}]$ & $584,5 \times 10^{-12}$ \\
$d_{33}[\mathbf{m} / \mathbf{V}]$ & $390,0 \times 10^{-12}$ \\
$\varepsilon_{11}^{S} / \varepsilon_{0}$ & 830,0 \\
$\varepsilon_{33}^{S} / \varepsilon_{0}$ & 913,0 \\
$\varepsilon_{0}\left[\mathbf{C}^{2} /(\mathbf{N} \mathbf{m})\right]$ & $8,854238837 \times 10^{-12}$ \\
\hline $\mathbf{\rho}\left[\mathbf{k g} / \mathbf{m}^{3}\right]$ & 7800 \\
\hline
\end{tabular}

A matriz (resina epóxi) possui comportamento isotrópico com módulo de elasticidade de 4,5 GPa, constante dielétrica de 0,0797 nF / m, e densidade de $1480 \mathrm{~kg} / \mathrm{m}^{3}$. 
TABELA 4.3-2 - Dimensões do transdutor Midé Modelo QP10n (MIDÉ, 2010)

\begin{tabular}{cc}
\hline Dimensão & Valor \\
\hline Largura $[\mathrm{mm}]$ & 25,4 \\
\hline Comprimento [mm] & 50,8 \\
\hline Espessura [mm] & 0,381 \\
\hline Faixa de tensão [V] & \pm 200 \\
\hline
\end{tabular}

Para as análises via MEF requisitadas pela metodologia, empregou-se o Volume Elementar Representativo evidenciado na Figura (4.3-2). Sendo que o mesmo foi analisado, empregando um elemento tridimensional com função de forma parabólica (C3D20E nomenclatura do ABAQUS), que possui três graus de liberdade de deslocamento e um grau de liberdade adicional elétrico.

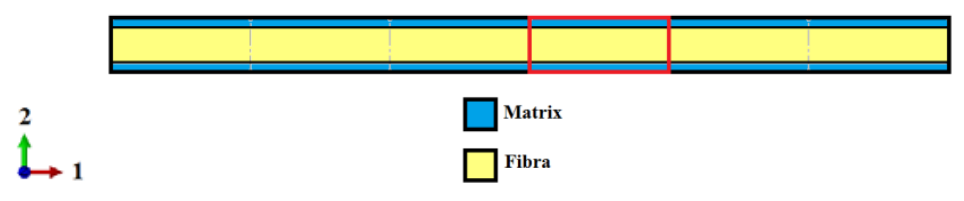

(a)

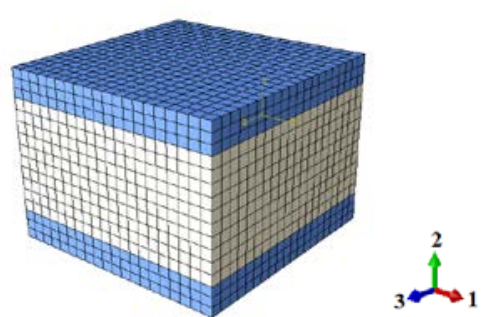

(b)

FIGURA 4.3-2 - Representação do esquemática do transdutor piezelétrico: (a) Célula unitária periódica selecionada; (b) Volume Elementar Representativo (VER) - correspondente à célula unitária

Entretanto, vale ressaltar que o modelo utilizado pela metodologia proposta apresenta condições de paralelismo das faces nas três direções (Figura (4.3-3a)), diferentemente do que acontece no transdutor da Midé (Figura (4.3-3b)), onde o compósito possui apenas uma camada. Assim, na direção 2, não deveria ser imposta a condição de paralelismo entre as faces.

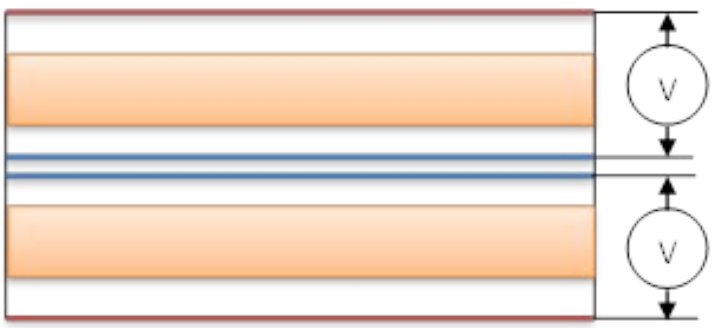

(a)

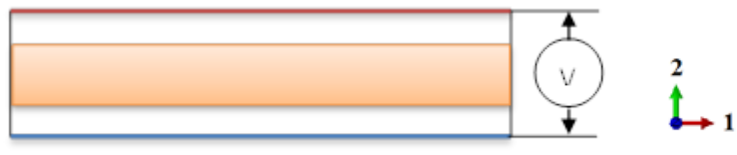

(b)

FIGURA 4.3-3 - (a) Transdutor par o qual a metodologia foi desenvolvida; (b) Transdutor da Midé . 
De acordo com o que foi discutido no Capítulo 2, verifica-se que o comprimento $(\delta)$ associado ao VER deve ser maior do que a dimensão característica da homogeneidade e, muito menor do que a dimensão característica do meio em análise. Com base nesta hipótese, o material poder ser considerado como um meio globalmente homogêneo e o problema de contorno sobre este corpo pode ser resolvido empregando propriedades médias associadas com a escala de comprimento $\delta$. Sendo assim, considerou-se nas análises, as direções 1 e 3 (Figura (4.3-2)), ou seja transversal e paralela a fibra. Para tal dividiu-se a largura do transdutor piezelétrico por 50 e, o comprimento por 100, como evidenciado pela Figura (4.34).

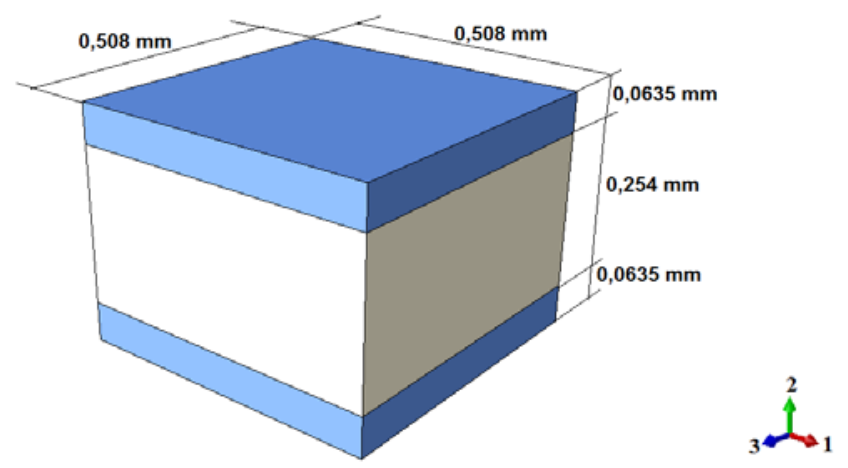

FIGURA 4.3-4 - Dimensões do Volume Elementar Representativo (VER) para representar o transdutor da Midé.

Devido ao fato do fabricante (Midé) prover as propriedades da fibra em termos de flexibilidade e piezeletricidade $d$, ou seja, não sendo compatível com o que é requisitado pelo programa ABAQUS, faz-se necessário o emprego das seguintes relações (discutidas no Capítulo 2, Item 2.4):

$$
c_{p r}^{E}=\delta_{p g}\left(s_{q r}^{E}\right)^{-1}, \quad e_{i p}=d_{i q} c_{q p}^{E}
$$

Após seguir todas as recomendações supracitadas, o próximo passo é a realização das análises via MEF como requisitado pela metodologia proposta, sendo que na Figura (4.3-5), pode-se observar os resultados numéricos. Com base nestes resultados, então, calcula-se os coeficientes efetivos para o, então, transdutor da Midé, que será colado a uma viga de alumínio. 

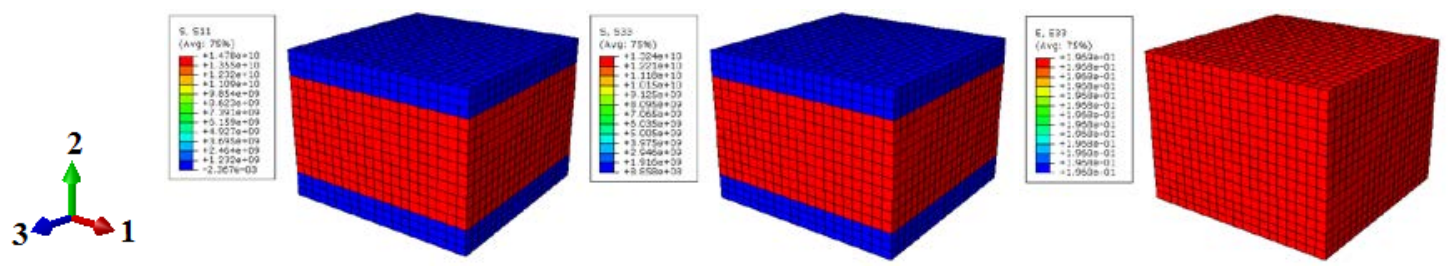

(a) Primeira análise: $T_{11}, T_{33}$ e $S_{33}$
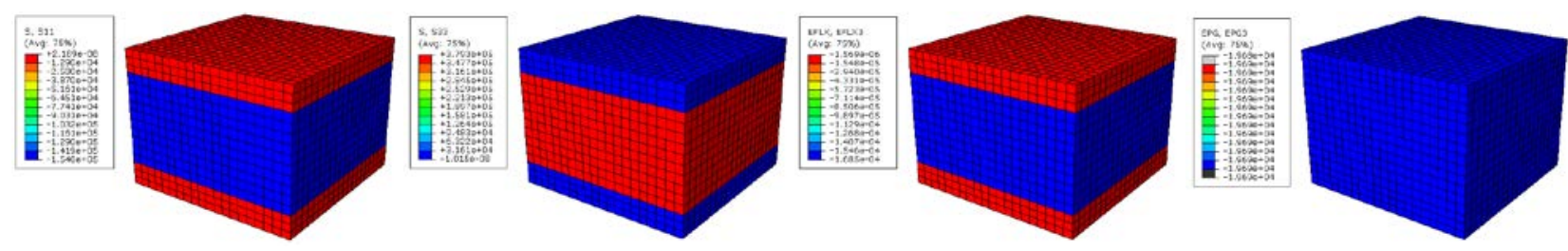

(b) Segunda análise: $T_{11}, T_{33} D_{3}$ e $E_{3}$
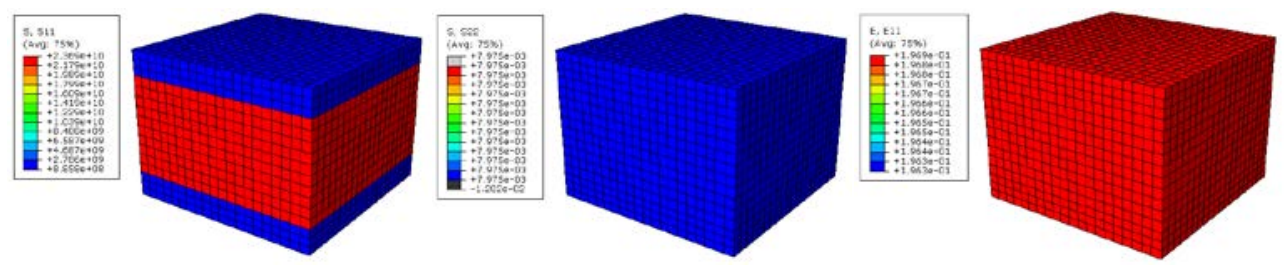

(c) Terceira análise: $T_{11}, T_{22}$ e $S_{11}$
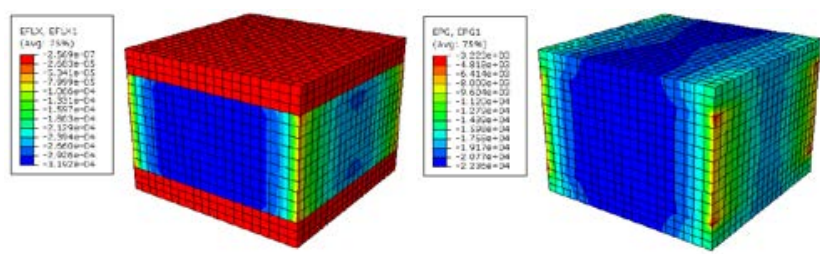

(d) Quarta análise: $\mathrm{D}_{1}$ e $\mathrm{E}_{1}$
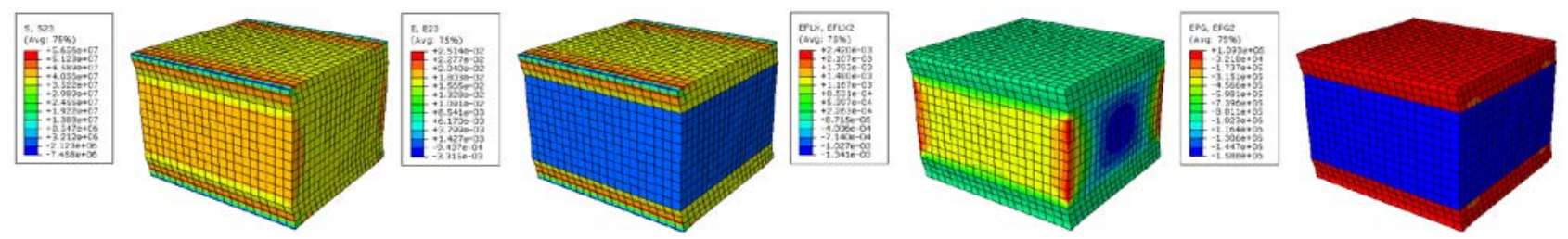

(f) Sexta análise: $T_{23}, S_{23} D_{2}$ e $E_{2}$ 
As propriedades efetivas calculadas são mostradas na Tabela (4.3-3) e serão utilizadas nas próximas análises computacionais, que visam simular a resposta dinâmica de uma viga de alumínio sob a condição engastada-livre, contendo em sua superfície dois transdutores piezelétricos da Midé.

TABELA 4.3-3 - Propriedades Efetivas obtidas via metodologia para o transdutor Midé QP10n

\begin{tabular}{|c|c|}
\hline Coeficiente Efetivo & Valor \\
\hline$C_{11}^{e f f}[\mathrm{GPa}]$ & 81,73 \\
\hline$c_{12}^{e f f}$ [GPa] & 5,23 \\
\hline$C_{13}^{\text {eff }}$ [GPa] & 50,06 \\
\hline$C_{33}^{\text {eff }}$ [GPa] & 46,35 \\
\hline$c_{44}^{\text {eff }}$ [GPa] & 5,91 \\
\hline$c_{66}^{e f f}[\mathbf{G P a}]$ & 5,63 \\
\hline$e_{13}^{e f f}\left[\mathrm{C} / \mathbf{m}^{2}\right]$ & $-5,24$ \\
\hline$e_{15}^{e f f}\left[\mathbf{C} / \mathbf{m}^{2}\right]$ & 1,13 \\
\hline$e_{33}^{e f f}\left[\mathrm{C} / \mathbf{m}^{2}\right]$ & 12,85 \\
\hline$\varepsilon_{11}^{e f f}[\mathbf{n F} / \mathbf{m}]$ & 6,89 \\
\hline$\varepsilon_{33}^{e f f}[\mathrm{nF} / \mathrm{m}]$ & 5,73 \\
\hline$\rho\left[\mathrm{kg} / \mathrm{m}^{3}\right]$ & 7400 \\
\hline * considerando $c^{\mathrm{E}}$ e $\varepsilon^{\mathrm{S}}$ & \\
\hline
\end{tabular}

O modelo em elementos finitos da viga em balanço possui, portanto, elementos ativos incorporados, ou seja, elementos que apresentam comportamento piezelétrico. Os elementos piezelétricos são modelados, assumindo a hipótese de que os mesmos estejam perfeitamente colados junto à viga, podendo ser polarizados em paralelo ou em série. Além disso, tais elementos piezelétricos devem ser dispostos estrategicamente ao longo da viga, como será discutido posteriormente.

Vale ressaltar que para o material compósito, o sistema de coordenadas local (1-2-3) é definido em função do reforço, ou seja, a direção 3 está alinhada com a “fibra”, ao passo que a direção 1 é normal ao reforço e a direção 2 é normal ao plano da lâmina. Todavia, para a pastilha piezelétrica, tem-se que a direção 3 (sistema de coordenadas local) está relacionada com a direção longitudinal da pastilha, e as direções 2 e 3 estão relacionadas com as direções 
da seção transversal da pastilha. Portanto, considerando as condições supracitadas, constata-se que a direção de polarização está alinhada com a direção 2 da pastilha piezelétrica.

Outro aspecto importante da modelagem computacional é garantir o acoplamento mecânico entre a viga e a pastilha. Uma vez assegurado tal acoplamento mecânico, é necessário definir condições adequadas para a leitura do potencial elétrico das pastilhas. Naturalmente, as propriedades dielétricas da pastilha QP10n impedem que o excesso de cargas elétricas induzidas localmente na superfície livre de cada pastilha se distribua uniformemente.

Duas condições de contorno elétricas podem ser consideradas: 1) Pastilhas piezelétricas em circuito aberto; 2) Pastilhas piezelétricas em circuito fechado. Para o caso 1, os nós da base são aterrados e a superfície livre respeita a condição de equipotencialidade. Sendo que as condições de contorno na superfície equipotencial são típicas de uma interface condutor-espaço livre. Para o caso 2, os nós da base e do topo são aterrados, de forma que os potenciais elétricos no topo e na base de cada pastilha sejam mantidos invariavelmente constantes. A pastilha, portanto, comporta-se como um dispositivo em curto-circuito. Fisicamente, tem-se que as cargas superficiais geradas são escoadas para "fora da” pastilha, por meio de fios condutores, de forma à mantê-la descarregada (PAGANI, 2009).

O aterramento dos nós das superfícies das pastilhas coladas à viga é realizado impondo-se que o potencial seja nulo em qualquer estado de deformação. O objetivo do aterramento é definir um valor de referência em relação aos quais, as tensões elétricas induzidas nos nós das superfícies livres serão medidas. Além disso, para os modelos, adotouse a hipótese de adesão perfeita entre a viga de alumínio e os materiais piezelétricos através do comando "tie” do programa ABAQUS.

\subsubsection{CARACTERÍSTICAS VIGA SEM PASTILHAS PIEZELÉTRICAS}

A fim de avaliar somente o modelo computacional da viga, verificou-se a capacidade de previsão das características dinâmicas de uma viga simples sem elementos piezelétricos. Para tal, ensaiou-se, em laboratório, uma viga de alumínio com dimensões $530 \times$ 50,85 × 3,3 mm sob a condição engastada-livre. A Figura (4.3-6a) mostra toda a montagem do ensaio modal experimental, detalhando os equipamentos e materiais necessários para realização do mesmo. O carregamento é dado por um martelo de impacto, que aplica uma entrada impulso 
na viga próximo da região de engaste (Figura (4.3-6a)). Por outro lado, o sinal de saída é capturado por acelerômetros colados nas posições P1 e P2 (Figura (4.3-6a)).

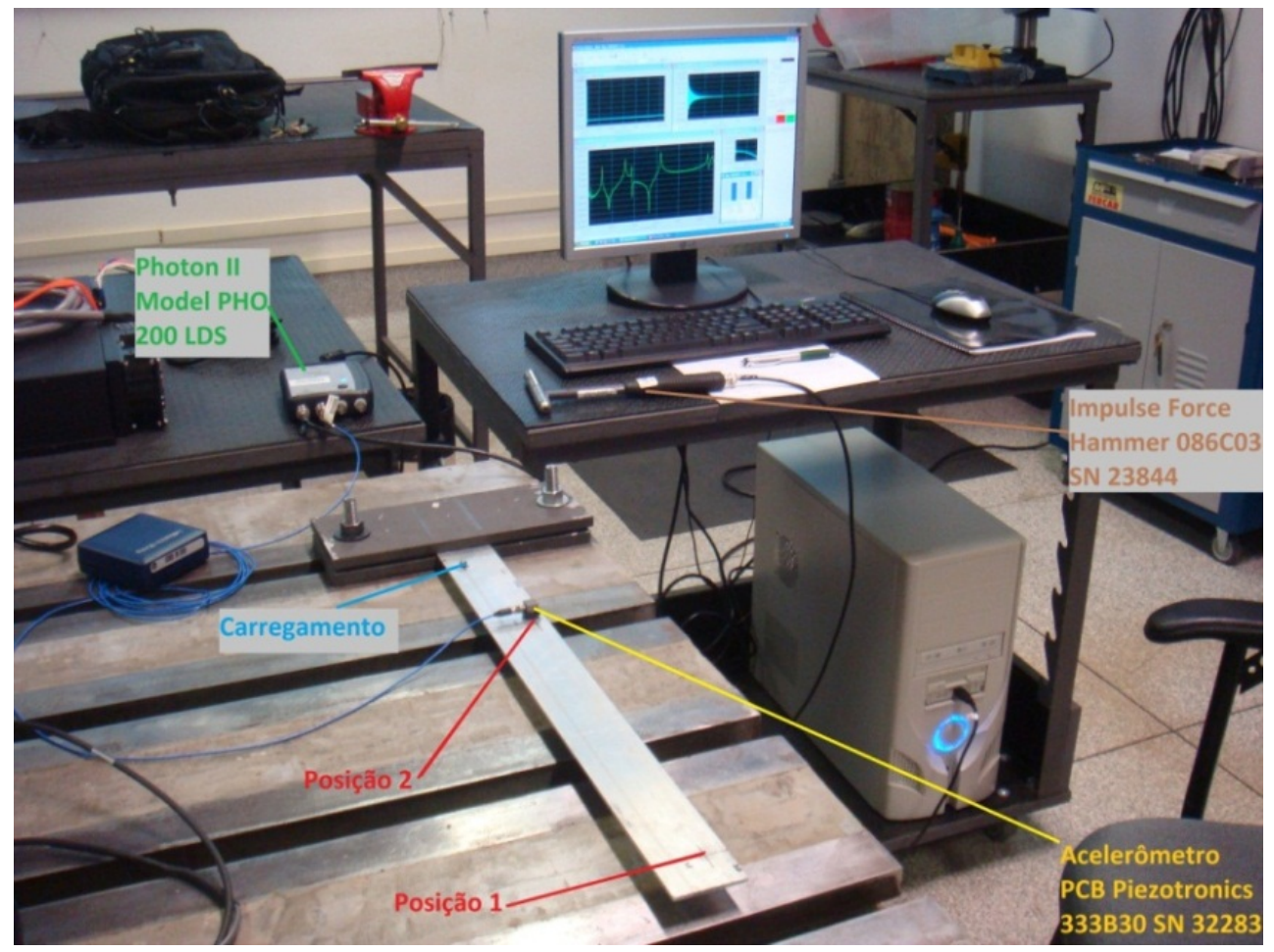

(a)

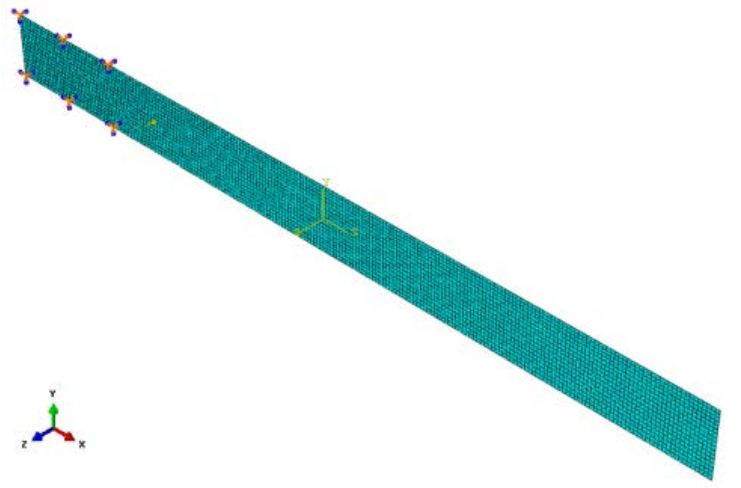

(b)

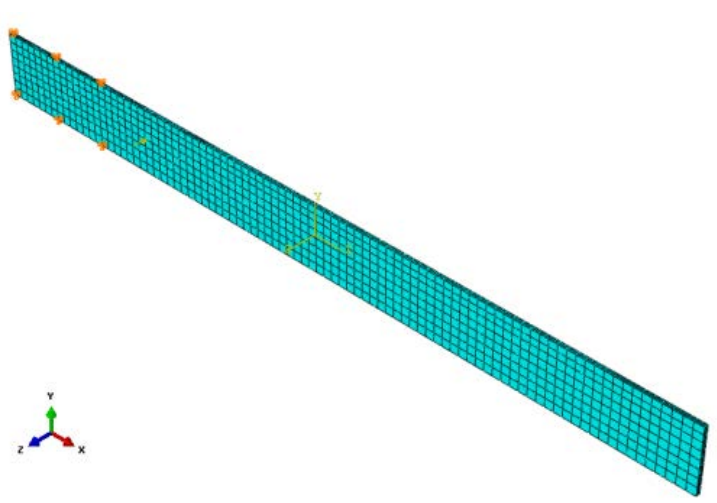

(c)

FIGURA 4.3-6 - (a) Esquema do ensaio experimental - equipamentos utilizados; (b) Modelo computacional (elementos tipo “shell”); (c) Modelo computacional(elementos tipo “solid”).

Em se tratando do modelo computacional, para a viga em alumínio foram atribuídos valores de propriedades mecânicas obtidos da literatura. Portanto, ao módulo de elasticidade foi atribuído o valor de $69 \mathrm{GPa}$, ao coeficiente de Poisson foi atribuído o valor 0,33 e, para a densidade foi atribuído o valor de $2697 \mathrm{~kg} / \mathrm{m}^{3}$. Além disso, dois modelos computacionais distintos foram estudados. O primeiro modelo é constituído por elementos do tipo "Shell” 
(Shell - S8) com interpolação parabólica, possuindo 8 nós com 6 graus de liberdade, 3 de translação e 3 de rotação por nó (Figura (4.3-6b)). O segundo modelo é constituído por elementos tipo “solid” (Solid - C3D20), também, com interpolação parabólica, possuindo 20 nós com 3 graus de liberdade de translação por nó (Figura (4.3-6c)). Além disso, cabe ressaltar que o referido modelo foi discretizado em 3 elementos ao longo da espessura.

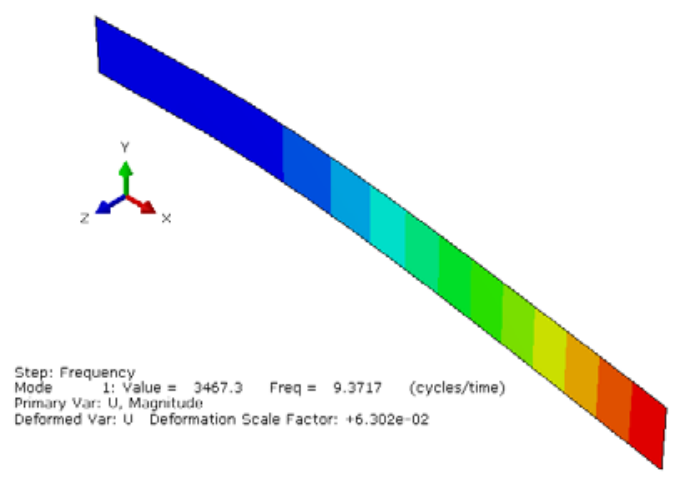

(a)

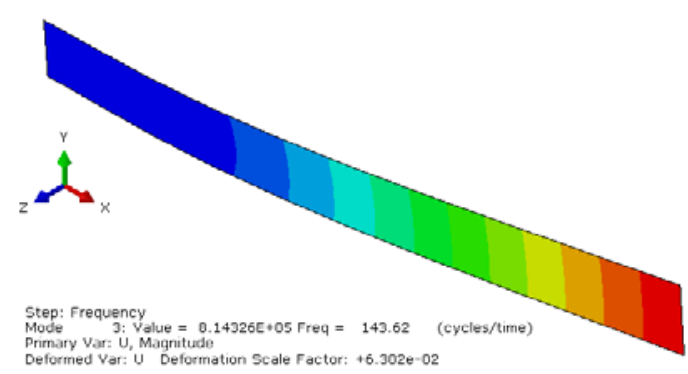

(c)

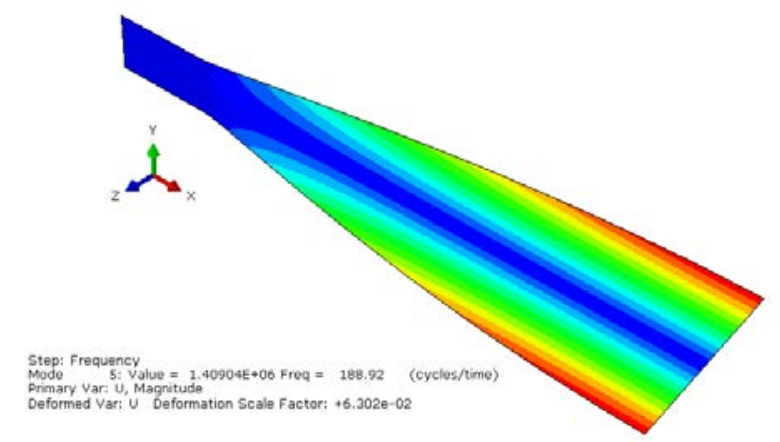

(e)

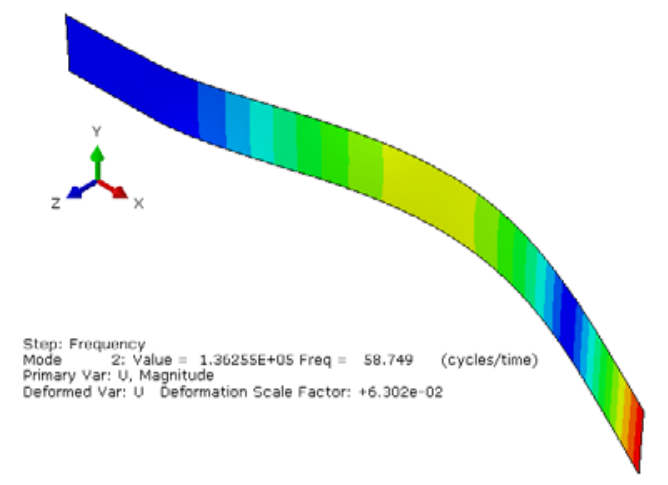

(b)

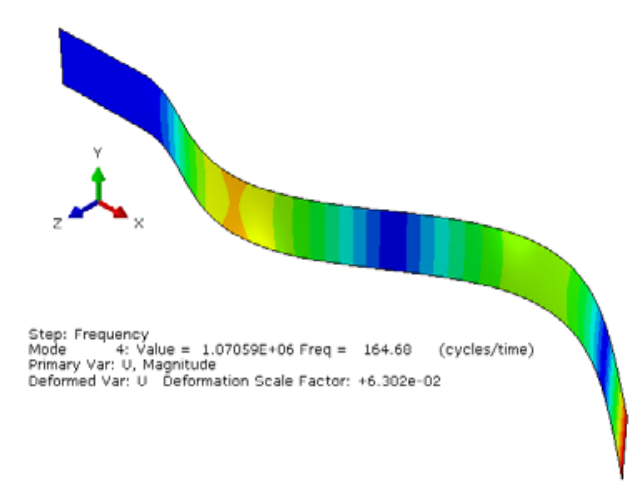

(d)

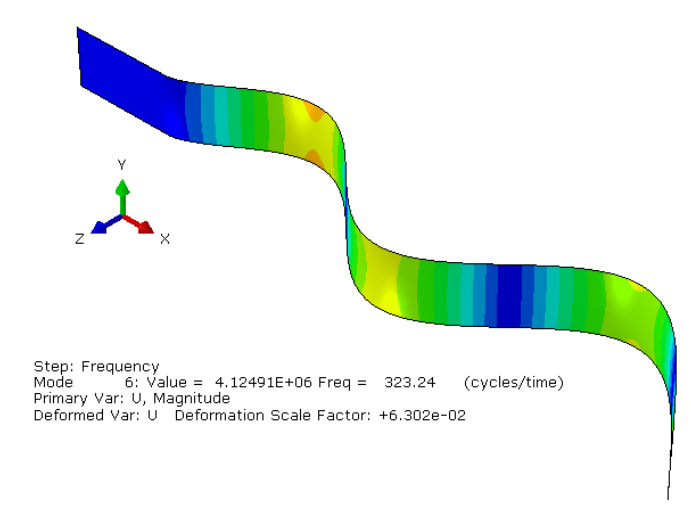

(f)

FIGURA 4.3-7 - Modos de vibrar da viga sem transdutores piezelétricos para elemento tipo Shell: (a) Modo 1; (b) Modo 2; (c) Modo 3; (d) Modo 4; (e) Modo 5 e (f) Modo6. 


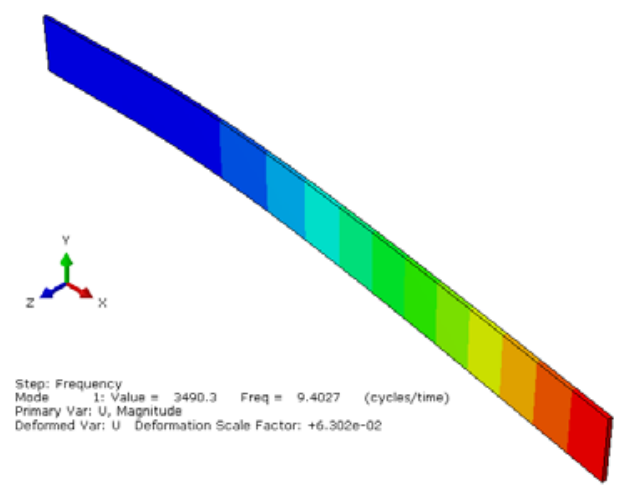

(a)

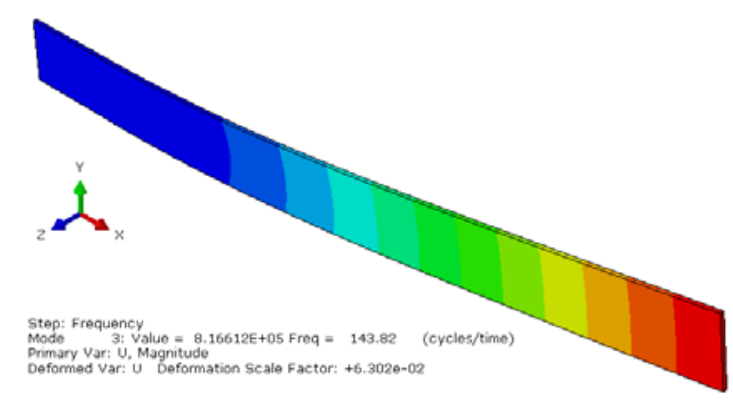

(c)

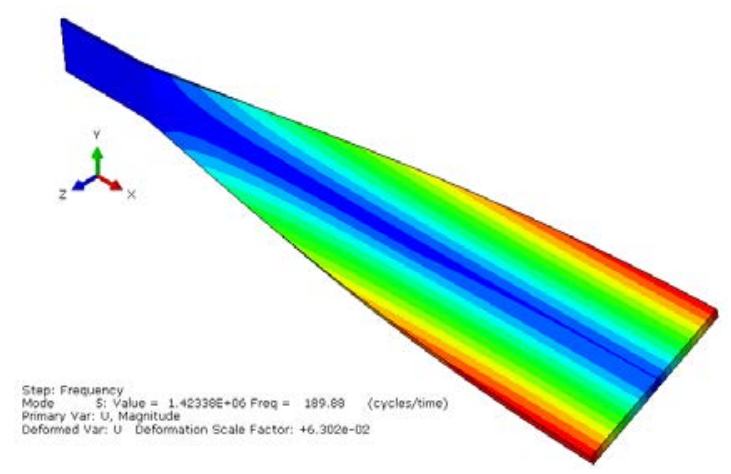

(e)

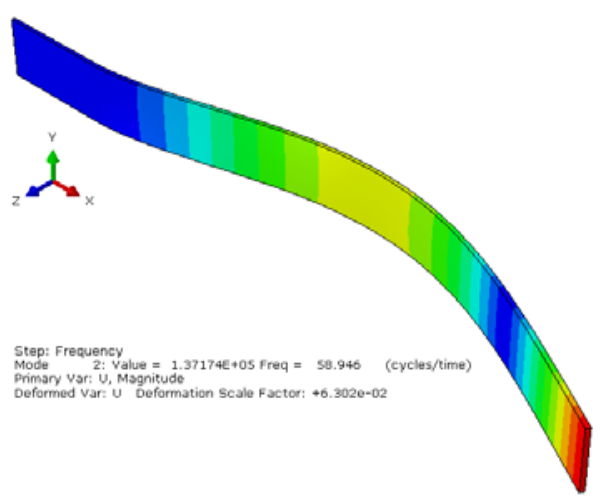

(b)

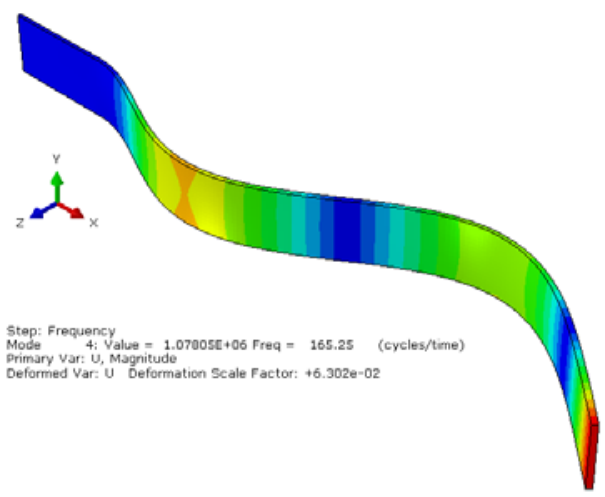

(d)

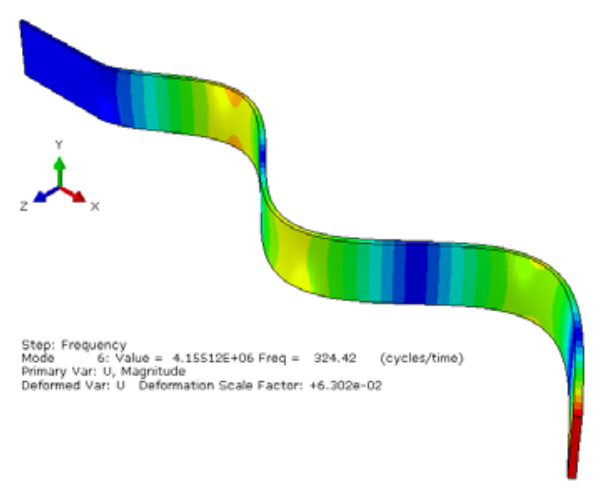

(f)

FIGURA 4.3-8 - Modos de vibrar da viga sem transdutores piezelétricos para elemento tipo Solid: (a) Modo 1; (b) Modo 2; (c) Modo 3; (d) Modo 4; (e) Modo 5 e (f) Modo6.

Para o modelo numérico, considerou-se um carregamento harmônico aplicado na viga localizado na mesma posição do ensaio experimental (Figura (4.3-6)), simulando a excitação de um shaker. A referida entrada harmônica é uma força senoidal transversal de amplitude $100 \mathrm{~N}$ concentrada em um nó localizado na parte superior da viga (Figura (4.3-6)). A frequência da força senoidal é aplicada em um intervalo de 0 a $500 \mathrm{~Hz}$, em passos de 1,0Hz. As Figuras (4.3-7) e (4.3-8) mostram os modos de vibrar obtidos pelas análises com elementos do tipo "shell” e do tipo “solid”. Por outro lado, as Figuras (4.3-8) e (4.3-9) 
ilustram os gráficos da Função de Resposta em Frequência (FRF) obtida através dos modelos computacionais e do ensaio experimental para as posições P1 e P2 dos acelerômetros. Vale ressaltara que a entrada é dada por uma força mecânica atuante na direção vertical, ao passo que a saída é dada pela aceleração vertical.

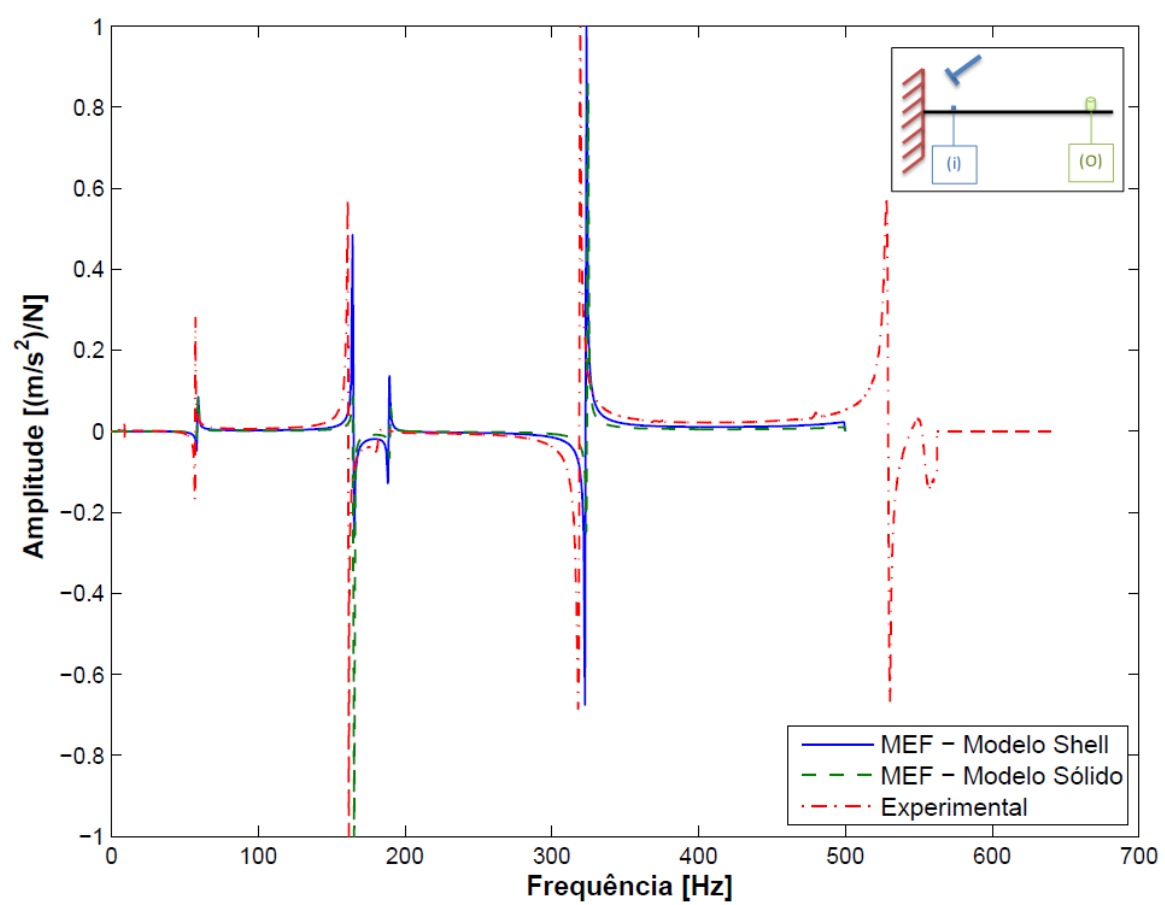

FIGURA 4.3-9 - FRF de uma viga sem elementos piezelétricos, gráfico linear x linear - Posição 1.

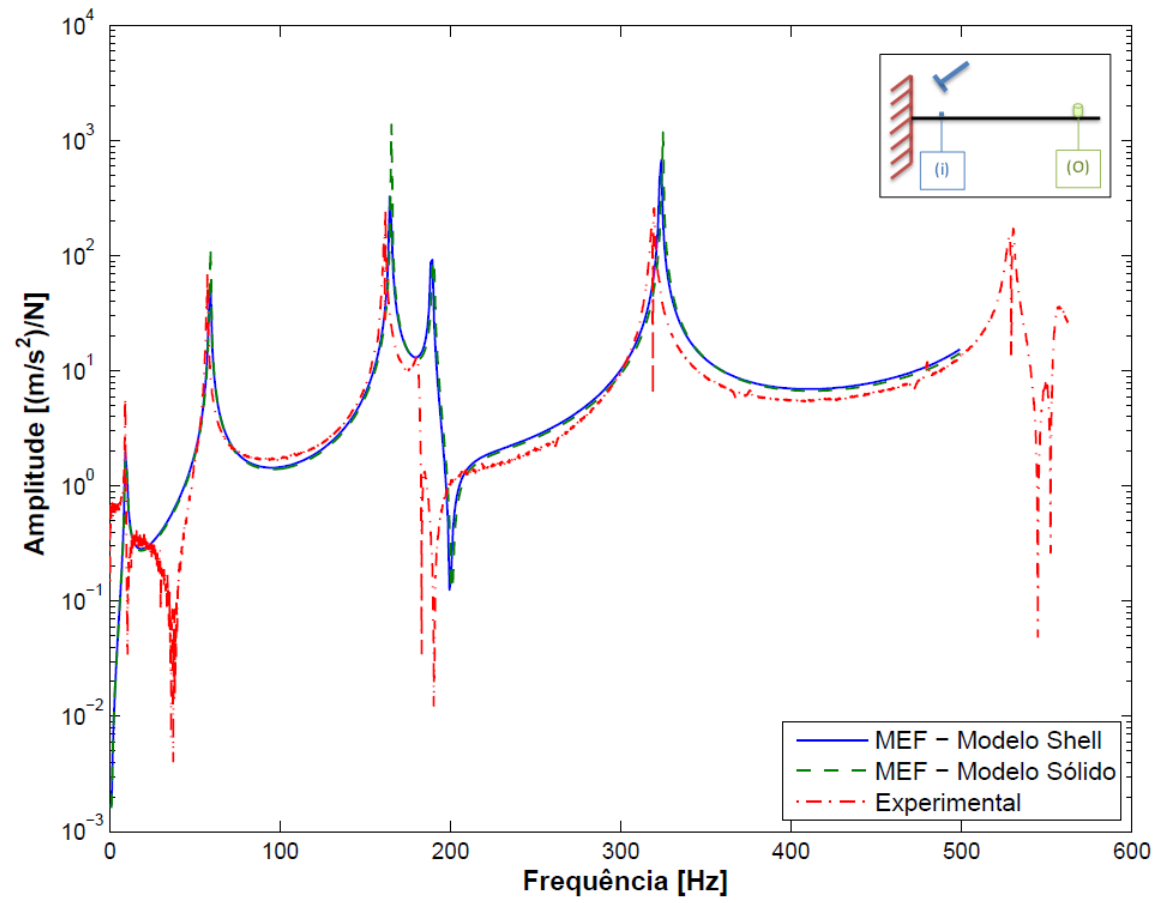

FIGURA 4.3-10 - FRF de uma viga sem elementos piezelétricos, gráfico log x linear - Posição 1. 


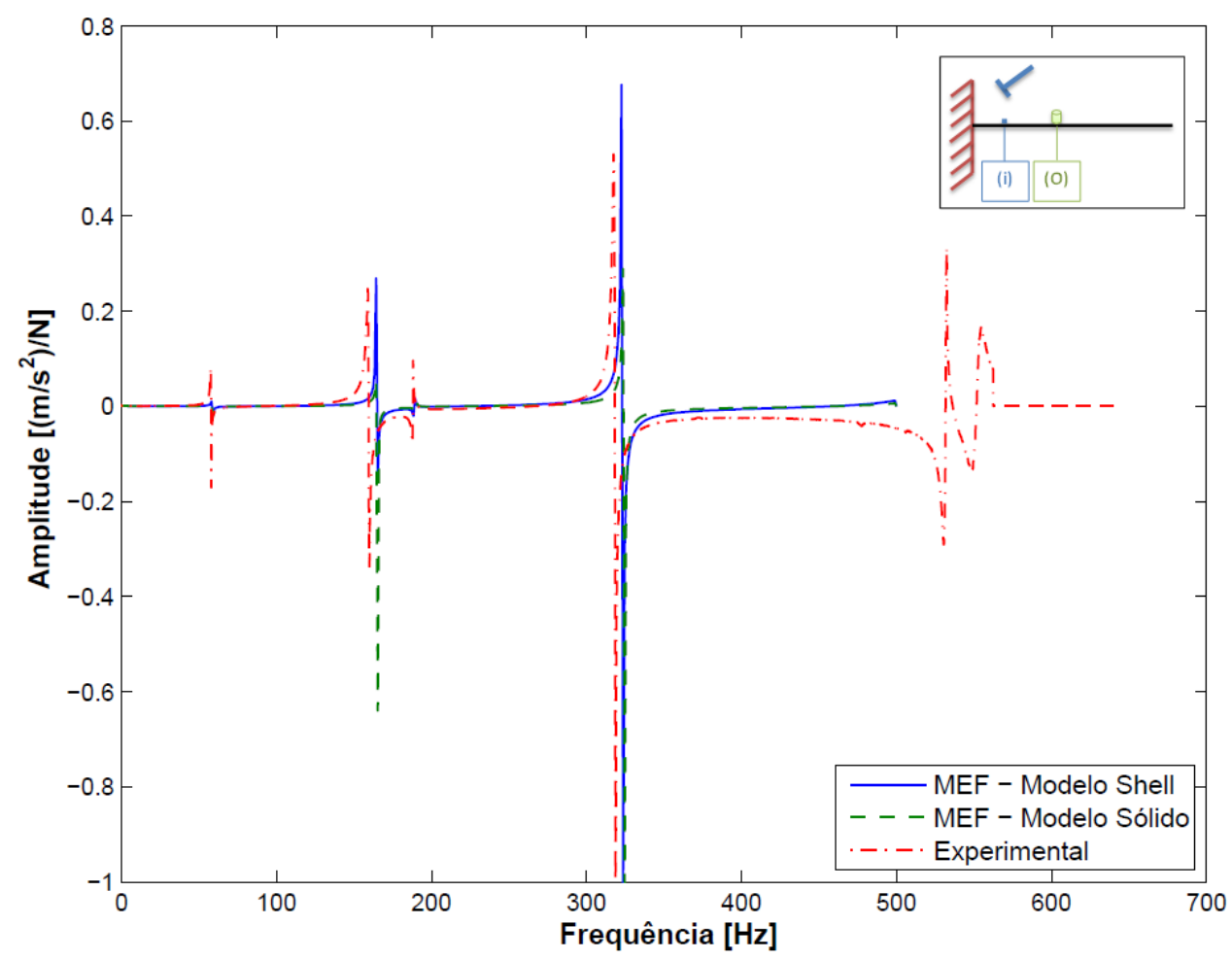

FIGURA 4.3-11 - FRF de uma viga sem elementos piezelétricos, gráfico linear x linear - Posição 2

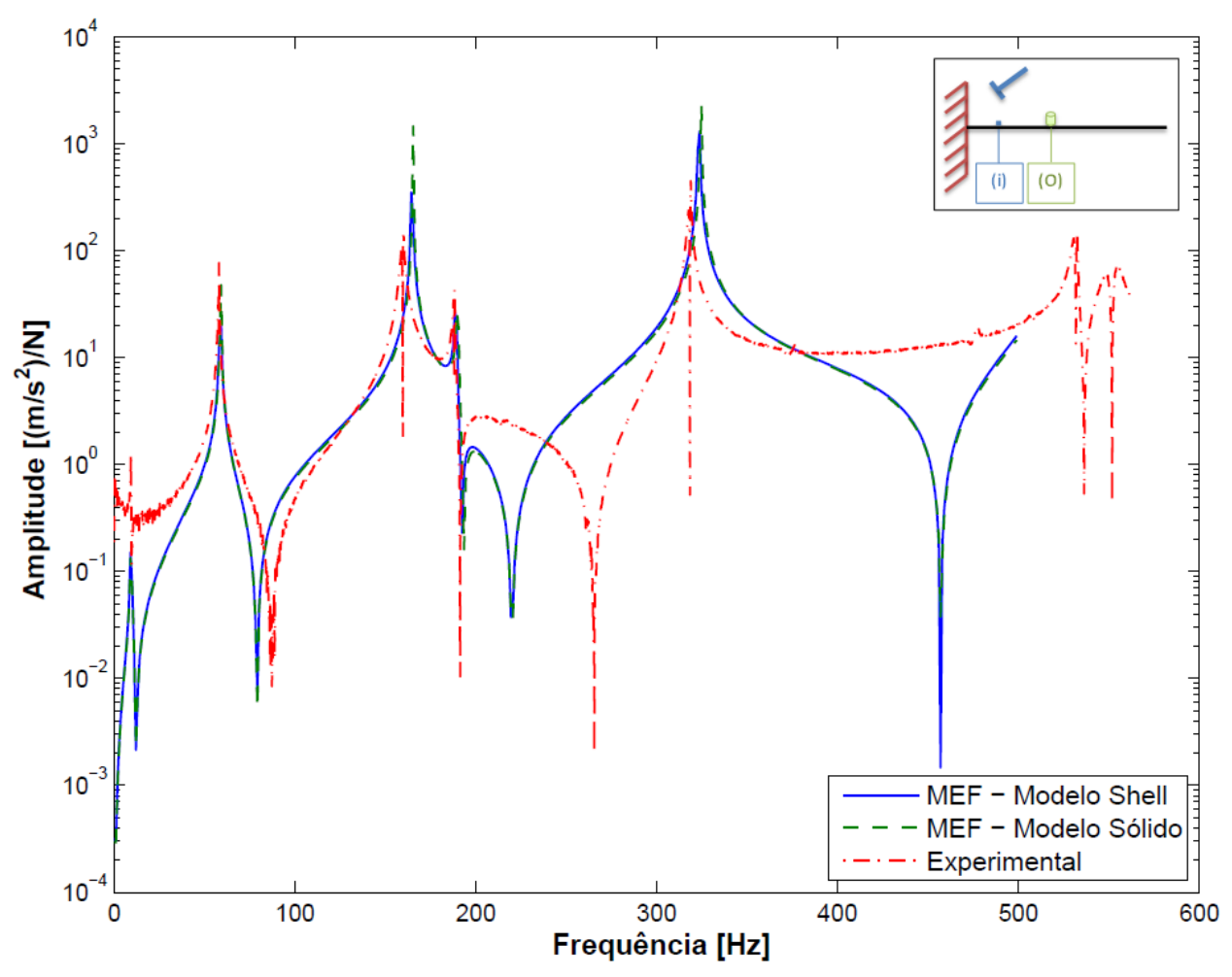

FIGURA 4.3-12 - FRF de uma viga sem elementos piezelétricos, gráfico log x linear - Posição 2 
Com base na análise das FRFs, verifica-se que a diferença máxima entre os resultados numéricos e experimentais não superam 3,00\%. Diferença esta plenamente justificável, devido a uma série de fatores, tais como: condições de contorno reais e aplicadas no modelo; incertezas quanto às propriedades da viga de alumínio; efeitos de amortecimento (desconsiderados nas simulações computacionais). Isto pode ser confirmado pelos valores das frequências não amortecidas do modelo, que são superiores aos valores das frequências amortecidas do experimento (Tabela (4.3-4)).

TABELA 4.3-4 - Valores das frequências para viga sem elemento piezelétrico

\begin{tabular}{|ccccccc}
\hline Tipo & $\mathbf{f}_{\mathbf{1}}[\mathbf{H z}]$ & $\mathbf{f}_{\mathbf{2}}[\mathbf{H z}]$ & $\mathbf{f}_{\mathbf{3}}[\mathbf{H z}]$ & $\mathbf{f}_{\mathbf{4}}[\mathbf{H z}]$ & $\mathbf{f}_{\mathbf{5}}[\mathbf{H z}]$ & $\mathbf{f}_{\mathbf{6}}$ [Hz] \\
\hline Análise & Flexão & Flexão & $\begin{array}{c}\text { Flexão } \\
\text { Plano XY }\end{array}$ & Flexão & Torção & Flexão \\
\hline Experimental - P1 & 10,31 & 57,18 & - & 161,56 & 183,12 & 318,90 \\
\hline Abaqus Solido - P1 & 10,02 & 59,11 & - & 166,33 & 190,38 & 325,65 \\
\hline Abaqus Shell - P1 & 10,01 & 58,66 & - & 165,33 & 189,37 & 323,64 \\
\hline Experimental - P2 & 9,68 & 57,96 & - & 159,68 & 188,12 & 318,28 \\
\hline Abaqus Solido - P2 & 9,98 & 59,26 & - & 165,33 & 193,38 & 324,64 \\
\hline Abaqus Shell - P2 & 9,84 & 58,93 & - & 164,32 & 192,38 & 323,64 \\
\hline
\end{tabular}

\subsubsection{CARACTERÍSTICAS DA VIGA COM PASTILHAS PIEZELÉTRICAS}

Após as análises dinâmicas da viga de alumínio em balanço, passa-se então, para a análise dinâmica da viga de alumínio, também em balanço, porém, com duas pastilhas piezelétricas coladas, mais especificamente, dois transdutores Midé QP10n. Sendo que uma das pastilhas piezelétricas é utilizada como atuador, ao passo que a outra, é utilizada como sensor. A posição do atuador e do sensor é ilustrada nas Figuras (4.3-13), (4.3-14) e (4.1315a). Esta posição deve-se ao fato da utilização da viga e das pastilhas para análises de monitoramento da integridade estrutural em trabalhos futuros. Dessa forma, serão 
introduzidos danos na estrutura e através das pastilhas piezelétricas buscar-se-á o determinar a localização e a quantificação dos mesmos.

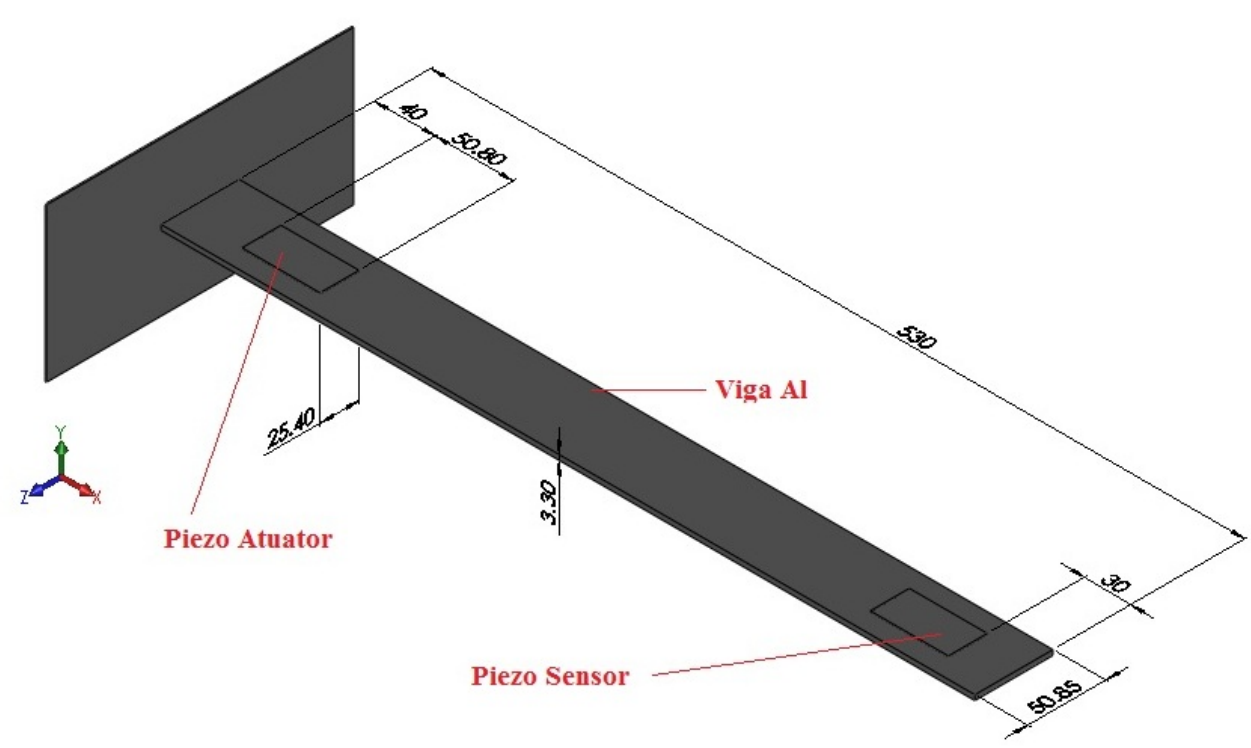

FIGURA 4.3-13 - Representação esquemática da viga utilizada (dimensões em mm)

Devido à pequena diferença de resposta entre os modelos analisados com elementos shell e solido e, devido ao Abaqus possuir somente elemento piezelétrico sólido, as demais análises foram realizadas, modelando a viga e as pastilhas piezelétricas como elementos sólidos.

Para a viga de alumínio foram atribuídas as mesmas dimensões e propriedades mecânicas da análise anterior, ou seja, sem transdutor piezelétrico. Assim, ensaiou-se a viga de alumínio com dimensões $530 \times 50,85 \times 3,3 \mathrm{~mm}$ sob a condição engastada-livre. As propriedades da viga possui módulo de elasticidade de 69 GPa, o coeficiente de Poisson foi atribuído o valor 0,33 e, para a densidade foi atribuído o valor de $2697 \mathrm{~kg} / \mathrm{m}^{3}$.O modelo da viga de alumínio foi elaborado utilizando elementos sólidos com interpolação parabólica, possuindo 20 nós com 3 graus de liberdade de translação por nó (C3D20) (Figura (4.3-15b)).

Para as pastilhas piezelétricas foram atribuídas às propriedades descritas na Tabela (4.3-3), sendo estas obtidas através do emprego da metodologia proposta. Assim, as pastilhas piezelétricas homogeneizadas foram modeladas através de elementos sólidos, também, com interpolação parabólica, possuindo 20 nós com 4 graus de liberdade por nó (C3D20E), sendo 3 para as translações e 1 para potencial elétrico (Figura (4.3-15b)). 
Os potenciais elétricos para as superfícies superiores e inferiores de cada pastilha piezelétrica são acoplados aos potenciais elétricos dos nós “mestres” atribuídos a cada superfície, empregando a opção “equation” do programa ABAQUS. Sendo que as grandezas utilizadas foram monitoradas nestes nós. Além disso, para as superfícies das pastilhas piezelétricas coladas ao material compósito, atribuiu-se potencial igual a zero durante toda a análise. A leitura do potencial elétrico em um nó específico (do elemento finito C3D20E) da superfície livre proverá informações locais a cerca do valor da tensão elétrica induzida. Além disso, para os modelos, adotou-se a hipótese de adesão perfeita entre a viga e os transdutores piezelétricos através do comando "tie" do programa ABAQUS.

Para o ensaio experimental, um sinal aleatório é aplicado no piezo atuador e, então, mede-se a saída através do piezo sensor. Com base nos sinais de entrada e saída, pode-se obter a FRF. Para o modelo numérico, considerou-se um carregamento elétrico harmônico aplicado na pastilha próxima ao engaste (Figura (4.3-14)). A referida entrada harmônica é uma diferença de potencial elétrico senoidal de amplitude variando de $-100 \mathrm{~V}$ a $100 \mathrm{~V}$. Sendo que a frequência do potencial elétrico senoidal é aplicada em um intervalo de 0 a $600 \mathrm{~Hz}$, em passos de $1,0 \mathrm{~Hz}$.

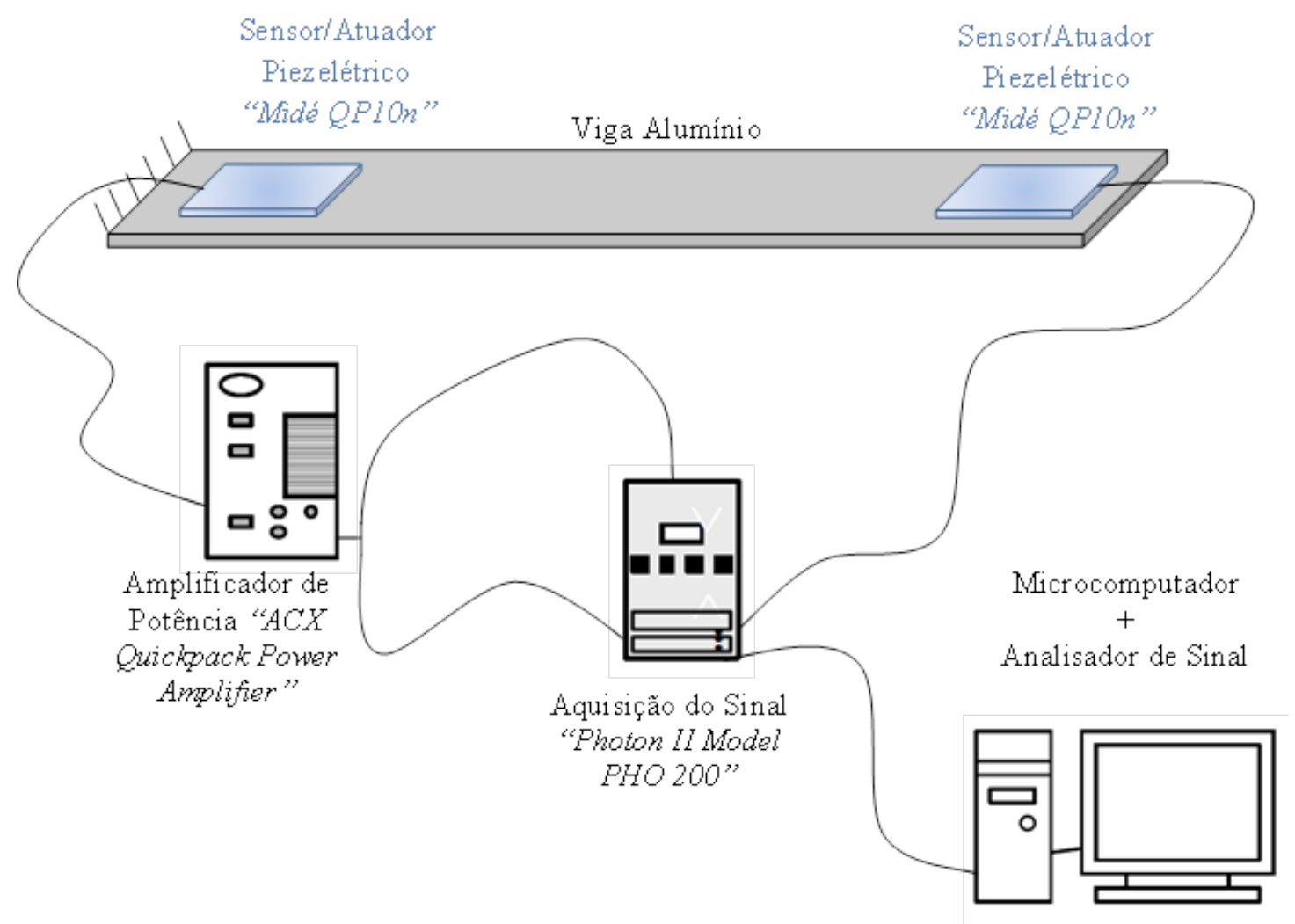

FIGURA 4.3-14 - Esquema do ensaio experimental - equipamentos utilizados. 


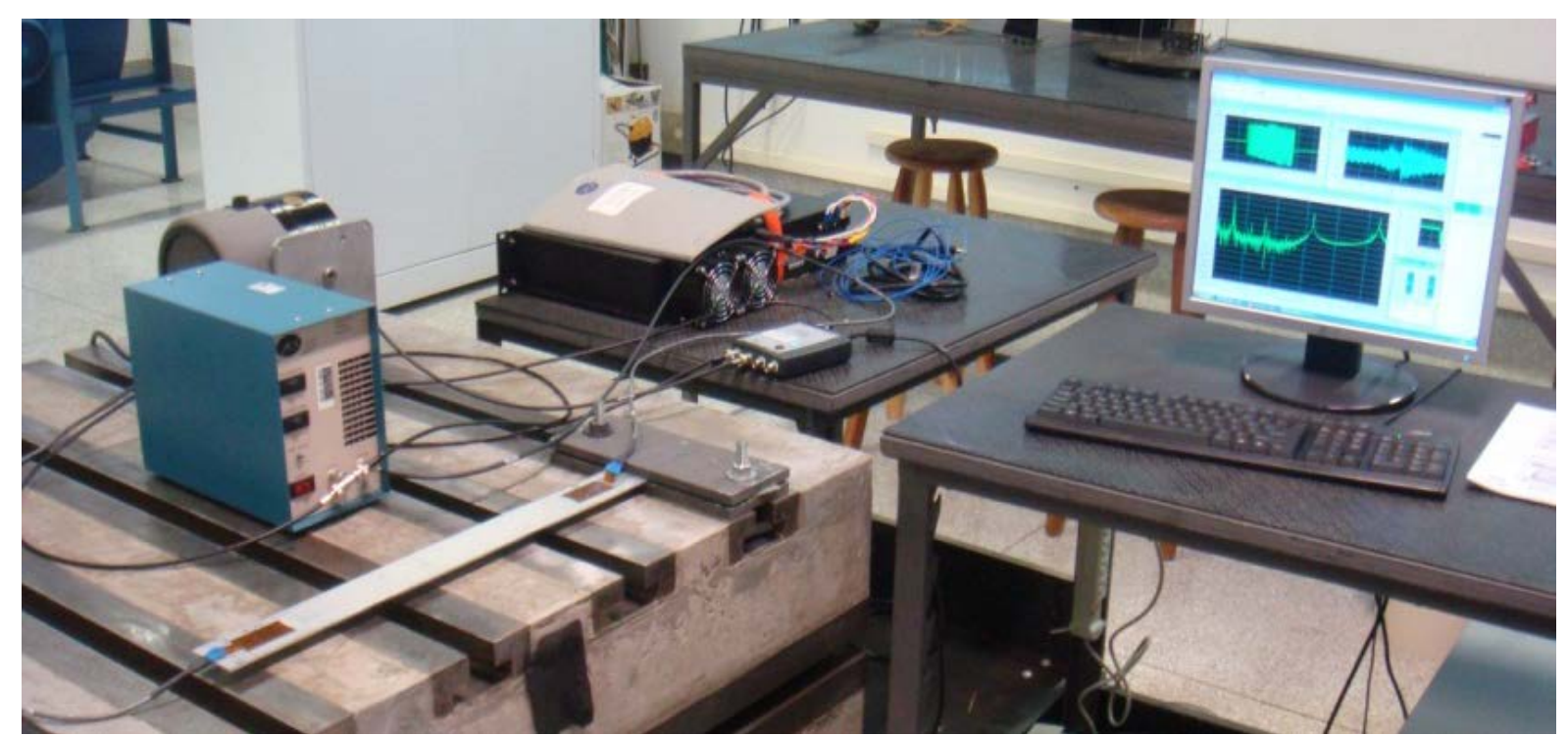

(a)

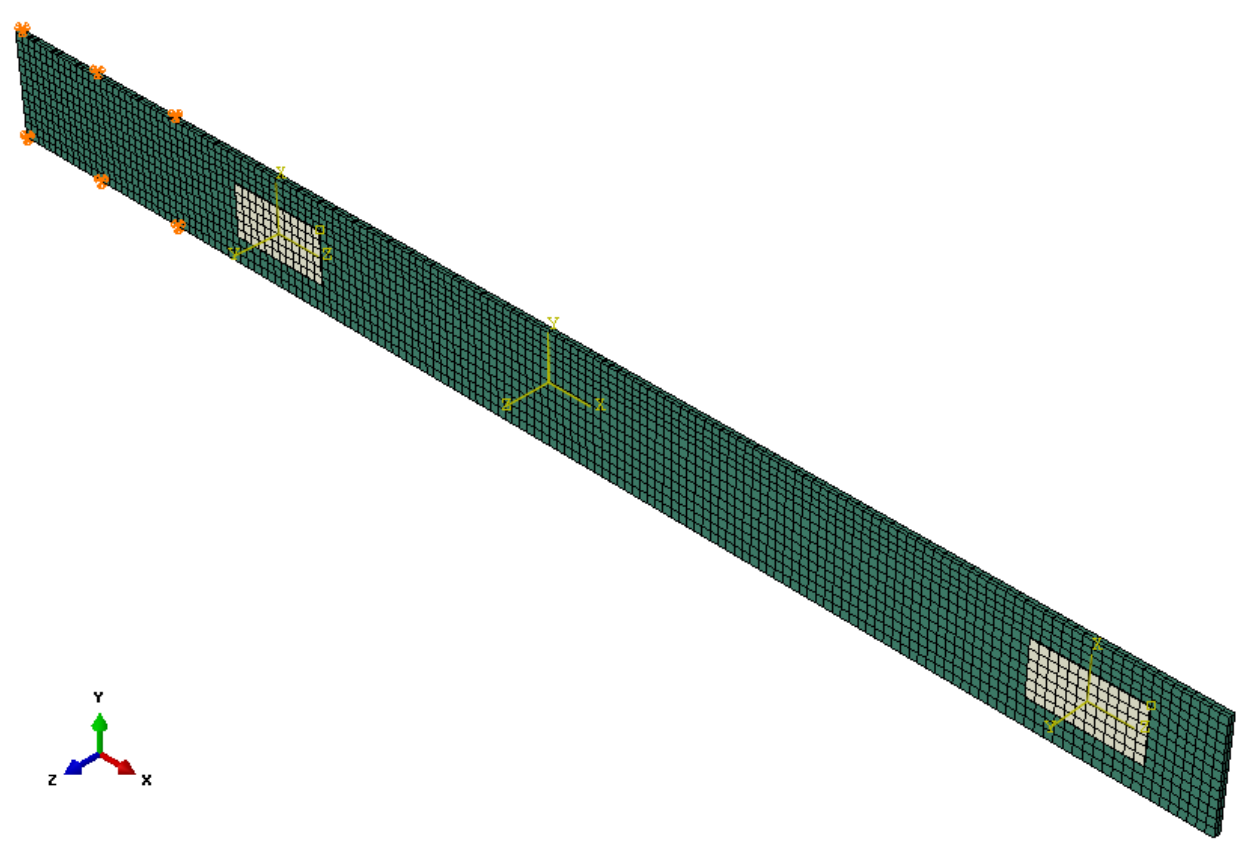

(b)

FIGURA 4.3-15 - (a) Montagem da viga em balanço na base inercial - Ensaio experimental; (b) Modelo computacional da viga com transdutores piezelétricos.

De posse do modelo computacional supracitado, pode-se obter também as Funções de Resposta em Frequência (FRFs) via MEF, que por sua vez foram comparadas com as FRFs experimentais. Sendo que, novamente, desconsideraram-se os efeitos de amortecimento para as análises numéricas. A Figura (4.3-16) evidencia os seis primeiros modos de vibrar da viga com as pastilhas piezelétricas coladas. 


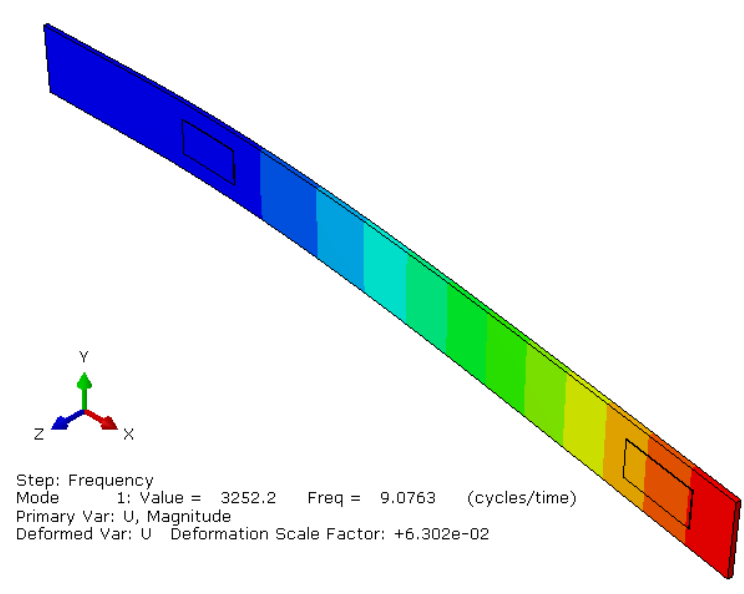

(a)

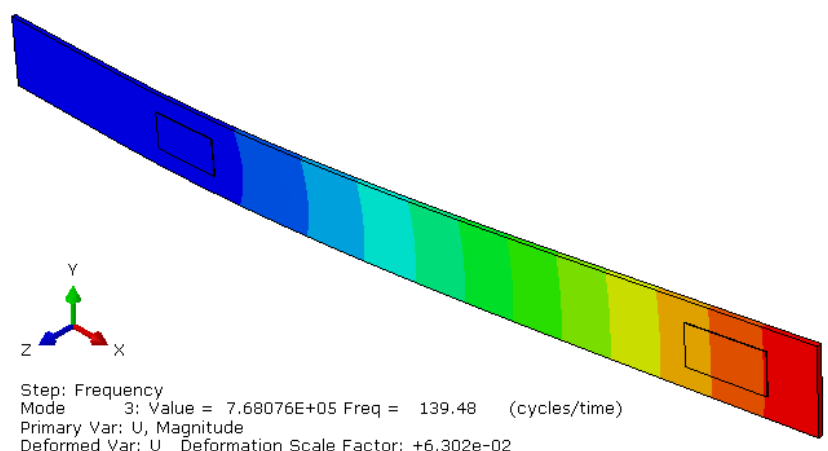

(c)

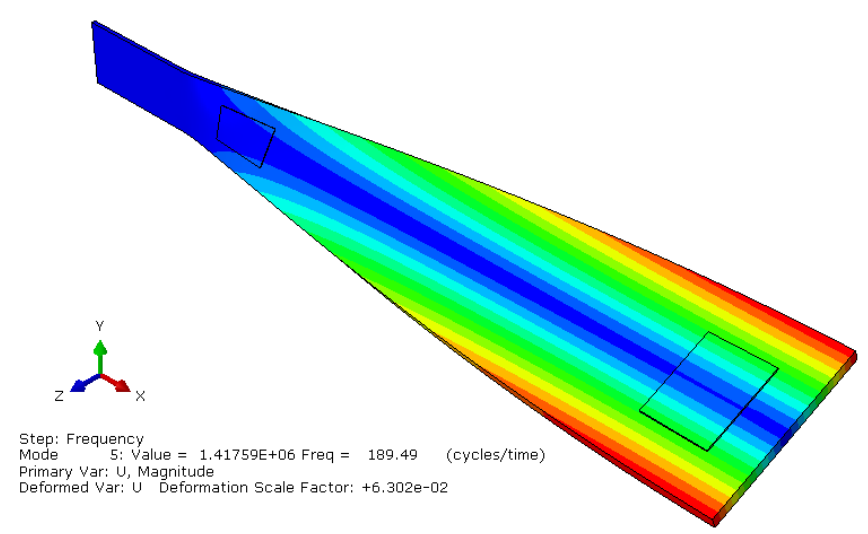

(e)

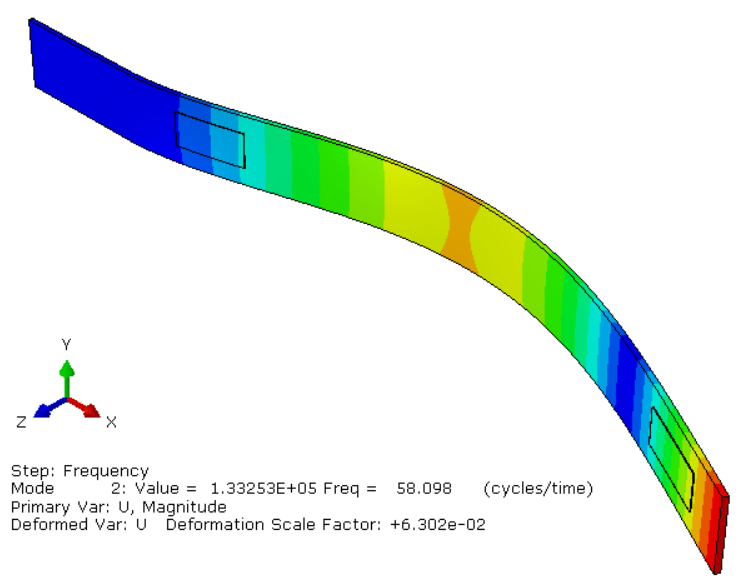

(b)

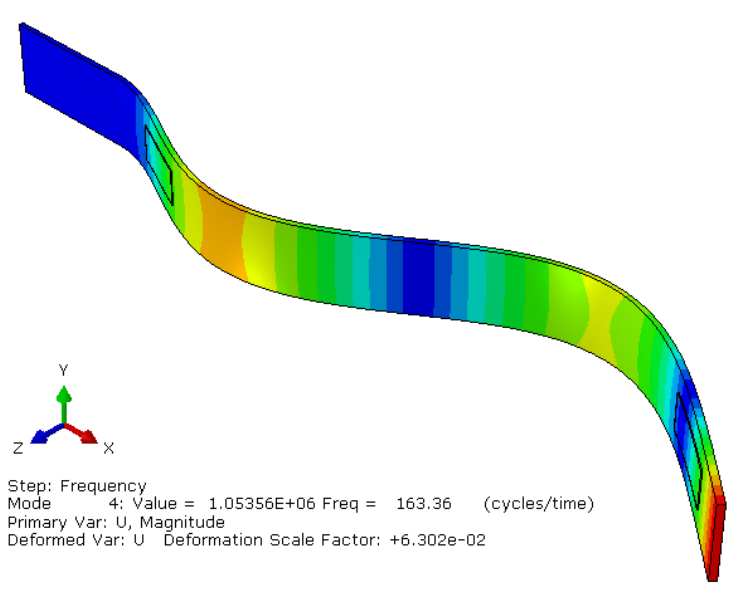

(d)

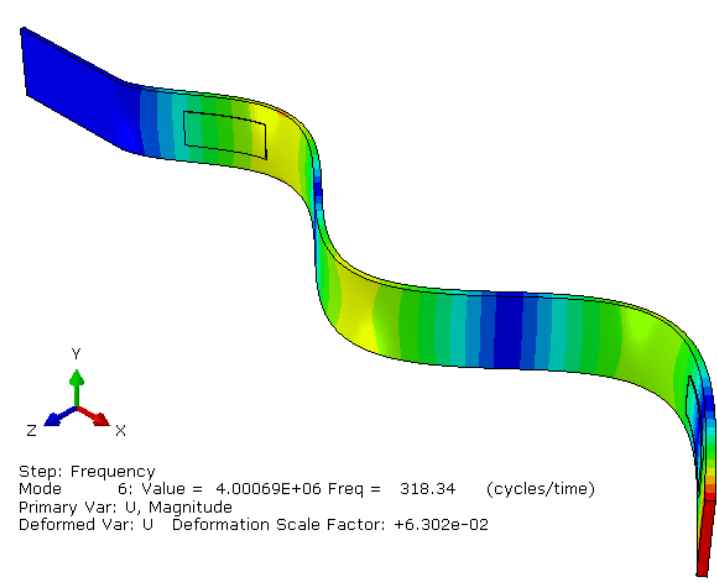

(f)

FIGURA 4.3-16 - Modos de vibrar da viga com os transdutores piezelétricos: (a) Modo 1; (b) Modo 2; (c) Modo 3; (d) Modo 4; (e) Modo 5 e (f) Modo6. 
Os resultados apresentados nas Figuras (4.3-17) e (4.3-18) demonstram que a metodologia apresentada é confiável para prever o comportamento dinâmico de uma "viga inteligente”. Algumas das diferenças apresentadas entre a FRF experimental e a computacional podem ser explicadas pela ausência dos efeitos de amortecimento nas simulações computacionais, condições de contornos reais e aplicadas, incertezas quanto às propriedades do material da viga, bem como, pela própria determinação dos coeficientes efetivos dos transdutores. Observa-se, ainda, que a FRF experimental apresenta certo ruído para a faixa de frequência entre 0 e $100 \mathrm{~Hz}$. Todavia, assume-se que tais ruídos são baixos e, portanto, não influenciam no comportamento da mesma. Além disso, deve-se ressaltar que foram analisadas diferentes situações, tais como:

- Pastilha piezelétrica como atuador: Figura (4.3-17) e (4.3-18)

- Pastilha piezelétrica colocada em circuito aberto: Figuras (4.3-19), (4.3-20), (4.3-21) e (4.3-22) (a ser discutido no próximo item).

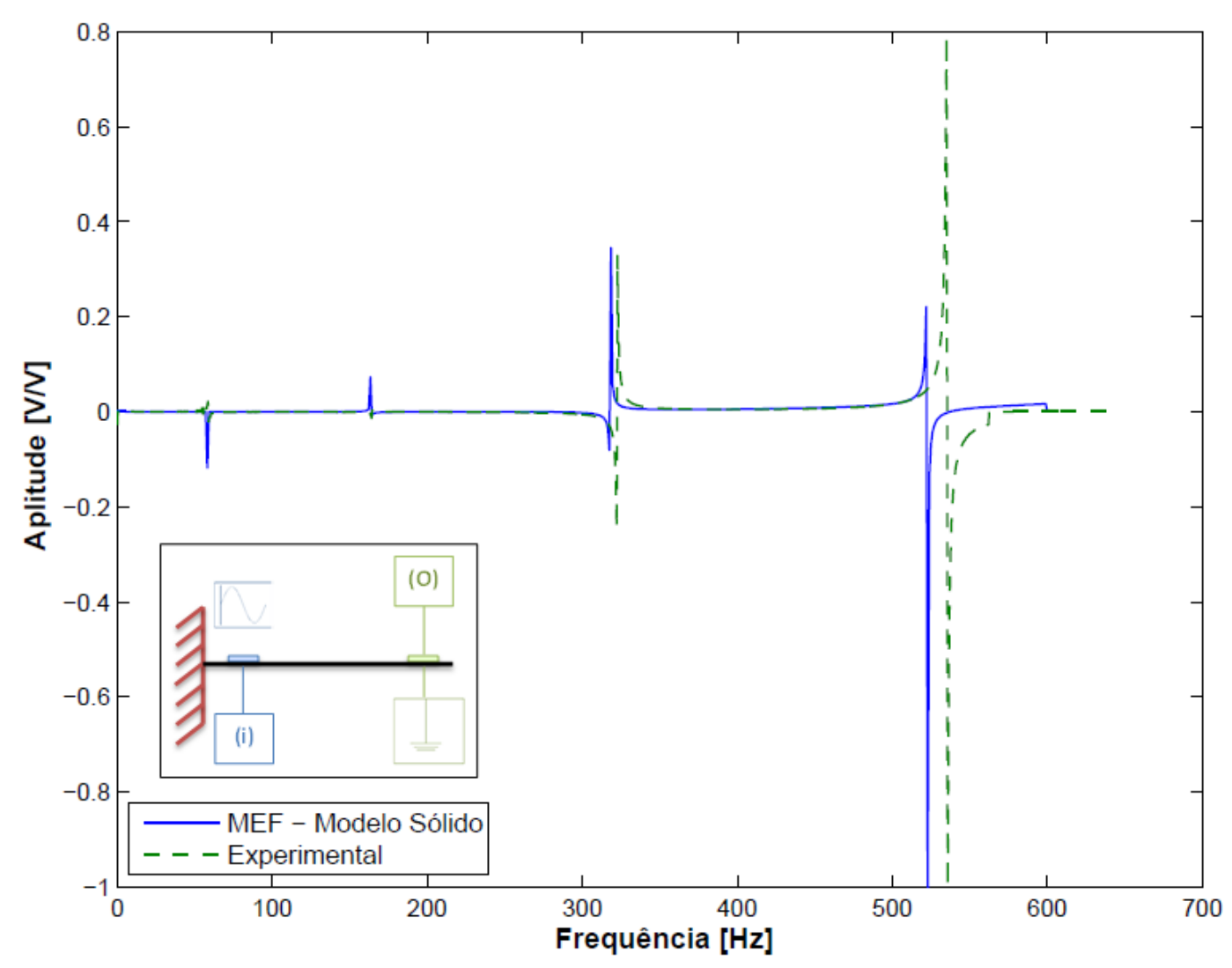

FIGURA 4.3-17 - FRF de uma viga com elementos piezelétricos atuador e sensor, gráfico linear x linear 


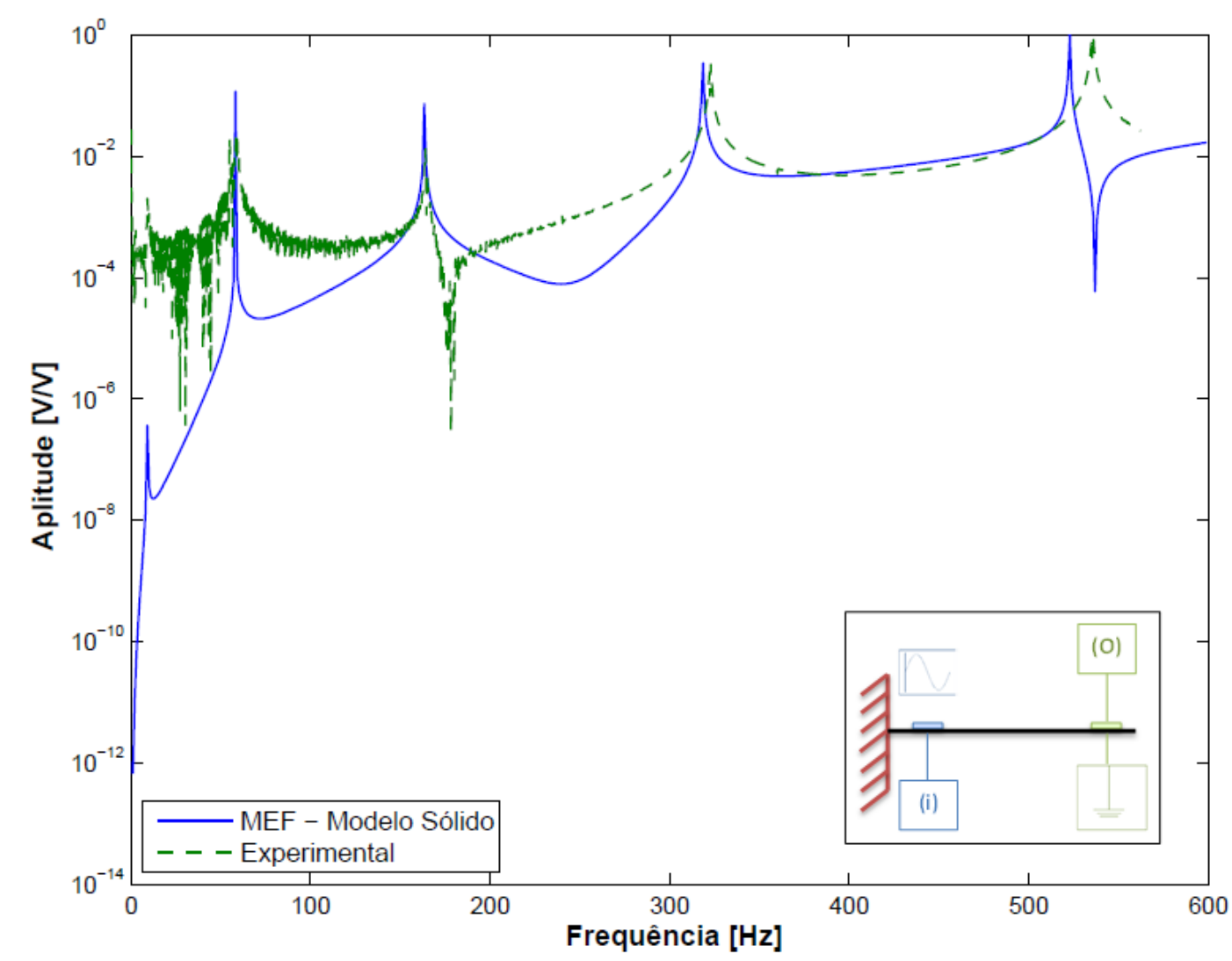

FIGURA 4.3-18 - FRF de uma viga com elementos piezelétricos atuador e sensor, gráfico log x linear

Para uma melhor comparação das FRFs obtidas, a Tabela (4.3-5) apresenta os resultados, considerando as pastilhas piezelétricas como atuador e sensor. Constata-se que a diferença relativa entre os resultados experimental e numérico não é superior a 2,0\%, mostrando, assim, a potencialidade da metodologia proposta. Haja vista que as propriedades efetivas dos transdutores piezelétricos foram obtidas através da mesma.

TABELA 4.3-5 - Valores das frequências para viga com elementos piezelétricos sensor e atuador: computacional $\times$ experimental

\begin{tabular}{lccccccc}
\hline \multicolumn{1}{c}{ Tipo } & $\mathbf{f}_{\mathbf{1}}[\mathbf{H z}]$ & $\mathbf{f}_{\mathbf{2}}[\mathbf{H z}]$ & $\mathbf{f}_{\mathbf{3}}[\mathbf{H z}]$ & $\begin{array}{c}\mathbf{f}_{\mathbf{4}} \\
{[\mathbf{H z}]}\end{array}$ & $\mathbf{f}_{\mathbf{5}}[\mathbf{H z}]$ & $\mathbf{f}_{\mathbf{6}}[\mathbf{H z}]$ & $\mathbf{f}_{\mathbf{7}}[\mathbf{H z}]$ \\
\hline Análise & Flexão & Flexão & $\begin{array}{c}\text { Flexão } \\
\text { Plano XY }\end{array}$ & Flexão & Torção & Flexão & Flexão \\
\hline Experimental & 9,37 & 58,44 & - & 164,37 & - & 322,81 & 535,68 \\
\hline Abaqus Sólido & 9,07 & 58,10 & - & 163,36 & - & 318,34 & 522,70 \\
\hline
\end{tabular}




\subsubsection{ANÁlises ACERCA DOS RESULTADOS COM E SEM ELEMENTOS PIEZELÉTRICOS}

A seguir, as próximas análises consistem em realizar as simulações considerando as pastilhas piezelétricas em circuito aberto. Em se tratando do ensaio experimental, tem-se que um carregamento é aplicado pelo martelo de impacto na viga próximo ao engaste (Figura (4.3-6a)). Ao passo que o sinal de saída é mensurado por acelerômetros colados nas posições P1 e P2. Em se tratando do modelo computacional, aplica-se um carregamento harmônico na viga na mesma posição do ensaio experimental (Figura (4.3-6)), simulando a excitação de um shaker. A referida entrada harmônica é uma força senoidal transversal de amplitude $100 \mathrm{~N}$ concentrada em um nó próximo ao engaste (Figura (4.3-6)). A frequência da força senoidal é aplicada em um intervalo de 0 a $600 \mathrm{~Hz}$, em passos de 1,0Hz.

A Tabela (4.3-6) mostra as diferenças entre os resultados obtidos via procedimento experimental e modelo computacional, considerando os elementos piezelétricos em circuito aberto, para as posições P1 e P2, como evidenciam as Figuras (4.3-19), (4.3-20), (4.3-21) e (4.3-22). Na Tabela (4.3-6) buscou-se verificar a influência das pastilhas piezelétricas coladas à estrutura e, constatou-se que as diferenças relativas não foram superiores a 2,0\%. Estas diferenças estão associadas a diversos fatores como: incertezas nas propriedades do material da viga, condições de contorno reais e aplicadas no modelo, bem como, efeitos de amortecimento desconsiderados no modelo.

TABELA 4.3-6 - Valores das frequências para viga com elementos piezelétricos em circuito aberto

\begin{tabular}{|c|c|c|c|c|c|c|c|}
\hline Tipo & $\mathbf{f}_{1}[\mathbf{H z}]$ & $\mathbf{f}_{2}[\mathrm{~Hz}]$ & $\mathbf{f}_{3}[\mathrm{~Hz}]$ & $\mathbf{f}_{4}[\mathrm{~Hz}]$ & $\mathbf{f}_{5}[\mathrm{~Hz}]$ & $\mathbf{f}_{6}[\mathrm{~Hz}]$ & $\mathbf{f}_{6}[\mathrm{~Hz}]$ \\
\hline Análise & Flexão & Flexão & $\begin{array}{c}\text { Flexão } \\
\text { Plano XY }\end{array}$ & Flexão & Torção & Flexão & Flexão \\
\hline Experimental - P1 & 9,65 & 56,56 & - & 158,75 & 182,68 & 315,31 & 524,06 \\
\hline Abaqus Solido - P1 & 9,03 & 58,36 & - & 163,04 & 188,20 & 321,64 & 522,08 \\
\hline
\end{tabular}




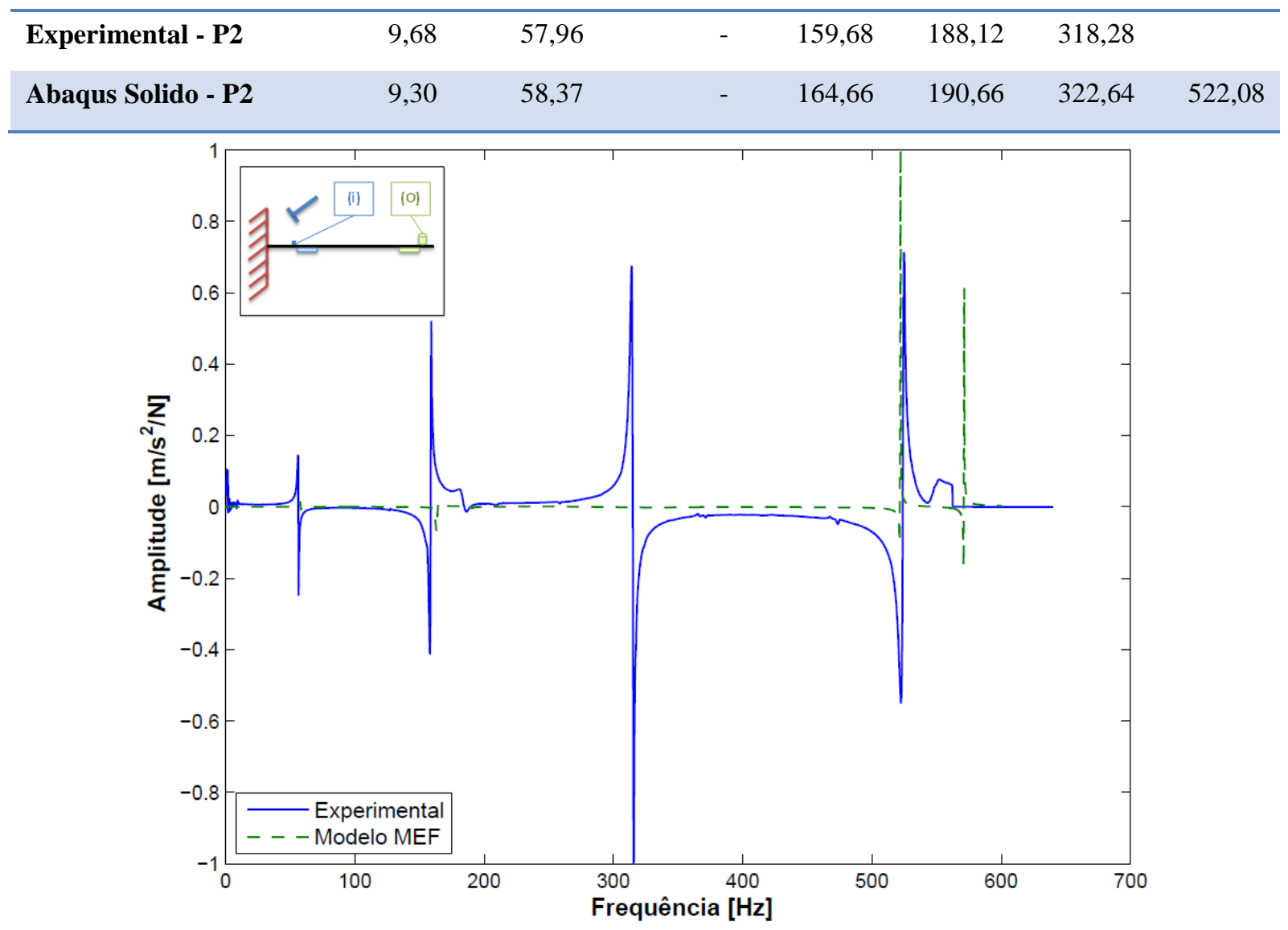

FIGURA 4.3-19 - FRF de uma viga com elementos piezelétricos em circuito aberto, gráfico linear x linear Posição 1

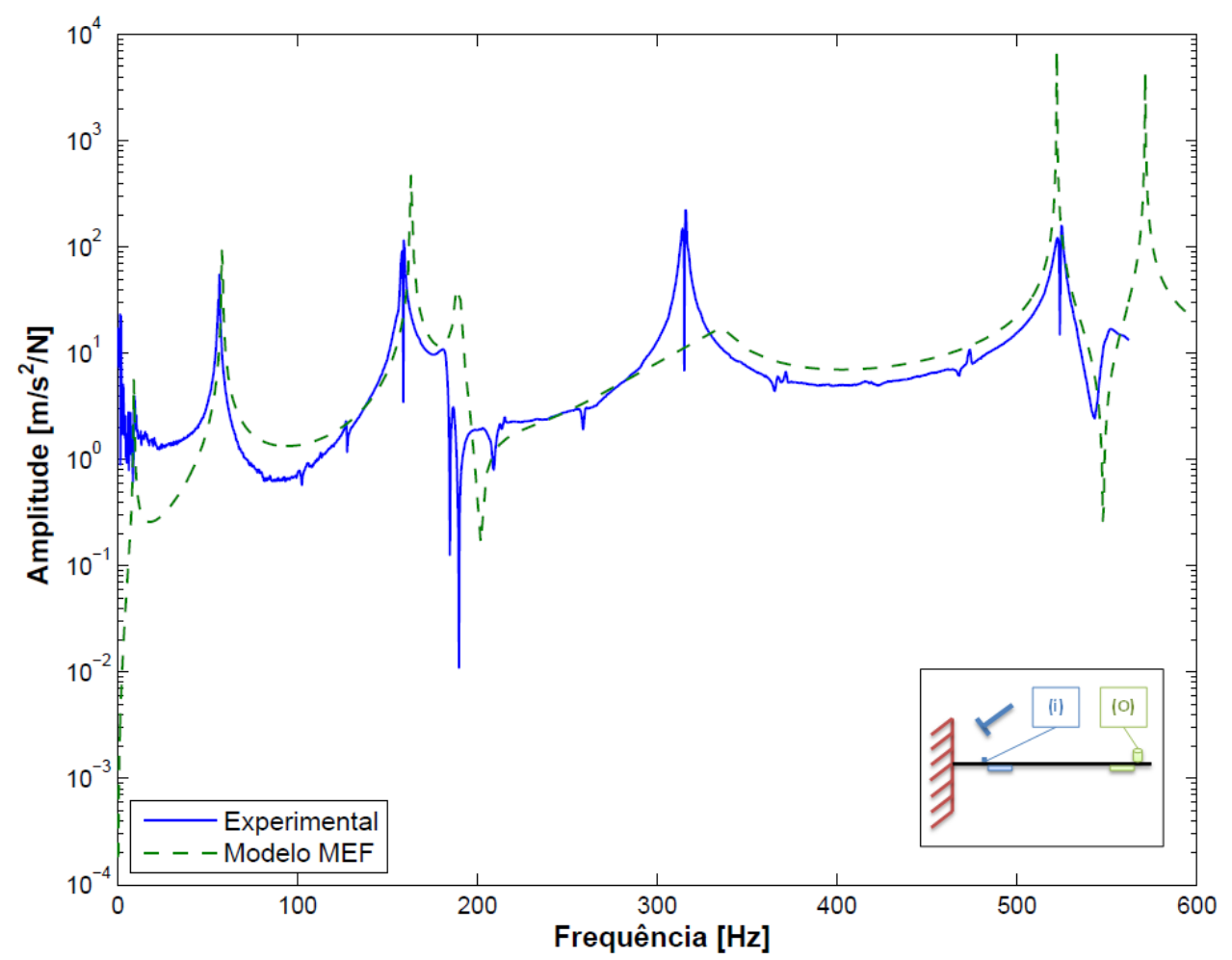


FIGURA 4.3-20 - FRF de uma viga com elementos piezelétricos em circuito aberto, gráfico log x linear Posição 1

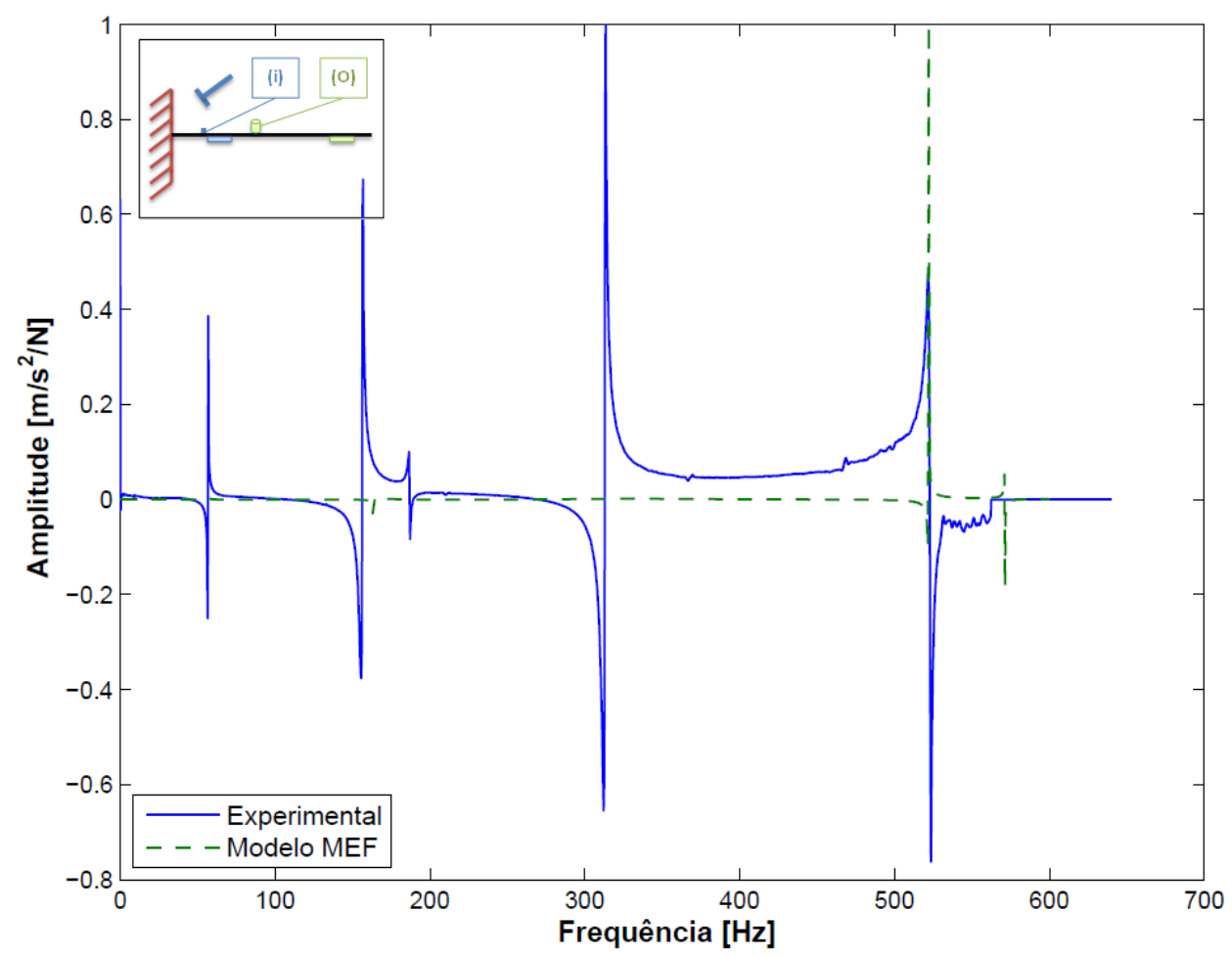

FIGURA 4.3-21 - FRF de uma viga com elementos piezelétricos em circuito aberto, gráfico linear x linear Posição 2

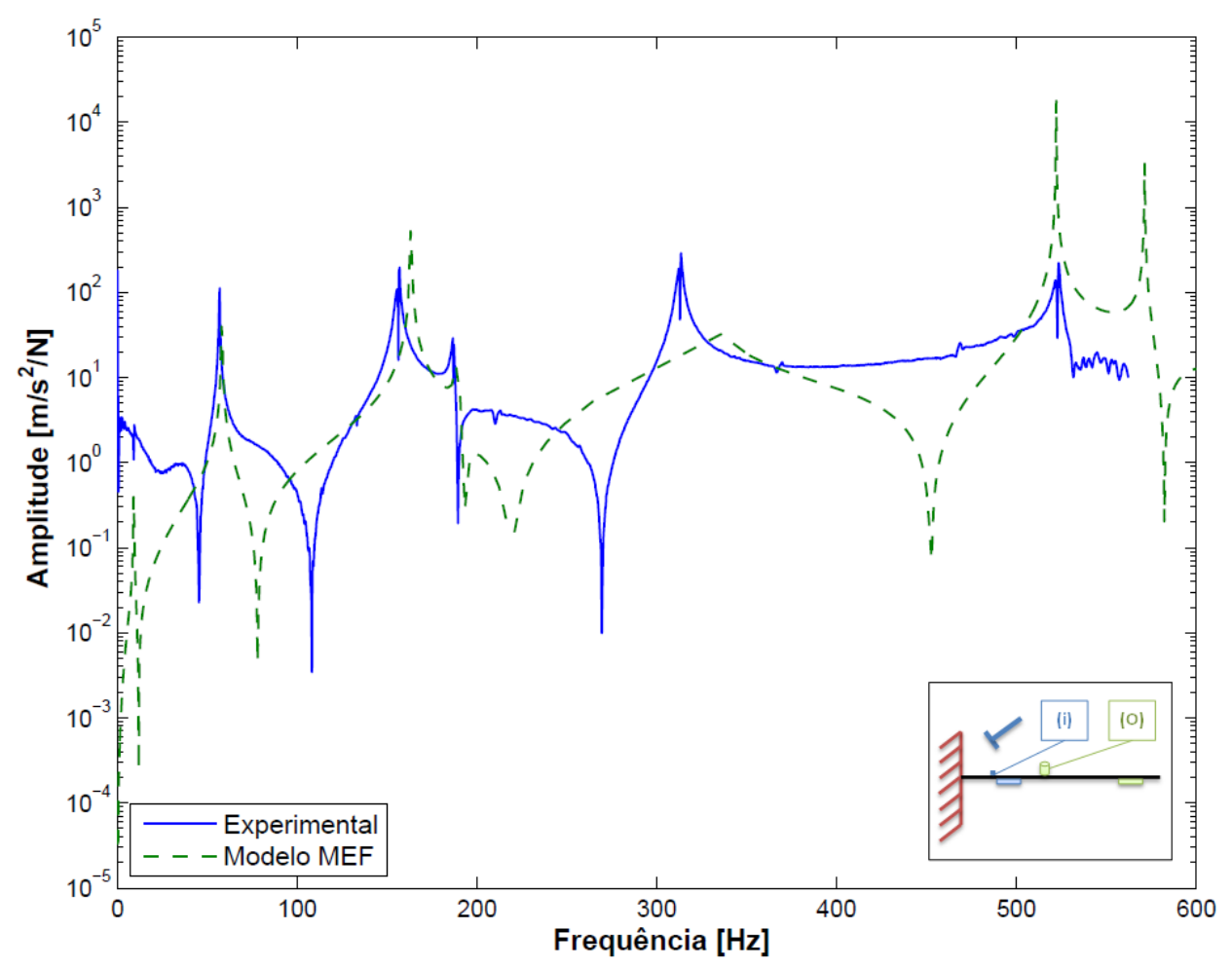


FIGURA 4.3-22 - FRF de uma viga com elementos piezelétricos em circuito aberto, gráfico log x linear Posição 2

A Tabela (4.3-7) apresenta as diferenças de resultados somente entre as FRFs experimentais, comparando a viga sem elementos piezelétricos e com elementos piezelétricos em circuito aberto.

TABELA 4.3-7 - Valores das frequências para viga: sem piezo x com piezo

\begin{tabular}{|c|c|c|c|c|c|c|c|}
\hline Tipo & $\mathbf{f}_{1}[\mathbf{H z}]$ & $\mathbf{f}_{2}[\mathbf{H z}]$ & $\mathbf{f}_{3}[\mathbf{H z}]$ & $\mathbf{f}_{4}[\mathrm{~Hz}]$ & $\mathbf{f}_{5}[\mathrm{~Hz}]$ & $\mathbf{f}_{6}[\mathrm{~Hz}]$ & $\mathbf{f}_{7}[\mathbf{H z}]$ \\
\hline Análise & Flexão & Flexão & $\begin{array}{c}\text { Flexão } \\
\text { Plano XY }\end{array}$ & Flexão & Torção & Flexão & Flexão \\
\hline Exp. Sem Piezo - P1 & 10,31 & 57,18 & - & 161,56 & 183,12 & 318,90 & 529,22 \\
\hline Exp. Com Piezo OC - P1 & 9,65 & 56,56 & - & 158,75 & 182,68 & 315,31 & 524,06 \\
\hline Exp. Sem Piezo - P2 & 9,68 & 57,96 & - & 159,68 & 188,12 & 318,28 & 531,72 \\
\hline Exp. Com Piezo OC - P2 & 9,37 & 56,87 & - & 156,56 & 186,87 & 313,12 & 522,81 \\
\hline
\end{tabular}

Com base na Tabela (4.3-7), verifica-se que a estrutura com as pastilhas piezelétricas apresentaram valores de frequência natural ligeiramente inferiores. Tal fato pode ser explicado, considerando que foi introduzido um componente de massa e amortecimento localizado no sistema (duas pastilhas piezelétricas). Contudo as diferenças entre os modos para os dois casos, com e sem pastilha piezelétrica, considerando um carregamento senoidal de $100 \mathrm{~N}$ aplicado perpendicular à viga, e obtendo os resultados através de acelerômetros colados nas posições P1 e P2, não foram superiores a $2 \%$. Isto implica que a pastilha piezelétrica colada a viga não ocasionou mudanças significativas nas frequências e nos modos de vibrar da estrutura.

As Figuras (4.3-23), (4.3-24), (4.3-25) e (4.3-26) mostram as Funções de Resposta em Frequência para as duas posições (P1 e P2) de aquisição via acelerômetros. Sendo que para as Figuras (4.3-23) e (4.3-25), os gráficos são apresentados em escala linear x linear, e para as Figuras (4.3-24) e (4.3-26), os gráficos são apresentados em escala logarítmica x linear. Devese ressaltar que esta última forma de apresentação é mais usual e, permite uma melhor 
visualização dos fenômenos que ocorrem na estrutura para o carregamento harmônico senoidal aplicado.

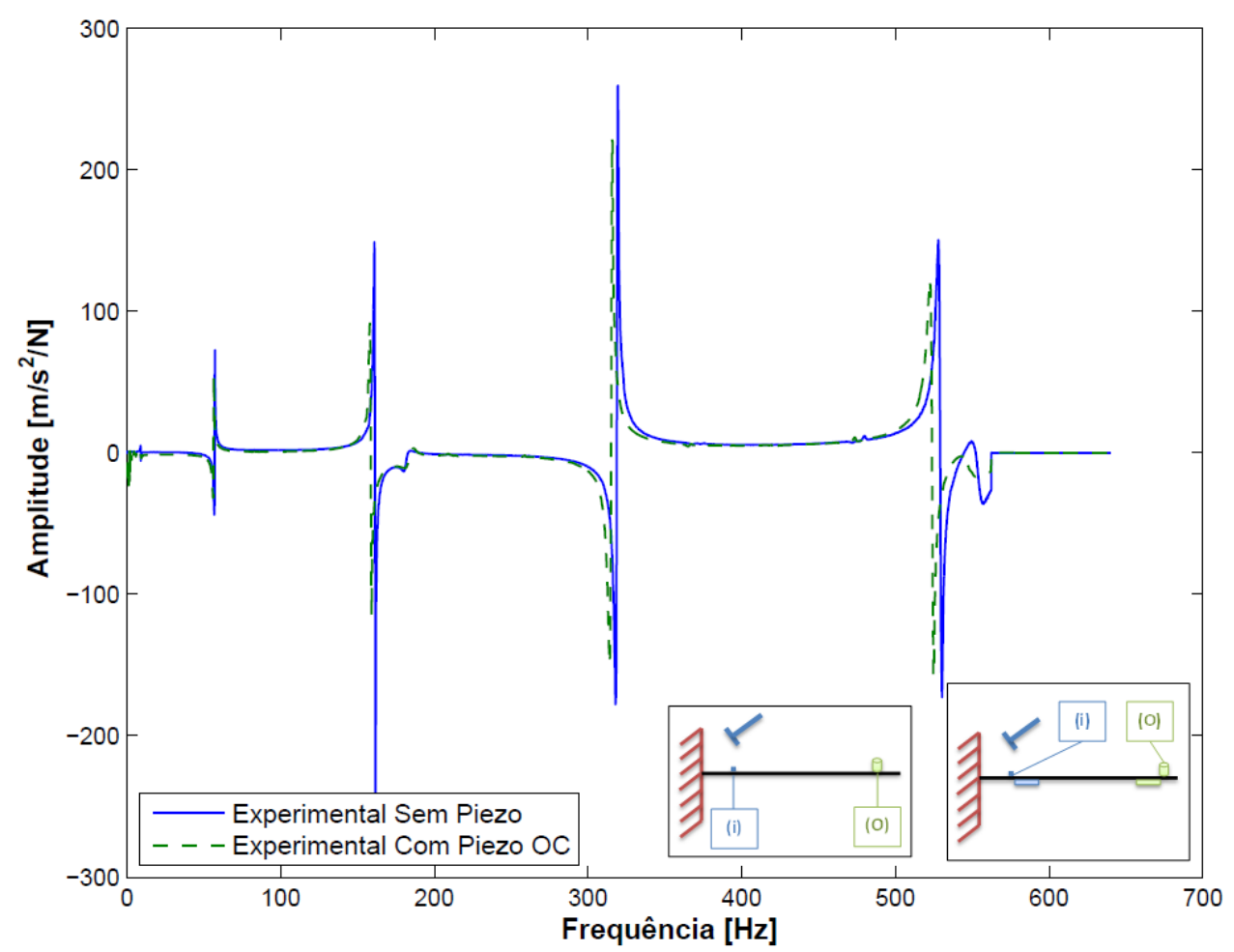

FIGURA 4.3-23 - FRF de uma viga sem elementos piezelétricos e com elementos piezelétricos em curto circuito, gráfico linear x linear - Posição 1

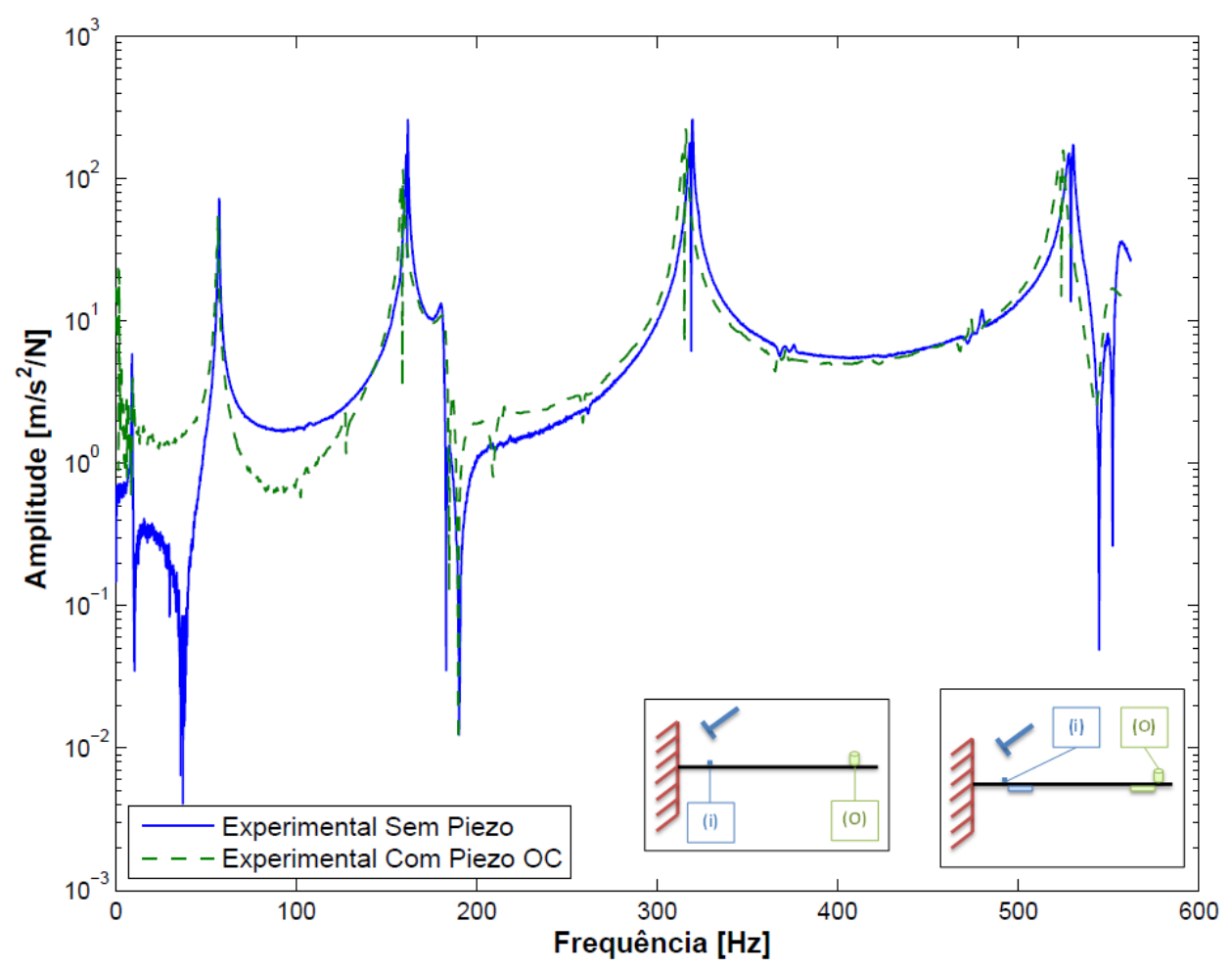


FIGURA 4.3-24 - FRF de uma viga sem elementos piezelétricos e com elementos piezelétricos em curto circuito, gráfico log x linear - Posição 1

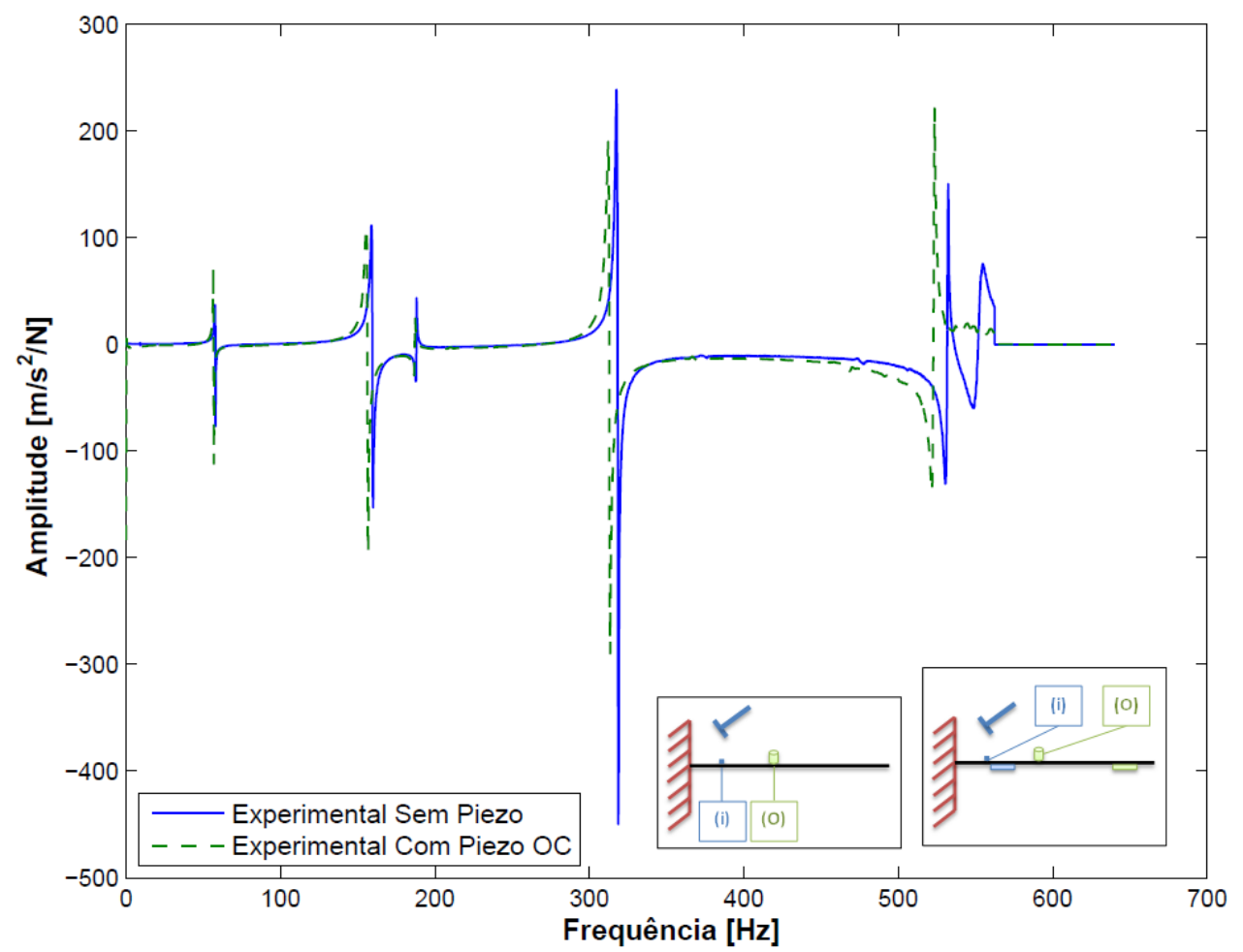

FIGURA 4.3-25 - FRF de uma viga sem elementos piezelétricos e com elementos piezelétricos em curto circuito, gráfico linear x linear - Posição 2

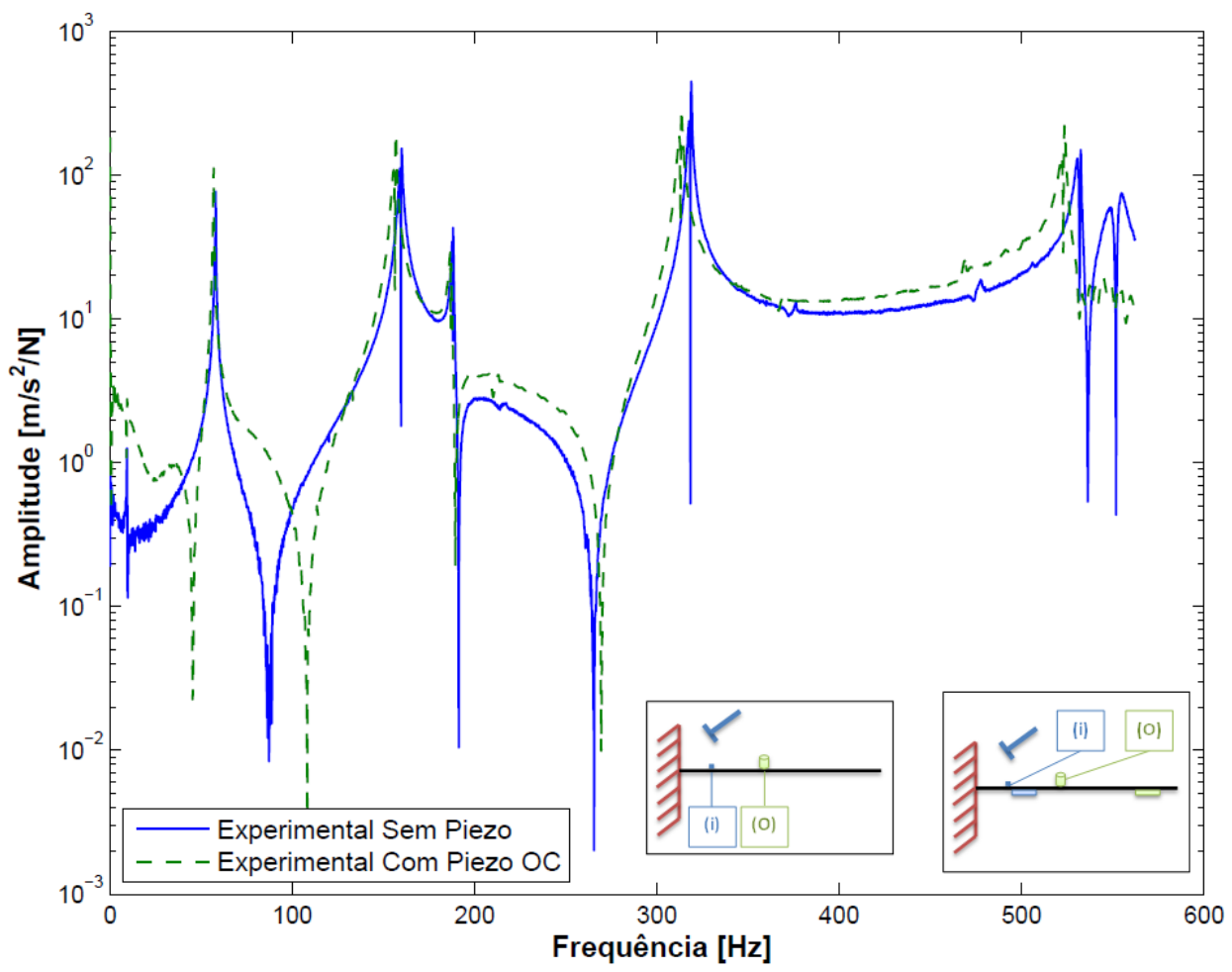

FIGURA 4.3-26 - FRF de uma viga sem elementos piezelétricos e com elementos piezelétricos em curto circuito, gráfico log x linear - Posição 2 
Por fim, realizou-se uma análise comparativa sobre os coeficientes efetivos. As Tabelas (4.3-8) e (4.3-9), juntamente com as Figuras (4.3-27) e (4.3-27) apresentam as diferenças encontras caso os coeficientes fossem variados em 10 vezes e 100 vezes do valor calculado através da metodologia. Como pode-se observar essas variações nos coeficientes produzem variações na resposta do sistema.

TABELA 4.3-8 - Valores das frequências para viga com elementos piezelétricos sensor e atuador: experimental $\times$ computacional $\times$ computacional com erro nos coeficientes

\begin{tabular}{lccccccc}
\hline \multicolumn{1}{c}{ Tipo } & $\mathbf{f}_{\mathbf{1}}[\mathbf{H z}]$ & $\mathbf{f}_{\mathbf{2}}[\mathbf{H z}]$ & $\mathbf{f}_{\mathbf{3}}[\mathbf{H z}]$ & $\begin{array}{c}\mathbf{f}_{\mathbf{4}} \\
{[\mathbf{H z}]}\end{array}$ & $\mathbf{f}_{\mathbf{5}}[\mathbf{H z}]$ & $\mathbf{f}_{\mathbf{6}}[\mathbf{H z}]$ & $\mathbf{f}_{\mathbf{7}}[\mathbf{H z}]$ \\
\hline Análise & Flexão & Flexão & $\begin{array}{c}\text { Flexão } \\
\text { Plano XY }\end{array}$ & Flexão & Torção & Flexão & Flexão \\
\hline Experimental & 9,37 & 58,44 & - & 164,37 & - & 322,81 & 535,68 \\
\hline MEF Sem erro & 9,07 & 58,10 & - & 163,36 & - & 318,34 & 522,70 \\
\hline MEF Erro 10x & 9,01 & 57.09 & & 161,26 & & 301,51 & 485.81 \\
\hline MEF Erro 100x & 11.02 & 60.10 & & 167.28 & & 339.56 & 595.99 \\
\hline
\end{tabular}

TABELA 4.3-9 - Valores das amplitudes máximas para viga com elementos piezelétricos sensor e atuador: experimental $\times$ computacional $\times$ computacional com erro nos coeficientes

\begin{tabular}{|c|c|c|c|c|c|c|c|}
\hline Tipo & $A_{1}[V / V]$ & $A_{2}[V / V]$ & $\begin{array}{c}\mathbf{A}_{3} \\
{[\mathrm{~V} / \mathrm{V}]}\end{array}$ & $\mathbf{A}_{4}[\mathbf{V} / \mathrm{V}]$ & $\begin{array}{c}\mathbf{A}_{5} \\
{[\mathbf{V} / \mathbf{V}]}\end{array}$ & $A_{6}[V / V]$ & $\mathbf{A}_{7}[\mathbf{V} / \mathbf{V}]$ \\
\hline Análise & Flexão & Flexão & $\begin{array}{c}\text { Flexão } \\
\text { Plano XY }\end{array}$ & Flexão & Torção & Flexão & Flexão \\
\hline Experimental & 8.00E-04 & 1.29E-02 & - & $6.40 \mathrm{E}-04$ & - & $1.92 \mathrm{E}-01$ & 2.50E-01 \\
\hline MEF Sem erro & 33.84E-18 & 112.01E-12 & - & 69.81E-12 & - & 76.14E-12 & $948.42 \mathrm{E}-12$ \\
\hline MEF Erro 10x & 3.07E-18 & 23.13E-15 & - & 4.95E-12 & - & $34.26 \mathrm{E}-12$ & $68.12 \mathrm{E}-12$ \\
\hline MEF Erro 100x & 622.09E-21 & $2.66 \mathrm{E}-15$ & - & 231.05E-15 & - & 3.34E-12 & $12.26 \mathrm{E}-12$ \\
\hline
\end{tabular}




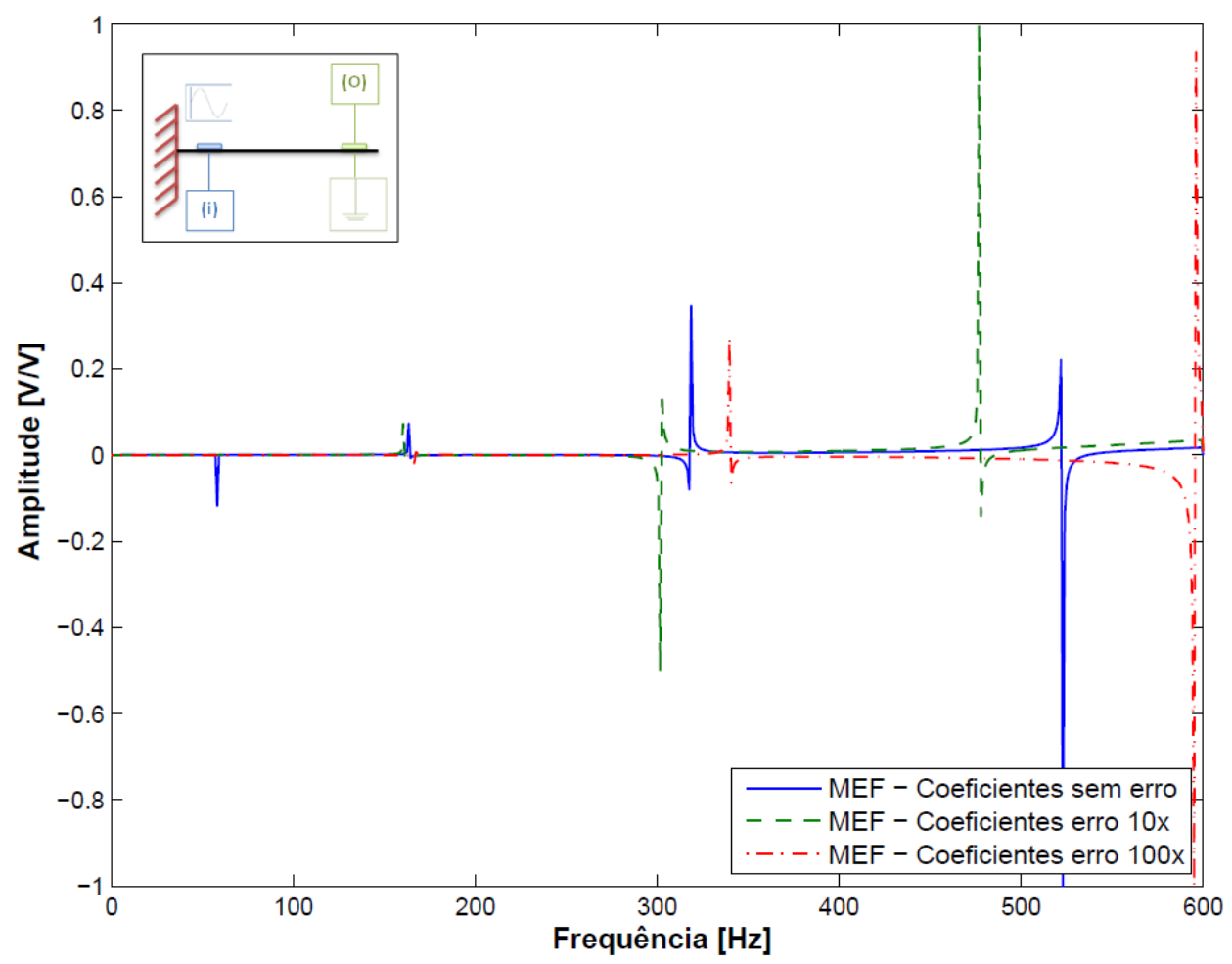

FIGURA 4.3-27 - FRF de uma viga com elementos piezelétricos modificando os coeficientes, gráfico linear $\mathrm{x}$ linear

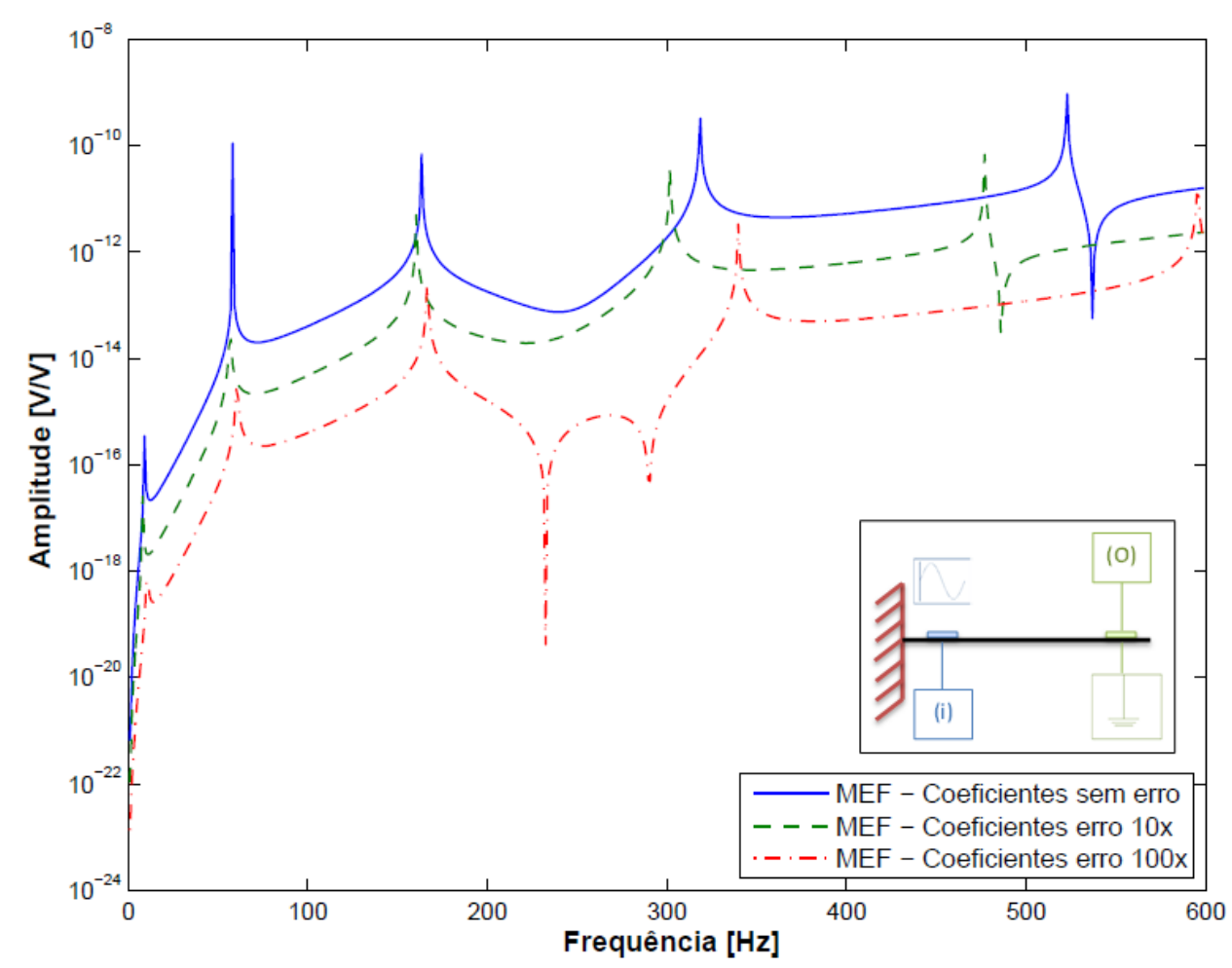

FIGURA 4.3-28 - FRF de uma viga com elementos piezelétricos modificando os coeficientes, gráfico log x linear 


\section{Conclusões e Perspectivas Futuras}

O objetivo principal deste trabalho foi o desenvolvimento de uma metodologia eficiente para determinação das propriedades efetivas de compósitos piezelétricos, sendo estes coeficientes capazes de representar o comportamento de uma estrutura piezelétrica atuando. Inicialmente, verificou-se que a formulação matemática adotada para a referida metodologia, encontra-se detalhada no Capítulo 2. Sendo que a mesma foi baseada nas equações constitutivas piezelétricas que são listadas na norma EE ANSI/IEEE Std. 176-1987. Portanto, as relações constitutivas empregadas no presente trabalho são lineares e relacionam os campos mecânicos e elétricos de materiais piezelétricos. Além disso, consideram uma união perfeita entre a fibra e a matriz.

Os resultados referentes à avaliação da metodologia proposta, ou seja, os Estudos de Caso I e II, evidenciam que os melhores resultados para os coeficientes efetivos estão associados à resposta do compósito na direção da fibra. Por outro lado, os coeficientes associados à resposta nas direções transversais à fibra, demonstram diferenças relativas maiores entre os resultados determinados por métodos analíticos e os obtidos via metodologia proposta. Conclui-se que estes coeficientes são influenciados principalmente pelo comportamento do material compósito ao cisalhamento transversal. Além disso, estes valores diferem para arranjos hexagonais e quadráticos, pois os carregamentos são aplicados de forma diferente. No caso do arranjo quadrático, tem-se que os carregamentos são aplicados em toda a matriz polimérica, ao passo que no arranjo hexagonal, os carregamentos são aplicados tanto sobre a matriz como sobre a fibra piezelétrica.

Concluí-se também que a metodologia é muito sensível quanto à aplicação dos carregamentos e das condições de contorno. Assim, a mesma requer uma atenção especial neste aspecto. Se as condições de contorno não são aplicadas corretamente, então movimentos de corpo rígido podem ocorrer e, assim, prejudicar a qualidade dos cálculos numéricos. No entanto, o emprego de condições de contorno excessivas pode levar a uma situação de overconstraints, e assim, novamente prejudicar a qualidade do resultado computacional. 
Considerando o Estudo de Caso III, sendo que a metodologia foi aplicada para determinar as propriedades efetivas de pastilhas piezelétricas empregadas para monitorar uma viga de alumínio em balanço, verificou-se que as diferenças relativas entre os resultados experimentais e computacionais não foram superiores a 2,0\%, mostrando a potencialidade da metodologia.

Sendo assim, com base nos resultados apresentados, verifica-se que a metodologia desenvolvida é uma alternativa adequada para se determinar coeficientes efetivos de materiais compósitos inteligentes, principalmente para o caso de AFCs. Portanto, tem-se que a metodologia proposta possui potencialidades e limitações, sendo que as suas potencialidades são extremamente atrativas, uma vez que sub-rotinas em Python foram desenvolvidas para automatizar o processo de inserção das condições de contorno, evitando assim, um trabalho demasiadamente grande, bem como, possíveis erros humanos neste tipo de tarefa.

Por fim, a metodologia proposta pode ser empregada não somente para auxiliar no projeto de compósitos inteligentes, auxiliando na escolha do tipo de fibra e na fração volumétrica de fibra mais adequada, mas também, no projeto de estruturas inteligentes, que empregam transdutores piezelétricos para monitorarem sua integridade estrutural.

Como perspectivas futuras têm-se a determinação das propriedades efetivas através de ensaios em laboratório, por exemplo, através de propagação de ondas, bem como a simulação de uma união não perfeita entre a fibra e a matriz. Outro fator relevante é a não aplicação de condições de contorno uniformes, uma vez que os constituintes possuem diferente rigidez, assim aplicar condições separadas para a fibra e a matriz. Além disso, o desenvolvimento de modelos não lineares para obter a resposta de compósitos inteligentes pode gerar benefícios. 


\section{REFERÊNCIAS BIBLIOGRÁFICAS}

ABAQUS, Documentation. Pawtucket: Hibbitt, Karlsson \& Sorensen, 2010.

ABOUDI, J. Mechanics of Composite Materials, A Unified Micromechanical Approach. Elsevier Science Publishers, Amsterdam, 1991.

AGNES, G. S.; INMAN, D. J. Nonlinear piezoelectric vibration absorbers. Smart Materials and Structure. v.5, p.704-714, 1996.

ASM INTERNATIONAL HANDBOOK COMMITTEE. Volume 2 - Properties and Selection: Nonferrous Alloys and Special-Purpose Materials. Ohio: 1992. 3470p.

ASM INTERNATIONAL HANDBOOK COMMITTEE. Volume 21 - Composites. Ohio: 2005. 2605p.

AZZOUZ, M. S.; MEI, C.; BEVAN, J. S.; RO, J. J. Finite element modeling of MFC/AFC actuators and performance of MFC. Journal of Intelligent Material Systems and Structures, v.12, p.601-612, 2001.

BAKHVAlOV, N. S.; PANASENKO, G. P. Homogenization Averaging Processes in Periodic Media. Kluwer, Dordrecht, 1989.

BENDSÙE, M. P.; KIKUCHI N. Generating optimal topologies in structural design using homogenization method. Computer Methods in Applied Mechanics and Engineering v.71, p.197-224, 1988.

BENSSOUSAN, A.; LIONS, J. L.; PAPANICOULAU, G. Asymptotic analysis for periodic structures. Amesterdam, North Holland, 1978.

BENT, A. A.; HAGOOD, N. W. Development of piezoelectric fiber composites for structural actuation. In: Proceeding of the 34th AIAA/ASME/ASCE/AHS Structures, Structural Dynamics and Materials Conference, volume Paper No. 931717-CP, La Jolla, CA, 3625-3638 pp, 1993. 
BENT, A.; HAGOOD, N.; RODGERS, J. Anisotropic actuation with piezoelectric fiber composites. Journal of Intelligent Material Systems and Structures, v.6, p.338-349, 1995.

BENT, A., HAGOOD, N. Piezoelectric fiber composites with interdigitated electrode. J. Intell. Mater. Syst. Struct 8, 903-919, 1997.

BENVENISTE, Y.; DVORAK, G. J. Uniform fields and universal relations in piezoelectric composites. Journal of the Mechanics and Physics of Solids, vol. 40, n. 6, pp. 1295-1312, 1992.

BENVENISTE, Y. Universal Relations in piezoelectric composites with eigenstress and polarization fields, Part I: Binary Media-Local fields and effective behavior. Journal of Applied Mechanics, v.60, p.265-269, 1993.

BERGANDER, A. Control wear testing and integration of stick slip micropositioning. Theses (Phd) - Faculté Sciences Et Techniques de L’ingénieur - Institut de Production et Robotique, École Polytechnique Fédérale de Lausanne, 189p, 2003.

BERGER, H.; GABBERT, U.; KOPPE, H.; RODRIGUEZ-RAMOS, R.; BRAVOCAstillero, J.; GUinOVART-DiAZ, R.; Otero, J. A.; MAUGIN, G. A. Finite element and asymptotic homogenization methods applied to smart composite materials. Computational Mechanics, v.33 p.61-7, 2003.

BERGER, H.; KARI, S.; GABBERT, U.; RODRIGUEZ-RAMOS, R.; GUINOVART, R.; OTERO, J. A.; BRAVO-CASTILLERO, J. An analytical and numerical approach for calculating effective material coefficients of piezoelectric fiber composites. International Journal of Solids and Structures, v. 42, n.21-22, p.5692-5714, 2005.

BERGER, H.; KARI, S.; GABERT, U.; RODRIGUEZ-RAMOS, R.; BRAVOCASTILLERO, J.; GUINOVART-DÍAZ, R.; SABINA, F. J.; MAUGIN, G. A. Unit cell models of piezoelectric fiber composites for numerical and analytical calculation of effective properties. Smart Materials and Structures, vol. 15, pp. 451458, Apr., 2006. 
BERGER, H.; KARI, S.; GABBERT, U.; RODRÍGUEZ-RAMOS R.; BRAVOCASTILLERO, J.; GUINOVART-DÍAZ, R. Evaluation of effective material properties of randomly distributed short cylindrical fiber composites using a numerical homogenization technique. Journal of Mechanics of Materials and Structures, v.2, n.8, p.1561-1570, 2007.

BISCANI, F,; NASSER, H.; BELOUTTAR, S.; CARRERA, E. Equivalent electro-elastic properties of Macro Fiber Composite (MFC) transducers using asymptotic expansion approach. Composites: Part B, v.42, p.444-455, 2011.

BISEGNA, P.; LUCIANO, R. Variational bounds for the overall properties of piezoelectric composites. Journal of the Mechanics and Physics of Solids, v.44, n.4, p.583-602, apr. 1996.

BISEGNA, P.; LUCIANO, R. On methosds for bounding the overall properties of periodic piezoelectric fibrous composites. Journal of the Mechanics and Physics of Solids, v.45, n.8, p.1329-1356, 1997.

BRAVO-CASTILLERO, J. B.; OTERO, J. A.; RODRÍGUEZ-RAMOS, R.; BOURGEAT, A. Asymptotic homogenization of laminated piezocomposite materials. International Journal of Solids and Structures, v.35, p.527-541, 1998.

BRAVO-CASTILLERO, J.; GUINOVART-DIAZ, R.; SABINA, F. J.; RODRÍGUEZRAMOS, R. Closed form expressions for the effective coefficients of a fiberreinforced composite with transversely isotropic constituents - II. Piezoelectric and square symmetry. Mechanics of Materials, v.33, p.237-248, 2001.

BRAVO-CASTILLERO, J.; RODRÍGUEZ-RAMOS, R.; MECHKOUR, H.; OTERO, J. A.; SABINA, F. J. Homogenization of magneto-electro-elastic multilaminated materials. The Quarterly Journal of Mechanics and Applied Mathematics, v.61, n.3, p.311-332, 2008.

BRAVO-CASTILLERO, J. Notas de aula da disciplina de Métodos para o cálculo de leis efetivas de compostos elásticos não lineares. Escola de Engenharia de São Carlos Universidade de São Paulo, São Carlos, Brasil, 2010. 
CHAN, H. L. W.; UNSWORTH, J. Simple model for piezoelectric ceramic/polymer 1-3 composites used in ultrasonic transducer applications. IEEE Transactions on Ultrasonics, Ferroelectrics and Frequency Control, v.36, n.4, p.434-441, jul. 1989.

CHEE, C. Y. K. Static shape control of laminated composite plate smart structures using piezoelectric actuators. Doctor’s Thesis, University of Sydney, Sydney, 213p, 2000.

CHEN, T. Piezoelectric properties of multiphase fibrous composites: some theoretical results. Journal of the Mechanics and Physics of Solids, v. 41, n. 11, p. 1781-1794, 1993.

CHOPRA, I. Review of state of art of smart structures and integrated systems. AIAA Journal, v.40, n.11, p.2145-2187, 2002.

CIORANESCU, D.; PAULIN, J. S. J. Homogenization in open sets with holes. Journal of Mathematical Analysis and Applications, v.71, p.590-607, 1979.

CRAWLEY, E. F. Intelligent structures for aerospace: A technology overview and assessment. AIAA Journal, v.32, n.8, p.1689-1699, 1994.

DERAEMAEKER, A.; BENELECHI, S.; BENJEDDOU, A.; PREUMONT, A. Analytical and numerical computation of homogenized properties of MFCs: application to a composite boom with MFC actuators and sensors. In: Proceedings of III ECCOMAS Thematic Conference on Smart Structures and Materials, Gdansk, Poland, 2007.

DERAEMAEKER, A.; NASSER, H.; BENJEDDOU, A.; PREUMONT, A. Mixing rules for the piezoelectric properties of macro fiber composites. Journal of Intelligent Material Systems and Structures, v.20, n.12, p.1391-1518, 2009.

DERAEMAEKER A.; NASSER H. Numerical evaluation of the equivalent properties of Macro Fiber Composite (MFC) transducers using periodic homogenization. International Journal of Solids and Structures. v.47, p.3272-3285, 2010.

DUNN, M. L.; TAYA, M. Micromechanics predictions of the effective electroelastic moduli of piezoelectric composites. International Journal of Solids and Structures, v.30, n.2, p.161-175, 1993. 
EIRAS, J. A. Sensores Teoria e Aplicacoes - Capitulo 2: Materiais piezelétricos. Grupo de Cerâmicas Ferroelétricas - Departamento de Física - Universidade Federal de São Carlos, Brasil, 2004.

GAUDENZI, P. On the electo mechanical response of active composite materials with piezoelectric inclusions. Computers \& Structures, v.65, n.2, p.157-168, 1997.

GHASEMI-NEJHAD, M. N.; RUSS, R.; POURJALALI, S. Manufacturing and testing of active composite panels with embedded piezoelectric sensors and actuators. Journal of Intelligent Material Systems and Structures, v.16, n.4, p.319-333, apr. 2005.

GHASEMI-NEJHAD, M. N.; POURJALALI, S.; UYEMA, M.; YOUSEFPOUR, A. Finite Element Method for active vibration suppression of smart composite structures using piezoelectric materials. Journal of Thermoplastic Composite Materials, v.13, n.3, p.309-352, may. 2006.

GIURGIUTIU, V. Multifunctional vehicle structural health monitoring opportunities with piezoelectric wafer active sensors, Report University of South Carolina, Mechanical Engineering Department Columbia, SC 29208, 11p, 2010.

GUEDES, J. M.; KIKUCHI, N. Pre and post processing for materials based on the homogenization method with adaptive finite element methods. Computer Methods in Applied Mechanics and Engineering, v.83, p.143-198, 1990.

GUENNAM, A. E.; LUCCIONI, B. M. FE modeling of a closed box beam with piezoelectric fiber composite patches. Smart Materials and Structures. v.15, p.16051615, 2006.

GUINOVART-DÍAZ， R.; BRAVO-CASTILLERO， J.; RODRÍGUEZ-RAMOS， R.; SABINA, F. J.; MARTÍNEZ-ROSADO, R. Overall properties of piezocomposite materials 1-3. Materials Letters, v.48, p.93-98, mar. 2001a.

GUINOVART-DÍAZ， R.; BRAVO-CASTILLERO， J.; RODRÍGUEZ-RAMOS， R.; SABINA, F. J. Closed-form expressions for the effective coefficients of fiberreinforced composite with transversely isotropic constituents. I: Elastic and hexagonal symmetry. Journal of the Mechanics and Physics of Solids, v.49, p.14451462, $2001 b$. 
GUINOVART-DÍAZ， R.; BRAVO-CASTILLERO， J.; RODRÍGUEZ-RAMOS， R.; MARTÍNEZ-ROSADO, R.; SERRANÍA, F.; NAVARRETE, M. Modeling of elastic transversely isotropic composite using the asymptotic homogenization method. Some comparisons with other models. Materials Letters, v.56, p.889-894, nov. 2002.

HAGOOD, N. W.; VON FLOTOW, A. Damping of structural vibrations with piezoelectric materials and passive electrical networks. Journal of Sound and Vibration, v.146, n.2, p.243-268, April, 1991.

HAGOOD, N. W.; KINDEL, R.; GKANDI, K.; GAUDENZI, P. Improving transverse actuation of piezoceramics using interdigitated surface electrodes. In: Proceedings on SPIE, Smart Structures and Materials: Smart Structures and Intelligent Systems, Albuquerque, NM, USA., vol. 1917, pp. 341-35, 1993.

HASSANI, B.; HINTON, E. A review of homogenization and topology optimization I homogenization theory for media with periodic structure. Computers and Structures v.69, p.707-717, 1998.

HORNER, G. Piezoelectric composite device and method for making same. International patent application WO0217407, 2002.

IEEE. NORMA. ANSI /IEEE Std 176-1987: An American National Standard : IEEE Standard on Piezoelectricity. New York, NY, USA: IEEE, 74p, 1987.

ISOLDI, L. A. Analise estática e dinâmica de estruturas delgadas de materiais compostos laminados incluindo materiais piezelétricos. 2008. 2230p. Tese (Phd Engenharia Mecânica) - Escola de Engenharia da Universidade Federal do Rio Grande do Sul, Brasil, 2008.

JIN, K. K.; HUANG, Y.; LEE, Y. H.; HA, S. K. Distribution of Micro Stresses and Interfacial Tractions in Unidirectional Composites. Journal of Composite Materials, v.42, p.1825-1849, 2008.

KAR-GUPTA, R.; VENKATESH, T.A. Electromechanical response of 1-3 piezoelectric composites: effect of poling characteristics. Journal af Applied Physics, v.98, n.5, 14pp., sep. 2005. 
KAR-GUPTA, R.; VENKATESH, T.A. Electromechanical response of 1-3 piezoelectric composites: an analytical model. Acta Materialia, v.55, n.3, p.1093-1108, feb. 2007a.

KAR-GUPTA, R.; VENKATESH, T.A. Electromechanical response of 1-3 piezoelectric composites: a numerical model to assess the effects of fiber distribution. Acta Materialia, v.55, p.1275-1292, 2007b.

LARBI, W.; DEU, J.-F.; OHAYON, R. Finite element formulation of smart piezoelectric composite plates coupled with acoustic fluid. Composite Structures, v.94, p.501509, 2012.

LAZARUS, K.; LUNDSTROM, M.; MOORE, J.; CRAWLEY, E. Packaged strain actuator. US Patent 5687462, 1997.

LEO, D. J. Engineering Analysis of Smart Material Systems. John Wiley \& Sons, Inc: Hoboken, New Jersey, 2007.

MELNYKOWYCZ, M.; KORNMANN, X.; HUBER, C.; BARBEZAT, M.; BRUNNER, A. J. Performance of integrated active fiber composites in fiber reinforced epoxy laminates. Smart Materials and Structures, v.15, p.204-212, 2006.

MIDÉ, QuickPack Products Material Properties \& Spec Sheets, Midé Technology Corporation, Medford MA, USA, 2010.

MORENO, M. E., TITA, V. and MARQUES, F. D. Finite element analysis applied to evaluation of effective material coefficients for piezoelectric fiber composites. In: BRAZILIAN SYMPOSIUM ON AEROSPACE ENG. \& APPLICATIONS, 2009, São José dos Campos, Brazil. Anais... 2009.

MORENO, M. E., TITA, V. and MARQUES, F. D. Influence of boundary conditions on the determination of effective material properties for active fiber composites. In: PAN-AMERICAN CONGRESS OF APPLIED MECHANICS, 2010, Foz do Iguaçu, Brazil. Anais... 2010.

NAN, C.-W. Physics of inhomogeneous inorganic materials, Progress in Materials Science, v.37, p.1-116, 1993a. 
NAN, C.-W. Comment on 'relationships between the effective properties of transversely isotropic piezoelectric composites' : K. Schulgasser (1992) j. mech. phys. Solids, v.40, p.473-479, Journal of the Mechanics and Physics of Solids, v.41, p.1567-1570, 1993b.

NAN, C.-W.; JIN, F.-S. Multiple-scattering approach to effective properties of piezoelectric composites. Phisical Review B, v.48, p.8578-8582, 1993c.

NAN, C.-W.; CAI, K.-F.; YUAN, R.-Z. A relation between multiplescattering theory and micromechanical models of effective thermoelastic properties. Ceramics International, v.22, p.457-461, 1996.

NEWNHAM, R. E.; SKINNER, D. P.; CROSS, L. E. Connectivity and piezoelectricpyroelectric composites. Materials Research Bulletin, v.13, p.525-536, 1978.

ODEGARD, G. M. Constitutive modeling of piezoelectric polymer composites. Acta Materialia, v.52, p.5315-5330, 2004.

PAGANI JR, C. C.; TRINDADE, M. A. Optimization of modal filters based on arrays of piezoelectric sensors. Smart Materials and Structures, v.18, p.095046+, 2009.

PAIK, S. H.; YOON, T. H.; SHIN, S. J.; KIM, S. J. Computational Material Characterization of Active Fiber Composite. Journal of Intelligent Material Systems and Structures, v.18, P.19-28, 2007;

PANASENKO, G. P. Multi-Scale Modelling for Structures and Composites. Springer 2005.

PANDA, S.; RAY, M. C. Nonlinear analysis of smart functinally graded plates integrated with a layer of piezoelectric fiber reinforced composite. Smart Materials and Structures, v.15, p.1595-1604, 2006.

PANDA, S.; RAY, M. C. Active constrained layer damping of geometrically nonlinear vibrations of functionally graded plates using piezoelectric fiber-reinforced composites. Smart Materials and Structures, v.17, 15 pp. 2008 .

PANDA, S.; RAY, M.C. Nonlinear finite element analysis of functionally graded plates integrated with patches of piezoelectric fiber reinforced composite. Finite Elements in Analysis and Design, v.44, p.493-504, 2008b. 
PARADIES, R.; MELNYKOWYCZ, M. Numerical stress investigation for piezoelectric elements with circular cross section and interdigitated electrodes. Journal of Intelligent Material Systems and Structures, v.18, p.963-972, sep. 2007.

PÉREZ-FERNANDEZ, L. D. Un enfoque integrador de métodos asintóticos y variacionales para la evaluación del comportamiento efectivo de materiales compuestos magneto-electro-elásticos no lineales provistos de una estructura periódica. 2009. 120p. Tesis (Phd en Ciencias Matemáticas) - Instituto de Cibernética, Matemática y Física, Departamento de Física Aplicada, La Habana, Cuba, 2009.

PETTERMANN, H. E.; SURESH, S. A comprehensive unit cell model: a study of coupled effects in piezoelectric 1-3 composites. International Journal of Solids and Structures, v.37, n.39, p.5447-5464, sep. 2000.

POIZAT, C.; SESTER, M. Effective properties of composites with embedded piezoelectric fibres. Computational Materials Science, v.16, n.1-4, p.89-97, 1999.

RAO, C. V. M.; PRASAD, G. Characterization of 1-3 piezoelectric polymer composites a numerical and analytical evaluation procedure for thickness mode vibrations. Condensed Matter Physics v.13, n.1, p.13703: 1, 2010.

RODRÍGUEZ-RAMOS, R.; SABINA， F. J.; GUINOVART-DÍAZ， R.; BRAVOCATILLERO, J. Closed form expressions for the effective coefficients of a fiberreinforced composite with transversely isotropic constituents - I. Elastic and square symmetry. Mechanics of Materials, v.33, p.223-235, 2001.

SABINA, F. J; RODRÍGUEZ RAMOS, R.; BRAVO CASTILLERO, J.; GUINOVART DÍAZ, R. Closed-form expressions for the effective coefficients of fibre-reinforced composite with transversely isotropic constituents-II: Piezoelectric and hexagonal symmetry. Journal of the Mechanics and Physics of Solids, v.49, p.1463-1479, 2001.

SANCHEZ-PALENCIA, E. Non Homogeneous Media and Vibration Theory. Lecture Notes in Physics. vol. 127. Springer, Berlin, 1980.

SCHULGASSER, K. Relationships between the effective properties of transversely isotropic piezoelectric composites. Journal of the Mechanics and Physics of Solids, v.40, p.473-479, 1992. 
SEVOSTIANOV, I.; LEVIN, V.; KACHANOV, M. On the modeling and design of piezocomposites with prescribed properties. Archive of Applied Mechanics, v.71, p.733-747, 2001.

SHINDE VISHAL, V., Development of Active Fiber Sensors and a Data Acquisition Module for a Structural Neural System, Thesis (Masters of Science) - University of Cincinnati, Mechanical Engineering, Cincinnati, Ohio,123p, 2005.

SILVA E. C. N.; FONSECA, J. S. O.; KIKUCHI, N. Optimal Design of Piezoelectric Microstructures. Computational Mechanics, Estados Unidos, v.19, n.5, p.397-410, 1997.

SILVA, E. C. N.; FONSECA, J. S. O.; KIKUCHI, N. Optimal design of periodic piezocomposites. Computer Methods in Applied Mechanics and Engineering, v.159, n.1-2, p.49-77, jul. 1998.

SILVA, E. C. N.; KIKUCHI, N. Design of piezoelectric transducers using topology optimization. Smart Materials and Structures, v.8, p.350-364, 1999.

SILVA, F. C. G., Modelagem de uma placa de materiais compósitos e piezelétricos pelo método dos elementos finitos. Aplicação de controle de vibração, Dissertação (Mestrado) - Universidade Federal de Santa Catarina, Programa de Pós-Graduação em Engenharia Mecânica, 175p, 2007.

SMITH, W. A.; AULD, B. A. Modeling 1-3 composite-piezoelectrics: thickness-mode oscillations. IEEE Transactions on Ultrasonics, Ferroelectrics and Frequency Control, v.38, n.1, p.40-47, jan. 1991.

SODANO, H. A.; Macro-Fiber Composites for Sensing, Actuation and Power Generation. Thesis (Phd), Faculty of the Virginia Polytechnic Institute and State University, Blacksburg, Virginia, United States, 2003.

SUZUKI, K.; KIKUCHI, N. A homogenization method for shape and topology optimization. Computer Methods in Applied Mechanics and Engineering, v.93, p.291-318, 1991.

TAN, P.; TONG, L. Micro-electromechanics models for piezoelectric-fiber-reinforced composite materials. Composites Science and Technology, v.61, p.759-769, 2001. 
TAN, X. G.; VU-QUOC, L. Optimal solid shell element for large deformable composite structures with piezoelectric layers and active vibration control. International Journal for Numerical Methods in Engineering, v.64, n.15, p.1981-2013, dec. 2005.

TEPLY, J. L.; DVORAK, G. C. Bounds on overall instantaneous properties of elastoplastic composites. Journal of the Mechanics and Physics of Solids, v.36, n.1, p.29-58, 1988.

TRINDADE, M. A.; BENJEDDOU A. Modelling and Characterization of Shear Actuated Piezoelectric Fibre Composites. In: Tenth International Conference On Computational Structures Technology, 2010, Stirlingshire, Scotland. Anais... 2010.

TRINDADE, M. A.; BENJEDDOU A. Finite element homogenization technique for the characterization of d15 shear piezoelectric macro-fibre composites. Smart Materials and Structures, v.20, n.7, 075012, 2011.

WIERACH, P. Elektromechanisches funktionsmodul. German Patent DE 10051784 C1, 2002.

WIERACH, P. Low profile piezo actuators based on multilayer technology. In: Proceedings of 17th International Conference on Adaptive Structures and Technologies (ICAST2006), Taipei, Taiwan, October, 2006.

WILKIE, W. K.; HIGH, W. J.; MIRICK, P. H.; FOX, R. L.; LITTLE, B. D.; BRYANT, R. G.; HELLBAUM, R. F.; JALINK, A. J. Low-cost piezocomposite actuator for structural control applications. In: Industrial and Commercial Applications of Smart Structures Technologies. In: SPIE 7th International Symposium on Smart Structures and Materials, Newport Beach, California, 2000.

WILLIAMS, B. R.; PARK, G.; INMAN, D. J.; WILKIE, W. K. An overview of composite actuators with piezoceramic fibers. In: Proceedings of 20th International Modal Analysis Conference (IMAC), Los Angeles, USA, 2002a.

WILLIAMS, B. R.; GRIMSLEY, B. W.; INMAN, D. J.; WILKIE, W. K. Manufacturing and mechanics-based characterization of Macro Fiber Composite actuators. In: Proceedings of IMECE 02, New Orleans, Louisiana, USA, 2002b. 
XIA, Z.; ZHANG, Y.; ELLYIN, F. A unified periodical boundary conditions for representative volume elements of composites and applications. International Journal of Solids and Structures v.40, p1907-1921, 2003.

ZAMBRAnO, M. V.; PEREIRA, A. H. A. Curso de Materiais e Dispositivos Piezelétricos:

Fundamentos e Desenvolvimento. ATCP do Brasil Soluções Piezelétricas, São Carlos, Brasil, 2004. 


\section{ANEXOS}

\subsection{ANEXO 1 - TEOREMA DAS MÉDiAS}

Seja compósitos periódicos que ocupam um domínio com fronteira suave a volume, e que se consegue obter a repetibilidade da célula unitária. Este compósito é formado por $\mathrm{N}$ fases que se assume acoplamento perfeito, ou seja, todas das magnitudes contínuas através da superfície de contato entre as faces. Sabe-se que a homogeneização de um compósito se refere a encontrar a dependência funcional entre as médias das variáveis do modelo que descreve o comportamento físico. Anteriormente ao passo da homogeneização consiste em conhecer as médias em termos das relações superficiais das variáveis, ou seja, as condições de contorno aplicadas ao compósito, independentemente das restrições constitutivas. Portanto, um VER (Volume Elementar Representativo) de volume V sob a ação de um campo de tensões ou deformações macroscopicamente homogêneas, a tensão média se define por:

$$
\left\langle T_{i j}\right\rangle=\frac{1}{|V|} \int_{A} t_{i}^{0}\left(x_{j}\right) d S
$$

onde $T_{i j}$ é o tensor de tensões infinitesimal. $E$ a deformação média é dada por:

$$
\left\langle S_{i j}\right\rangle=\frac{1}{2|V|} \int_{A}\left(u_{i}^{0} n_{j}+u_{j}^{0} n_{i}\right) d S
$$

sendo $S_{\mathrm{ij}}$ o tensor de deformação infinitesimal. E a tensão elétrica média dada por: 


$$
\left\langle D_{m}\right\rangle=\frac{1}{|V|} \int_{A} d^{0}\left(x_{m}\right) d S
$$

onde $\mathrm{D}_{\mathrm{i}}$ é o vetor campo elétrico infinitesimal. $\mathrm{E}$ o deslocamento elétrico médio dado por:

$$
\left\langle E_{m}\right\rangle=\frac{1}{|V|} \int_{A} \varphi^{0}\left(n_{m}\right) d V
$$

sendo $E_{\mathrm{i}} \mathrm{O}$ vetor deslocamento elétrico infinitesimal.

\section{Condições de Contorno Homogêneas}

A aplicação de condições de contorno homogêneas sobre a superfície de um corpo homogêneo produz um campo homogêneo. Tais condições de contorno são obtidas impondo deslocamentos na superfície R na forma:

$$
u_{i}(R)=S_{i j}^{0} \quad x_{j}
$$

onde $\mathrm{S}_{\mathrm{ij}}{ }^{0}$ são deformações constantes e, $\mathrm{x}_{\mathrm{j}}$ as componentes do vetor normal unitário exterior a $\mathrm{R}$. As trações $\mathrm{t}_{\mathrm{i}}$ podem ser impostas sobre $\mathrm{R}$ de tal maneira que,

$$
t_{i}=T_{i j}^{0} \quad n_{j}
$$

onde $\mathrm{T}_{\mathrm{ij}}{ }^{0}$ são tensões constantes e $\mathrm{n}_{\mathrm{j}}$ as componentes do vetor normal unitário exterior a $\mathrm{R}$. $\mathrm{O}$ “deslocamento elétrico” $\lambda$ pode também ser imposto sobre R na forma de:

$$
\lambda(R)=-E_{i}^{0} \quad x_{i}
$$

onde $\mathrm{E}_{\mathrm{i}}{ }^{0}$ são os deslocamentos elétricos constantes e $\mathrm{x}_{\mathrm{i}}$ as componentes do vetor normal unitário exterior a R. 


$$
\phi=D_{j}^{0} n_{j}
$$

onde $\mathrm{D}_{\mathrm{i}}{ }^{0}$ são os deslocamentos elétricos constantes e, $\mathrm{x}_{\mathrm{i}}$ as componentes do vetor normal unitário exterior a R.

\section{Teorema da Deformação Média}

Este teorema versa que a média das deformações sobre $\mathrm{V}$ para condições de contorno do tipo descrito pela Equação (7.5) coincide com as deformações constantes $\mathrm{S}_{\mathrm{ij}}{ }^{0}$, ou seja: $\left\langle S_{i j}^{0}\right\rangle=S_{i j}^{0}$.

A seguir, o referido teorema será demonstrado para o caso mais simples de um compósito bifásico cujas componentes ocupam os volumes $\mathrm{V}_{1}$ e $\mathrm{V}_{2}$, de maneira que $\mathrm{V}=\mathrm{V}_{1}+$ $\mathrm{V}_{2}$. As relações de Cauchy sobre cada fase $\alpha=1,2$ são:

$$
S_{i j}^{(\alpha)}=\frac{1}{2}\left(u_{i, j}^{(\alpha)}+u_{j, i}^{(\alpha)}\right)
$$

Substituindo a Equação (7.9) na Equação (7.2) conduz-se a,

$$
2 V\left\langle S_{i j}\right\rangle=\int_{A}\left(u_{i, j}^{1}+u_{j, i}^{1}\right) d A+\int_{A}\left(u_{i, j}^{2}+u_{j, i}^{2}\right) d A
$$

Através do uso do Teorema de Gauss obtém-se:

$$
\int_{V} u_{i, p} d V=\int_{A} u_{i} n_{p} d A
$$

Implica que,

$$
2 V\left\langle S_{i j}\right\rangle=\int_{A_{1}}\left(u_{i}^{1} n_{j}+u_{j}^{1} n_{i}\right) d A+\int_{A_{2}}\left(u_{i}^{2} n_{j}+u_{j}^{2} n_{i}\right) d A
$$


Sendo $R_{1}$ e $R_{2}$, as superfícies que limitam as fases 1 e 2 , respectivamente. As superfícies $\mathrm{R}_{1}$ e $\mathrm{R}_{2}$ contém a interface $\mathrm{R}_{12}$ e a superfície externa $\mathrm{R}$. Nota-se assim que os hemisférios norte ( $\mathrm{R}_{1}$ ' para a fase 1$)$ e sul ( $\mathrm{R}_{2}$ ' para a fase 2$)$ da esfera estão separados por um círculo, que é o equador dado por $\mathrm{R}_{12}$. Assim, tem-se que $\mathrm{R}_{1}=\mathrm{R}_{1}{ }^{\prime}+\mathrm{R}_{12}, \mathrm{R}_{2}=\mathrm{R}_{2}{ }^{\prime}+\mathrm{R}_{12}$ e $\mathrm{R}$ $=\mathrm{R}_{1}^{\prime}+\mathrm{R}_{2}^{\prime}$ ).
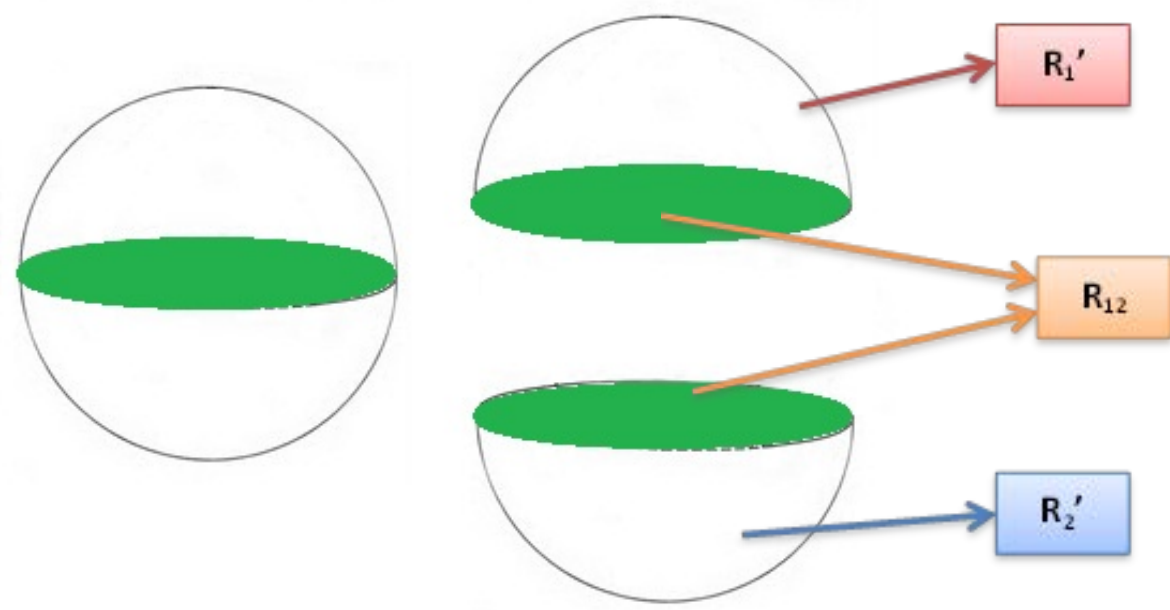

FIGURA 7.1-1 - Representação das Superfícies de Estudo

Supondo contato perfeito entre as faces, ou seja,

$$
u_{i}^{(1)}=u_{i}^{(2)} \quad \text { sobre } R_{12}
$$

sendo que as contribuições de $\mathrm{R}_{12}$ para ambas as integrais da Equação (7.12) se cancelam entre si. Isto conduz a:

$$
\left\langle S_{i j}\right\rangle=\frac{1}{2 V} \int_{A}\left(u_{i} n_{j}+u_{j} n_{i}\right) d A
$$

Substituindo a Equação (7.5) na Equação (7.14), obtém-se:

$$
\left\langle S_{i j}\right\rangle=S_{i j}^{0}
$$




\section{$\underline{\text { Teorema da Tensão Média }}$}

Este teorema estabelece que o problema de contorno representado pelas equações de equilíbrio na ausência de forças gravitacionais, em V, sujeito a condições de equilíbrio do tipo mostrado pela Equação (7.6), sobre S, conduz a igualdade: $\left\langle T_{i j}\right\rangle=T_{i j}^{0}$.

A equação de equilíbrio na ausência de forças gravitacionais, em V, é dada por:

$$
T_{i j, j}=0
$$

O qual implica em

$$
\left(T_{i k} x_{j}\right)_{, k}=T_{i k, k} x_{j}+T_{i k} \delta_{j, k}=T_{i j}
$$

Substituindo a Equação (7.17) na Equação (7.1) tem-se,

$$
V\left\langle T_{i j}\right\rangle=\int_{V}\left(T_{i k} x_{j}\right)_{, k} d V
$$

Pelo Teorema de Gauss Equação (7.11) obtém-se:

$$
2 V\left\langle T_{i j}\right\rangle=\int_{A_{1}} T_{i k}^{1} x_{j} n_{k}^{1} d A+\int_{A_{2}} T_{i k}^{2} x_{j} n_{k}^{2} d A
$$

Considerando que as trações são contínuas na interface $\mathrm{R}_{12}$, ou seja, que,

$$
T_{i j}^{(1)} n_{j}^{(1)}=-T_{i j}^{(2)} n_{j}^{(2)} \quad \text { sobre } \quad R_{12}
$$

As condições de $\mathrm{R}_{12}$ nas integrais do membro direito da Equação (7.18) se cancelam entre si e a mesma pode ser reescrita da seguinte forma: 


$$
\begin{gathered}
V\left\langle T_{i j}\right\rangle=\int_{A} T_{i k} x_{j} n_{k} d A \\
V\left\langle T_{i j}\right\rangle=T_{i j}^{0} \int_{A} x_{j} n_{k} d A \\
V\left\langle T_{i j}\right\rangle=T_{i j}^{0} \int_{V} x_{j, k} d V \\
V\left\langle T_{i j}\right\rangle=T_{i j}^{0} V \delta_{j k} \\
V\left\langle T_{i j}\right\rangle=T_{i j}^{0} V
\end{gathered}
$$

Portanto,

$$
\left\langle T_{i j}\right\rangle=T_{i j}^{0}
$$

\section{Teorema do “Deslocamento Elétrico” Médio}

Este teorema versa que a média do “deslocamento elétrico" sobre V para condições de contorno do tipo descrito pela Equação (7.7) coincide com as deformações constantes $S_{i j}{ }^{0}$, ou seja: $\left\langle E_{m}^{0}\right\rangle=E_{m}^{0}$.

Considerando E tal que:

$$
\begin{gathered}
E_{i}=\lambda_{, i} \\
E_{i}=\lambda_{, i} \\
\left.\lambda\right|_{A}=E^{0} \\
E^{0}=E_{i}^{0} x_{i} \text { são uniformes }
\end{gathered}
$$

Considerando as condições supracitadas, tem-se que: 


$$
\begin{gathered}
\left\langle E_{i}\right\rangle=\left\langle\lambda_{, i}\right\rangle=\frac{1}{|V|} \int_{A} \lambda n_{i} d S \\
\left\langle E_{i}\right\rangle=\frac{1}{|V|} \int_{A} E^{0} n_{i} d S
\end{gathered}
$$

Aplicando as condições de contorno uniformes descritas pela Equação (7.7) tem-se:

$$
\begin{gathered}
V\left\langle E_{i}\right\rangle=\int_{A} E_{j}^{0} x_{j} n_{i} d S \\
V\left\langle E_{i}\right\rangle=E_{j}^{0} \int_{V} x_{j, i} d V \\
V\left\langle E_{i}\right\rangle=E_{j}^{0} V \delta_{j i} \\
V\left\langle E_{i}\right\rangle=E_{i}^{0} V
\end{gathered}
$$

Portanto,

$$
\left\langle E_{i}\right\rangle=E_{i}^{0}
$$

\section{$\underline{\text { Teorema da Tensão Elétrica Média }}$}

Este teorema estabelece que o problema de contorno representado pelas equações de equilíbrio na ausência de forças gravitacionais, em $\mathrm{V}$, sujeito a condições de equilíbrio do tipo mostrado pela Equação (7.8) sobre S, conduz a igualdade: $\left\langle D_{m}^{0}\right\rangle=D_{m}^{0}$.

Considerando D tal que:

$$
\begin{gathered}
D_{i, i}=0 \\
\left.D_{i} n_{i}\right|_{A}=D^{0}
\end{gathered}
$$




$$
D^{0}=D_{i}^{0} n_{i} \text { são uniformes }
$$

Considerando as condições supracitadas, tem-se que:

$$
\begin{gathered}
\left\langle D_{i}\right\rangle=\left\langle D_{j} \delta_{i j}\right\rangle=\left\langle D_{j} x_{i, j}\right\rangle=\left\langle\left(D_{j} x_{i}\right)_{, j}-D_{j, j} x_{i}\right\rangle=\left\langle\left(D_{j} x_{i}\right)_{, j}\right\rangle \\
\left\langle D_{i}\right\rangle=\frac{1}{|V|} \int_{A} D_{i} x_{i} n_{j} d S \\
\left\langle D_{i}\right\rangle=\frac{1}{|V|} \int_{A} \phi x_{i} d S
\end{gathered}
$$

Aplicando as condições de contorno uniformes descritas pela Eq. (7.8) tem-se:

$$
\left\langle D_{i}\right\rangle=\frac{1}{|V|} \int_{A} D_{j}^{0} x_{j} n_{i} d S
$$

De forma análoga a tensão mecânica, tem-se que:

$$
\begin{gathered}
V\left\langle D_{i}\right\rangle=D_{j}^{0} \int_{V} x_{j, i} d V \\
V\left\langle D_{i}\right\rangle=D_{j}^{0} V \delta_{j i}
\end{gathered}
$$

Aplicando a propriedade de Delta de Kronecker, tem-se

$$
V\left\langle D_{i}\right\rangle=D_{i}^{0} V
$$

Portanto,

$$
\left\langle D_{i}\right\rangle=D_{j}^{0}
$$




\subsection{ANEXO 2 - MÉTODO HOMOGENEIZAÇÃO ASSINTÓtICA}

O método de homogeneização é aplicado em materiais compósitos, que são caracterizados por possuírem dois ou mais materiais diferentes, que juntos formam uma unidade que cuja propriedade é distinta das componentes individuais. O método de homogeneização é um método matemático que permite encontrar as propriedades efetivas de um material compósito a partir das propriedades físicas e geométricas de seus componentes. Em particular, o Método de Homogeneização Assintótica (Asymptotic Homogenization Method - AHM), desenvolvido por Bensoussan et al. (1978), Sánchez-Palencia (1980) e Bakhvalov e Panasenko (1989), é utilizado para encontrar os coeficientes que representam as propriedades efetivas de um meio com estrutura periódica.

O método consiste na busca da solução do problema de valor de contorno (PVC) na forma de uma expansão assintótica das variáveis de interesse em termos de séries de potência de um parâmetro geométrico. Este parâmetro é dado pela razão entre o tamanho característico da célula periódica do compósito e o tamanho representativo do compósito. O método garante que a solução do PVC original converge para a solução do problema homogeneizado quando o parâmetro geométrico tende a zero. Porém, a aplicação deste método necessita da solução de PVCs locais, sobre a célula periódica, para a determinação dos coeficientes efetivos do meio homogeneizado.

Para homogeneização de meios fibrosos com duas fases transversalmente isotrópicas não piezelétricas, parte-se da seguinte equação, sendo $S=2$ ou 3 :

$$
\frac{\partial}{\partial x_{j}}\left(c_{i j k l}\left(\frac{x}{\varepsilon}\right)\right)+f_{i}=0, \quad x \in \Omega \subset \mathbb{R}^{s}, \quad x \in \partial \Omega, \quad u_{k}=0,
$$

Sendo,

$$
\begin{aligned}
& C_{i j k l}=c_{j i k l}=c_{i j l k}=c_{k l i j}, \quad \text { onde } c_{i j k l} \text { são } Y \text {-periódicas } \\
& \exists c>0 \\
& C_{i j k l} \varepsilon_{i j} \varepsilon_{i j} \geq \varepsilon_{i j} \varepsilon_{i j} \forall c \in \mathrm{E}_{3}^{s} \\
& y=\frac{x}{\varepsilon}, \quad \varepsilon=\frac{l}{L},
\end{aligned}
$$




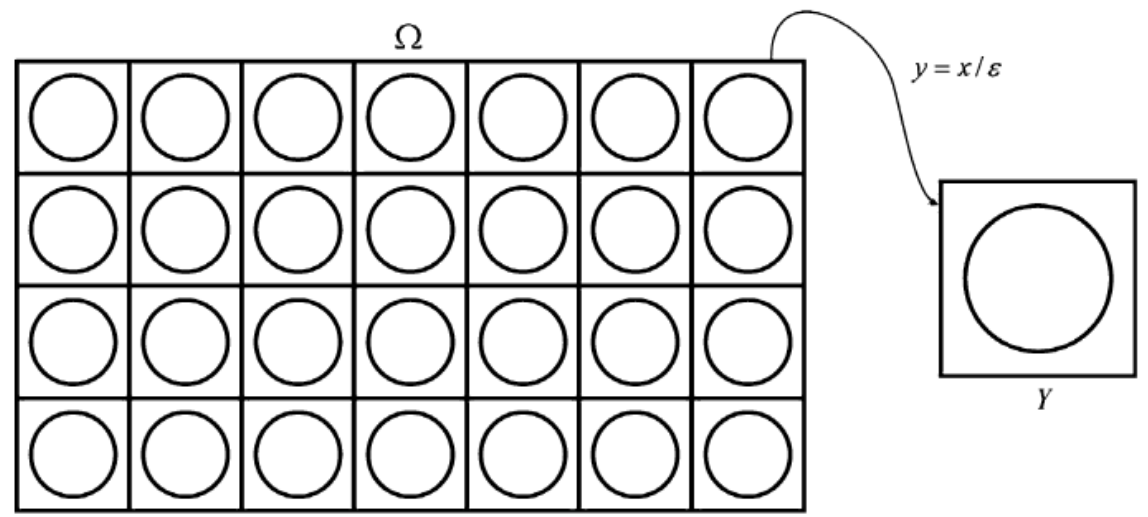

FIGURA 7.2-1 - Descrição do domínio periódico e sua respectiva célula unitária. (BRAVO-CASTILLERO, 2008)

Segundo o método da homogeneização assintótica,

$$
\begin{array}{ll}
u_{k} \approx v_{k}(x)+\varepsilon N_{k p q(y)} & \frac{\partial v_{p}(x)}{\partial x_{q}}+O(\varepsilon) \\
u_{k}^{0} & \downarrow \\
u_{k}^{1}(x, y)
\end{array}
$$

Assim,

$$
\begin{aligned}
& \overline{c_{\hat{i} j p q}} \frac{\partial^{2} v_{p}(x)}{\partial x_{j} \partial x_{k}}+f i=0, \quad x \in \Omega, \\
& v_{p}=0, \quad x \in \partial \Omega
\end{aligned}
$$

Onde,

$$
\overline{c_{i j p q}}=\left\langle c_{i j p q}(y)+c_{i j k l}(y) \partial N_{k p q}(y)\right\rangle
$$

Deve-se resolver o problema $\left(\mathrm{pq}^{\mathrm{L}}\right)$, e assim achar $\mathrm{N}_{\mathrm{kpq}}(\mathrm{y})$, sendo Y-periódica tal que: 


$$
\begin{gathered}
\frac{\partial}{\partial y_{j}}\left(c_{i j k l} \frac{\partial N_{k p q}}{\partial y_{l}}+c_{i j p q}\right)=0 \quad \text { em } \quad Y \\
\frac{\partial}{\partial y_{\alpha}}\left(c_{i \alpha k \beta}^{(\gamma)} \frac{\partial N_{k p q}^{(\gamma)}}{\partial y_{\beta}}+c_{i \alpha p q}^{(\gamma)}\right)=0 \quad \text { em } \quad Y_{\gamma} \quad e(\gamma=1,2)
\end{gathered}
$$

Para o caso transversalmente isotrópico, tem-se:

$$
\begin{aligned}
& (i=1) \quad\left(c_{1111}^{(\gamma)}-c_{1212}^{(\gamma)}\right) N_{\alpha(p q)}^{(\gamma)}, \alpha_{1}+c_{1212}^{(\gamma)} N_{1(p q)}^{(\gamma)}, \alpha \alpha=0 \\
& (i=2) \quad\left(c_{1111}^{(\gamma)}-c_{1212}^{(\gamma)}\right) N_{\alpha(p q)}^{(\gamma)}, \alpha_{2}+c_{1212}^{(\gamma)} N_{2(p q)}^{(\gamma)}, \alpha \alpha=0 \\
& (i=3) \quad\left(c_{1111}^{(\gamma)}-c_{1212}^{(\gamma)}\right) N_{\alpha(p q)}^{(\gamma)}, \alpha_{3}+c_{1212}^{(\gamma)} N_{3(p q)}^{(\gamma)}, \alpha \alpha=0
\end{aligned}
$$

Derivada em relação a 3 igual a zero

Assim, algumas hipóteses são adotadas:

Equações são iguais para todos os problemas pq;

Sistemas são desacoplados;

$\checkmark$ Lineares e homogêneos;

Equações de Lamé.

Condições de unicidade:

$$
\left\langle N_{k(p q)}\right\rangle=0
$$

Condições de continuidade sobre $\Sigma$ :

$$
\left[\left[N_{k(p q)}\right]\right]=0 \Rightarrow N_{k(p q)}^{(1)}=N_{k(p q)}^{(2)} \quad \text { se } y \in \Sigma
$$


Condição de fluxo:

$$
\begin{aligned}
& \left(c_{i \alpha k \beta}^{(1)} \frac{\partial N_{k(p q)}^{(1)}}{\partial y_{\beta}}+c_{i \alpha p q}^{(1)}\right) n_{\alpha}=\left(c_{i \alpha k \beta}^{(2)} \frac{\partial N_{k(p q)}^{(2)}}{\partial y_{\beta}}+c_{i \alpha p q}^{(2)}\right) n_{\alpha} \\
& \left(c_{i \alpha k \beta}^{(1)} N_{k(p q), \beta}^{(1)}-c_{i \alpha k \beta}^{(2)} N_{k(p q), \beta}^{(2)}\right) n_{\alpha}=\left(c_{i \alpha p q}^{(1)}-c_{i \alpha p q}^{(2)}\right) n_{\alpha} \\
& \left(\sigma_{i \alpha(p q)}^{(1)}-\sigma_{i \alpha(p q)}^{(2)}\right) n_{\alpha}=\left(c_{i \alpha p q}^{(1)}-c_{i \alpha p q}^{(2)}\right) n_{\alpha}
\end{aligned}
$$

Assim

$$
\left[\left[\sigma_{i \alpha(p q)}\right]\right] n_{\alpha}=-\left[\left[c_{i \alpha p q}\right]\right] n_{\alpha}
$$

Problema ${ }_{11} \mathrm{~L}$ :

$$
\begin{array}{ll}
i=1 \ldots & =-\left[\left[c_{1 \alpha 11}\right]\right] n_{\alpha} \Rightarrow \ldots=-\left[\left[c_{1111}\right]\right] n_{1} \\
i=2 \ldots & =-\left[\left[c_{2 \alpha 11}\right]\right] n_{\alpha} \Rightarrow \ldots=-\left[\left[c_{2211}\right]\right] n_{2} \\
i=3 \ldots & =-\left[\left[c_{3 \alpha 11}\right]\right] n_{\alpha} \Rightarrow \ldots=0
\end{array}
$$

Assim,

$$
\begin{aligned}
& \sigma_{i \alpha(p q)} n_{\alpha}=c_{i \alpha k \beta} N_{k(p q)}, n_{\alpha} \\
& \sigma_{i \alpha(p q)} n_{\alpha}=c_{3 \alpha k \beta} N_{k(p q),{ }_{\beta}} n_{\alpha} \\
& \sigma_{i \alpha(p q)} n_{\alpha}=c_{31 k \beta} N_{k(11), \beta} n_{1}+c_{32 k \beta} N_{k(11), \beta} n_{2} \\
& \sigma_{i \alpha(p q)} n_{\alpha}=c_{3131} N_{3(11), 1} n_{1}+c_{3232} N_{3(11), 2} n_{2} \\
& N_{1(11)} \neq 0, \quad N_{2(11)} \neq 0, \quad N_{3(11)}=0
\end{aligned}
$$


Problema ${ }_{22} \mathrm{~L}$ :

$$
\begin{array}{llll}
i=1 \ldots & =-\left[\left[c_{1 \alpha 22}\right]\right] n_{\alpha} \Rightarrow \ldots & =-\left[\left[c_{1122}\right]\right] n_{1} \\
i=2 \ldots & =-\left[\left[c_{2 \alpha 22}\right]\right] n_{\alpha} \Rightarrow \ldots & =-\left[\left[c_{2222}\right]\right] n_{2} \\
i=3 \ldots & =-\left[\left[c_{3 \alpha 22}\right]\right] n_{\alpha} \Rightarrow \ldots & =0 \\
N_{1(22)} \neq 0, & N_{2(22)} \neq 0, \quad N_{3(22)}=0, &
\end{array}
$$

Problema ${ }_{33} \mathrm{~L}$ :

$$
\begin{array}{llll}
i=1 \ldots & =-\left[\left[c_{1 \alpha 33}\right]\right] n_{\alpha} \Rightarrow \ldots & =-\left[\left[c_{1133}\right]\right] n_{1} \\
i=2 \ldots & =-\left[\left[c_{2 \alpha 33}\right]\right] n_{\alpha} \Rightarrow \ldots & =-\left[\left[c_{2233}\right]\right] n_{2} \\
i=3 \ldots & =-\left[\left[c_{3 \alpha 33}\right]\right] n_{\alpha} \Rightarrow \ldots & =0 \\
N_{1(33)} \neq 0, & N_{2(33)} \neq 0, \quad N_{3(33)}=0, &
\end{array}
$$

Problema ${ }_{12} \mathrm{~L}$ :

$$
\begin{array}{lrl}
i=1 \ldots & =-\left[\left[c_{1 \alpha 12}\right]\right] n_{\alpha} \Rightarrow \ldots & =-\left[\left[c_{1212}\right]\right] n_{2} \\
i=2 \ldots & =-\left[\left[c_{2 \alpha 12}\right]\right] n_{\alpha} \Rightarrow \ldots & =-\left[\left[c_{2112}\right]\right] n_{1} \\
i=3 \ldots & =-\left[\left[c_{3 \alpha 12}\right]\right] n_{\alpha} \Rightarrow \ldots & =0 \\
N_{1(12)} \neq 0, & N_{2(12)} \neq 0, \quad N_{3(12)}=0, &
\end{array}
$$

Problema ${ }_{13} \mathrm{~L}$ : deformação fora do plano.

$$
\begin{array}{lrll}
i=1 \ldots & =-\left[\left[c_{1 \alpha 13}\right]\right] n_{\alpha} \Rightarrow \ldots & =0 \\
i=2 \ldots & =-\left[\left[c_{2 \alpha 13}\right]\right] n_{\alpha} \Rightarrow & \ldots & =0 \\
i=3 \ldots & =-\left[\left[c_{3 \alpha 13}\right]\right] n_{\alpha} \Rightarrow & \ldots & =-\left[\left[c_{3113}\right]\right] n_{1} \\
N_{1(13)} \neq 0, & N_{2(13)}=0, \quad N_{3(13)}=0, &
\end{array}
$$


Problema ${ }_{13} \mathrm{~L}$ : deformação fora do plano.

$$
\begin{array}{llll}
i=1 \ldots & =-\left[\left[c_{1 \alpha 23}\right]\right] n_{\alpha} \Rightarrow \ldots & =0 \\
i=2 \ldots & =-\left[\left[c_{2 \alpha 23}\right]\right] n_{\alpha} \Rightarrow \ldots & =0 \\
i=3 \ldots & =-\left[\left[c_{3 \alpha 23}\right]\right] n_{\alpha} \Rightarrow & \ldots & =-\left[\left[c_{3223}\right]\right] n_{2} \\
N_{1(23)} \neq 0, & N_{2(23)}=0, \quad N_{3(23)}=0, &
\end{array}
$$

Considerando:

$$
c_{1111}=c_{2222}, \quad C_{1133}=c_{2233}, \quad C_{2323}=c_{1313},
$$

Tem-se,

$$
\begin{aligned}
& L_{11}+L_{22} \\
& -\left[\left[c_{1111}+c_{1122}\right]\right] n_{1} \\
& -\left[\left[c_{2211}+c_{1111}\right]\right] n_{2} \\
& 0
\end{aligned}
$$

$$
N_{k}=N_{k(11)}+N_{k(22)}
$$

$\mathrm{L}_{33}$ dividido por $\left[\left[c_{1133}\right]\right]$, tem-se:

$$
\begin{array}{ll}
\ldots=-n_{1} & \\
\ldots=-n_{2} & \frac{N_{k(33)}}{\left[\left[c_{1133}\right]\right]}=N_{k(33)} \\
\ldots & =0
\end{array}
$$


$\mathrm{L}_{11}+\mathrm{L}_{22}$

$$
N_{k}=\frac{\left(N_{k(11)}+N_{k(22)}\right)}{\left[\left[C_{1111}+c_{1122}\right]\right]}=\frac{\left(N_{k(11)}+N_{k(22)}\right)}{[[2 k]]}
$$

Para o caso transversalmente isotrópico de acordo com Hill, tem-se:

$$
\begin{aligned}
& \frac{c_{1111}+c_{1122}}{2}=k \\
& c_{2233}=c_{1133}=l \\
& c_{3333}=n \\
& c_{1212}=m \\
& c_{2323}=c_{1313}=p
\end{aligned}
$$

Assim,

$$
\frac{N_{k(11)}+N_{k(22)}}{2[[k]]}=\frac{N_{k(33)}}{[[l]]}
$$

Se o comportamento global é transversalmente isotrópico, então:

$$
\begin{array}{ccc}
L_{11} & L_{22} & L_{33} \\
C_{1111} & C_{1122} & C_{1133} \\
c_{2211} & C_{2222} & C_{2233} \\
C_{3311} & C_{3322} & C_{3333} \\
0 & 0 & 0 \\
0 & 0 & 0 \\
0 & 0 & 0
\end{array}
$$


Assim,

$$
\overline{C_{i j p q}}=\left\langle c_{i j p q}+C_{i j k \beta} N_{k(p q), \beta}\right\rangle
$$

Para $\mathrm{L}_{11}$, tem-se,

$$
\begin{aligned}
& \bar{C}_{i j 11}=\left\langle C_{i j 11}+C_{i j k \beta} N_{k(11)}, \beta\right. \\
& \bar{C}_{1111}=\left\langle C_{1111}+C_{11 k \beta} N_{k(11)}, \beta\right\rangle \\
& \bar{c}_{1111}=\left\langle c_{1111}\right\rangle+\left\langle c_{1111} N_{1(11), 1}+c_{1122} N_{2(11), 2}\right\rangle \\
& \bar{C}_{2211}=\left\langle C_{2211}+C_{22 k \beta} N_{k(11)}, \beta\right. \\
& \bar{c}_{2211}=\left\langle c_{2211}\right\rangle+\left\langle C_{2211} N_{1(11), 1}+c_{2222} N_{2(11), 2}\right\rangle \\
& \bar{C}_{1111}+\bar{c}_{2211}=\left\langle c_{1111}+c_{2211}\right\rangle+\left\langle\left(c_{1111}+c_{2211}\right) N_{1(11) r_{1}}+\left(c_{1111}+c_{2211}\right) N_{2(11)},_{2}\right\rangle \\
& \bar{C}_{1111}+\bar{C}_{2211}=\left\langle c_{1111}+c_{2211}\right\rangle+\left\langle\left(c_{1111}+c_{2211}\right) N_{\alpha(11)}, \alpha\right\rangle
\end{aligned}
$$

Da mesma forma procede-se para obtenção dos demais coeficientes, juntamente com a inclusão dos termos de acoplamento piezelétrico e dielétrico. 


\subsection{ANEXo 3 - MÉtodo dos CAMPos UniformeS}

Considerando um compósito piezelétrico transversalmente isotrópico e a matriz polimérica não piezelétrica $\left(e^{m}=0\right)$. Onde $f$ denota a fração volumétrica de fibra e $\varepsilon^{m}=\varepsilon_{11}^{m}$. Segundo Nan e Jin (1993), os 11 coeficientes efetivos podem ser calculados como segue:

$$
\begin{aligned}
& k=c_{11}+c_{12} \\
& m=c_{11}-c_{12} \\
& k^{*}=\frac{k^{m}\left(k^{f}+m^{m}\right)+f m^{m}\left(k^{f}-k^{m}\right)}{k^{f}+m^{m}-f\left(k^{f}-k^{m}\right)} \\
& m=m^{m} \frac{k^{m}\left(m^{m}+m^{f}\right)+2 m^{m} m^{f}+f k^{m}\left(m^{f}-m^{m}\right)}{k^{m}\left(m^{m}+m^{f}\right)+2 m^{m} m^{f}-f\left(k^{m}+2 m^{m}\right)\left(m^{f}-m^{m}\right)} \\
& c_{11}^{*}=\frac{k+m}{2} \\
& c_{12}^{*}=\frac{k-m}{2} \\
& c_{13}^{*}=\frac{c_{12}^{m}\left(k^{f}-k^{*}\right)+c_{13}^{f}\left(k^{*}-k^{m}\right)}{k^{f}-k^{m}} \\
& c_{33}^{*}=c_{11}^{m}+f\left(c_{33}^{f}-c_{11}^{m}\right)-2 f \frac{\left(k^{f}-k^{*}\right)\left(c_{33}^{f}-c_{12}^{m}\right)^{2}}{\left(k^{f}-m^{m}\right)\left(k^{f}-k^{m}\right)} \\
& c_{44}^{*}=m^{m} \frac{m^{m}+2 c_{44}^{f}+f\left(2 c_{44}^{f}-m^{m}\right)}{2\left(m^{m}+2 c_{44}^{f}\right)-2 f\left(2 c_{44}^{f}-m^{m}\right)}
\end{aligned}
$$




$$
\begin{gathered}
c_{66}^{*}=\frac{c_{11}^{*}-c_{12}^{*}}{2} \\
e_{13}^{*}=\frac{f e_{13}^{f}\left(k^{*}+m^{m}\right)}{\left(k^{f}+m^{m}\right)} \\
e_{15}^{*}=\frac{f e_{15}^{f} \varepsilon^{m}\left(m^{m}+2 c_{44}^{*}\right)}{\left.(1+f) \varepsilon^{m}+(1-f) \varepsilon_{11}^{f}\right]\left(m^{m}+2 c_{44}^{f}\right)} \\
\varepsilon_{11}^{*}=\varepsilon^{m} \frac{(1-f) \varepsilon^{m}+(1+f) \varepsilon_{11}^{f}-\frac{2 f e_{15}^{f}\left(e_{15}^{*}-e_{15}^{f}\right)}{\left(m^{m}+2 c_{55}^{f}\right)}}{(1+f) \varepsilon^{m}+(1-f) \varepsilon_{11}^{f}} \\
\varepsilon_{33}^{*}=\varepsilon^{m}+f\left(\varepsilon_{33}^{f}-\varepsilon^{m}\right)-\frac{2 f e_{13}^{f}\left(e_{13}^{*}+c_{13}^{f}\right)}{\left(k^{f}+m^{m}\right)} \\
\left(k^{f}+m^{m}\right)
\end{gathered}
$$

onde os sobrescritos $f$ nas constantes piezelétricas representam a fase fibra e $m$ representa a fase matriz e o * representa os coeficientes efetivos homogeneizados.

As Equações (7.79) a (7.93) não apenas apresentam os resultados dos 11 coeficientes efetivos para a fração volumétrica de fibra e as constantes para as duas fases (fibra e matriz), mas também fornecem as relações entre estas 11 constantes efetivas para um compósito transversalmente isotrópico. 


\subsection{ANEXO 4 - EFEITO DAS CONDIÇÕES DE CONTORNO ELÉTRICAS E MECÂNICAS}

As propriedades de materiais piezelétricos são expressas matematicamente como uma relação entre as variáveis mecânicas, tensão e deformação, e duas variáveis elétricas, o campo elétrico e o deslocamento elétrico. Dessa forma, os efeitos piezelétricos diretos e inversos são escritos como um conjunto de equações lineares (LEO, 2007). Esse conjunto de equações para o efeito piezelétrico direto e inverso pode ser combinado em uma expressão matricial, relacionando, assim, a deformação e o deslocamento elétrico como uma função da tensão mecânica e do potencial elétrico aplicado:

$$
\left\{\begin{array}{l}
S \\
D
\end{array}\right\}=\left[\begin{array}{ll}
S & d \\
d & \varepsilon
\end{array}\right]\left\{\begin{array}{l}
T \\
E
\end{array}\right\}
$$

A “parte superior” da Equação (7.94) representa o efeito piezelétrico inverso, ao passo que a “parte inferior” representa o efeito piezelétrico direto. Entretanto há outras formas de se apresentar esta equação, como abordado no Capítulo 2 (item 2.4).

Contudo não há razão para que a Equação (7.94) tenha que ser expressa com as variáveis de tensão e campo elétrico como sendo variáveis independentes e, deformação e tensão elétrica como variáveis dependentes. A Equação (7.94) pode ser invertida a fim de se escrever as equações tensão e campo elétrico como sendo variáveis dependentes e, deslocamento e tensão elétrica, como variáveis independentes (LEO, 2007). Tomando a inversa da matriz, tem-se, portanto, a seguinte equação:

$$
\left\{\begin{array}{l}
T \\
E
\end{array}\right\}=\frac{1}{s \varepsilon-d^{2}}\left[\begin{array}{cc}
\varepsilon & -d \\
-d & s
\end{array}\right]\left\{\begin{array}{l}
S \\
D
\end{array}\right\}
$$

Reescrevendo a equação anterior, tem-se como resultado: 


$$
\left\{\begin{array}{l}
T \\
E
\end{array}\right\}=\left[\begin{array}{cc}
\frac{1}{s}\left(\frac{1}{1-d^{2} / s \varepsilon}\right) & -\frac{d / s \varepsilon}{1-d^{2} / s \varepsilon} \\
-\frac{d / s \varepsilon}{1-d^{2} / s \varepsilon} & \frac{1}{\varepsilon}\left(\frac{1}{1-d^{2} / s \varepsilon}\right)
\end{array}\right]\left\{\begin{array}{l}
S \\
D
\end{array}\right\}
$$

Vale ressaltar que o termo $d^{2} / s \varepsilon$ é frequentemente citado em análises de material piezelétrico. Haja vista que a raiz quadrada deste termo é chamada de coeficiente de acoplamento piezelétrico (LEO, 2007), sendo denotado por:

$$
k=\frac{d}{\sqrt{s \varepsilon}}
$$

Verifica-se, assim, que o coeficiente de acoplamento piezelétrico é sempre positivo e seu valor está entre “0” e 1. Os limites dos coeficientes de acoplamentos estão relacionados com as propriedades de conversão de energia no material piezelétrico, sendo que os mesmos representam o fato de que apenas uma fração da energia é convertida entre os domínios mecânicos e elétricos (LEO, 2007). Dessa forma, verifica-se que o coeficiente de acoplamento piezelétrico quantifica a conversão de energia e quando substituído na Equação (7.96), acarreta em:

$$
\left\{\begin{array}{l}
T \\
E
\end{array}\right\}=\left[\begin{array}{cc}
\frac{1}{s} \frac{1}{1-k^{2}} & -\frac{1}{d} \frac{k^{2}}{1-k^{2}} \\
-\frac{1}{d} \frac{k^{2}}{1-k^{2}} & \frac{1}{\varepsilon} \frac{1}{1-k^{2}}
\end{array}\right]\left\{\begin{array}{l}
S \\
D
\end{array}\right\}
$$

Simplificando a Equação (7.98), tem-se:

$$
\left\{\begin{array}{l}
T \\
E
\end{array}\right\}=\frac{1}{1-k^{2}}\left[\begin{array}{cc}
S^{-1} & -d^{-1} k^{2} \\
-d^{-1} k^{2} & \varepsilon^{-1}
\end{array}\right]\left\{\begin{array}{l}
S \\
D
\end{array}\right\}
$$


Como $0<k^{2}<1$ então, o termo $1 /\left(1-\mathrm{k}^{2}\right)$ deve ser maior do que 1 . Ainda, com base no acoplamento eletromecânico em materiais piezelétricos, verifica-se que as propriedades de um material piezelétrico dependem das condições de contorno mecânicas e elétricas. Assim, ao considerar um cubo piezelétrico na qual a flexibilidade mecânica (s) é determinada pela aplicação de uma tensão conhecida e a resposta medida pela deformação, tem-se que um parâmetro importante em ensaios é a condição de contorno elétrica existente entre as faces opostas. Assumindo uma condição de curto-circuito (fechado na Figura (7.4-1)), no qual as faces do cubo piezelétrico estão diretamente ligadas, como mostrado na Figura (7.4-1). A condição de contorno elétrica resulta em um campo elétrico igual a zero através das faces do material, mas permite que a carga flua do terminal positivo para o terminal negativo (LEO, 2007). Substituindo a condição de $E=0$ na Equação (7.94), tem-se como resultado as seguintes equações:

$$
\begin{aligned}
& S=s T \\
& D=d T
\end{aligned}
$$

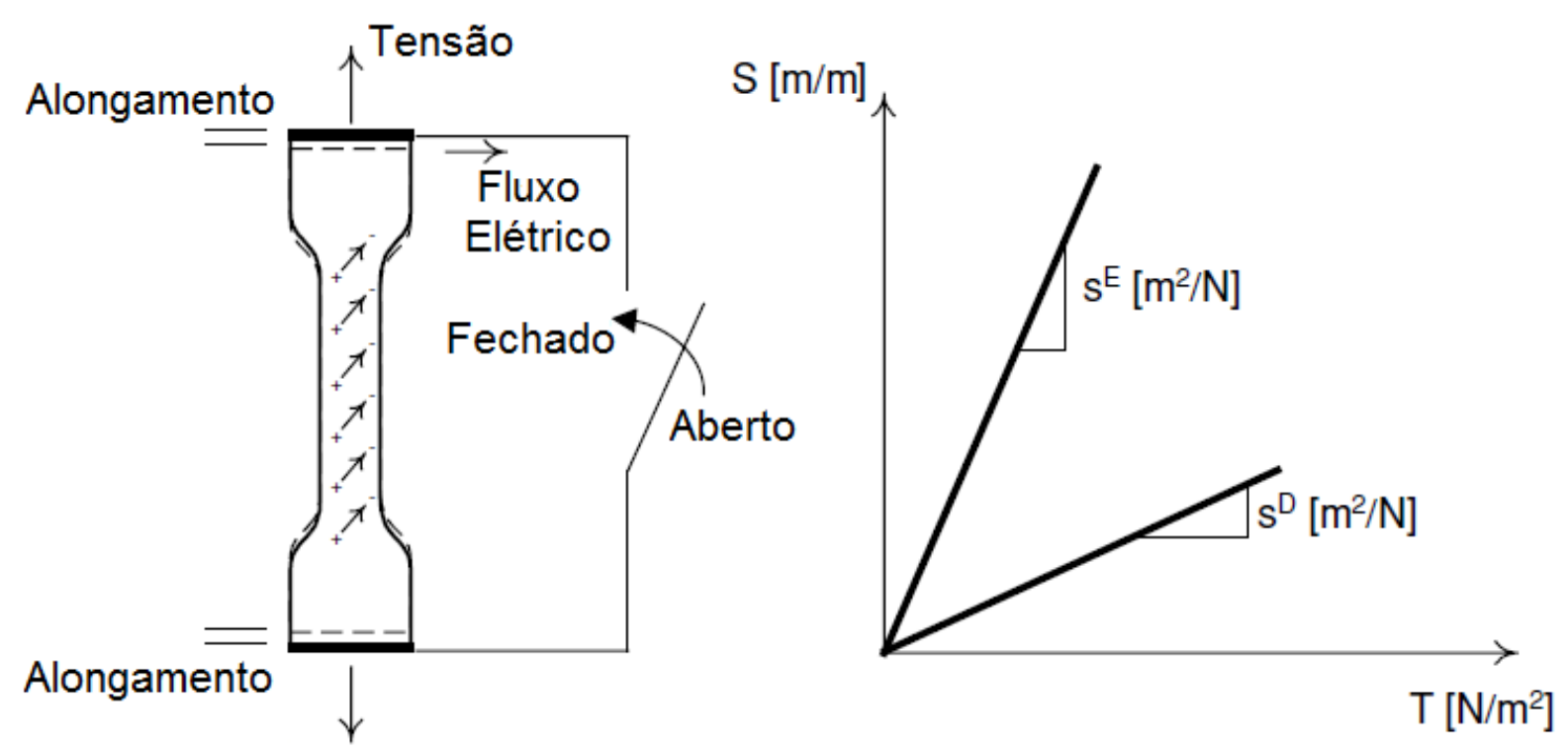

(a)

(b)

FIGURA 7.4-1 - Representação de um ensaio de Tensão-Deformação de um material piezelétrico (b) relações tensão-deformação como função das condições de contorno $\left(S^{E}\right.$ ou $\left.S^{D}\right)$. (LEO, 2007) 
Realizando a mesma experiência quando os terminais elétricos estão abertos tal que nenhuma carga poderá fluir entre as faces do material (circuito aberto na Figura (7.4-1)). Sendo assim, o deslocamento elétrico D = 0 (LEO, 2007), e a relação constitutiva expressa pela Equação (7.95) é reduzida a:

$$
\begin{aligned}
& T=\frac{1}{s\left(1-k^{2}\right)} S \\
& E=\frac{k^{2}}{d\left(1-k^{2}\right)} S
\end{aligned}
$$

Invertendo a Equação (7.96), tem-se:

$$
S= \begin{cases}s T & \text { curto circuito } \\ s\left(1-k^{2}\right) T & \text { circuito aberto }\end{cases}
$$

Nota-se assim, que a flexibilidade mecânica muda quando há mudanças nas condições de contorno elétricas. $\mathrm{O}$ fato de $\mathrm{k}^{2}>0$ indica que a flexibilidade mecânica diminui quando condições de contorno elétricas são modificadas de circuito aberto para curto-circuito. Por esta razão, não é adequado se referir a flexibilidade mecânica sem especificar a condição de contorno elétrica. Dessa forma, torna-se conveniente, então, adotar um índice sobrescrito para referir-se às condições de contorno associadas com a medida de uma propriedade particular (mecânica ou elétrica) (LEO, 2007). O índice sobrescrito E ou D refere-se a campo elétrico constante e a deslocamento elétrico constante, respectivamente, para uma propriedade mecânica. Reescrevendo a Equação (7.98), empregando os índices, tem-se:

$$
S= \begin{cases}s^{E} T & \text { curto circuito } \\ s^{E}\left(1-k^{2}\right) T & \text { circuito aberto }\end{cases}
$$


Deve-se destacar que a Equação (7.105b) foi obtida com base em um circuito aberto $(\mathrm{D}=0)$, assim, constata-se que uma relação entre a flexibilidade mecânica em curto-circuito e a flexibilidade mecânica em circuito aberto pode ser dada como:

$$
s^{D}=s^{E}\left(1-k^{2}\right)
$$

Uma relação análoga existe para especificar a permissividade dielétrica. Essa relação é dada pelo campo de deslocamento aplicado, que por sua vez depende das condições de contorno mecânicas. Uma condição de tensão livre $(T=0)$ é conseguida através da aplicação de um campo sem restrições mecânicas aplicadas no contorno do material piezelétrico (LEO, 2007). Por outro lado, uma condição de deformação livre ( $S=0$ ) é obtida pelo engastamento de ambos os lados do material, tal que o movimento seja igual à zero (LEO, 2007). Realizando uma análise semelhante à apresentada para as condições de contorno elétricas, conclui-se que:

$$
\varepsilon^{S}=\varepsilon^{T}\left(1-k^{2}\right)
$$

Nota-se, assim, que os coeficientes piezelétricos podem ser obtidos para quaisquer condições de contorno elétricas ou mecânicas aplicadas inicialmente, pois, em seguida, os mesmos podem ser calculados para outras condições. Deve-se destacar que para o presente trabalho optou-se pela utilização do campo elétrico constante (E) e pela deformação mecânica constante (S). 


\subsection{ANEXo 5 - MOdOS DE VIBRAÇÃO EM MATERIAIS Piezelétricos}

Para materiais piezelétricos, tem-se que considerar que no estado polarizado sua simetria macroscópica é sempre do tipo $\infty \mathrm{mm}$. Assim, para determinar suas propriedades piezelétricas, é necessário preparar as amostras com diferentes geometrias e diferentes direções de polarização.

Um importante parâmetro em uma amostra piezelétrica é o coeficiente de acoplamento eletromecânico $\mathrm{k}^{2}$, que pode ser entendido como a habilidade do material piezelétrico em converter energia elétrica em mecânica ou vice-versa.

$$
\begin{aligned}
& \left.k^{2}=\frac{\text { energia mecânica convertida emelétrica }}{\text { energia mecânica total }}\right\} \text { Efeito direto } \\
& \text { ou } \\
& \left.k^{2}=\frac{\text { energia mecânica convertida em mecânica }}{\text { energia elétrica total }}\right\} \text { Efeito inverso }
\end{aligned}
$$

Essa grandeza física é um tensor e, portanto depende das direções da tensão e do campo elétrico.

A Tabela (7.5-1) apresenta as geometrias mais comuns utilizadas para analisar transdutores piezelétricos, bem como as condições de contorno aplicadas e os coeficientes que podem ser determinados. As letras (T) e (L) se referem ao acoplamento transversal ou longitudinal, respectivamente. O sinal $(\leftrightarrow)$ indica a direção de vibração correspondente ao modo que será excitado (EIRAS, 2004). 
TABELA 7.5-1 - Modos de Vibração para pastilhas piezelétricas (EIRAS, 2004)

\begin{tabular}{|c|c|c|c|c|c|}
\hline & Comptrin do tranduton & Condiçã & le contorno & Fator de Acoplamento & Constante \\
\hline & Geometria do transution & Elástica & Elétrica & $\left(k^{2}\right)$ & Elástica \\
\hline $\begin{array}{l}1 \\
(\mathrm{~T})\end{array}$ & & $T_{1}=T_{3} \approx 0$ & $\frac{\partial E_{3}}{\partial x_{2}}=0$ & $k_{31}^{2}=\frac{d_{31}^{2}}{s_{11}^{E} \varepsilon_{33}^{T}}$ & $\frac{1}{s_{11}^{E}}$ \\
\hline $\begin{array}{l}2 \\
(\mathrm{~L})\end{array}$ & Longi & $T_{1}=T_{2} \approx 0$ & $\frac{\partial D_{3}}{\partial x_{2}}=0$ & $k_{33}^{2}=\frac{d_{33}^{2}}{s_{33}^{E} \varepsilon_{33}^{T}}$ & $\frac{1}{S_{33}^{D}}$ \\
\hline $\begin{array}{l}3 \\
(\mathrm{~T})\end{array}$ & Radial/Extensional & $T_{3} \approx 0$ & $\frac{\partial E_{3}}{\partial r}=0$ & $k_{p}^{2}=\frac{2}{(1-\sigma)} \frac{d_{31}^{2}}{s_{11}^{E} \varepsilon_{33}^{T}}$ & $C_{e f .}^{E} \quad$ (b) \\
\hline $\begin{array}{l}4 \\
(\mathrm{~T})\end{array}$ & Radial/Dilatacional & $S_{3} \approx 0$ & $\frac{\partial E_{3}}{\partial r}=0$ & $k_{p}^{\prime 2}=\frac{2}{\left(1-\sigma^{\prime}\right)} \frac{e_{31}^{2}}{c_{11}^{E} \varepsilon_{33}^{T}}$ & $c_{11}^{E}$ \\
\hline $\begin{array}{l}5 \\
(\mathrm{~T})\end{array}$ & & $\begin{array}{l}S_{2} \approx 0 \\
T_{3} \approx 0\end{array}$ & $\frac{\partial E_{3}}{\partial x_{1}}=0$ & $k_{31}^{\prime 2}={\frac{e_{31}^{\prime 2}}{C_{e f}^{E} \varepsilon_{e f}^{T}}}^{(\mathrm{d})}$ & $C_{e f .}^{E} \quad(\mathrm{~b})$ \\
\hline $\begin{array}{l}6 \\
(\mathrm{~T})\end{array}$ & & $\begin{array}{l}S_{3} \approx 0 \\
T_{2} \approx 0\end{array}$ & $\frac{\partial E_{3}}{\partial x_{1}}=0$ & $k_{31}^{\prime \prime 2}=\frac{e_{31}^{\prime^{\prime \prime 2} 2}}{c_{e f}^{\prime E} \varepsilon_{e f}^{\prime \prime T}}{ }^{(\mathrm{e})}$ & $C_{e f .}^{\prime E}(\mathrm{f})$ \\
\hline $\begin{array}{l}7 \\
\text { (L) }\end{array}$ & & $\begin{array}{l}S_{1} \approx 0 \\
S_{2} \approx 0\end{array}$ & $\frac{\partial D_{3}}{\partial x_{3}}=0$ & $k_{t}^{2}=\frac{e_{33}^{2}}{c_{33}^{D} \varepsilon_{33}^{S}}$ & $c_{33}^{D}$ \\
\hline $\begin{array}{l}8 \\
(\mathrm{~L})\end{array}$ & & $\begin{array}{l}S_{2} \approx 0 \\
S_{3} \approx 0\end{array}$ & $\frac{\partial E_{3}}{\partial x_{1}}=0$ & $k_{t e}^{2}=\frac{e_{31}^{2}}{c_{11}^{E} \varepsilon_{33}^{S}}$ & $c_{11}^{E}$ \\
\hline $\begin{array}{l}9 \\
(\mathrm{~L})\end{array}$ & & $S_{4} \approx 0$ & $\frac{\partial D_{1}}{\partial x_{1}}=0$ & $k_{15}^{2}=\frac{e_{15}^{2}}{c_{55}^{D} \varepsilon_{11}^{S}}$ & $c_{55}^{D}$ \\
\hline $\begin{array}{l}10 \\
(\mathrm{~T})\end{array}$ & $z_{2}^{\prime}$ & $S_{6} \approx 0$ & $\frac{\partial E_{1}}{\partial x_{1}}=0$ & $k_{15}^{\prime 2}=\frac{e_{15}^{2}}{c_{55}^{E} \varepsilon_{11}^{s}}$ & $c_{55}^{E}$ \\
\hline 11 & & & & $k_{h}^{2}=\frac{d_{h}^{2}}{s_{h}^{E} \varepsilon_{33}^{T}}$ & \\
\hline $\begin{array}{l}\text { (a) } v \\
\text { (b) } c_{e f}^{E} \\
\text { (c) } \sigma \\
\text { (d) } e_{31}^{\prime}\end{array}$ & $\begin{array}{l}s_{12}^{E} / s_{11}^{E} \text { - coeficiente de Poiss } \\
=1 / s_{11}^{E}\left(1-\sigma^{2}\right)=c_{11}^{E}-\left(c_{13}^{E}\right)^{2} / c_{33}^{E} \\
-c_{12}^{E} / c_{11}^{E} ; \quad \varepsilon_{33}^{T}=\varepsilon_{33}^{T}\left(1-k_{33}^{2}\right) \\
e_{31}-e_{33} c_{13}^{E} / c_{33}^{E} ; \quad \varepsilon_{e f}^{T}=\varepsilon_{33}^{T}(1-\end{array}$ & & 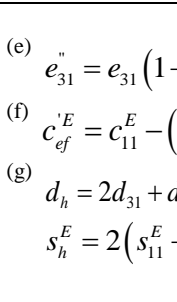 & $\begin{array}{l}\left./ c_{11}^{E}\right) \\
{ }^{2} / c_{11}^{E} \\
+4 s_{13}^{E}+s_{33}^{E}\end{array}$ & \\
\hline
\end{tabular}




\subsection{ANEXO 5 - DETERMINAÇÃO DA FRF}

Depois de realizada as simulações através do software Abaqus, para a obtenção de uma Função de Resposta em Frequência (FRF), deve-se proceder da seguinte maneira:

1) Abra o arquivo de resultados (*.odb), em seguida abra a aba "History Output” e selecione os nós que foram selecionado para a entrada (I) e a saída (O). Clique com o botão direito do mouse no nome do nó selecionado e em seguida clique em "Save As” (Figura 7.4-1). Na próxima aba de um nome a sua variável (Entrada) (No exemplo Piezo-1). Repita o procedimento para a variável saída (no exemplo Piezo-2).

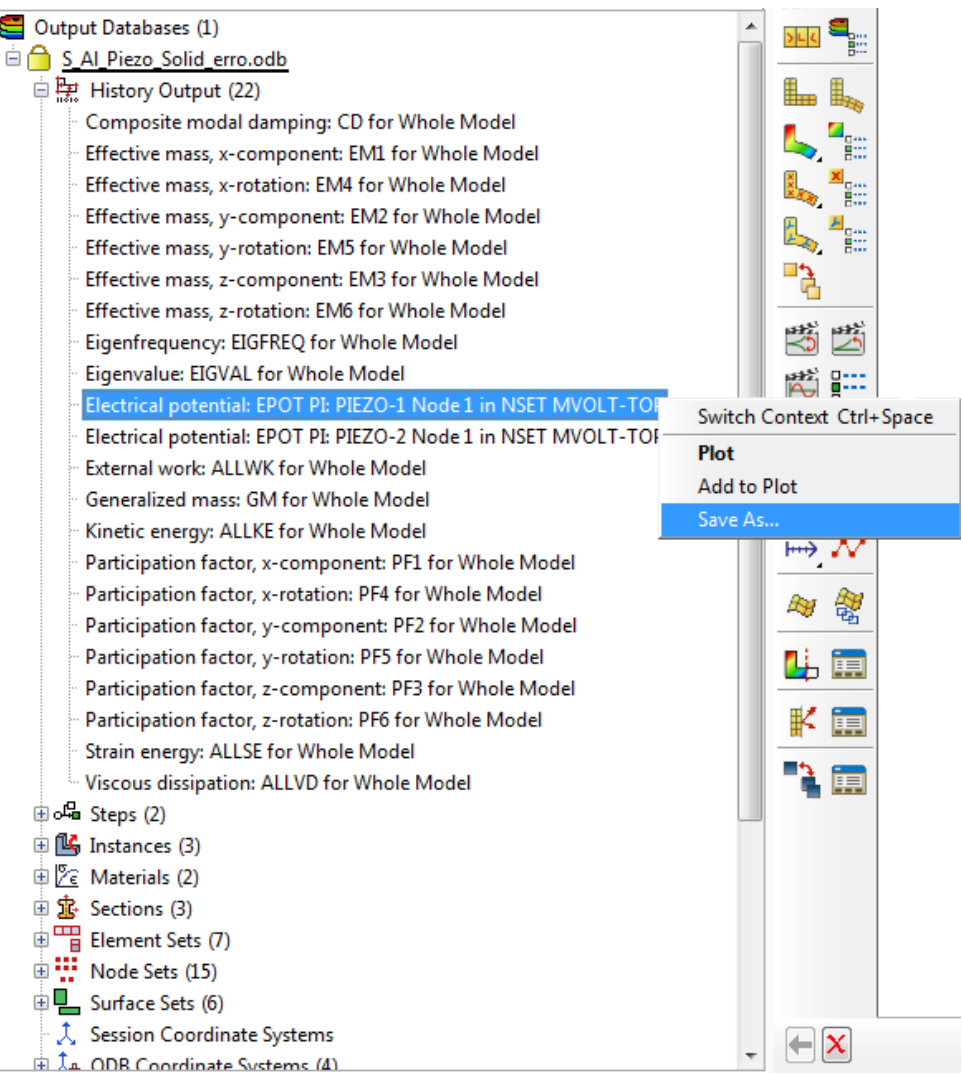

FIGURA 7.6-1 - Seleção da variável de entrada (voltagem pastilha 1)

\begin{tabular}{|c|c|c|}
\hline \multicolumn{2}{|c|}{ II Save XY Data As } & $\sqrt{3}$ \\
\hline \multirow{3}{*}{$\begin{array}{l}\text { Name: } \\
\text { Note: }\end{array}$} & \multicolumn{2}{|l|}{ Entrada } \\
\hline & \multicolumn{2}{|c|}{$\begin{array}{l}\text { XY Data are saved only for the } \\
\text { current Abaqus session. }\end{array}$} \\
\hline & OK & Cancel \\
\hline
\end{tabular}


2) Após salvo os dados, clique em "Create XY Data”, em seguida selecione “Operate on XY data”, e em seguida “Continue...” (Figura 7.4-3).

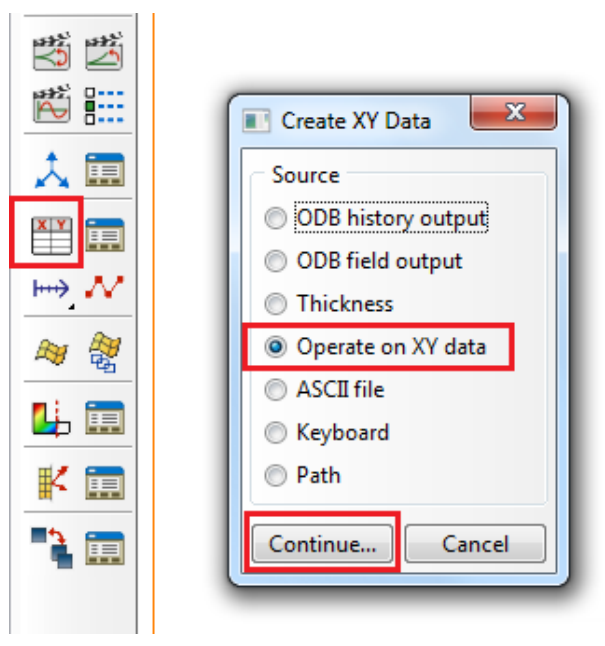

FIGURA 7.6-3 - Operando com os dados de entrada e saida

3) Na próxima aba,poderá realizar operações com os dados anteriormente salvos. Assim deve-se inserir a seguinte equação:

abs ( "Saida" / "Entrada" )

4) O próximo passo é salvar a equação, para isso clique em "Save As", em seguida de um nome a sua nova variável, e clique em “OK” (Figura 7.4-4). Nesta etapa foi criada a função de resposta em frequência para o problema em questão, para isso divide-se a resposta do sistema, pastilha piezelétrica 2 (em volts), pala entrada senoidal aplicada ao pastilha piezelétrica 1 (em volts). Devido ao fato de ser mais usual apresentar o gráfico da FRF logarítmica X linear, os valores devem ser sempre positivos, assim utilizase o módulo desta divisão. 


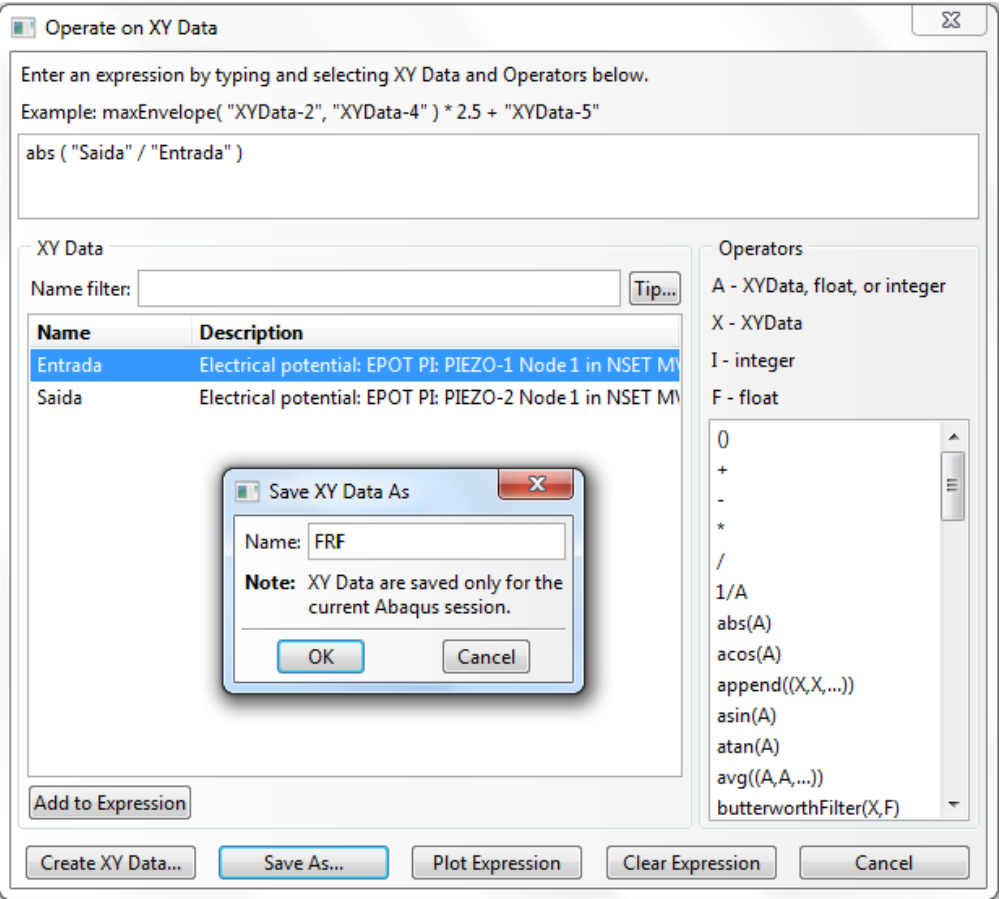

FIGURA 7.6-4 - Criação da equação da função de resposto em frequência (FRF)

5) Para plotar a equação, selecione a expressão dada pelo nome “FRF” em seguida clique em "Plot Expression” e aparecerá na tela o gráfico da função (Figura 7.4-6).

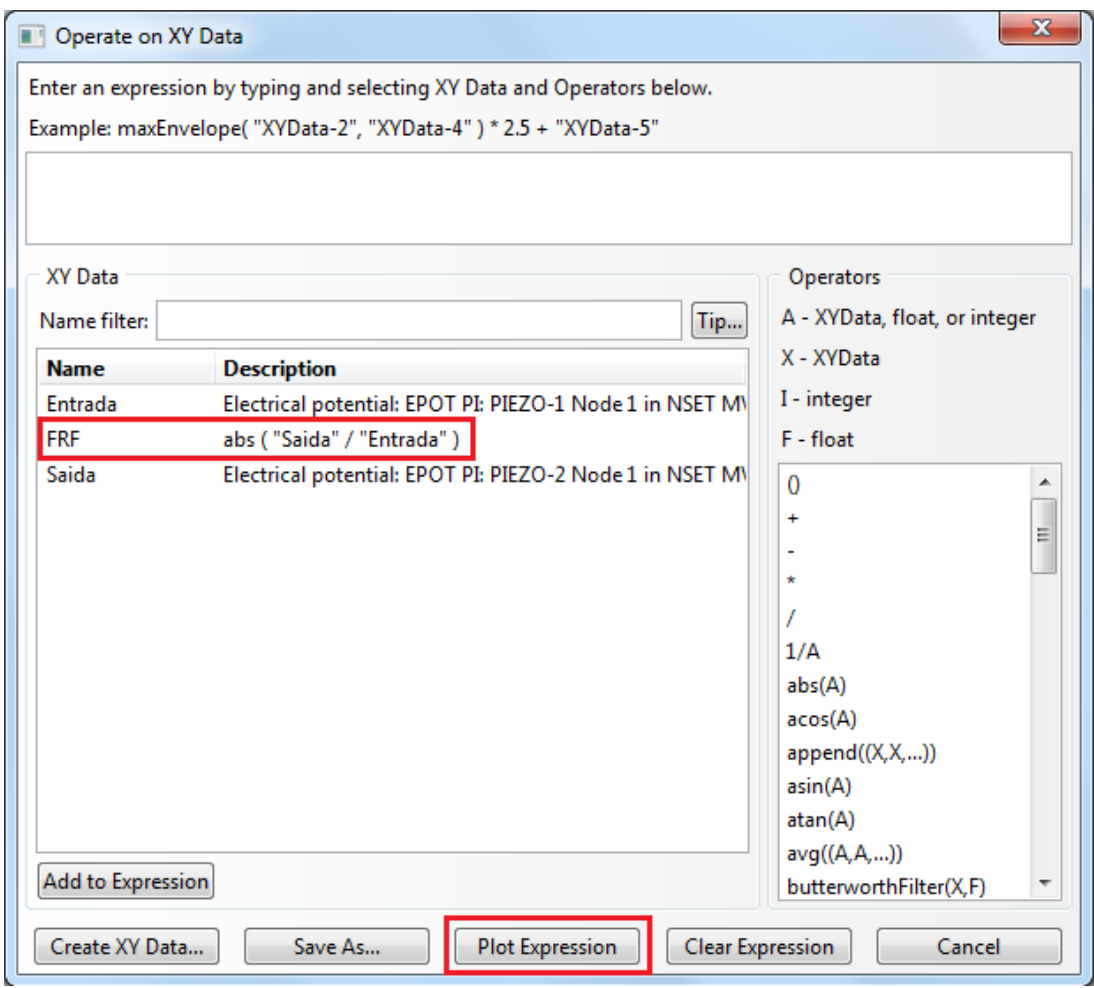

FIGURA 7.6-5 - Plotando a equação da FRF 


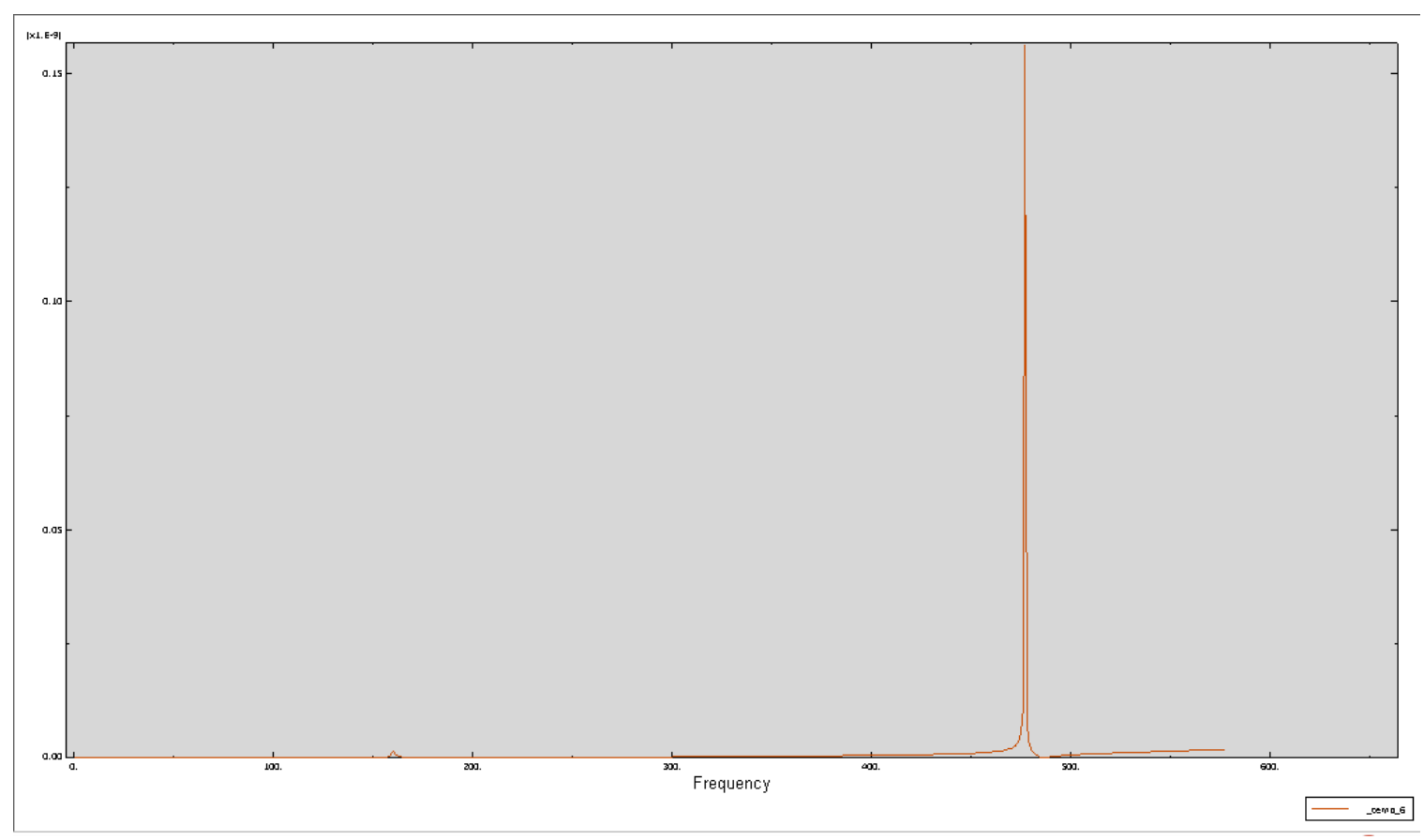

FIGURA 7.6-6 - Modulo da FRF - escala linear X linear

6) Para mudar o eixo Y para a escala logarítmica, clique duas vezes no eixo Y e na janela que surgir selecione a escala log (Figura 7.4-7).

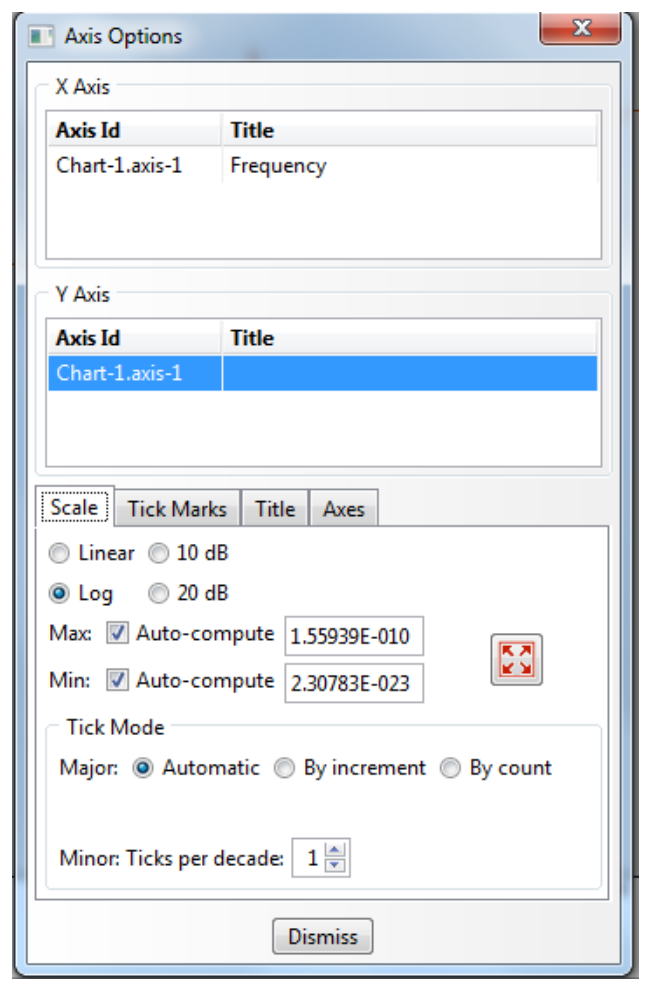

FIGURA 7.6-7 - Mudança de escala do eixo Y para log 


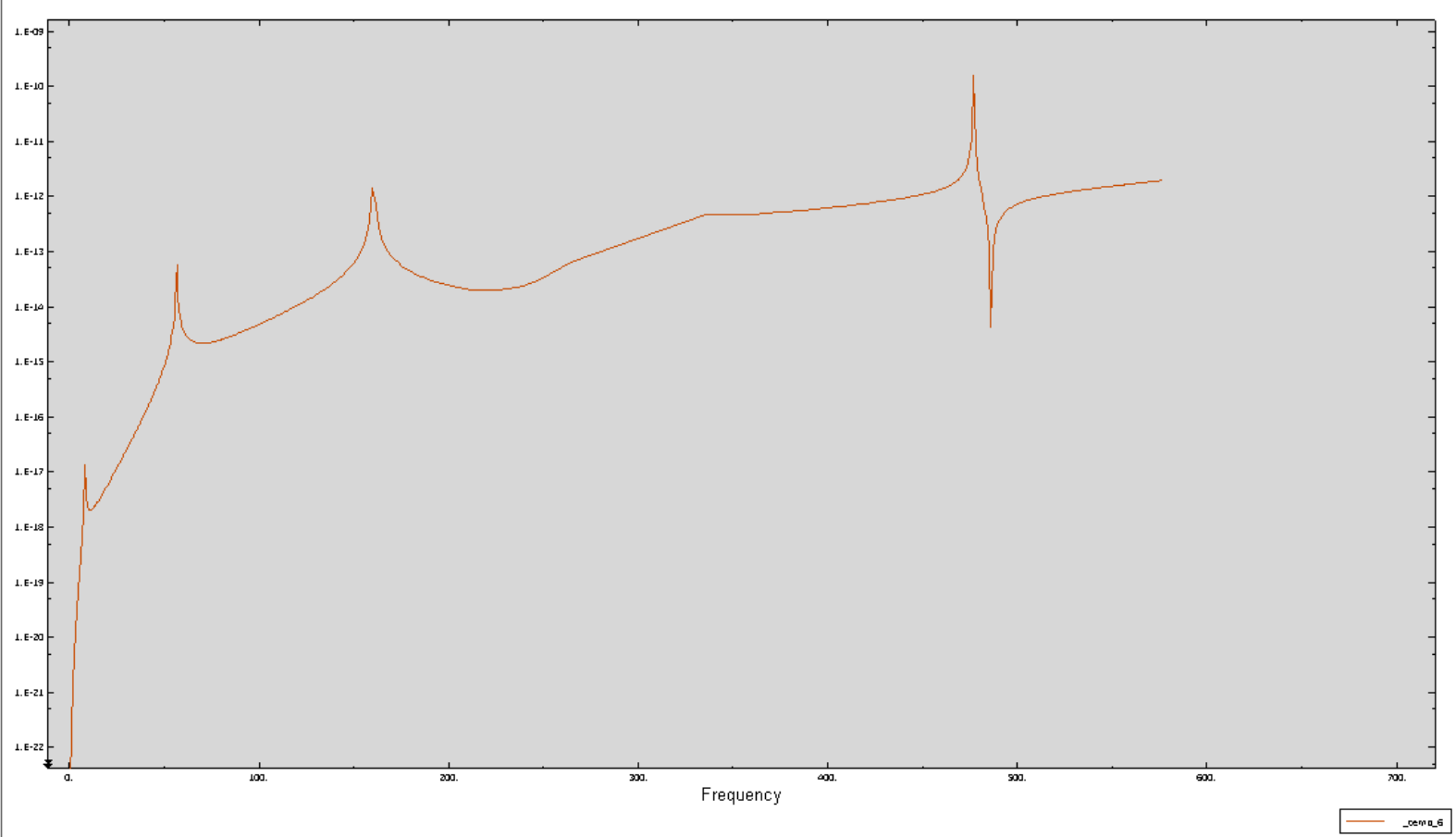

FIGURA 7.6-8 - Função de resposta em frequência - Escala log X linear 


\subsection{Anexo 6 - Publicações Vinculadas ao Projeto}

O referido trabalho de Mestrado frutificou várias publicações em diferentes fases. Segue assim, uma lista de artigos publicados, submetidos e/ou aceitos para publicação:

$\square$ MEDEIROS, R.; MORENO, M. E.; MARQUES, F. D.; TITA, V. Analysis and design of the numerical methodology to evaluation effective coefficients for smart composite materials. Finite Elements in Analysis and Design. 2012. (Submetido).

$\square$ MEDEIROS, R.; TITA, V.; RAMOS, R. R.; GUINOVART-DIAZ, R.; BRAVOCASTILlERO, J.; OTERO, J. A. Numerical and analytical analyses for AFC piezoelectric composite material coefficients. Journal of Intelligent Material Systems and Structures. 2012. (Submetido).

У MEDEIROS, R.; TITA, V.; RAMOS, R. R.; GUINOVART-DIAZ, R.; BRAVOCASTILLERO, J.; OTERO, J.; SABINA, F.J. Numerical and analytical approaches for computing the effective elastic properties in composite materials under imperfect contact adherence. In: 10th World Congress on Computational Mechanics (WCCM). 2012 (Submetido).

$\square$ MEDEIROS, R.; MORENO, M. E.; MARQUES, F. D.; TITA, V. Effective properties evaluation for smart composite materials. Journal of the Brazilian Society of Mechanical Sciences and Engineering - 2011 - (Aceito).

$\square$ RIBEIRO, M. L.; MEDEIROS, R.; SARTORATO, M; TITA, V. Detecção de dano em cilindros de compósito empregando material piezelétrico. In: VII National Congress of Mechanical Engineering, São Luis, Maranhão, Brazil, Proceedings of CONEM, 2012. (Aceito).

$\square$ SARTORATO, TITA, V.; MEDEIROS, R.; M; RIBEIRO, M. L. Detecção de dano em cilindros de compósito empregando material piezelétrico. In: VII National Congress of Mechanical Engineering, São Luis, Maranhão, Brazil, Proceedings of CONEM, 2012. (Aceito). 
$\square$ MEDEIROS, R.; TITA, V.; VENTURINI NETO, S. Método experimental de análise de junções metal-compósito para estruturas aeronáuticas. Revista da Universidade da Força Aérea, v. 24, p. 57-68 2011.

$\square$ MEDEIROS, R.; TITA, V.; RIBEIRO, M. L.; MORENO, M. E.; VENTURINI NETO, S. Study of aeronautic fastened hybrid joints metal-composite. In: 21st International Congress of Mechanical Engineering, Rio Grande do Norte, Brazil, Proceedings of COBEM, 2011.

$\square$ VIEIRA, A.C., MEDEIROS, R., GUEDES, R. M., MARQUES, A. T., TITA, V. Visco-elastic-plastic properties of suture fibers made of PLA-PCL In: VI International Materials Symposium MATERIAIS 2011, 2011, Guimarães (Portugal). Proceedings of Materiais, 2011.

$\square$ MEDEIROS, R.; TITA, V. Resposta eletromecânica de compósitos inteligentes com fibras piezelétricas: uma abordagem numérica para determinação dos coeficientes efetivos utilizando o teorema das médias. Cadernos de Engenharia de Estruturas, v. 13, n 58, p. 17-32 2011.

$\square$ MEDEIROS, R.; MORENO, M. E.; TITA, V. Electromechanical response of 1-3 piezoeletric fiber composites: a unit cell approach for numerical evaluation of effective properties. In: VI National Congress of Mechanical Engineering, Campina Grande, Paraíba, Brazil, Proceedings of CONEM, 2010. 